Simulação numérica direta de escoamento transicional sobre uma superfície contendo rugosidade

Larissa Alves Petri 



\title{
Simulação numérica direta de escoamento transicional sobre uma superfície contendo rugosidade
}

\author{
Larissa Alves Petri
}

Orientador: Prof. Dr. Leandro Franco de Souza

Tese apresentada ao Instituto de Ciências Matemáticas e de Computação - ICMC-USP, como parte dos requisitos para obtenção do título de Doutor em Ciências - Ciências de Computação e Matemática Computacional. VERSÃO REVISADA 
Ficha catalográfica elaborada pela Biblioteca Prof. Achille Bassi e Seção Técnica de Informática, ICMC/USP, com os dados fornecidos pelo(a) autor(a)

Alves Petri, Larissa

Simulação numérica direta de escoamento

transicional sobre uma superfície contendo

rugosidade / Larissa Alves Petri; orientador

Leandro Franco de Souza. -- São Carlos, 2015.

$146 \mathrm{p}$.

Tese (Doutorado - Programa de Pós-Graduação em Ciências de Computação e Matemática Computacional) -Instituto de Ciências Matemáticas e de Computação, Universidade de São Paulo, 2015.

1. métodos de alta ordem. 2. transição laminarturbulenta em camada limite. 3. simulação numérica direta. 4. método de fronteiras imersas. 5. computação paralela. I. Franco de Souza, Leandro, orient. II. Título. 
Dedico às pessoas que mais amo na vida:

minha família. 



\section{Agradecimentos}

A Deus por esta oportunidade.

A minha família que está sempre presente em minha vida.

Ao professor Leandro Franco de Souza pela orientação, apoio e paciência.

A Benjamin Plogmann, Werner Würz e Markus Kloker pelas colaborações.

Aos meus amigos, em especial, os companheiros do LMACC, que compartilharam os momentos de alegrias e dificuldades durante este período.

A FAPESP pelo apoio financeiro fornecido através das bolsas de estudos.

Ao ICMC - USP pela oportunidade de qualificação e crescimento científico.

E finalmente a todos que contribuíram para a realização deste trabalho. 


\section{Resumo}

Em diversos escoamentos sobre superfícies há a presença de protuberâncias, como por exemplo rebites, parafusos e juntas. Estas protuberâncias podem influenciar a camada limite, acelerando a transição do escoamento do estado laminar para o estado turbulento. Em alguns casos isto pode ser indesejável, já que o escoamento turbulento implica necessariamente em uma força de atrito maior do que aquela referente ao escoamento laminar. Existem alguns aspectos neste tipo de escoamento que ainda não estão bem compreendidos. O objetivo deste trabalho é estudar a influência de uma rugosidade isolada no escoamento sobre uma superfície. Este estudo contribui para se entender o que ocorre em casos de maior complexidade. O estudo é de natureza computacional, em que se utiliza simulação numérica direta das equações de Navier-Stokes. A técnica de fronteiras imersas é utilizada para representar a rugosidade no escoamento sobre a superfície. O código numérico é verificado por meio do método de soluções manufaturadas. Comparações entre resultados experimentais, da teoria de estabilidade linear e numéricos também são utilizados para a validação do código. Resultados obtidos com diferentes alturas de rugosidade e variações no gradiente de pressão permitiram analisar a influência de elemento rugoso tridimensional em escoamentos de camada limite.

Palavras-chave: métodos de alta ordem, transição laminar-turbulenta em camada limite, simulação numérica direta, método de fronteiras imersas, computação paralela. 


\section{Abstract}

The presence of protuberances on surfaces, for example, rivets, screws and gaskets, can influence the boundary layer by accelerating the transition from laminar flow to turbulent flow. In some cases this may be undesirable, since the turbulent flow involves frictional forces greater than the ones at the laminar regime. There are some aspects of the flow in the boundary layer perturbed by a single roughness element that are not well understood. The aim of this work is to study the influence of an isolated roughness on the boundary layer. This study is a step towards to the understanding of what can happen in more complex cases. The nature of this study is computational, therefore a Direct Numerical Simulation code is used. The immersed boundary method is used to represent the roughness in the flow on the surface. The numerical code is verified via the Method of Manufactured Solutions. Comparisons between experimental data, Linear Stability Theory and numerical results are also used for the validation of the code. Results obtained with different roughness heights and variations in the pressure gradient allowed the analysis of the influence of a three-dimensional roughness element in boundary layer flows.

Keywords: high-order methods, laminar-turbulent transition in boundary layer, Direct Numerical Simulation, immersed boundary method, parallel computing. 


\section{Lista de Figuras}

1.1 Experimento de Reynolds (extraído de Reynolds (1883)). . . . . . . . . . . . . . . . . 2

1.2 Vórtices ferradura a montante de um cilindro em uma camada limite (extraído de Dyke (1982)). 4

1.3 Estruturas formadas por uma rugosidade cilíndrica em uma camada limite (extraído de Delery

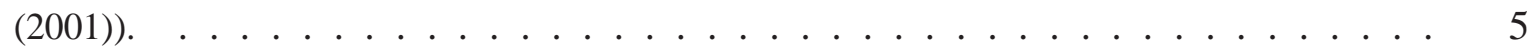

1.4 Estrutura dos vórtices ferradura e grampo de cabelo (extraído de Robinson (1991)). . . . . . 6

1.5 Vórtices grampo de cabelo em uma camada limite laminar (extraído de Dyke (1982)). . . . . 6

2.1 Domínio computacional. . . . . . . . . . . . . . . . . . 12

3.1 Decomposição e sobreposição do domínio para a paralelização, por exemplo, usando 4 EPs. . 19

3.2 Efeito do filtro de Gibbs na transformada de Fourier de uma função descontínua. . . . . . . 30

3.3 Aumento nas regiões 1 e 2 da figura $3.2 \ldots \ldots \ldots \ldots$

3.4 Esquematização do ciclo $\mathrm{V}$ utilizado no método multimalha. . . . . . . . . . . . . . . . . 34

3.5 Ponderação utilizada para as operações de restrição. . . . . . . . . . . . . . . . . 35

3.6 Ponderação utilizada para a interpolação bilinear. . . . . . . . . . . . . . . . . 36

3.7 Ilustração do processo de comunicação entre dois subdomínios adjacentes. . . . . . . . . . . 39

4.1 Variáveis da solução bidimensional. . . . . . . . . . . . . . . . . . . . 47

4.2 Erro $E$ para a solução bidimensional ( $E$ - em escala logarítmica). * representa as malhas com estiramento na direção $y . \ldots \ldots$. . . . . . . . . . . . . . . . . . 49

4.3 Erro $E$ para a solução tridimensional ( $E$ - em escala logarítmica). * representa as malhas com estiramento na direção $y \ldots \ldots \ldots \ldots$. . . . . . . . . . . . . . . 52 
4.4 Características da camada limite. . . . . . . . . . . . . . . . . . 55

4.5 Amplitude de $u^{\prime}$ na direção $x$ ( $a m p$ - em escala logarítmica). Três diferentes frequências de perturbação são consideradas: $F=396 \mathrm{~Hz}, 549 \mathrm{~Hz}$ e $701 \mathrm{~Hz}$. . . . . . . . . . . . . . . . 57

5.1 Distribuição de $v$ e $w$ como vetores, em diferentes posições $x$, para o caso P0 com $h_{r}=0,1 \delta_{1}$. 62

5.1 Distribuição de $v$ e $w$ como vetores, em diferentes posições $x$, para o caso $\mathrm{P} 0$ com $h_{r}=0,1 \delta_{1}$

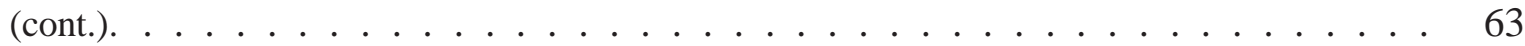

5.2 Distribuição de $u$ e $w$ como vetores, em $y=0,05$, para o caso P0 com $h_{r}=0,1 \delta_{1} \ldots \ldots 63$

5.3 Distribuição de $u$ e $v$ como vetores, em $z=0$, para o caso P0 com $h_{r}=0,1 \delta_{1} \ldots \ldots$. . . . 64

5.4 Perfil de $u$ normal à superfície, em $z=0$, para o caso $\mathrm{P} 0$ com $h_{r}=0,1 \delta_{1}$. . . . . . . . . 64

5.5 Distribuição de $v$ e $w$ como vetores, em diferentes posições $x$, para o caso P0 com $h_{r}=0,2 \delta_{1}$. 65

5.5 Distribuição de $v$ e $w$ como vetores, em diferentes posições $x$, para o caso $\mathrm{P} 0$ com $h_{r}=0,2 \delta_{1}$

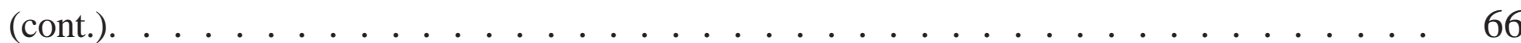

5.6 Distribuição de $u$ e $w$ como vetores, em $y=0,1$, para o caso P0 com $h_{r}=0,2 \delta_{1} \ldots \ldots 67$

5.7 Distribuição de $u$ e $v$ como vetores em $z=0$, para o caso P0 com $h_{r}=0,2 \delta_{1}$. . . . . . 67

5.8 Perfil de $u$ normal à superfície em $z=0$, para o caso P0 com $h_{r}=0,2 \delta_{1} \ldots \ldots$. . . . . 68

5.9 Distribuição de $v$ e $w$ como vetores, em diferentes posições $x$, para o caso P0 com $h_{r}=0,3 \delta_{1}$. 69

5.9 Distribuição de $v$ e $w$ como vetores, em diferentes posições $x$, para o caso $\mathrm{P} 0$ com $h_{r}=0,3 \delta_{1}$

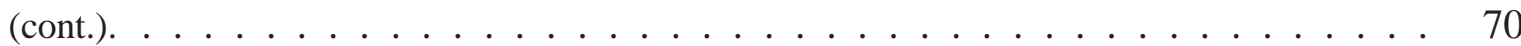

5.10 Distribuição de $u$ e $w$ como vetores em $y=0,2$, para o caso P0 com $h_{r}=0,3 \delta_{1} \ldots \ldots$. . . 71

5.11 Distribuição de $u$ e $v$ como vetores em $z=0$, para o caso $\mathrm{P} 0$ com $h_{r}=0,3 \delta_{1}$. . . . . . . 71

5.12 Perfil de $u$ normal à superfície em $z=0$, para o caso $\mathrm{P} 0$ com $h_{r}=0,3 \delta_{1} \ldots \ldots \ldots 72$

5.13 Distribuição de $v$ e $w$ como vetores, em diferentes posições $x$, para o caso P0 com $h_{r}=0,4 \delta_{1}$. 73

5.13 Distribuição de $v$ e $w$ como vetores, em diferentes posições $x$, para o caso $\mathrm{P} 0$ com $h_{r}=0,4 \delta_{1}$

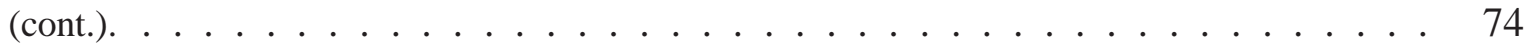

5.14 Distribuição de $u$ e $w$ como vetores em $y=0,3$, para o caso P0 com $h_{r}=0,4 \delta_{1} \ldots \ldots 74$

5.15 Distribuição de $u$ e $v$ como vetores em $z=0$, para o caso $\mathrm{P} 0$ com $h_{r}=0,4 \delta_{1}$. . . . . . . 75

5.16 Perfil de $u$ normal à superfície em $z=0$, para o caso $\mathrm{P} 0$ com $h_{r}=0,4 \delta_{1} \ldots \ldots$. . . . . 75

5.17 Distribuição de $v$ e $w$ como vetores, em diferentes posições $x$, para o caso P0 com $h_{r}=0,5 \delta_{1} . \quad 76$

5.17 Distribuição de $v$ e $w$ como vetores, em diferentes posições $x$, para o caso $\mathrm{P} 0$ com $h_{r}=0,5 \delta_{1}$

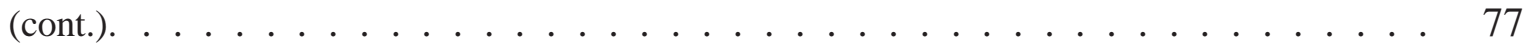


5.18 Distribuição de $u$ e $w$ como vetores em $y=0,4$, para o caso P0 com $h_{r}=0,5 \delta_{1} \ldots \ldots 78$

5.19 Distribuição de $u$ e $v$ como vetores em $z=0$, para o caso $\mathrm{P} 0$ com $h_{r}=0,5 \delta_{1}$. . . . . . . 79

5.20 Perfil de $u$ normal à superfície em $z=0$, para o caso $\mathrm{P} 0 \mathrm{com} h_{r}=0,5 \delta_{1} \ldots \ldots \ldots$

5.21 Distribuição de $v$ e $w$ como vetores, em diferentes posições $x$, para o caso $\mathrm{P} 0$ com $h_{r}=0,6 \delta_{1}$. 80

5.21 Distribuição de $v$ e $w$ como vetores, em diferentes posições $x$, para o caso P0 com $h_{r}=0,6 \delta_{1}$

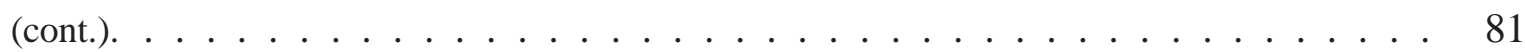

5.22 Distribuição de $u$ e $w$ como vetores em $y=0,5$, para o caso P0 com $h_{r}=0,6 \delta_{1} \ldots \ldots 1$

5.23 Distribuição de $u$ e $v$ como vetores em $z=0$, para o caso P0 com $h_{r}=0,6 \delta_{1}$. . . . . . . 82

5.24 Perfil de $u$ normal à superfície em $z=0$, para o caso $\mathrm{P} 0$ com $h_{r}=0,6 \delta_{1} \ldots \ldots \ldots 2$

5.25 Distribuição de $v$ e $w$ como vetores, em diferentes posições $x$, para o caso $\mathrm{P} 0$ com $h_{r}=0,7 \delta_{1}$. 83

5.25 Distribuição de $v$ e $w$ como vetores, em diferentes posições $x$, para o caso P0 com $h_{r}=0,7 \delta_{1}$

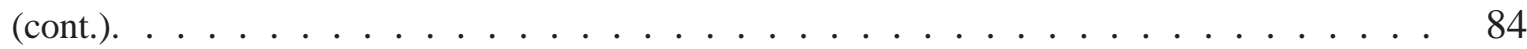

5.26 Distribuição de $u$ e $w$ como vetores em $y=0,6$, para o caso P0 com $h_{r}=0,7 \delta_{1} \ldots \ldots 5$

5.27 Distribuição de $u$ e $v$ como vetores em $z=0$, para o caso $\mathrm{P} 0$ com $h_{r}=0,7 \delta_{1}$. . . . . . 85

5.28 Perfil de $u$ normal à superfície em $z=0$, para o caso $\mathrm{P} 0$ com $h_{r}=0,7 \delta_{1} \ldots \ldots$. . . . . 86

5.29 Distribuição de $v$ e $w$ como vetores, em diferentes posições $x$, para o caso P0 com $h_{r}=0,8 \delta_{1}$. 87

5.30 Distribuição de $u$ e $w$ como vetores em $y=0,7$, para o caso P0 com $h_{r}=0,8 \delta_{1} \ldots \ldots 8$

5.31 Distribuição de $u$ e $v$ como vetores em $z=0$, para o caso $\mathrm{P} 0$ com $h_{r}=0,8 \delta_{1} \ldots \ldots 8$

5.32 Perfil de $u$ normal à superfície em $z=0$, para o caso $\mathrm{P} 0 \mathrm{com} h_{r}=0,8 \delta_{1} \ldots \ldots$. . . . . 89

5.33 Distribuição de $v$ e $w$ como vetores, em diferentes posições $x$, para o caso P0 com $h_{r}=0,9 \delta_{1}$. 90

5.33 Distribuição de $v$ e $w$ como vetores, em diferentes posições $x$, para o caso P0 com $h_{r}=0,9 \delta_{1}$

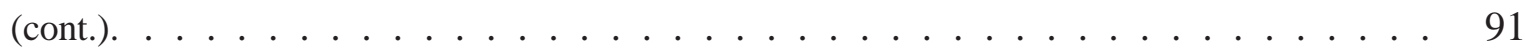

5.34 Distribuição de $u$ e $w$ como vetores em $y=0,8$, para o caso P0 com $h_{r}=0,9 \delta_{1}$. . . . . 91

5.35 Distribuição de $u$ e $v$ como vetores em $z=0$, para o caso $\mathrm{P} 0$ com $h_{r}=0,9 \delta_{1} \ldots \ldots 92$

5.36 Perfil de $u$ normal à superfície em $z=0$, para o caso $\mathrm{P} 0$ com $h_{r}=0,9 \delta_{1} \ldots \ldots \ldots 2$

5.37 Distribuição de $v$ e $w$ como vetores, em diferentes posições $x$, para o caso P0 com $h_{r}=1,0 \delta_{1}$. 93

5.37 Distribuição de $v$ e $w$ como vetores, em diferentes posições $x$, para o caso P0 com $h_{r}=1,0 \delta_{1}$

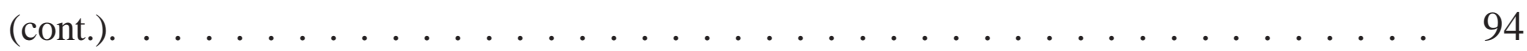

5.38 Distribuição de $u$ e $w$ como vetores em $y=0,9$, para o caso P0 com $h_{r}=1,0 \delta_{1} \ldots \ldots 9$

5.39 Distribuição de $u$ e $v$ como vetores em $z=0$, para o caso $\mathrm{P} 0$ com $h_{r}=1,0 \delta_{1} \ldots \ldots 9$

5.40 Perfil de $u$ normal à superfície em $z=0$, para o caso $\mathrm{P} 0 \mathrm{com} h_{r}=1,0 \delta_{1} \ldots \ldots$. . . . . . 96 
5.41 Distribuição de $v$ e $w$ como vetores, em diferentes posições $x$, para o caso PA com $h_{r}=0,4 \delta_{1}$. 97

5.42 Distribuição de $u$ e $w$ como vetores em $y=0,3$, para o caso PA com $h_{r}=0,4 \delta_{1} \ldots \ldots 9$

5.43 Distribuição de $u$ e $v$ como vetores em $z=0$, para o caso PA com $h_{r}=0,4 \delta_{1} \ldots \ldots 98$

5.44 Perfil de $u$ normal à superfície em $z=0$, para o caso PA com $h_{r}=0,4 \delta_{1}$. . . . . . . . 99

5.45 Distribuição de $v$ e $w$ como vetores, em diferentes posições $x$, para o caso PA com $h_{r}=0,5 \delta_{1} .100$

5.45 Distribuição de $v$ e $w$ como vetores, em diferentes posições $x$, para o caso PA com $h_{r}=0,5 \delta_{1}$

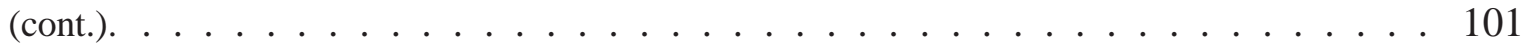

5.46 Distribuição de $u$ e $w$ como vetores em $y=0,4$, para o caso PA com $h_{r}=0,5 \delta_{1} \ldots \ldots 101$

5.47 Distribuição de $u$ e $v$ como vetores em $z=0$, para o caso PA com $h_{r}=0,5 \delta_{1} \ldots \ldots 102$

5.48 Perfil de $u$ normal à superfície em $z=0$, para o caso PA com $h_{r}=0,5 \delta_{1} \ldots \ldots$. . . . . 102

5.49 Distribuição de $v$ e $w$ como vetores, em diferentes posições $x$, para o caso PA com $h_{r}=0,6 \delta_{1} .103$

5.49 Distribuição de $v$ e $w$ como vetores, em diferentes posições $x$, para o caso PA com $h_{r}=0,6 \delta_{1}$ (cont.). . . . . . . . . . . . . . . . . . . . . . . 104

5.50 Distribuição de $u$ e $w$ como vetores em $y=0,5$, para o caso PA com $h_{r}=0,6 \delta_{1} \ldots \ldots 104$

5.51 Distribuição de $u$ e $v$ como vetores em $z=0$, para o caso PA com $h_{r}=0,6 \delta_{1} \ldots \ldots 105$

5.52 Perfil de $u$ normal à superfície em $z=0$, para o caso PA com $h_{r}=0,6 \delta_{1} \ldots \ldots 105$

5.53 Distribuição de $v$ e $w$ como vetores, em diferentes posições $x$, para o caso PF com $h_{r}=0,5 \delta_{1}$

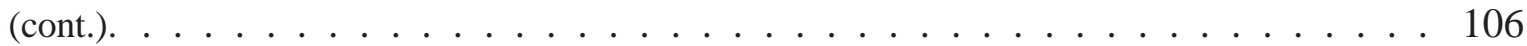

5.53 Distribuição de $v$ e $w$ como vetores, em diferentes posições $x$, para o caso PF com $h_{r}=0,5 \delta_{1} .107$

5.54 Distribuição de $u$ e $w$ como vetores em $y=0,4$, para o caso PF com $h_{r}=0,5 \delta_{1} \ldots \ldots$. . . 108

5.55 Distribuição de $u$ e $v$ como vetores em $z=0$, para o caso PF com $h_{r}=0,5 \delta_{1}$. . . . . . 108

5.56 Perfil de $u$ normal à superfície em $z=0$, para o caso PF com $h_{r}=0,5 \delta_{1} \ldots \ldots$. . . . . 109

5.57 Distribuição de $v$ e $w$ como vetores, em diferentes posições $x$, para o caso PF com $h_{r}=0,6 \delta_{1} .110$

5.58 Distribuição de $u$ e $w$ como vetores em $y=0,5$, para o caso PF com $h_{r}=0,6 \delta_{1} \ldots \ldots 111$

5.59 Distribuição de $u$ e $v$ como vetores em $z=0$, para o caso PA com $h_{r}=0,6 \delta_{1} \ldots \ldots 111$

5.60 Perfil de $u$ normal à superfície em $z=0$, para o caso PF com $h_{r}=0,6 \delta_{1} \ldots \ldots \ldots 112$

A.1 Variáveis da segunda solução bidimensional. . . . . . . . . . . . . . . . . . . 130

A.2 Erro $E$ para a segunda solução bidimensional ( $E$ - em escala logarítmica). * representa as malhas com estiramento na direção $y \ldots \ldots$. . . . . . . . . . . . . . . . . . 131 
A.3 Erro $E$ para a solução tridimensional A ( $E$ - em escala logarítmica). * representa as malhas com estiramento na direção $y \ldots \ldots$. . . . . . . . . . . . . . . . . . 133

A.4 Erro $E$ para a solução tridimensional B ( $E$ - em escala logarítmica). ${ }^{*}$ representa as malhas com estiramento na direção $y \ldots \ldots$. . . . . . . . . . . . . . . . . 135

A.5 Erro $E$ para a solução tridimensional C ( $E$ - em escala logarítmica). * representa as malhas com estiramento na direção $y$. . . . . . . . . . . . . . . . . . . . . . . . . 137

A.6 Erro $E$ para a solução tridimensional D ( $E$ - em escala logarítmica). * representa as malhas com estiramento na direção $y \ldots$. . . . . . . . . . . . . . . . . . . . . . . . 139

B.1 Características da camada limite para o escoamento do caso A. . . . . . . . . . . . . . 142

B.2 Características da camada limite para o escoamento do caso B. . . . . . . . . . . . . . . 143

B.3 Perfis de velocidade $u$ ao longo da direção normal à superfície para o escoamento do caso B. 144

B.4 Características da camada limite para o escoamento do caso C . . . . . . . . . . . . . . 145

B.5 Amplitude de $u^{\prime}$ na direção $x$, para o escoamento com gradiente de pressão próximo de zero e frequência de perturbação $F=549 \mathrm{~Hz}(a m p$ - em escala logarítmica) . . . . . . . . . . . 146 


\section{Lista de Tabelas}

4.1 Malhas sem estiramento na direção $y$ usadas na verificação do código base. . . . . . . . . . 48

4.2 Malhas com estiramento na direção y usadas na verificação do código base. . . . . . . . . . 48

4.3 Ordem de convergência para todas as variáveis calculadas com o MMS para o caso bidimen-

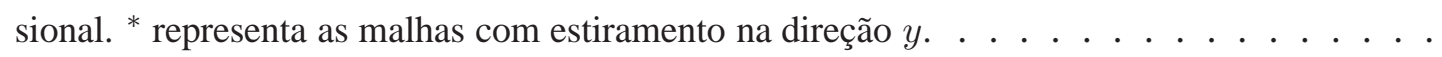

4.4 Ordem de convergência para todas as variáveis calculadas com o MMS para o caso tridimen-

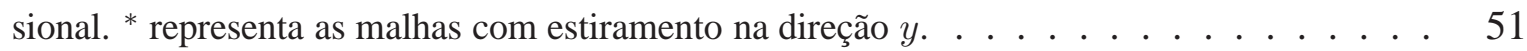

4.5 Desvio máximo (em \%) entre os resultados numéricos e os dados experimentais. . . . . . . 55

A.1 Ordem de convergência para todas as variáveis calculadas com o MMS para o caso bidimensional, com a segunda solução manufaturada. * representa as malhas com estiramento na direção $y \ldots \ldots \ldots \ldots \ldots \ldots \ldots$

A.2 Ordem de convergência para todas as variáveis calculadas com o MMS para o caso tridimensional, com a solução A. * representa as malhas com estiramento na direção y. . . . . . . . 133

A.3 Ordem de convergência para todas as variáveis calculadas com o MMS para o caso tridimensional, com a solução B. * representa as malhas com estiramento na direção y. . . . . . . . . 134

A.4 Ordem de convergência para todas as variáveis calculadas com o MMS para o caso tridimensional, com a solução C. * representa as malhas com estiramento na direção y. . . . . . . . 136

A.5 Ordem de convergência para todas as variáveis calculadas com o MMS para o caso tridimensional, com a solução D. * representa as malhas com estiramento na direção y. . . . . . . . 140

B.1 Desvio máximo (em \%) entre os resultados numéricos e os dados experimentais para o caso A. 142

B.2 Desvio máximo (em \%) entre os resultados numéricos e os dados experimentais para o caso B. 143 
B.3 Desvio máximo (em \%) dos perfis de velocidade $u$ ao longo da direção $y$, entre os resultados numéricos e os dados experimentais para o caso B. . . . . . . . . . . . . . . . . . . . 144

B.4 Desvio máximo (em \%) entre os resultados numéricos e os dados experimentais para o caso C. 144 


\section{Abreviaturas e siglas}

BSJR Bolha de Separação a Jusante da Rugosidade

CFD Computational Fluid Dynamics (Dinâmica dos fluidos computacional)

DNS Direct Numerical Simulation (Simulação numérica direta)

EDP Equação Diferencial Parcial

EP Elemento de Processamento

FAS Full Approximation Scheme (Esquema de aproximação total)

FS Falkner-Skan

FW Full Weight (Peso total)

LSOR Line Successive Over Relaxation (Método de sobrerrelaxação sucessiva por linhas)

LST Linear Stability Theory (Teoria de estabilidade linear)

MES Method of Exact Solutions (Método das soluções exatas)

MII Método de Interfaces Imersas

MMS Method of Manufactured Solutions (Método das soluções manufaturadas)

SI Straight Injection (Injeção direta)

SOR Successive Over Relaxation (Método de sobrerrelaxação sucessiva)

TS Tollmien-Schlichting

VLCRP Vórtices Longitudinais Contrarrotativos Primários

VLCRS Vórtices Longitudinais Contrarrotativos Secundários

VLCRT Vórtices Longitudinais Contrarrotativos Terciários 
VTFMR Vórtice Tipo Ferradura a Montante da Rugosidade 


\section{Lista de Símbolos}

$a, b, c \quad$ Termos não lineares das equações de transporte de vorticidade no espaço físico

amp Variação da amplitude de perturbação da velocidade

$\mathcal{A} \quad$ Amplitude da perturbação

$A_{k}, B_{k}, C_{k}$ Termos não lineares das equações de transporte de vorticidade no espaço de Fourier

$d_{r} \quad$ Diâmetro da rugosidade

E $\quad$ Erro

$f_{p}(x) \quad$ Função utilizada para introdução de perturbações não estacionárias

$f_{x} \quad$ Termo forçante do método de fronteiras imersas na direção longitudinal

$f_{y} \quad$ Termo forçante do método de fronteiras imersas na direção normal à superfície

$f_{z} \quad$ Termo forçante do método de fronteiras imersas na direção transversal

$f_{1}(x) \quad$ Função utilizada para relaminarização do escoamento na saída do domínio

$f_{2}(x) \quad$ Função utilizada para relaminarização do escoamento na entrada do domínio

F $\quad$ Frequência de perturbação dimensional

$F_{x_{k}} \quad$ Termo forçante do método de fronteiras imersas na direção longitudinal no espaço de Fourier 
$F_{y_{k}} \quad$ Termo forçante do método de fronteiras imersas na direção normal à superfície no espaço de Fourier

$F_{z_{k}} \quad$ Termo forçante do método de fronteiras imersas na direção transversal no espaço de Fourier

$h_{r} \quad$ Altura da rugosidade

$h_{x} \quad$ Espaçamento de malha na direção longitudinal

$h_{y} \quad$ Espaçamento de malha na direção normal à superfície

$h_{y_{0}} \quad$ Primeiro espaçamento de malha na direção normal à superfície

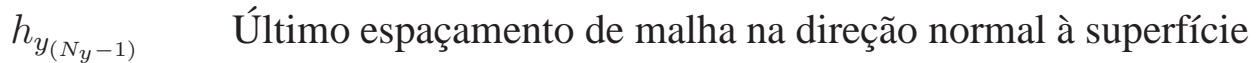

$h_{z} \quad$ Espaçamento de malha na direção transversal

$H_{12} \quad$ Fator de forma da camada limite

$i \quad$ Índice na direção longitudinal

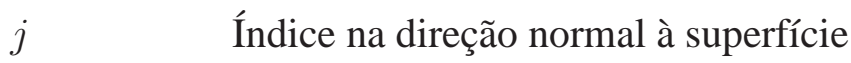

$k \quad$ Modo de Fourier na direção transversal

$K \quad$ Número total de modos de Fourier na direção transversal

$\tilde{L} \quad$ Comprimento de referência

$N \quad$ Número total de pontos da malha

$N_{E P} \quad$ Número total de pontos em cada elemento de processamento

$N_{x} \quad$ Número total de pontos na direção longitudinal

$N_{y} \quad$ Número total de pontos na direção normal à superfície

$p \quad$ Ordem de convergência calculada

$P(y) \quad$ Polinômio das soluções manufaturadas

$r_{f} \quad$ Fator de relaxação do método de fronteira imersa

Re Número de Reynolds

$s_{f} \quad$ Fator de estiramento de malha

$t \quad$ Tempo

$u \quad$ Componente de velocidade na direção longitudinal

$u^{\prime} \quad$ Perturbação da componente de velocidade na direção longitudinal

$u_{b} \quad$ Componente de velocidade na direção longitudinal para o escoamento base

$u_{e} \quad$ Velocidade na fronteira da camada limite 
$u_{F S} \quad$ Componente de velocidade na direção longitudinal para a solução de Falkner-Skan

$u$

$U_{k}$

$\tilde{U}_{\infty}$

$v$

$v_{b}$

$v_{F S}$

$V_{k}$

$w$

$W_{k}$

$x$

$x_{0}$

$x_{1}$

$x_{2}$

$x_{3}$

$x_{4}$

$x_{\max }$

$y$

$y_{\max }$

Vetor do campo de velocidades

Componente de velocidade na direção longitudinal no espaço de Fourier

Velocidade de referência

Componente de velocidade na direção normal à superfície

Componente de velocidade na direção normal à superfície para o escoamento base

Componente de velocidade na direção normal à superfície para a solução de Falkner-Skan

Componente de velocidade na direção normal à superfície no espaço de Fourier

Componente de velocidade na direção transversal

Componente de velocidade na direção transversal no espaço de Fourier

Coordenada na direção longitudinal

Coordenada na direção longitudinal do contorno de entrada do domínio computacional

Coordenada na direção longitudinal do início da região de introdução das perturbações próximo ao contorno de entrada

Coordenada na direção longitudinal do fim da região de introdução das perturbações próximo ao contorno de entrada

Coordenada na direção longitudinal do início da região de relaminarização do escoamento próximo ao contorno de saída

Coordenada na direção longitudinal do fim da região de relaminarização do escoamento próximo ao contorno de saída

Coordenada na direção longitudinal do contorno de saída do domínio computacional

Coordenada na direção normal à superfície

Coordenada na direção normal à superfície do contorno superior do domínio computacional

z $\quad$ Coordenada na direção transversal 
$\dot{\alpha} \quad$ Vetor de número de onda

$\alpha_{r} \quad$ Parte real do número de onda longitudinal

$\beta_{H} \quad$ Parâmetro de Hartree

$\beta_{k} \quad$ Número de onda transversal

$\delta_{i b} \quad$ Função que define a posição do corpo imerso no escoamento

$\delta_{1} \quad$ Espessura de deslocamento da camada limite

$\delta_{2} \quad$ Espessura de deslocamento da quantidade de movimento da camada limite

$\delta t \quad$ Passo de tempo

$\varepsilon \quad$ Valor de referência

$\theta_{k} \quad$ Fase da perturbação

$\lambda_{z} \quad$ Comprimento de onda fundamental

$\tilde{\nu} \quad$ Viscosidade cinemática

$\sigma \quad$ Filtro de Gibbs

$\omega_{t_{k}} \quad$ Frequência de perturbação adimensional

$\omega_{x} \quad$ Componente de vorticidade na direção longitudinal

$\omega_{y} \quad$ Componente de vorticidade na direção normal à superfície

$\omega_{z} \quad$ Componente de vorticidade na direção transversal

$\omega_{z_{b}} \quad$ Componente de vorticidade na direção transversal para o escoamento base

$\omega_{z_{F S}} \quad$ Componente de vorticidade na direção transversal para Falkner-Skan

$\Omega_{x_{k}} \quad$ Componente de vorticidade na direção longitudinal no espaço de Fourier

$\Omega_{y_{k}} \quad$ Componente de vorticidade na direção normal à superfície no espaço de Fourier

$\Omega_{z_{k}} \quad$ Componente de vorticidade na direção transversal no espaço de Fourier 


\section{Sumário}

1 Introdução 1

1.1 Revisão bibliográfica . . . . . . . . . . . . . . . . . . . 1

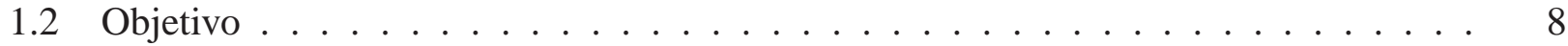

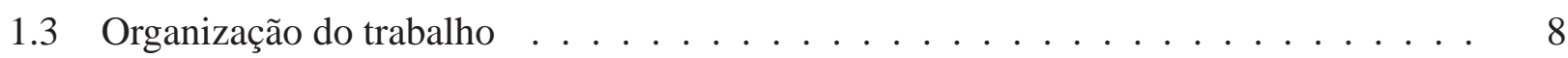

2 Formulação matemática $\quad 9$

2.1 Equações do modelo . . . . . . . . . . . . . . . . . . . . . 9

2.2 Sistema de referência e domínio de integração . . . . . . . . . . . . . . 11

2.3 Escoamento base . . . . . . . . . . . . . . . . . . . 13

2.4 Condições de contorno . . . . . . . . . . . . . . . . . . . . . . 13

2.4.1 Condições de contorno para o escoamento base . . . . . . . . . . . . . . 14

2.4.2 Condições de contorno para o escoamento tridimensional . . . . . . . . . . . 14

3 Método numérico $\quad 17$

3.1 Decomposição do domínio . . . . . . . . . . . . . . . . 18

3.2 Método espectral . . . . . . . . . . . . . . . . . . . . . . . 19

3.3 Derivadas temporais . . . . . . . . . . . . . . . 20

3.4 Derivadas espaciais . . . . . . . . . . . . . . . . 22

3.4 .1 Estiramento de malha . . . . . . . . . . . . . . . 23

3.5 Representação da rugosidade . . . . . . . . . . . . . . . . . . . . 23

3.5.1 Revisão bibliográfica de métodos de fronteiras imersas . . . . . . . . . . . . 24 
3.5.2 Método de interfaces imersas . . . . . . . . . . . . . . . . . 26

3.5.3 Método de fronteiras imersas . . . . . . . . . . . . . . . . . 26

3.6 Filtro de Gibbs . . . . . . . . . . . . . . . . . . . 27

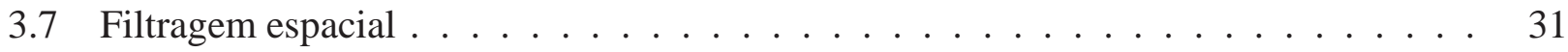

3.8 Relaminarização do escoamento . . . . . . . . . . . . . . . . . . 32

3.9 Solução da equação de Poisson . . . . . . . . . . . . . . . . . 33

3.10 Cálculo da vorticidade na superfície . . . . . . . . . . . . . 39

3.11 Introdução de perturbações . . . . . . . . . . . . . . . . . . . . . . 40

3.12 Método numérico . . . . . . . . . . . . . . . . . . . . . . 41

4 Verificação e validação

4.1 Verificação X validação . . . . . . . . . . . . . . . . . . . . . 43

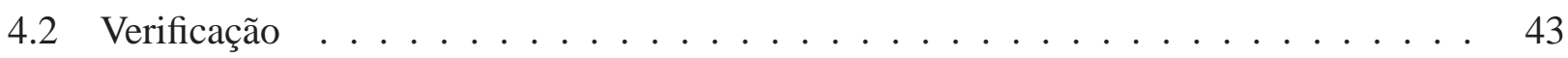

4.2.1 Método das soluções manufaturadas . . . . . . . . . . . . . . . . 44

4.2.2 Cálculo da ordem de convergência . . . . . . . . . . . . . . . . 45

4.2 .3 Verificação do código base bidimensional . . . . . . . . . . . . . . 46

4.2 .4 Verificação do código DNS tridimensional . . . . . . . . . . . . . . . 50

4.3 Validação . . . . . . . . . . . . . . . . . . . . 53

4.3.1 Características da camada limite . . . . . . . . . . . . . . 53

4.3.2 Desenvolvimento da amplitude de perturbação . . . . . . . . . . . 56

4.4 Conclusão . . . . . . . . . . . . . . . . . . . . . . . 57

5 Resultados $\quad 59$

5.1 Escoamento contendo rugosidade . . . . . . . . . . . . . . . . 59

5.1.1 Caso P0 - escoamento com gradiente de pressão próximo de zero . . . . . . 61

5.1.2 Caso PA - escoamento com gradiente de pressão adverso . . . . . . . . . . 96

5.1.3 Caso PF - escoamento com gradiente de pressão favorável . . . . . . . . 106

5.2 Conclusão . . . . . . . . . . . . . . . . . . . . . . 112

6 Conclusões $\quad 115$

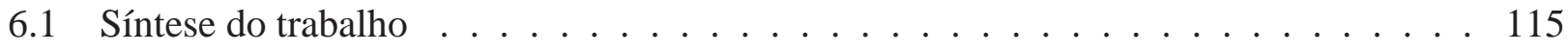

6.2 Considerações finais sobre os resultados . . . . . . . . . . . . . . . . 117 
6.3 Trabalhos futuros . . . . . . . . . . . . . . . . . 117

$\begin{array}{lr}\text { Referências bibliográficas } & 128\end{array}$

A Demais resultados de verificação 129

A.1 Verificação do código base bidimensional . . . . . . . . . . . . . . . . . . . . . . 129

A.2 Verificação do código DNS tridimensional . . . . . . . . . . . . . . . . 132

B Demais resultados de validação $\quad 141$

B.1 Características da camada limite . . . . . . . . . . . . . . . . . . . 141

B.1.1 Resultados do caso A . . . . . . . . . . . . . . . . . . . . . . . . 142

B.1.2 Resultados do caso B . . . . . . . . . . . . . . . . . . . . . . . 142

B.1.3 Resultados do caso C . . . . . . . . . . . . . . . . . . . . . . 144

B.2 Desenvolvimento da amplitude de perturbação . . . . . . . . . . . . . . . . . 145 


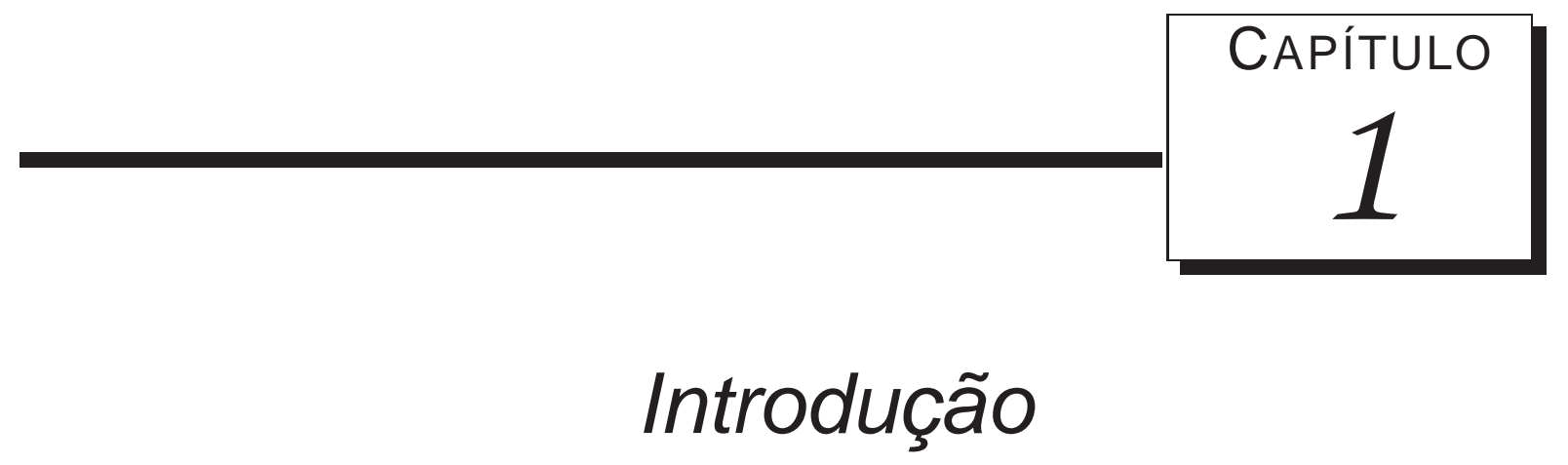

A presença de irregularidades na superfície de asas de aeronaves ou pás de turbinas eólicas (rebites, junções, insetos, etc) pode ocasionar a antecipação da transição do regime laminar para o turbulento. Esta antecipação afeta o escoamento de forma a aumentar custos e reduzir desempenho. Neste trabalho pretende-se investigar a influência de uma rugosidade isolada neste tipo de escoamento.

A seguir, é apresentada uma revisão bibliográfica que vai desde o início do estudo da transição em escoamentos até o estado da arte da transição influenciada por rugosidades. Em seguida, o objetivo do presente estudo é apresentado. Por fim, faz-se uma descrição da organização geral do trabalho.

\subsection{Revisão bibliográfica}

A transição de escoamento laminar para turbulento foi primeiramente estudada por Osborne Reynolds, em seu famoso experimento de 1883 (Reynolds, 1883). Neste experimento, ilustrado na figura 1.1, Reynolds analisou o escoamento de água em tubos de vidro, utilizando tinta para a visualização. Ele observou que, quando a velocidade do escoamento era baixa, uma linha reta se formava no tubo, como visto na figura 1.1a. Esse regime de escoamento foi denominado de laminar. Conforme ele aumentava a vazão de água, a partir de determinado ponto, a tinta começava a se espalhar até tingir toda a água (figura 1.1b). O ponto a partir do qual a tinta se espalhava se aproximava da entrada do tubo conforme a velocidade aumentava. Porém, mesmo com a mais alta velocidade empregada por 
Reynolds, esse ponto não chegava à entrada do domínio. O regime de escoamento a partir desse ponto de transição foi denominado turbulento. Ainda nesse experimento, Reynolds observou as estruturas formadas antes do escoamento se tornar totalmente turbulento, através de feixes de luz colocados na lateral do tubo (vide figura 1.1c).

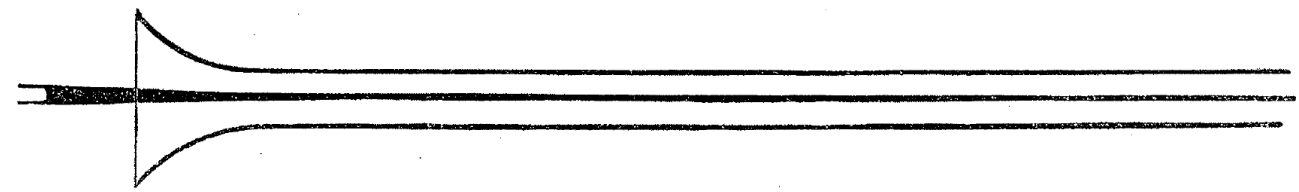

(a) Escoamento laminar, com baixa velocidade.

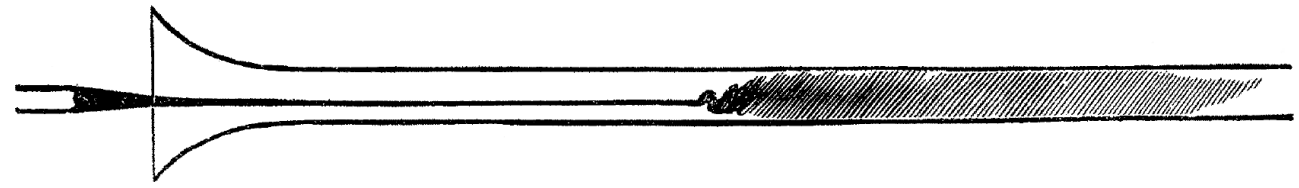

(b) Escoamento turbulento, a certa distância da entrada do tubo.

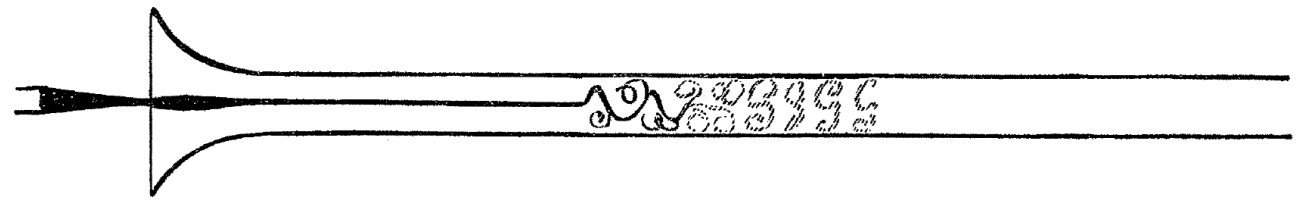

(c) Estruturas vorticais antes do escoamento se tornar turbulento.

Figura 1.1: Experimento de Reynolds (extraído de Reynolds (1883)).

Em 1904, Prandtl publicou o primeiro trabalho a respeito da teoria de camada limite (Prandtl, 1904). Blasius e Boltze, ambos alunos de Prandtl, dão sequência aos estudos de camada limite (Blasius, 1908; Boltze, 1908). Em particular, Blasius (1908) estuda o desenvolvimento da camada limite sobre uma placa plana. Por alguns anos, os únicos estudos a respeito de camada limite vieram do grupo de Prandtl, em Göttingen. Somente na década de 1930 o conceito de camada limite começou a ser conhecido mundialmente (Tani, 1977). Com as publicações de Tollmien (1929) e Schlichting (1933) iniciou-se o estudo de transição em camada limite. Desde então, a transição laminar-turbulenta em camada limite tem sido um importante tema de estudo.

A importância desse estudo deve-se tanto ao entendimento do comportamento da camada limite quanto ao desenvolvimento de tecnologia associada a escoamentos aerodinâmicos e hidrodinâmicos. Muitos avanços foram feitos no intuito de se definir a natureza da instabilidade e do processo de transição (Reynolds, 1894; Morkovin, 1969; Tani, 1969; Stuart, 1971; Reshotko, 1976; Rott, 1990). Nestes estudos, identificou-se que os fatores mais importantes no processo de transição em camada limite são o gradiente de pressão do escoamento externo, a presença de rugosidade na superfície e a intensidade das perturbações no escoamento livre. 


\section{1 - Revisão bibliográfica}

Em particular, os efeitos de uma rugosidade na camada limite são o tema de um grande número de estudos (Citro et al., 2014; Kozlov et al., 2014; Brynjell-Rahkola et al., 2014). A maior parte da literatura relacionada ao efeito aerodinâmico da rugosidade se refere à rugosidade distribuída por uma extensa área da superfície. Em geral, estes estudos abordam aspectos estatísticos e buscam encontrar correlações empíricas para coeficientes de arrasto e transferência de calor. No entanto, pouco se tem avançado no entendimento da influência de rugosidade isoladas no processo de transição. Neste contexto, busca-se com o presente trabalho contribuir para o estado da arte dos efeitos de uma rugosidade isolada na camada limite.

O efeito de rugosidades bidimensionais (rugosidades que não variam na direção transversal) é relativamente simples. No que tange ao processo de transição para turbulência, os experimentos indicam a existência de uma altura crítica adimensional de rugosidade. Abaixo desta altura, o escoamento não sofre transição e a rugosidade é chamada subcrítica. Do contrário, ela é chamada supercrítica. Esta altura depende de vários fatores como formato da rugosidade e nível de turbulência do escoamento externo (Tani, 1961). O efeito de uma rugosidade é a geração de um perfil de velocidade inflexional à jusante desta rugosidade. Este perfil inflexional é instável e pode dar origem à turbulência. Um estudo detalhado deste processo foi realizado por Klebanoff et al. (1992). Outro trabalho que trata dos efeitos de uma rugosidade bidimensional em camada limite turbulenta foi apresentado por Nigim e Cockrell (1985).

Em geral, o efeito da rugosidade é induzir a antecipação da transição. Uma rugosidade tridimensional não é tão efetiva quando uma rugosidade bidimensional na indução da transição (Klebanoff et al., 1955; Tani, 1961). Além disso, o comportamento do escoamento com uma rugosidade tridimensional é muito mais crítico. Para uma protuberância bidimensional, o ponto de transição se move gradualmente em direção à rugosidade, à medida que se aumenta a velocidade. Já para uma protuberância tridimensional, quando a velocidade aumenta, a partir de um valor crítico, o ponto de transição se move rapidamente em direção à protuberância.

No processo de transição devido a uma rugosidade tridimensional, várias questões permanecem em aberto. Klebanoff e Tidstrom (1959) mostraram que, em um camada limite laminar e sem gradiente de pressão, uma onda de Tollmien-Schlichting (TS) tridimensional com intensidade da ordem de $2 \%$ em relação ao escoamento livre pode ter um comportamento linear. Similarmente, Miksad (1972) observou que uma perturbação instável em uma camada livre de cisalhamento, com intensidade maior que $2 \%$ em relação ao escoamento livre, também tem um comportamento linear. Com isso, é razoável 
dizer que, a um número de Reynolds subcrítico, as instabilidades têm um comportamento linear.

O número de Reynolds crítico, baseado na altura da rugosidade, delimita a separação entre instabilidades lineares e não lineares. Em escoamentos com número de Reynolds subcrítico, as perturbações podem, inicialmente, ser amplificadas. Porém, elas não conseguem se sustentar e acabam se dissipando lateralmente, até serem amortecidas, conforme são levadas pelo escoamento a regiões mais estáveis. Para escoamentos com número de Reynolds maior que o valor crítico, as instabilidades tornam-se não lineares e as perturbações não satisfazem a teoria linear (Klebanoff et al., 1992).

Um levantamento da literatura mais antiga sobre os efeitos de uma rugosidade tridimensional isolada em uma camada limite laminar ou turbulenta pode ser encontrado em Sedney (1973). O autor reporta a existência de um número de estruturas de escoamentos típicas em escoamentos ao redor de protuberâncias em camada limite. Em primeiro lugar, existe uma separação a montante da rugosidade que dá origem a um vórtice. Este vórtice é esticado pelo escoamento ao redor da rugosidade, formando uma ferradura (vide figura 1.2).

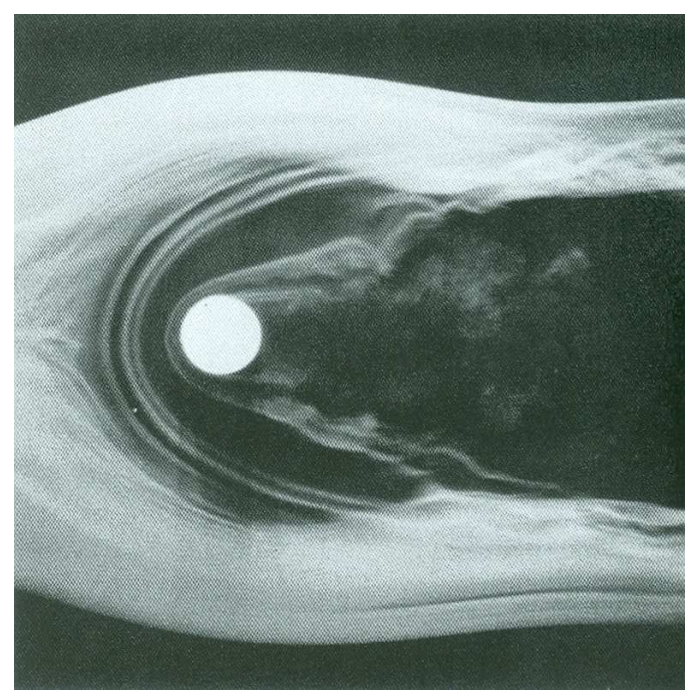

Figura 1.2: Vórtices ferradura a montante de um cilindro em uma camada limite (extraído de Dyke (1982)).

Os braços da ferradura formam vórtices longitudinais que persistem por distâncias consideráveis à jusante da protuberância. Adicionalmente, vórtices espirais se elevam da superfície da placa na região da esteira próxima à protuberância. Esses vórtices podem ser vistos na figura 1.3. Detalhes do desenvolvimento da esteira dependem do escoamento ser laminar, transicional ou turbulento, mas os elementos acima descritos estão sempre presentes.

O escoamento sobre uma rugosidade é um exemplo de configuração no qual pode haver separação tridimensional da camada limite. No entanto, a escassez na investigação do tema contrasta com sua 


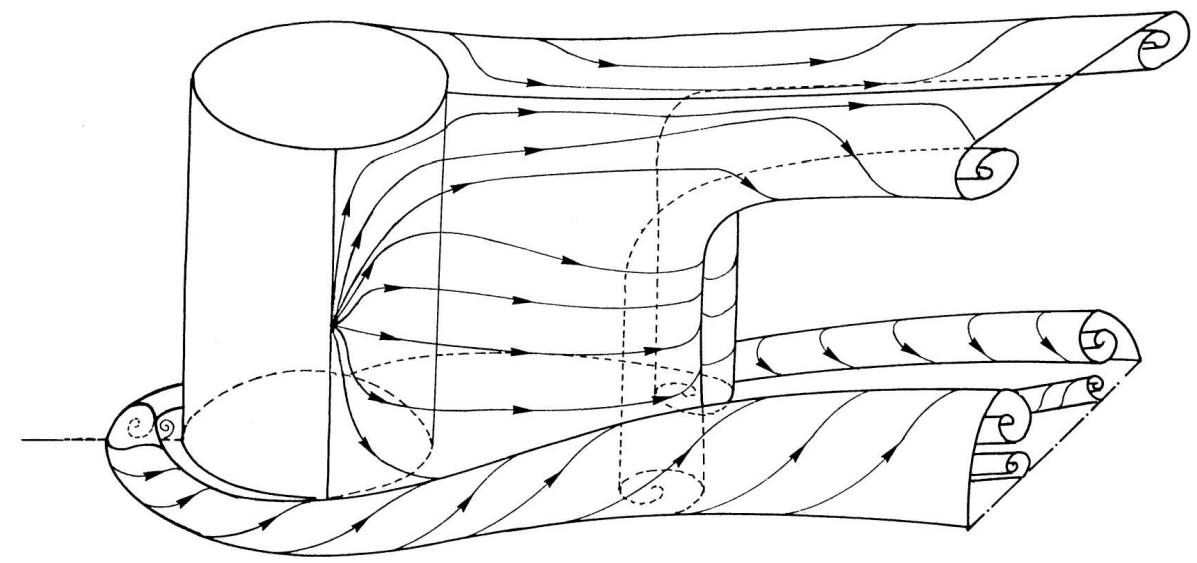

Figura 1.3: Estruturas formadas por uma rugosidade cilíndrica em uma camada limite (extraído de Delery (2001)).

importância tecnológica. A separação tridimensional pode apresentar topografias muito complexas em relação àquela da separação bidimensional, como, por exemplo, a formação de vórtices espirais (Delery, 2001). Estes vórtices espirais podem estar associados a um desprendimento periódico de vórtices na esteira de um cilindro. Eles são formados a partir da deflexão do escoamento que passa sobre a rugosidade e se orientam na direção do escoamento, podendo se conectar formando um vórtice tipo grampo de cabelo. A formação dos vórtices grampo de cabelo pode ser vista na figura 1.4. Ainda, na figura 1.5, fotos de experimentos mostram vórtices grampo de cabelo em vistas superior (1.5a) e lateral (1.5b) ao escoamento. O que frequentemente se observa em um experimento é o desprendimento periódico deste tipo de vórtice.

Outro tipo de vórtice formado em escoamentos sobre rugosidades é o vórtice ferradura (figuras 1.2 e 1.4). Verifica-se em visualizações de escoamentos que, dependendo dos parâmetros envolvidos, pode haver a formação de mais do que um destes vórtices. Devido à complexidade do fenômeno, a maior parte dos estudos se dedicaram à visualização do escoamento (Gregory e Walker, 1951; Mochizuki, 1961; Tani et al., 1962; Gupta, 1980). Os resultados obtidos por técnicas de visualização têm um caráter mais qualitativo do que quantitativo.

Uma análise quantitativa detalhada foi feita por Klebanoff et al. (1992), em que um banco de dados muito rico sobre o problema é apresentado. Tanto o escoamento livre permanente quanto o oscilatório foram considerados. A frequência de desprendimento dos vórtices grampo de cabelo a partir da rugosidade e o seu desenvolvimento até a turbulência foram investigados. Foi ainda analisado se estes vórtices poderiam formar um perfil inflexional e se a origem da turbulência estaria relacionada a isto, como no trabalho de Klebanoff e Sargent (1962). Klebanoff e Sargent (1962) investigaram o processo 


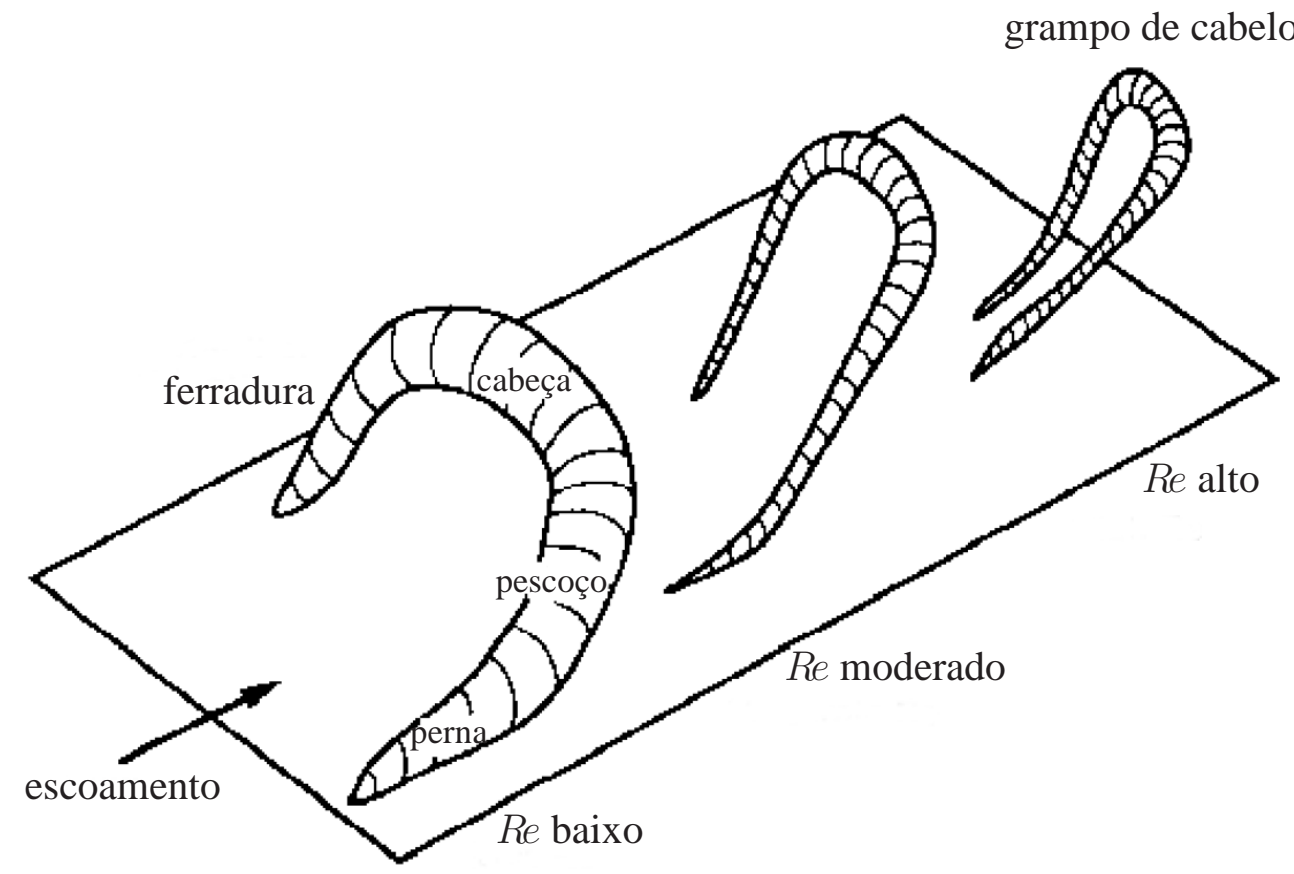

Figura 1.4: Estrutura dos vórtices ferradura e grampo de cabelo (extraído de Robinson (1991)).

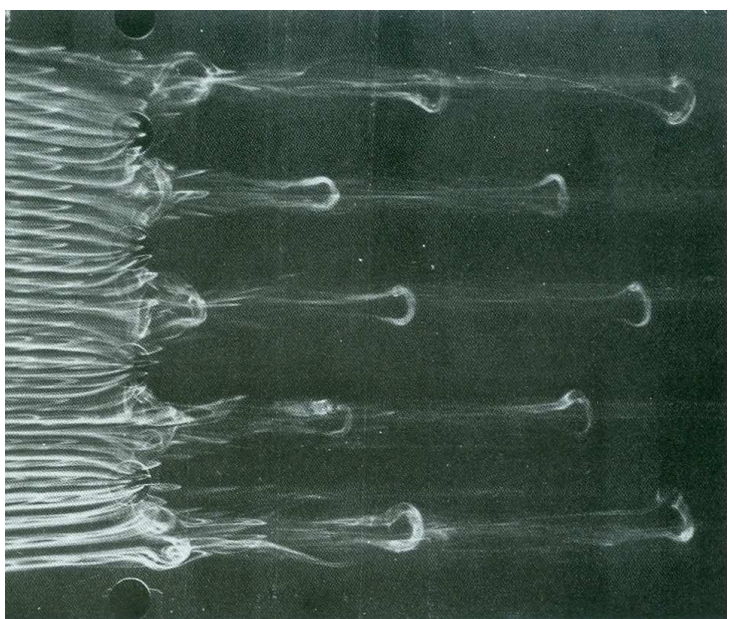

(a) Vista superior.

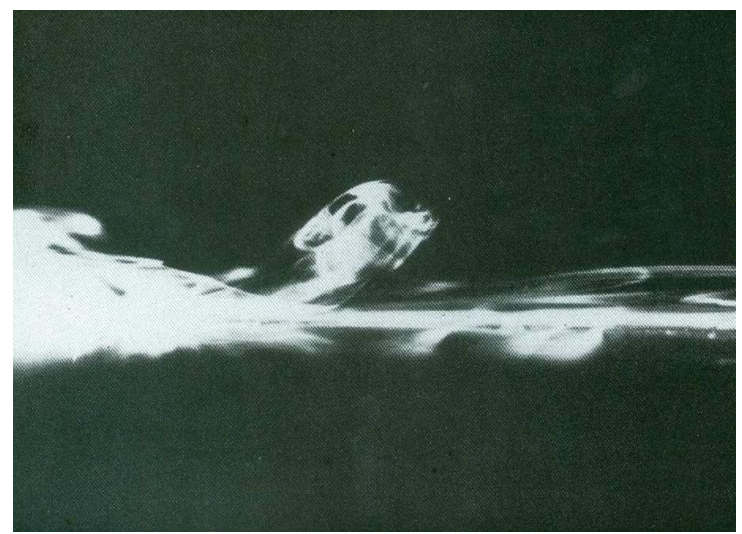

(b) Vista lateral.

Figura 1.5: Vórtices grampo de cabelo em uma camada limite laminar (extraído de Dyke (1982)).

de transição para um escoamento de Blasius em uma placa plana e estabeleceram uma analogia entre um perfil inflexional de instabilidade secundária, que ocorre nos últimos estágios da transição, e o comportamento do escoamento com um elemento rugoso tridimensional.

Apesar dos avanços feitos por Klebanoff et al. (1992) não gerarem resultados conclusivos, um modelo de duas regiões foi proposto para o desenvolvimento da camada limite turbulenta: uma região próxima à parede, onde existe interação entre os vórtices grampo de cabelo e o vórtice ferradura, e uma região distante da parede, onde os vórtices grampo de cabelo dão origem a vórtices anulares. 


\section{1 - Revisão bibliográfica}

A semelhança da instabilidade de um par de vórtices longitudinais foi estudada por Crow (1970). A análise da evolução da esteira turbulenta, em particular, a sua difusão na direção transversal, não foi realizada em detalhe. Os próprios autores informaram que tal análise estava planejada, mas esta, aparentemente, nunca foi realizada.

Os anos 90 assistiram a uma grande evolução das técnicas e recursos em mecânica dos fluidos computacional. Isto permitiu simulações detalhadas de escoamentos complexos, entre os quais, o escoamento ao redor de uma partícula esférica imersa em uma camada limite laminar, realizada por Saiki e Biringen (1997). Este escoamento tem semelhança com o escoamento sobre uma rugosidade cilíndrica na superfície. Ambos os casos, subcrítico e supercrítico, foram considerados. No caso subcrítico, verificou-se a formação de ondas TS que, no entanto, não conduziram à turbulência. No caso supercrítico a turbulência se originava por um processo de transição abrupta (bypass transition). Os autores não diferenciam entre a transição associada à partida da simulação e o processo de transição que ocorre de forma permanente, depois que o transiente de partida se dissipa. Isto dificulta a análise destes resultados. A partícula esférica imersa não forma um vórtice ferradura e esta é a principal diferença em relação àquele associado a uma rugosidade. Uma revisão detalhada sobre a origem e evolução de ondas TS, assim como do mecanismo de transição abrupta, pode ser encontrada em Medeiros (2000) e Medeiros e Mendonça (2000).

Um estudo de instabilidade secundária a partir de superfícies curvas foi realizado por Souza (2003). No caso estudado, a instabilidade centrífuga gera vórtices longitudinais contra-rotativos, chamados de vórtices de Görtler. Estes vórtices são semelhantes aos que foram observados experimentalmente a jusante de uma rugosidade. Os vórtices de Görtler transformam o escoamento bidimensional do tipo Blasius em um escoamento tridimensional com perfis inflexionais nas direções transversal e normal à parede. De acordo com a literatura investigada, cada inflexão leva a um tipo de instabilidade secundária, que pode ser do tipo sinuoso ou do tipo varicoso. Estes aspectos também podem ser investigados computacionalmente no caso da rugosidade, verificando qual tipo de instabilidade secundária acontece para diferentes relações altura-largura da rugosidade em relação à altura da camada limite.

Em suma, o que se percebe desta revisão bibliográfica é que existem muitas questões pendentes no que concerne aos mecanismos de transição associados a rugosidades em camada limite, assim como da influência da rugosidade em camadas limites turbulentas. De fato, isto não é surpreendente pela complexidade do escoamento em questão. A análise de rugosidades isoladas, como a feita neste 
estudo, pode preencher uma lacuna importante neste tema.

\subsection{Objetivo}

A transição do regime laminar para o turbulento em uma camada limite influenciado por um elemento rugoso é um tema de interesse. Esse tipo de escoamento pode ocorrer, por exemplo, em asas de aeronaves ou pás de turbinas eólicas, que podem conter rebites, junções, insetos, poeira ou corrosão. A presença dessas irregularidades ocasiona o deslocamento do ponto de transição, reduzindo a sustentação e aumentando o coeficiente de arrasto. Como consequência, tem-se uma redução na performance, que pode se refletir como um aumento no consumo de combustível ou redução na produção de energia. O estudo da transição induzida por um elemento rugoso pode auxiliar na desenvolvimento de aerofólios mais eficientes.

No presente trabalho, pretende-se estudar a influência de uma rugosidade cilíndrica isolada no ponto de transição de um escoamento em camada limite, com diferentes gradientes de pressão.

\subsection{Organização do trabalho}

No Capítulo 2 é feita a descrição da formulação matemática do problema em estudo, apresentando o domínio utilizado e as equações do modelo, com suas condições de contorno.

Em seguida, no Capítulo 3, são apresentadas as discretizações das equações e os métodos numéricos utilizados para a resolução numérica dessas equações.

No Capítulo 4 é feita uma breve revisão bibliográfica de verificação e validação. Em seguida, são apresentados os resultados que mostram a verificação e validação do código numérico.

Na sequência, no Capítulo 5, os resultados das simulações numéricas de uma rugosidade isolada sobre uma superfície são apresentados. Ainda neste capítulo, é feita uma comparação dos resultados, a fim de identificar a influência dos diferentes parâmetros no escoamento em estudo.

Finalmente, no Capítulo 6 são apresentadas as contribuições deste trabalho e são feitas conclusões e considerações finais, juntamente com proposta de melhorias e trabalhos futuros. 


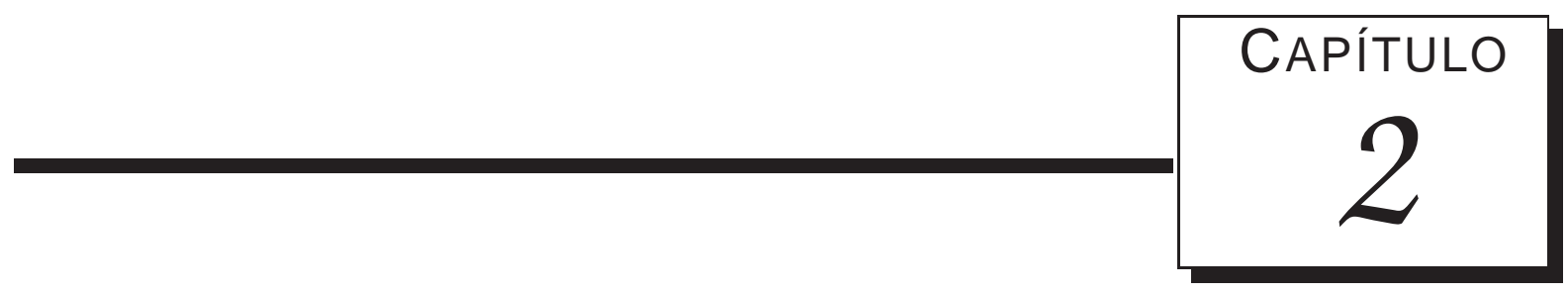

\section{Formulação matemática}

Neste capítulo são apresentadas as equações que modelam o problema e a formulação vorticidade-velocidade, que é adotada aqui para a simulação numérica de escoamentos incompressíveis. Além disso, também são mostrados o sistema de coordenadas utilizado e as condições iniciais e de contorno envolvidas.

\subsection{Equações do modelo}

As equações do modelo são as equações de Navier-Stokes para escoamentos incompressíveis, com viscosidade constante, para fluidos newtonianos, escritas em coordenadas cartesianas. A forma adimensional das equações é utilizada para os resultados apresentados neste estudo. A adimensionalização com base nas escalas de velocidade, comprimento e viscosidade levam ao número de Reynolds, que é definido como:

$$
R e=\frac{\tilde{U}_{\infty} \tilde{L}}{\tilde{\nu}}
$$

em que $\tilde{U}_{\infty}$ é a velocidade de referência, $\tilde{L}$ é o comprimento de referência e $\tilde{\nu}$ é a viscosidade cinemática do fluido. A velocidade de referência é a velocidade do escoamento fora da camada limite, na entrada do domínio, e o comprimento de referência é uma distância a partir do bordo de ataque. A vantagem em se utilizar quantidades adimensionais é que mesmos fenômenos físicos, com diferentes 
escalas e/ou propriedades, podem ser observados, desde que o número de Reynolds seja igual. Isto faz com que os resultados aqui mostrados sejam mais gerais.

Pode-se relacionar as variáveis dimensionais e adimensionais, em coordenadas cartesianas, através das seguintes relações:

$$
\begin{aligned}
& x=\frac{\tilde{x}}{\tilde{L}} ; \quad y=\frac{\tilde{y} \sqrt{R e}}{\tilde{L}} ; \quad z=\frac{\tilde{z}}{\tilde{L}} ; \quad u=\frac{\tilde{u}}{\tilde{U}_{\infty}} ; \quad v=\frac{\tilde{v} \sqrt{R e}}{\tilde{U}_{\infty}} ; \quad w=\frac{\tilde{w}}{\tilde{U}_{\infty}} ; \\
& \omega_{x}=\frac{\tilde{w}_{x} \tilde{L}}{\tilde{U}_{\infty} \sqrt{R e}} ; \quad \omega_{y}=\frac{\tilde{w}_{y} \tilde{L}}{\tilde{U}_{\infty}} ; \quad \omega_{z}=\frac{\tilde{w}_{z} \tilde{L}}{\tilde{U}_{\infty} \sqrt{R e}} ; \quad t=\frac{\tilde{t} \tilde{U}_{\infty}}{\tilde{L}},
\end{aligned}
$$

em que as variáveis com til ( ) denotam as variáveis dimensionais; $x, y$ e $z$ são as coordenadas espaciais nas direções longitudinal, normal à superfície e transversal, respectivamente; $u, v$ e $w$ são as componentes de velocidade nas direções $x, y$ e $z$, respectivamente; $\omega_{x}, \omega_{y}$ e $\omega_{z}$ são as componentes de vorticidade em cada direção; e $t$ é o tempo.

A vorticidade pode ser definida como o negativo do rotacional do vetor velocidade (Fasel et al., 1990; Rist e Fasel, 1995; Kloker, 1998; Stemmer et al., 2000; Bonfigli, 2005; Wassermann e Kloker, 2005). A componente adimensional de vorticidade em cada direção pode ser escrita como:

$$
\begin{aligned}
\omega_{x} & =\frac{1}{R e} \frac{\partial v}{\partial z}-\frac{\partial w}{\partial y} \\
\omega_{y} & =\frac{\partial w}{\partial x}-\frac{\partial u}{\partial z} \\
\omega_{z} & =\frac{\partial u}{\partial y}-\frac{1}{R e} \frac{\partial v}{\partial x}
\end{aligned}
$$

Usando o fato que os campos de velocidade e vorticidade são solenoidais, pode-se obter as seguintes equações de transporte de vorticidade em cada direção:

$$
\begin{aligned}
& \frac{\partial \omega_{x}}{\partial t}+\frac{\partial a}{\partial y}-\frac{\partial b}{\partial z}=\nabla^{2} \omega_{x}+\frac{1}{R e} \frac{\partial f_{y}}{\partial z}-\frac{\partial f_{z}}{\partial y}, \\
& \frac{\partial \omega_{y}}{\partial t}+\frac{\partial c}{\partial z}-\frac{\partial a}{\partial x}=\nabla^{2} \omega_{y}+\frac{\partial f_{z}}{\partial x}-\frac{\partial f_{x}}{\partial z}, \\
& \frac{\partial \omega_{z}}{\partial t}+\frac{\partial b}{\partial x}-\frac{\partial c}{\partial y}=\nabla^{2} \omega_{z}+\frac{\partial f_{x}}{\partial y}-\frac{1}{R e} \frac{\partial f_{y}}{\partial x},
\end{aligned}
$$


em que

$$
\begin{aligned}
& a=v \omega_{x}-u \omega_{y}, \\
& b=u \omega_{z}-w \omega_{x}, \\
& c=w \omega_{y}-v \omega_{z},
\end{aligned}
$$

são os termos não lineares resultantes da convecção, estiramento e flexão dos vórtices. As variáveis $f_{x}, f_{y}$ e $f_{z}$ estão relacionadas com os termos fonte do método de fronteiras imersas (ver Seção 3.5.3). O operador laplaciano adimensional é denotado por:

$$
\nabla^{2}=\frac{1}{R e}\left(\frac{\partial^{2}}{\partial x^{2}}+\frac{\partial^{2}}{\partial z^{2}}\right)+\frac{\partial^{2}}{\partial y^{2}}
$$

Considerando a equação da continuidade, dada por:

$$
\frac{\partial u}{\partial x}+\frac{\partial v}{\partial y}+\frac{\partial w}{\partial z}=0
$$

e a definição de vorticidade, pode-se obter uma equação de Poisson para cada componente de velocidade:

$$
\begin{aligned}
& \frac{\partial^{2} u}{\partial x^{2}}+\frac{\partial^{2} u}{\partial z^{2}}=-\frac{\partial \omega_{y}}{\partial z}-\frac{\partial^{2} v}{\partial x \partial y}, \\
& \nabla^{2} v=-\frac{\partial \omega_{z}}{\partial x}+\frac{\partial \omega_{x}}{\partial z}, \\
& \frac{\partial^{2} w}{\partial x^{2}}+\frac{\partial^{2} w}{\partial z^{2}}=\frac{\partial \omega_{y}}{\partial x}-\frac{\partial^{2} v}{\partial y \partial x} .
\end{aligned}
$$

O conjunto de equações (2.4)-(2.6) e (2.8)-(2.10) modela o escoamento a ser simulado e é resolvido no domínio de integração apresentado na próxima seção.

\subsection{Sistema de referência e domínio de integração}

O sistema de referência considerado para as simulações numéricas é mostrado na figura 2.1. O eixo $x$ está alinhado com a superfície, na direção longitudinal ao escoamento. O eixo $y$ é normal à superfície, sua coordenada é nula na superfície e ele assume valores positivos na direção da camada 
limite. O eixo $z$ está na direção transversal, paralelo ao bordo de ataque, e é orientado de forma a satisfazer a regra da mão direita.

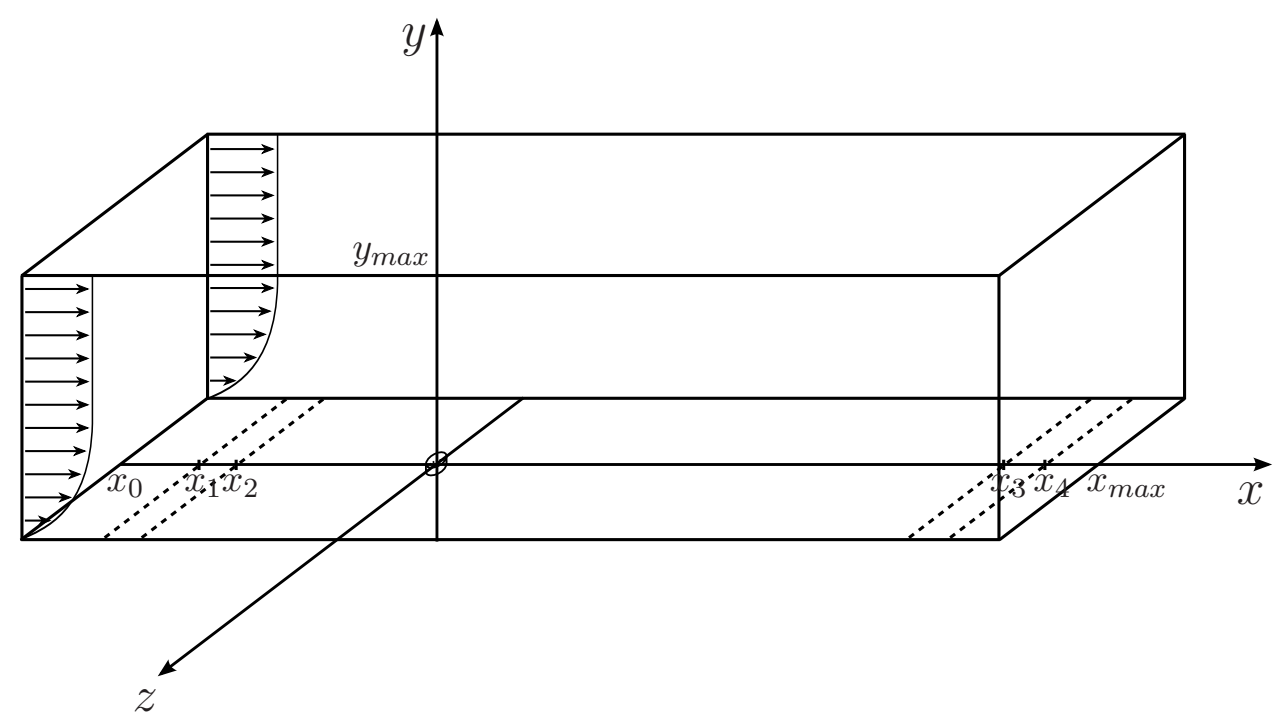

Figura 2.1: Domínio computacional.

Na direção longitudinal, o domínio se estende de $x_{0}$, certa distância a partir do bordo de ataque, até $x_{\max }$. Na direção normal, o domínio começa na superfície $(y=0)$ e termina em $y_{\max }$. A posição $y_{\max }$ é grande o suficiente de forma a garantir que as componentes de vorticidade sejam nulas no contorno superior. Na direção transversal, o escoamento é considerado periódico e o domínio inicia em $z=0$ e termina em $z=\lambda_{z}$, em que $\lambda_{z}$ é o comprimento de onda fundamental na direção $z$.

A região de introdução de perturbações está localizada entre os pontos $x_{1}$ e $x_{2}$. Estas perturbações são introduzidas através de sucção e injeção de massa (Fasel et al., 1990; Kloker, 1998; Souza, 2003). Os pontos $x_{0}$ e $x_{1}$, e $x_{3}$ e $x_{4}$ determinam as regiões de relaminarização. Estas regiões são usadas para evitar reflexões numéricas das perturbações nas fronteiras de entrada e saída de fluido, respectivamente (Kloker et al., 1993) (ver Seção 3.8).

A certa distância da entrada do domínio, tem-se uma rugosidade. Essa rugosidade tem forma cilíndrica e está colada à superfície $(y=0)$. Na direção transversal, o centro da rugosidade localiza-se no meio do domínio. A posição $x$ do centro da rugosidade, seu diâmetro $d_{r}$ e sua altura $h_{r}$ são definidos a partir dos dados experimentais (Plogmann et al., 2012). Mais detalhes sobre como a rugosidade é representada no código numérico são dados na Seção 3.5.

As condições iniciais e de contorno para a solução numérica das equações são definidas nas Seções 2.3 e 2.4 , respectivamente. 


\subsection{Escoamento base}

Para iniciar a simulação numérica, o escoamento base é computado considerando-se um domínio bidimensional.

Primeiramente, resolve-se a equação de Falkner-Skan (Falkner e Skan, 1931), considerando os dados experimentais como condição de contorno. Esta solução é utilizada como condição inicial para a simulação do escoamento base. As equações de Navier-Stokes bidimensionais são então resolvidas para atenuar os erros de simplificação da solução de Falkner-Skan.

As equações de Navier-Stokes bidimensionais para o escoamento base são:

$$
\begin{aligned}
& \frac{\partial \omega_{z_{b}}}{\partial t}+\frac{\partial\left(u_{b} \omega_{z_{b}}\right)}{\partial x}+\frac{\partial\left(v_{b} \omega_{z_{b}}\right)}{\partial y}=\frac{1}{R e} \frac{\partial^{2} \omega_{z_{b}}}{\partial x^{2}}+\frac{\partial^{2} \omega_{z_{b}}}{\partial y^{2}}, \\
& \frac{1}{R e} \frac{\partial^{2} v_{b}}{\partial x^{2}}+\frac{\partial^{2} v_{b}}{\partial y^{2}}=-\frac{\partial \omega_{z_{b}}}{\partial x}, \\
& \frac{\partial u_{b}}{\partial x}=-\frac{\partial v_{b}}{\partial y} .
\end{aligned}
$$

O código que resolve o escoamento base tem a mesma estrutura do código usado para resolver o problema tridimensional, sem a introdução de perturbações e a rugosidade. Para a simulação do escoamento base, o código é executado até atingir o estado estacionário, ou seja, até que o máximo da diferença entre os valores de vorticidade entre dois passos de tempo consecutivos seja menor que uma tolerância $\varepsilon$ prescrita. No presente trabalho adotou-se $\varepsilon=10^{-9}$ (Stemmer, 2001).

\subsection{Condições de contorno}

A escolha das condições de contorno é fundamental para a solução dos problemas modelados por equações diferenciais parciais, pois o comportamento físico da solução depende da escolha dessas condições.

Esta seção está dividida em duas partes: na primeira são apresentadas as condições de contorno para o escoamento base (Seção 2.4.1) e na segunda são discutidas as condições de contorno para o escoamento tridimensional (Seção 2.4), contendo a rugosidade e a introdução de perturbações. 


\subsubsection{Condições de contorno para o escoamento base}

Para que houvesse concordância entre os resultados experimental e numérico, os dados medidos no experimento (Plogmann et al., 2012) foram usados como condição de contorno para a simulação numérica.

A velocidade na fronteira da camada limite $u_{e}$ é imposta de forma a aproximar o parâmetro de Hartree $\beta_{H}$ para a equação de Falkner-Skan. Com o auxílio do parâmetro $\beta_{H}$, uma solução de similaridade é calculada como solução inicial, para acelerar a convergência (Stemmer, 2001).

Na entrada do domínio $\left(x=x_{0}\right)$, a solução de similaridade de Falkner-Skan é prescrita, fazendo com que os valores das variáveis dependentes sejam constantes, ou seja,

$$
\left.u_{b}\right|_{x=x_{0}}=u_{F S},\left.\quad v_{b}\right|_{x=x_{0}}=v_{F S},\left.\quad \omega_{z_{b}}\right|_{x=x_{0}}=\omega_{z_{F S}} .
$$

No contorno de saída $\left(x=x_{\max }\right)$, as seguintes condições são utilizadas:

$$
\left.\frac{\partial^{2} u_{b}}{\partial x^{2}}\right|_{x=x_{\max }}=\left.\frac{\partial^{2} v_{b}}{\partial x^{2}}\right|_{x=x_{\max }}=\left.\frac{\partial^{2} \omega_{z_{b}}}{\partial x^{2}}\right|_{x=x_{\max }}=0 .
$$

Na superfície $(y=0)$, as componentes de velocidade são nulas $\left(\left.u_{b}\right|_{y=0}=\left.v_{b}\right|_{y=0}=0\right)$, devido às condições de impermeabilidade e não deslizamento. A condição de contorno para a vorticidade é dada por:

$$
\left.\frac{\partial \omega_{z_{b}}}{\partial x}\right|_{y=0}=-\frac{\partial^{2} v_{b}}{\partial y^{2}}
$$

No contorno superior $\left(y=y_{\max }\right)$, a velocidade local na fronteira da camada limite $u_{e}(x)$ dos dados experimentais é imposta $\left(\left.u_{b}\right|_{y=y_{\max }}=u_{e}\right)$. Para a velocidade $v_{b}$ adota-se a seguinte condição:

$$
\left.\frac{\partial v_{b}}{\partial y}\right|_{y=y_{\max }}=-\frac{\partial u_{e}}{\partial x}
$$

$\mathrm{O}$ valor de $y_{\max }$ deve ser grande o suficiente para satisfazer a condição $\left.\omega_{z_{b}}\right|_{y=y_{\max }} \simeq 0$.

\subsubsection{Condições de contorno para o escoamento tridimensional}

Com os resultados da simulação do escoamento base, pode-se simular o escoamento tridimensional, introduzindo ou não perturbações, para entender a física do processo de transição. No caso de 
introdução de perturbações, a mesma é feita através de sucção e injeção de massa na superfície (como apresentado na Seção 3.11).

Na entrada do domínio $\left(x=x_{0}\right)$, as componentes de velocidade e vorticidade permanecem inalteradas e iguais às variáveis médias durante a simulação. Uma região de amortecimento foi implementada próximo à fronteira de entrada, mais detalhes são dados na Seção 3.8.

Próximo ao contorno de saída também foi implementada uma zona de relaminarização para dissipar as perturbações. Esta técnica evita reflexões de perturbações para dentro do domínio, conforme explicado na Seção 3.8. Considerando esta técnica, pode-se adotar a seguinte condição no contorno de saída:

$$
\left.\frac{\partial^{2} g}{\partial x^{2}}\right|_{x=x_{\max }}=0,
$$

em que $g=\left\{u, v, w, \omega_{x}, \omega_{y}, \omega_{z}\right\}$.

Na superfície $(y=0)$, as componentes de velocidade $u$ e $w$ são nulas $\left(\left.u\right|_{y=0}=\left.w\right|_{y=0}=0\right)$, devido à condição de não deslizamento. A velocidade $v$ é zero, exceto na região entre os pontos $x_{1} \mathrm{e}$ $x_{2}$, onde são introduzidas as perturbações. As componentes de vorticidade são calculadas usando as seguintes expressões:

$$
\begin{aligned}
& \left.\left(\frac{\partial^{2} \omega_{x}}{\partial x^{2}}+\frac{\partial^{2} \omega_{x}}{\partial z^{2}}\right)\right|_{y=0}=\frac{\partial}{\partial z} \nabla^{2} v-\frac{\partial^{2} \omega_{y}}{\partial y \partial x}, \\
& \left.\omega_{y}\right|_{y=0}=0 \\
& \left.\frac{\partial \omega_{z}}{\partial x}\right|_{y=0}=-\nabla^{2} v+\frac{\partial \omega_{x}}{\partial z} .
\end{aligned}
$$

A equação (2.12) resulta das definições das componentes de vorticidade (equações (2.1)-(2.3)), da equação da continuidade (2.7) e da equação:

$$
\nabla \cdot(\nabla \times \boldsymbol{u})=\frac{\partial \omega_{x}}{\partial x}+\frac{\partial \omega_{y}}{\partial y}+\frac{\partial \omega_{z}}{\partial z}=0
$$

A equação (2.13) resulta da definição das componentes de vorticidade (equações (2.1)-(2.3)), da equação (2.14) e da equação de Poisson (2.9), reescrita de forma a isolar o termo $\frac{\partial \omega_{z}}{\partial x}$.

No contorno superior $\left(y=y_{\max }\right)$, assume-se que as perturbações da velocidade decaem exponencialmente quando afasta-se da superfície. Considerando que $y_{\max }$ é grande o suficiente, as com- 
ponentes de vorticidade são definidas como zero $\left(\left.\omega_{x}\right|_{y=y_{\max }}=\left.\omega_{y}\right|_{y=y_{\max }}=\left.\omega_{z}\right|_{y=y_{\max }}=0\right)$. Para a componente normal da velocidade, o decaimento exponencial é prescrito como:

$$
\left.\frac{\partial v}{\partial y}\right|_{y=y_{\max }}=-\left.\frac{\dot{\alpha}}{\sqrt{R e}} v\right|_{y=y_{\max }},
$$

em que $\dot{\alpha}=\sqrt{\alpha_{r}^{2}+\beta_{k}^{2}}$ é o vetor número de onda (Kundu, 1990); $\alpha_{r}$ é a parte real do número de onda longitudinal, calculado pela análise linear; $\beta_{k}$ é o número de onda transversal; e $k$ é o modo de Fourier. Apesar do número de onda longitudinal mudar à medida que as ondas se propagam no escoamento, a adoção de um número de onda $\dot{\alpha}$ constante para este contorno não tem influência considerável nos resultados obtidos (Meitz e Fasel, 2000; Stemmer, 2001).

Para as fronteiras na direção transversal $\left(z=0\right.$ e $\left.z=\lambda_{z}\right)$, são empregadas condições periódicas. Então, para todas as variáveis e suas derivadas são adotadas as seguintes condições:

$$
\begin{aligned}
& \left.g\right|_{z=0}=\left.g\right|_{z=\lambda_{z}}, \\
& \left.\frac{\partial^{n} g}{\partial z^{n}}\right|_{z=0}=\left.\frac{\partial^{n} g}{\partial z^{n}}\right|_{z=\lambda_{z}},
\end{aligned}
$$

em que $n$ indica o grau da derivada e $g=\left\{u, v, w, \omega_{x}, \omega_{y}, \omega_{z}\right\}$.

No próximo capítulo são apresentados os métodos numéricos para a solução das equações apresentadas. 


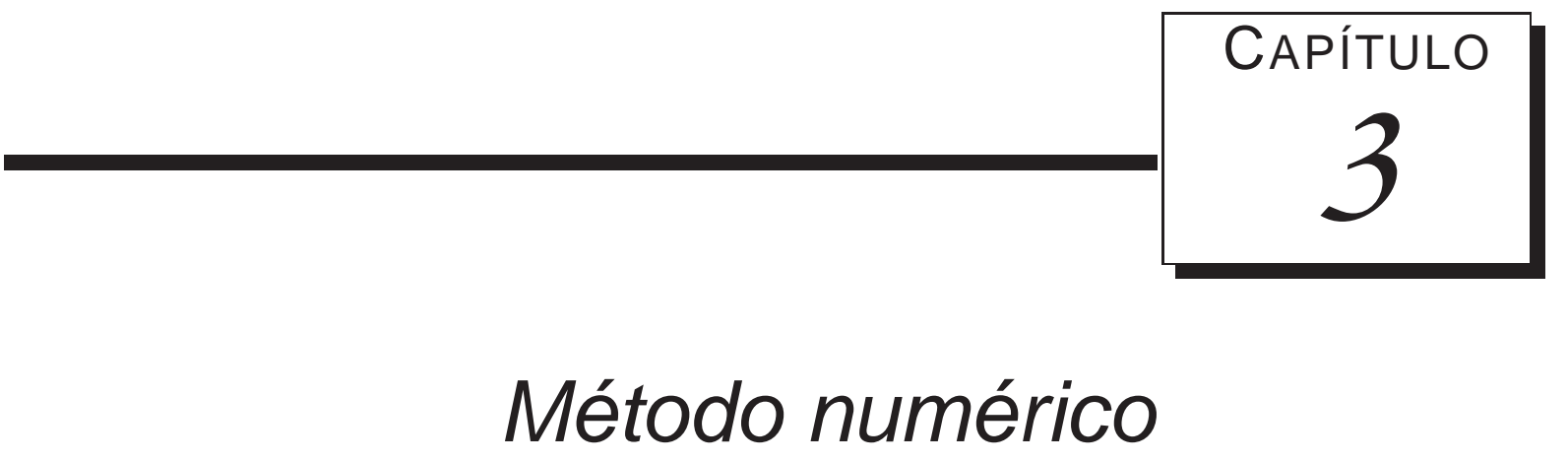

No presente trabalho foi desenvolvido um programa de computador que resolve numericamente as equações que governam escoamentos incompressíveis, escritas em um sistema de coordenadas cartesianas. As simulações numéricas realizadas se inserem no contexto da Simulação Numérica Direta (DNS - do inglês Direct Numerical Simulation) (Silvestrini, 2000; Souza, 2003; Citro et al., 2014; Kozlov et al., 2014; Brynjell-Rahkola et al., 2014). Neste capítulo é descrito o método numérico empregado para a solução das equações apresentadas no capítulo anterior.

Como o fenômeno físico estudado envolve um grande número de escalas no tempo e no espaço, o código numérico precisa ter características não dissipativas e não dispersivas para representar todas as escalas relevantes. Por essa razão, um integrador numérico do tipo Runge-Kutta com quarta ordem de precisão é utilizado. Além disso, as derivadas espaciais são calculadas através de métodos de diferenças finitas compactas de alta ordem nas direções $x$ e $y$ (Lele, 1992; Mahesh, 1998; Souza et al., 2005), e do método espectral na direção transversal (z), obtendo-se assim alta ordem de precisão, tanto espacial quanto temporal.

Devido ao fato do fenômeno em estudo concentrar-se próximo à superfície, grande quantidade de pontos é necessária nessa região. Com o objetivo de reduzir a quantidade total de pontos, foi utilizado um estiramento de malha na direção normal à superfície (Babucke e Kloker, 2009). Além disso, a fim de reduzir o tempo de simulação, adotou-se uma técnica de paralelização, baseada na decomposição 
do domínio.

Este capítulo foi dividido da seguinte maneira: na Seção 3.1 é mostrado como é realizada a decomposição do domínio para a paralelização. Em seguida, na Seção 3.2, é mostrado o método espectral usado na direção transversal (z). Na seção seguinte (Seção 3.3), é apresentado o método numérico que é utilizado para as derivadas temporais. Na sequência (Seção 3.4), é mostrado o método para o cálculo das derivadas espaciais nas direções longitudinal $(x)$ e normal à superfície $(y)$. A seção subsequente (Seção 3.5) apresenta o método de fronteiras imersas usado para representar a rugosidade. Na Seção 3.6 é descrito o fenômeno de Gibbs e o filtro utilizado para a eliminação deste fenômeno é mostrado. O filtro espacial utilizado para atenuar o efeito das altas frequências é apresentado na Seção 3.7. A Seção 3.8, mostra a técnica de relaminarização utilizada próximo aos contornos de entrada e saída. Na Seção 3.9 é mostrado o método para solução da equação de Poisson. O cálculo da vorticidade na superfície é apresentado na Seção 3.10. A seguir, na Seção 3.11, a forma como são introduzidas as perturbações é mostrada. Finalmente, na Seção 3.12, os passos efetuados para se obter a solução numérica das equações é apresentado.

\subsection{Decomposição do domínio}

Para as simulações computacionais é necessário uma malha extremamente fina, com grande quantidade de pontos. Para reduzir o tempo de processamento, o código foi paralelizado, usando decomposição de domínio. A decomposição foi feita na direção longitudinal, devido à maior quantidade de pontos nessa direção. Cada parte do domínio é resolvida em um elemento de processamento (EP), que pode ser um processador ou um núcleo de processamento de um cluster de computadores.

A figura 3.1 mostra como seria o domínio se fossem utilizados 4 EPs para a simulação numérica. Para garantir a precisão da solução numérica no domínio total, é necessária uma sobreposição entre os subdomínios vizinhos, como mostrado na figura 3.1. O número de pontos utilizados nessa sobreposição depende do número de níveis de malha empregado no método numérico utilizado para resolver a equação de Poisson. Quanto maior o número de níveis de malha, maior o número de pontos usados na sobreposição. Maiores detalhes sobre a interseção dos domínios e a comunicação necessária para a solução numérica da equação de Poisson podem ser vistos na Seção 3.9.

Para a comunicação (troca de mensagens) entre os processos utiliza-se a biblioteca MPI (do inglês Message-Passing Interface) (Pacheco, 1997). 


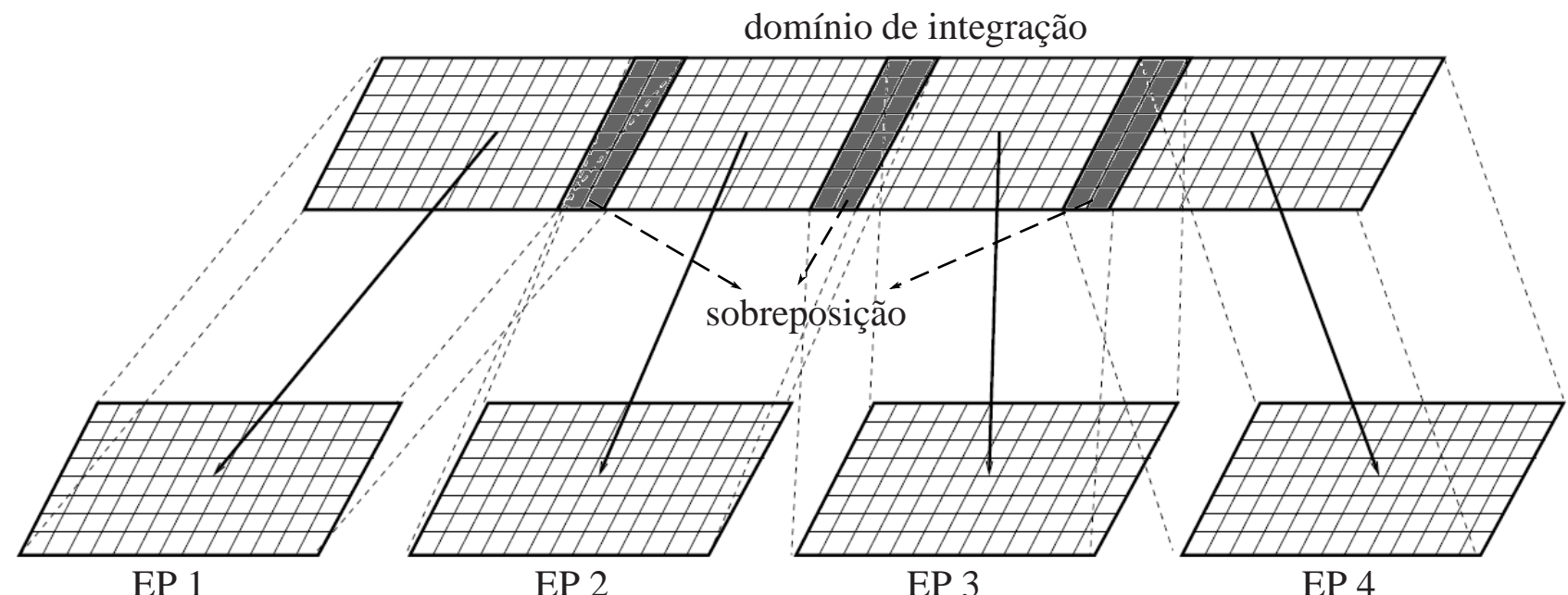

Figura 3.1: Decomposição e sobreposição do domínio para a paralelização, por exemplo, usando 4 EPs.

\subsection{Método espectral}

O escoamento é considerado periódico na direção transversal (z). Desta forma, é possível utilizar o método espectral nesta direção, por meio da introdução de transformadas de Fourier. A utilização destas transformadas simplifica a solução numérica do código, e, ao mesmo tempo, mantém alta ordem de precisão no cálculo das derivadas. Comparações de ordem de precisão entre métodos espectrais e métodos de diferenças finitas são mostradas em Canuto et al. (1988) e Zang et al. (1989). Explorando as condições de periodicidade, pode-se expandir os campos de velocidade e vorticidade em séries de Fourier, com $K$ modos de Fourier, da seguinte forma:

$$
g(x, y, z, t) \approx \sum_{k=0}^{K} G_{k}(x, y, t) e^{-i \beta_{k} z}
$$

em que $g=\left\{u, v, w, \omega_{x}, \omega_{y}, \omega_{z}, a, b, c, f_{x}, f_{y}, f_{z}\right\}$ representa as variáveis no espaço físico; $k$ é o modo de Fourier, que vai de 0 a $K ; G_{k}=\left\{U_{k}, V_{k}, W_{k}, \Omega_{x_{k}}, \Omega_{y_{k}}, \Omega_{z_{k}}, A_{k}, B_{k}, C_{k}, F_{x_{k}}, F_{y_{k}}, F_{z_{k}}\right\}$ representa as variáveis no espaço de Fourier; $i=\sqrt{-1}$; e $\beta_{k}$ é o número de onda transversal, dado por:

$$
\beta_{k}=\frac{2 \pi k}{\lambda_{z}}
$$

com $\lambda_{z}$ o comprimento de onda, na direção transversal, do modo fundamental de Fourier. Note que $G_{k}$ pode ser completamente complexa, ou seja, campos de perturbação tridimensionais não simétricos podem ser calculados. 
A substituição das transformadas de Fourier (equação (3.1)) nas equações de transporte de vorticidade (2.1)-(2.3) e nas equações de Poisson para as componentes de velocidade (2.8)-(2.10) fornece as equações governantes no espaço de Fourier, para cada modo $k$ de Fourier:

$$
\begin{aligned}
& \frac{\partial \Omega_{x_{k}}}{\partial t}+\frac{\partial A_{k}}{\partial y}+i \beta_{k} B_{k}=\nabla_{k}^{2} \Omega_{x_{k}}-\frac{1}{R e} i \beta_{k} F_{y_{k}}-\frac{\partial F_{z_{k}}}{\partial y}, \\
& \frac{\partial \Omega_{y_{k}}}{\partial t}-i \beta_{k} C_{k}-\frac{\partial A_{k}}{\partial x}=\nabla_{k}^{2} \Omega_{y_{k}}+\frac{\partial F_{z_{k}}}{\partial x}+i \beta_{k} F_{x_{k}}, \\
& \frac{\partial \Omega_{z_{k}}}{\partial t}+\frac{\partial B_{k}}{\partial x}-\frac{\partial C_{k}}{\partial y}=\nabla_{k}^{2} \Omega_{z_{k}}+\frac{\partial F_{x_{k}}}{\partial y}-\frac{1}{R e} \frac{\partial F_{y_{k}}}{\partial x}, \\
& \frac{\partial^{2} U_{k}}{\partial x^{2}}-\beta_{k}^{2} U_{k}=i \beta_{k} \Omega_{y_{k}}-\frac{\partial^{2} V_{k}}{\partial x \partial y}, \\
& \nabla_{k}^{2} V_{k}=-\frac{\partial \Omega_{z_{k}}}{\partial x}-i \beta_{k} \Omega_{x_{k}}, \\
& \frac{\partial^{2} W_{k}}{\partial x^{2}}-\beta_{k}^{2} W_{k}=\frac{\partial \Omega_{y_{k}}}{\partial x}+i \beta_{k} \frac{\partial V_{k}}{\partial y},
\end{aligned}
$$

em que

$$
\nabla_{k}^{2}=\left[\frac{1}{R e}\left(\frac{\partial^{2}}{\partial x^{2}}-\beta_{k}^{2}\right)+\frac{\partial^{2}}{\partial y^{2}}\right]
$$

Para se obter os produtos não lineares $\left(A_{k}, B_{k}\right.$ e $\left.C_{k}\right)$, transforma-se as componentes de velocidade e vorticidade para o espaço físico. Em seguida, realiza-se os produtos não lineares $(a, b$ e $c)$ no espaço físico. Finalmente, transforma-se as variáveis $a, b$ e $c$ de volta para o espaço de Fourier. Esta sequência de procedimentos representa um esforço computacional menor do que se os produtos fossem realizados no espaço de Fourier, quando se adota mais do que determinado número de modos de Fourier. O método resultante é denominado pseudoespectral.

\subsection{Derivadas temporais}

Neste estudo almeja-se capturar, com precisão, efeitos transientes e, para simular adequadamente estes efeitos, é necessário empregar incrementos de tempo na simulação numérica $(\delta t)$ relativamente pequenos, da mesma ordem de grandeza necessária para que os critérios de estabilidade numérica sejam satisfeitos.

Visando reduzir o esforço computacional, Souza et al. (2005) avaliou vários métodos para a in- 
tegração temporal. O resultado destes testes mostrou que, apesar de alguns métodos obterem vantagens, como baixo armazenamento (Williamson, 1980), o tempo total de simulação para o método de Runge-Kutta de quarta ordem é menor, pois pode-se trabalhar com passos de tempo maiores. Desta forma, foi implementado um método explícito do tipo Runge-Kutta de quatro estágios, com quarta ordem de precisão.

No entanto, a aplicação do método de Runge-Kutta de quarta ordem clássico para o problema em questão mostrou-se limitada, uma vez que houve interação entre ele, o método de fronteiras imersas e o filtro para tratamento do fenômeno de Gibbs. Essa interação ocasionou o aparecimento de oscilações que degradavam a solução numérica.

Foi então feita uma pesquisa bibliográfica de trabalhos que envolviam o uso de métodos do tipo Runge-Kutta e de filtro de Gibbs. Um dos trabalhos encontrados foi o de Xu e Wang (2006), no qual o termo filtrado é tratado de forma diferente nos passos do método Runge-Kutta. Este método foi implementado no código numérico e testado. Os resultados dos testes mostraram ausência de oscilações. Desta forma, o método de Runge-Kutta proposto por Xu e Wang (2006) é utilizado para a integração temporal no código de simulação numérica direta. Neste método são efetuados os seguintes passos para se avançar a solução no tempo:

$$
\begin{aligned}
q_{1} & =q^{(n)}+\frac{\delta t}{2}\left(r_{0}+s_{0}\right) \\
q_{2} & =q^{(n)}+\frac{\delta t}{2}\left(r_{1}+s_{1}\right) \\
q_{3} & =q^{(n)}+\delta t\left(r_{2}+s_{2}\right) \\
q^{(n+1)} & =q^{(n)}+\frac{\delta t}{6}\left(r_{0}+2 r_{1}+2 r_{2}+r_{3}+s_{3}\right),
\end{aligned}
$$

em que $q^{(n)}$ e $q^{(n+1)}$ representam as componentes de vorticidades nos passos de tempo $n$ e $n+1$, respectivamente; $q_{i}(i=1,2,3)$ representam os valores intermediários de vorticidade, calculados sem os termos forçantes do método de fronteiras imersas; $\delta t$ é o passo de tempo; $r_{i}(i=0,1,2,3)$ é o lado direito da equação de transporte de vorticidade (isolando-se a derivada temporal do lado esquerdo), também calculado sem os termos forçantes do método de fronteiras imersas; e $s_{i}(i=0,1,2,3)$ representa os termos forçantes do método de fronteiras imersas. 


\subsection{Derivadas espaciais}

O cálculo das derivadas espaciais nas direções $x$ e $y$ é realizado através do método de diferenças finitas compactas, ou diferenças compactas. As diferenças compactas, também conhecidas como diferenças Hermitianas, datam de 1878, de acordo com Kopal (1961). Kopal (1961) mostra em seu livro a utilização de interpolação Hermitiana e mostra que a ordem de precisão obtida através desta formulação é muito superior à obtida através da forma lagrangiana. Collatz (1966), na introdução de métodos hermitianos, diz que o ganho em precisão por este método não é obtido com a inclusão de mais pontos, como ocorre em outros métodos, mas baseado no fato de que a derivação de cada equação individual de diferenças é satisfeita em diversos pontos ao mesmo tempo, ao invés de em apenas um ponto. Collatz (1966) mostra que, em 1935, já existiam trabalhos científicos que utilizavam diferenças finitas compactas de quarta ordem para o cálculo de segunda derivada. O autor mostra ainda que a inclusão de derivada de primeira e segunda ordem em uma mesma fórmula aumenta a precisão da mesma, como é proposto por Mahesh (1998).

Vários pesquisadores já realizaram estudos otimizando e mostrando as vantagens em se utilizar diferenças finitas compactas (Hirsh, 1975; Adam, 1977; Lele, 1992; Mahesh, 1998; Souza et al., 2005). Os esquemas adotados neste estudo foram de quinta e sexta ordens de precisão. A vantagem do esquema adotado é que a matriz a ser resolvida, para se obter os valores da derivada, é tridiagonal. Para os pontos próximos ao contorno, Lele (1992) propõe aproximações de terceira e quarta ordens. Neste estudo são adotadas aproximações de sexta ordem para os pontos interiores ao domínio e aproximações de quinta ordem para os pontos no contorno, desenvolvidas por Souza et al. (2005). Pode ocorrer instabilidade numérica se aproximações de mesma ordem são usadas no contorno e no interior do domínio (Souza et al., 2005; Silva et al., 2010). Para a solução da equação de Poisson, no contorno superior, aproximações de segunda ordem são utilizadas nos pontos do contorno.

Como já foi comentado, há a necessidade da solução de um sistema tridiagonal para se encontrar o valor das derivadas, onde se leva em consideração todos os pontos na direção em que se está calculando a derivada. Para a solução do sistema tridiagonal, é utilizado o algoritmo de Thomas (Press et al., 1992). Na direção $x$, onde há o particionamento do domínio para paralelização do código, é necessária a adaptação desse algoritmo (Rogenski et al., 2015).

As matrizes adotadas para os cálculos da primeira e segunda derivadas na direção $x$ são as mesmas utilizadas por Souza (2003). As vantagens em se utilizar estas aproximações em estudos de transição 
laminar-turbulenta são apresentadas em Souza et al. (2005).

\subsubsection{Estiramento de malha}

Como o intuito do código DNS é resolver escoamentos em camada limite, a necessidade de resolução próximo à superfície justifica o uso de estiramento de malha na direção normal à superfície $(y)$ (Babucke e Kloker, 2009). A maneira mais simples de se aplicar esta técnica é considerar a variação do tamanho do espaçamento de malha $\left(h_{y}\right)$ como uma progressão geométrica, partindo da superfície. Dessa forma, tem-se uma malha mais refinada próximo à superfície, que é a região de interesse, e uma malha mais grossa próximo ao contorno superior, onde o escoamento tem um comportamento quase constante.

Outra vantagem do uso dessa técnica é a redução do número de pontos nessa direção, possibilitando que a simulação numérica necessite de menos tempo de execução.

O cálculo dos coeficientes sugerido por Linnick e Fasel (2005) foi implementado, testado e verificado e é aqui utilizado para as matrizes de cálculo das derivadas na direção y e para a solução da equação de Poisson.

\subsection{Representação da rugosidade}

Como mencionado anteriormente, para a discretização das equações, é utilizada uma malha cartesiana. No entanto, a rugosidade introduzida no domínio não se ajusta, necessariamente, à malha. Neste trabalho, a rugosidade consiste de um cilindro, perpendicular à superfície, localizado a certa distância do início do domínio $\left(x_{0}\right)$, como mostrado na figura 2.1. O método utilizado para representar esta rugosidade é apresentado nesta seção.

A maior parte dos problemas que tratam de escoamentos envolve geometrias complexas. A habilidade de se estudar numericamente escoamentos sobre estas geometrias é um dos principais desafios da dinâmica dos fluidos computacional. Uma grande variedade de métodos numéricos é empregada no estudo de escoamentos em torno de corpos de geometrias complexas. Neste estudo, a compreensão dos processos que levam à transição requerem resultados eficientes e precisos, pois uma enorme diversidade de escalas de comprimento e frequências estão presentes neste tipo de escoamento.

No presente trabalho, a classe de métodos de fronteiras imersas foi escolhida para a representação da rugosidade no domínio. 


\subsubsection{Revisão bibliográfica de métodos de fronteiras imersas}

O método de fronteiras imersas foi inicialmente desenvolvido por Peskin (1972), como uma alternativa ao uso de coordenadas generalizadas e transformação de coordenadas. Este método permite representar um ou mais corpos no interior do escoamento pela aplicação de um termo forçante acoplado às equações de Navier-Stokes. A princípio, não é necessária qualquer restrição na distribuição da velocidade, forma ou movimento do corpo. Assim sendo, este método permite a imposição de uma grande variedade de condições de contorno (von Terzi et al., 2001), incluindo superfícies livres, superfícies de fluido-fluido, fluido-sólido, etc.

O método proposto por Peskin (1972) trata da interação fluido-estrutura, em que objetos viscoelásticos incompressíveis (ou fronteiras elásticas) estão imersos e interagindo com fluidos incompressíveis viscosos. Neste caso, são utilizadas duas malhas, uma cartesiana fixa, para as variáveis eulerianas, e outra curvilínea móvel, para as variáveis lagrangianas. A interação entre as variáveis eulerianas, que representam o fluido, e lagrangianas, que representam a fronteira imersa, pode ser modelada por uma aproximação discreta da função delta de Dirac.

O campo de estudo do método de fronteiras imersas concentra-se principalmente em escoamentos com fronteiras móveis e ao redor de geometrias complexas (Peskin, 1972, 1977; Roma et al., 1999; Lai e Peskin, 2000; Peskin, 2002). O desenvolvimento de métodos computacionais robustos como alternativa para as técnicas que utilizam malhas elásticas, ou seja, malhas que se adaptam ao contorno do sólido que serve como obstáculo ao escoamento, é o principal objetivo da comunidade científica que estuda esse método.

Quando um fluido passa por um objeto, ele exerce uma força normal (pressão) à superfície do objeto e, devido à condição de não deslizamento na superfície do objeto, o fluido também exerce uma força tangencial (cisalhamento). Por outro lado, a superfície do objeto também exerce uma força, de sinal oposto, no fluido, fazendo com que a velocidade do fluido na superfície seja zero. Assim, tem-se que o fluido 'enxerga' o objeto através das forças normais e tangenciais ao longo da superfície do objeto.

Pode-se imaginar então, que se um conjunto de forças correto for aplicado ao fluido, este pode se comportar como se estivesse passando por um objeto sólido, ou seja, o efeito de certas condições de contorno pode ser modelado pela aplicação de uma força externa, ao invés de se especificar parâmetros para o contorno. Com isso, pode-se simular um escoamento que passa por um objeto utilizando 


\section{5 - Representação da rugosidade}

um domínio simples, com uma malha regular, e impondo forças para caracterizar a fronteira do objeto.

Pode-se utilizar uma função da forma:

$$
f\left(x_{s}, t\right)=c_{1} \int_{0}^{t} \boldsymbol{u}\left(x_{s}, t^{\prime}\right) d t^{\prime}+c_{2} \boldsymbol{u}\left(x_{s}, t\right)
$$

em que $f$ representa a força exercida pelo objeto imerso; $x_{s}$ são pontos na superfície do objeto; $\boldsymbol{u}$ é o campo de velocidades; $t$ é o tempo; e $c_{1}$ e $c_{2}$ são constantes negativas (Goldstein et al., 1993). Esta função representa a informação vinda do campo de velocidades, onde o primeiro termo é responsável pela criação da força que irá diminuir a velocidade do escoamento na superfície rígida (até que ela seja nula) e o segundo termo representa a força criada pelo arrasto de um obstáculo localizado no ponto $x_{s}$. A utilização dessa função nos pontos do contorno pode ser vista como a aplicação de forças que 'aprendem' a simular a condição de contorno desejada. Métodos que utilizam este tipo de força são também conhecidos como métodos de fronteira virtual (Goldstein et al., 1993; Saiki e Biringen, 1996; Lee, 2003; Lima e Silva et al., 2003).

Uma alternativa ao método de fronteiras imersas clássico (Peskin, 1972, 1977) é o método de interfaces imersas, que evita o uso da distribuição delta de Dirac para definir os termos forçantes, obtendo maior ordem de precisão (LeVeque e Li, 1994; Lee e LeVeque, 2003; Xu e Wang, 2006).

Outra opção já explorada é a de impor a condição de contorno por meio de multiplicadores de Lagrange, como no método de domínios fictícios (Glowinski et al., 1994; Girault e Glowinski, 1995; Glowinski et al., 1999). Neste caso, a dificuldade é transferida para a construção do espaço de multiplicadores.

Lew e Buscaglia (2008) apresentaram um método de imposição direta baseado em uma formulação de Galerkin descontínuo, que evita o tratamento caso-a-caso, simplesmente trocando a interpolação nas células interceptadas pelo contorno por uma interpolação descontínua, evitando assim o fenômeno de bloqueio (do inglês locking). Embora consiga impor fortemente as condições de contorno e obter precisão ótima, o método necessita de graus de liberdade adicionais.

Recentemente, têm surgido métodos de fronteiras imersas que atingem ordem de precisão superior a um, como os métodos propostos por Husain e Floryan (2008) e Codina e Baiges (2009), nos quais as condições de contorno são aproximadas de forma a minimizar a diferença entre as condições de contorno exata e aproximada em determinada norma. 


\subsubsection{Método de interfaces imersas}

A princípio, optou-se por utilizar o Método de Interfaces Imersas (MII), proposto por Linnick e Fasel (2005), por ser um método de alta ordem de precisão. A fim de se avaliar o funcionamento deste método, foram feitos testes envolvendo o cálculo de derivadas e a resolução da equação de Poisson em domínios uni e bidimensionais. Também foi feita uma simulação bidimensional, de um escoamento de Poiseuille com um obstáculo circular. Com isso, foi possível verificar a ordem de precisão do MII. Os resultados destes testes foram publicados e apresentados no 21st International Congress of Mechanical Engineering.

No entanto, nas simulações bidimensionais, notou-se que quando aumentava-se o número de Reynolds, o MII apresentava problemas de convergência. Em contato com os autores do método, identificou-se que a estabilidade só era garantida para escoamentos com $R e \leq 100$. Como os escoamentos tratados neste trabalho envolvem número de Reynolds bem maiores do que 100 (da ordem de $10^{5}$ ), a utilização deste método foi descartada.

Embora o MII não seja aplicável a esta pesquisa, seu uso na resolução numérica de problemas com $R e \leq 100$ se mostrou eficiente. Este método tem sido usado em outros trabalhos do grupo de pesquisa e tem fornecido resultados bastante satisfatórios.

\subsubsection{Método de fronteiras imersas}

Apesar da menor ordem de precisão, o método de fronteiras imersas se mostrou uma boa alternativa para a representação da rugosidade, por ser mais robusto na simulação de escoamentos com $\operatorname{Re}>10^{5}$.

No presente trabalho, foi utilizado o método de fronteiras imersas definido por Góis (2007). O trabalho de Góis (2007) envolvia escoamentos bidimensionais. Portanto, foram feitas modificações no método para possibilitar simulações tridimensionais. Essas modificações foram implementadas no código DNS.

Para a aplicação do método de fronteiras imersas em simulações de escoamentos incompressíveis é necessário a adição de termos forçantes às equações de Navier-Stokes. No caso, como é utilizada a formulação vorticidade-velocidade, esses termos tornam-se derivadas parciais dos termos originais, que são adicionados às equações de transporte de vorticidade. 


\section{5 - Representação da rugosidade}

Os termos forçantes $f_{x}, f_{y}$ e $f_{z}$, presentes nas equações (2.4)-(2.6), são dados por:

$$
\begin{aligned}
& f_{x}=\delta_{i b} r_{f} u, \\
& f_{y}=\delta_{i b} r_{f} v, \\
& f_{z}=\delta_{i b} r_{f} w,
\end{aligned}
$$

em que $\delta_{i b}$ é uma função que tem valor unitário dentro do corpo imerso no escoamento (no caso, a rugosidade) e é igual a zero fora do corpo imerso. Essa função serve para informar ao código numérico onde os termos forçantes devem ser aplicados. Para evitar descontinuidade na função $\delta_{i b}$, é adotada uma gaussiana na região de transição, que usa no máximo 5 pontos. Ainda, $r_{f}$ é o fator de relaxação do método de fronteiras imersas. Esse fator de relaxação serve para controlar a intensidade do termo forçante.

A principal vantagem da técnica de fronteiras imersas está na habilidade de modelar geometrias complexas, sem a necessidade de transformação de coordenadas, necessitando simplesmente de uma malha cartesiana uniforme. Embora este tipo de malha permita simplificações consideráveis em relação às malhas adaptadas à geometria, ainda resta a necessidade fundamental de ajustar a quantidade de nós da malha, a fim de representar a grande variedade de escalas de comprimento e tempo presentes no escoamento.

Em vista disso, foi feito um estudo a respeito do número mínimo de modos de Fourier necessários para representar adequadamente a rugosidade. Pelo seu formato cilíndrico, os planos de rugosidade perpendiculares à superfície são retângulos. Em teoria, para representar corretamente as quinas desses retângulos seriam necessários infinitos modos de Fourier. Contudo, do ponto de vista prático, é possível obter uma representação adequada dessas quinas, utilizando um número viável de modos. Neste estudo, notou-se que são necessários pelo menos 43 modos de Fourier (assumindo 128 pontos no espaço físico) para uma representação conveniente da rugosidade. A necessidade de se aumentar a quantidade de modos ocasionou o aumento no tempo médio de simulação (vide Capítulo 5).

\subsection{Filtro de Gibbs}

O fenômeno de Gibbs ocorre quando uma função descontínua é aproximada utilizando-se séries de Fourier truncadas. Aparecem oscilações próximo à descontinuidade, sub ou superestimando o valor da função (Raeen, 2008). No presente projeto, o fenômeno de Gibbs foi observado, devido à 
presença da rugosidade no domínio. Durante a simulação, as oscilações causadas por este fenômeno cresciam até deteriorar a solução numérica.

O estudo da bibliografia de métodos espectrais mostrou a necessidade de se usar um filtro para a eliminação deste fenômeno. Este filtro deve ser aplicado a uma ou mais variáveis no espaço de Fourier da seguinte forma: sejam $g_{k}$ uma variável qualquer, para cada modo $k$ de Fourier, e $\sigma(\eta)$ o filtro de Gibbs. A variável filtrada $\hat{g}_{k}$ é dada por:

$$
\hat{g}_{k}=\sigma(\eta) g_{k}
$$

em que $\eta=\frac{\pi k}{K}$ para cada modo $k$ de Fourier.

$\mathrm{Na}$ tentativa de eliminar as oscilações, cinco filtros foram implementados e testados. Dentre os filtros testados, estão filtros clássicos, como o exponencial, o de Lanczos e o cosseno levantado (do inglês raised cosine) (Wörner, 2004; Canuto et al., 2007). Além disso, dois outros filtros foram propostos: os filtros Souza-Dainezi e Souza-Petri. O filtro Souza-Dainezi é composto da combinação de uma análise de Fourier com o filtro cosseno levantado. Já o filtro Souza-Petri é uma combinação de uma função rampa (de amortecimento) também com o filtro cosseno levantado. A ideia por trás da criação destes filtros é aumentar o amortecimento das oscilações na proximidade da descontinuidade.

Os filtros utilizados neste trabalho são dados por:

\section{- Exponencial:}

$$
\sigma(\eta)=e^{-\eta^{2}}
$$

- Lanczos:

$$
\sigma(0)=1, \quad \sigma(\eta)=\frac{\sin (\eta)}{\eta}
$$

\section{- Cosseno levantado:}

$$
\sigma(\eta)=\frac{1+\cos (\eta)}{2}
$$


- Souza-Dainezi (proposto):

$$
\begin{aligned}
& \sigma(0)=1 \\
& \sigma(\eta)=\frac{a_{1}+a_{2} \cos (\eta)+a_{3} \cos (2 \eta)+a_{4} \cos (3 \eta)}{1+2 \alpha_{1} \cos (\eta)+2 \alpha_{2} \cos (2 \eta)}\left[\frac{1+\cos (\eta)}{2}\right]^{2} \\
& \text { em que } \alpha_{1}=-\frac{1}{2}, \alpha_{2}=0 \\
& a_{1}=\frac{11+10 \alpha_{1}-10 \alpha_{2}}{16} \\
& a_{2}=\frac{15+34 \alpha_{1}+30 \alpha_{2}}{32} \\
& a_{3}=\frac{-3+6 \alpha_{1}+26 \alpha_{2}}{16} \\
& a_{4}=\frac{1-2 \alpha_{1}+2 \alpha_{2}}{32}
\end{aligned}
$$

\section{- Souza-Petri (proposto):}

$$
\sigma(\eta)=\left\{1+[(-6 \eta+15) \eta-10] \eta^{3}\right\}\left[\frac{1+\cos (\eta)}{2}\right]^{0.6}
$$

A título de exemplo, seja a função descontínua $g(x)$, definida no intervalo $[0,2 \pi]$ e dada por:

$$
g(x)=\left\{\begin{array}{l}
0, \quad 0 \leq x<\frac{2 \pi}{3} \\
1, \quad \frac{2 \pi}{3} \leq x \leq \frac{4 \pi}{3} \\
0, \quad \frac{4 \pi}{3}<x \leq 2 \pi
\end{array}\right.
$$

Esta função é mostrada na figura 3.2 (linha preta contínua). Ainda na figura 3.2, são mostrados o efeito da transformada de Fourier nesta função sem a aplicação de filtro e o efeito da transformada com a aplicação dos filtros descritos acima. Para a transformada de Fourier foram utilizados 43 modos de Fourier (considerando 128 pontos no espaço físico).

Pode-se ver, na figura 3.2, as oscilações na função sem filtro e o amortecimento dessas oscilações quando aplica-se um filtro. Nas figuras 3.3a e 3.3b são mostradas ampliações das regiões 1 e 2 


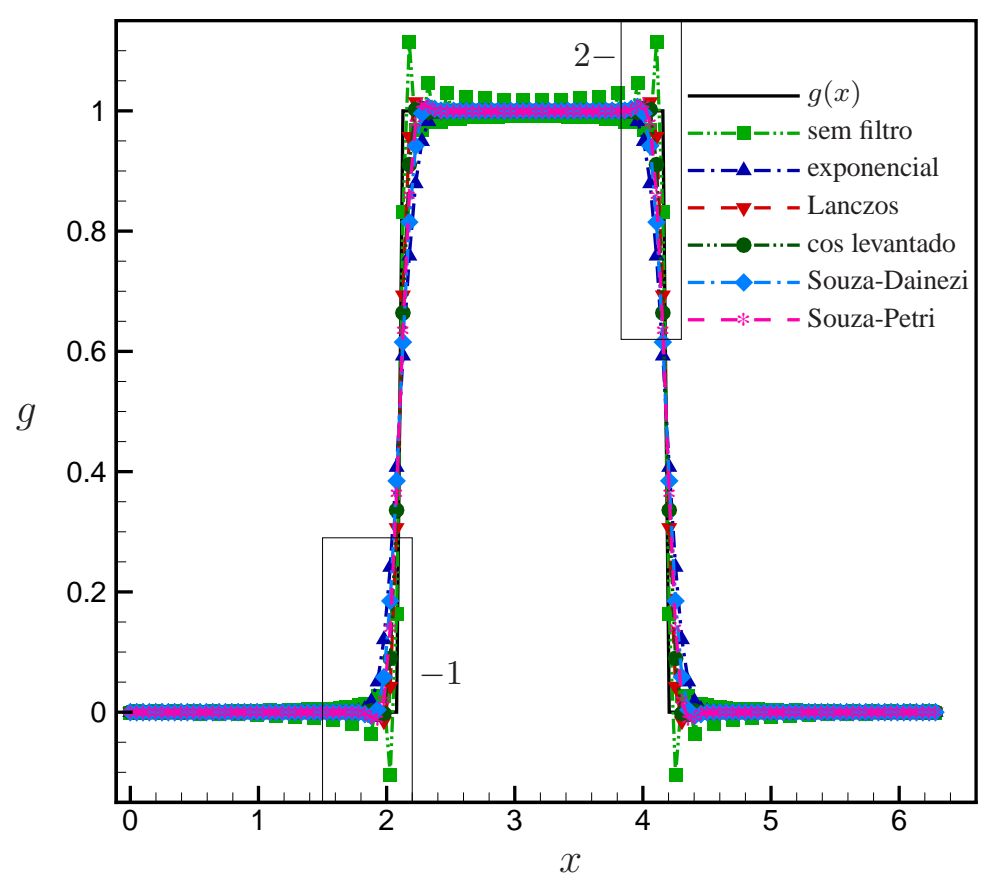

Figura 3.2: Efeito do filtro de Gibbs na transformada de Fourier de uma função descontínua.

da figura 3.2, respectivamente. Pode-se observar que a aplicação dos filtros reduz as oscilações na vizinhança da descontinuidade. Em particular, nota-se que o filtro exponencial, apesar de suavizar a função próximo à descontinuidade, é o único que não apresenta oscilações.

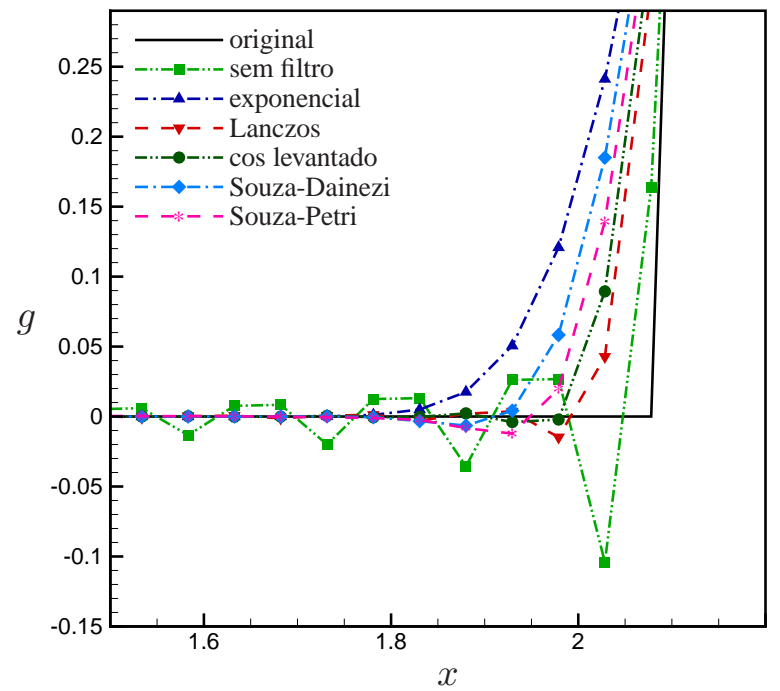

(a) Região 1 da figura 3.2.

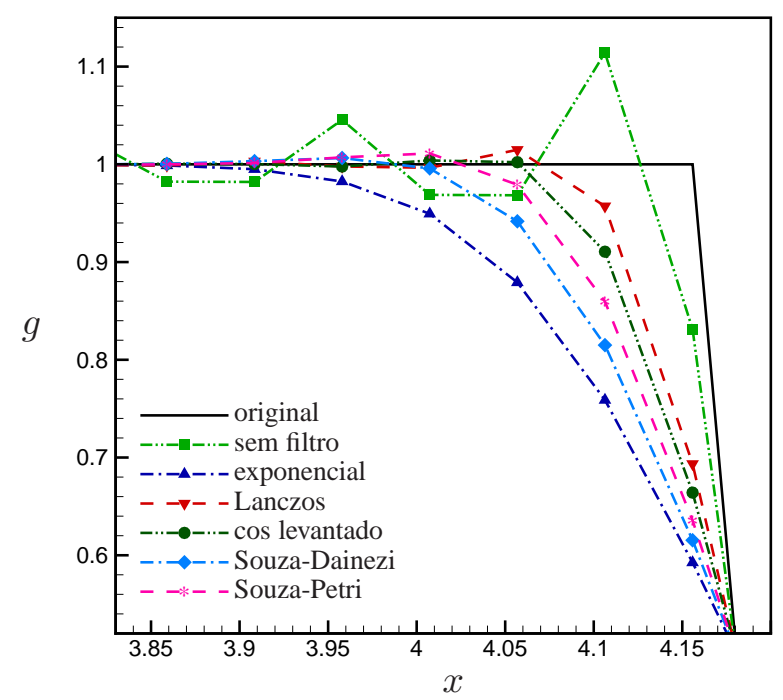

(b) Região 2 da figura 3.2.

Figura 3.3: Aumento nas regiões 1 e 2 da figura 3.2.

Esses cinco filtros foram então testados em um problema bidimensional, cujo domínio consiste de um corte no plano $x z$ da figura 2.1, a certa altura da superfície. Este teste foi feito em conjunto 
com o aluno de iniciação científica João Henrique Ribeiro Dainezi. Os resultados deste teste foram apresentados no $21^{\circ}$ SIICUSP, onde recebeu menção honrosa. Através deste teste bidimensional foi possível identificar que os filtros de Lanczos e cosseno levantado não conseguiam eliminar todas as oscilações. Por este motivo, esses dois filtros não foram utilizados nos testes subsequentes.

Em seguida, um teste no domínio tridimensional da figura 2.1 foi feito, considerando somente os filtros exponencial, Souza-Dainezi e Souza-Petri. Este teste mostrou que o filtro mais adequado ao tratamento do fenômeno de Gibbs para o problema em questão é o filtro exponencial.

Este filtro é então aplicado aos termos forçantes do método de fronteiras imersas a cada passo do método Runge-Kutta, em todas as simulações numéricas com a presença da rugosidade.

\subsection{Filtragem espacial}

A utilização de derivadas de alta ordem pode gerar instabilidades numéricas no código, introduzindo perturbações não físicas de alta frequência durante as simulações. Para evitar a contaminação dos resultados com estas perturbações não físicas, normalmente adota-se um filtro numérico, que elimina as altas frequências da solução.

Kloker (1998) apresenta uma técnica de filtragem onde se utilizam esquemas descentrados compactos de sexta ordem. O esquema funciona utilizando-se diferenças descentradas a montante e a jusante, alternadamente para cada passo do método Runge-Kutta.

Lele (1992) propõe métodos compactos de filtragem com diferentes ordens de precisão, dentre eles optou-se por utilizar um método com sexta ordem de precisão. Esta filtragem foi aplicada somente na direção $x$, a cada passo no tempo. O método consiste em recalcular a distribuição das componentes 
de vorticidade resolvendo-se o sistema tridiagonal:

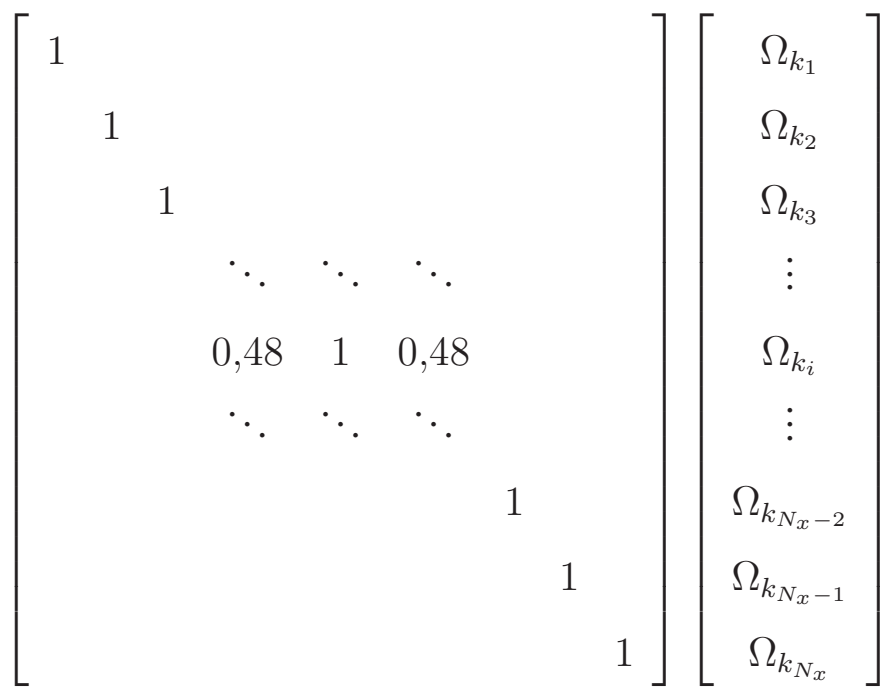

$$
\begin{aligned}
& =\left[\begin{array}{c}
0,9375 \Omega_{k_{1}}+0,25 \Omega_{k_{2}}-0,375 \Omega_{k_{3}}+0,25 \Omega_{k_{4}}-0,0625 \Omega_{k_{5}} \\
0,0625 \Omega_{k_{1}}+0,75 \Omega_{k_{2}}+0,375 \Omega_{k_{3}}-0,25 \Omega_{k_{4}}+0,0625 \Omega_{k_{5}} \\
-0,0625 \Omega_{k_{1}}+0,25 \Omega_{k_{2}}+0,625 \Omega_{k_{3}}+0,25 \Omega_{k_{4}}-0,0625 \Omega_{k_{5}} \\
\vdots \\
0,9875 \Omega_{k_{i}}+0,489375\left[\Omega_{k_{i+1}}+\Omega_{k_{i-1}}\right] \\
-0,00375\left[\Omega_{k_{i+2}}+\Omega_{k_{i-2}}\right]+0,000625\left[\Omega_{k_{i+3}}+\Omega_{k_{i-3}}\right] \\
\vdots \\
0,0625 \Omega_{k_{N_{x}-4}}-0,25 \Omega_{k_{N_{x}-3}}+0,375 \Omega_{k_{N_{x}-2}}+0,75 \Omega_{k_{N_{x}-1}}+0,0625 \Omega_{k_{N_{x}}} \\
-0,0625 \Omega_{k_{N_{x}-4}}+0,25 \Omega_{k_{N_{x}-3}}-0,375 \Omega_{k_{N_{x}-2}}+0,25 \Omega_{k_{N_{x}-1}}+0,9375 \Omega_{k_{N_{x}}}
\end{array}\right]
\end{aligned}
$$

A resolução deste sistema foi adaptada para a paralelização na direção longitudinal.

\subsection{Relaminarização do escoamento}

Em simulações numéricas de escoamentos onde existem perturbações do tipo convectivas que são transportadas para um certo contorno, pode haver reflexão destas perturbações e consequente alteração dos resultados físicos que se deseja estudar. Para evitar possíveis alterações, é adotada uma técnica de relaminarização do escoamento. Kloker et al. (1993) mostraram as vantagens de se utilizar esta técnica para evitar reflexões de ondas no contorno de saída, comparando-a com outras técnicas que têm a mesma finalidade. 
No presente trabalho foi implementada a relaminarização do escoamento próximo ao contorno de saída, entre os pontos $x_{3}$ e $x_{4}$ da figura 2.1. Entre estes dois pontos os valores das perturbações das componentes de vorticidade decaem até zero, de acordo com a função:

$$
\Omega_{k}^{*}(x, y, t)=f_{1}(x) \Omega_{k}(x, y, t)
$$

para $x_{3} \leq x \leq x_{4}$, em que $\Omega_{k}^{*}(x, y, t)$ é o valor da componente de vorticidade; $\Omega_{k}(x, y, t)$ é o valor da vorticidade após cada passo do método Runge-Kutta; e $f_{1}(x)$ é uma função rampa que varia de $f_{1}\left(x_{3}\right)=1$ até $f_{1}\left(x_{4}\right)=0$. Durante a execução do programa esta técnica de relaminarização é aplicada após cada passo do integrador temporal Runge-Kutta.

A função rampa proposta por Meitz (1996) foi utilizada neste estudo:

$$
f_{1}(x)=f_{1}(\varepsilon)=\left(1-\varepsilon^{50}\right)^{4} e^{-\frac{\varepsilon^{4}}{10}}
$$

em que $\varepsilon=\frac{x-x_{3}}{x_{4}-x_{3}}$, para $x_{3} \leq x \leq x_{4}$.

Em casos onde se estuda a propagação de ondas TS normalmente adota-se dois comprimentos de onda entre $x_{3}$ e $x_{4}$ e mais um comprimento de onda entre $x_{4}$ e $x_{\max }$ (Meitz, 1996).

Outra região de relaminarização, localizada próximo à entrada do domínio, também foi implementada no código. Como apontado por Meitz (1996), reflexões causadas por vórtices na direção longitudinal, na entrada do domínio, podem contaminar a solução numérica. A função rampa utilizada aqui é dada por:

$$
f_{2}(x)=f_{2}(\varepsilon)=6 \varepsilon^{5}-15 \varepsilon^{4}+10 \varepsilon^{3},
$$

em que $\varepsilon=\frac{x-x_{0}}{x_{1}-x_{0}}$, para $x_{0} \leq x \leq x_{1}$. Todas as componentes de vorticidade são multiplicadas por esta função nesta região.

\subsection{Solução da equação de Poisson}

A equação de Poisson a ser resolvida pode ser escrita da seguinte forma:

$$
\nabla^{2} f=s
$$


em que $\nabla^{2}$ é o operador laplaciano, $f$ é igual a $V_{k}$, a componente da velocidade do modo $k$ de Fourier na direção normal à superfície, e $s$ é o termo fonte da equação.

Para a solução dessa equação de Poisson, um algoritmo multimalha é utilizado. Os métodos multimalha podem resolver equações diferenciais parciais elípticas discretizadas em $N$ pontos em $N \log N$ iterações, enquanto outros métodos, como por exemplo o método de sobre relaxação sucessiva (SOR - do inglês Successive Over Relaxation), resolve em $N^{2}$ iterações. Um estudo da performance de métodos de solução da equação de Poisson em um código de simulação de escoamentos de fluidos incompressíveis é apresentada por Souza et al. (2006).

Existem vários métodos multimalha que resolvem problemas elípticos. Para mais detalhes de métodos multimalha pode-se consultar Briggs et al. (1986); Zhang (1996); Gupta et al. (1997); Zhang (1997); Spitaleri (2000). O algoritmo aqui adotado é o esquema de aproximação total FAS (do inglês Full Approximation Storage) (Stüben e Trottenberg, 1981). Neste estudo, é adotado um ciclo V com 4 malhas, como esquematizado na figura 3.4.

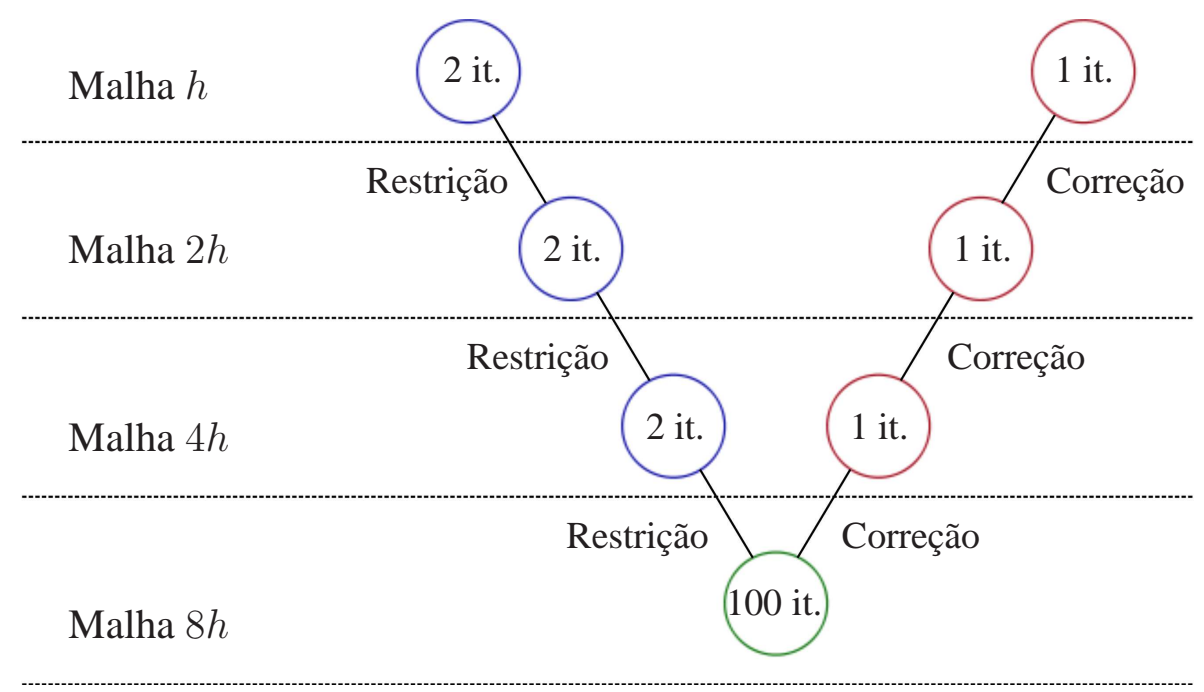

Figura 3.4: Esquematização do ciclo V utilizado no método multimalha.

De acordo com a figura, pode-se descrever os passos do algoritmo FAS da seguinte forma, partindo da malha $h$ (malha mais fina):

1. realiza-se duas iterações do método de sobre relaxação sucessiva por linha (LSOR - do inglês Line Successive Over Relaxation) na malha $h$, para resolver $\nabla^{2} f_{h}=s_{h}$;

2. calcula-se o resíduo $d_{h}=s_{h}-\nabla^{2} f_{h}$;

3. efetua-se a restrição SI da função $f_{h}^{i} \Rightarrow f_{2 h}^{0}$; 
4. efetua-se a restrição FW do resíduo $d_{h}^{i} \Rightarrow d_{2 h}^{0}$;

5. calcula-se o termo fonte para a malha $2 h, s_{2 h}=d_{2 h}^{0}+\nabla^{2} f_{2 h}^{0}$;

6. repete-se os passos de 1 a 5 até chegar na malha $8 h$ (malha mais grossa). Nesta malha são realizadas cem iterações do método LSOR, para resolver $\nabla^{2} f_{8 h}=s_{8 h}$;

7. calcula-se a correção da malha $8 h$, por meio da equação: $c_{8 h}=f_{8 h}^{i}-f_{8 h}^{0}$;

8. calcula-se a interpolação bilinear da correção $c_{8 h} \Rightarrow c_{4 h}$;

9. atualiza-se os valores de $f_{4 h}$, através da equação $f_{4 h}=f_{4 h}^{i}+c_{4 h}$;

10. realiza-se uma iteração do método LSOR na malha $4 h$, para resolver $\nabla^{2} f_{4 h}=s_{4 h}$;

11. repete-se os passos de 7 a 10 até chegar na malha $h$;

12. se $d_{h}>\varepsilon$, realiza-se um novo ciclo V. Caso contrário, o algoritmo para.

Na operação de restrição $S I$ (do inglês Straight Injection) os valores das variáveis na malha mais fina são passados diretamente para a malha mais grossa, sem o cálculo de médias. Já na restrição $F W$ (do inglês Full Weight) há uma ponderação dos valores das variáveis na malha mais fina para a malha mais grossa. As ponderações utilizadas para as restrições $S I$ e $F W$ são mostradas na figura 3.5.

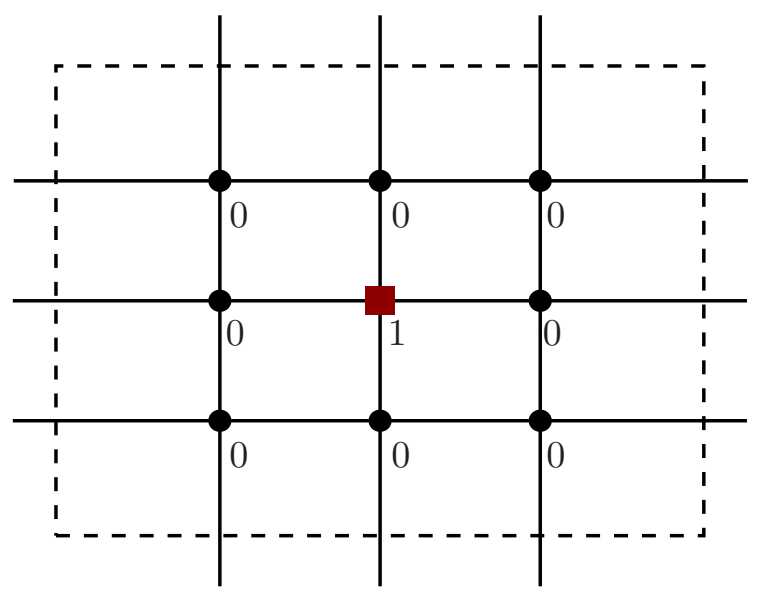

(a) SI.

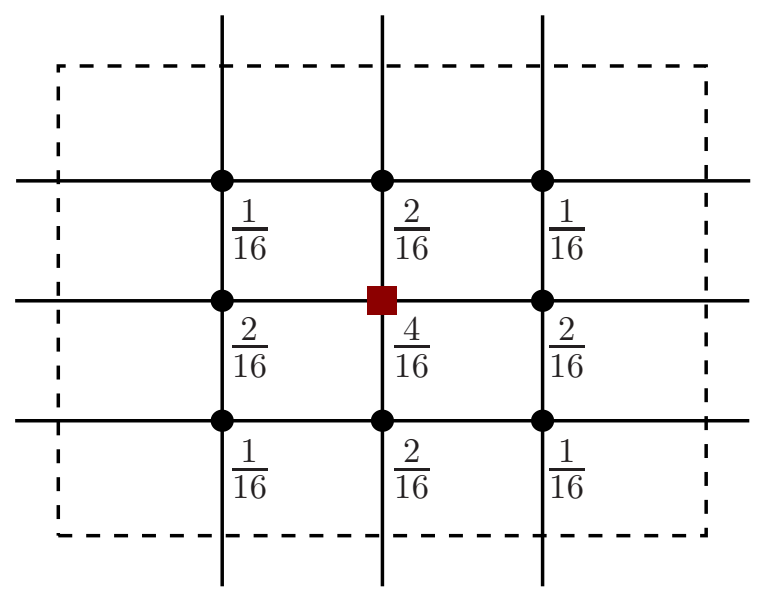

(b) FW.

Figura 3.5: Ponderação utilizada para as operações de restrição.

Para a operação de correção, uma interpolação bilinear é empregada. A ponderação dessa operação é mostrada na figura 3.6. 


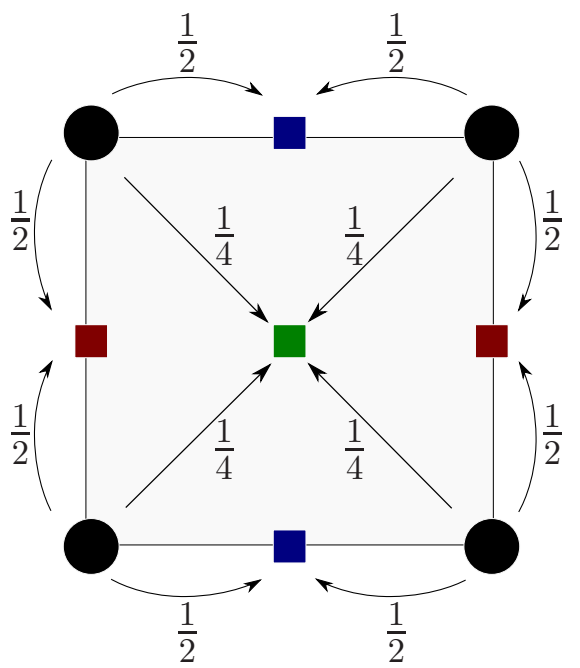

Figura 3.6: Ponderação utilizada para a interpolação bilinear.

Para que ocorra a suavização das altas frequências, o valor do fator de relaxação para o método LSOR, quando se está indo da malha mais grossa para a malha mais fina, deve ser igual a 1, caso contrário, não há garantia do funcionamento do método.

$\mathrm{O}$ número de ciclos $\mathrm{V}$ necessários para a solução da equação depende do valor do resíduo na malha mais fina $(h)$. Se este valor for menor que um valor de referência estipulado, o procedimento é interrompido e a aproximação obtida é tomada como resposta. $\mathrm{O}$ valor de referência adotado para as simulações realizadas foi $\varepsilon=10^{-6}$.

Levando-se em consideração o método espectral, e que $i$ corresponde a uma linha na direção y e $j$ corresponde a uma linha na direção $x$, a discretização da equação é realizada da seguinte maneira:

- Na direção $x$ as seguintes aproximações são utilizadas, para cada EP:

- Para $i=2$ :

$$
\left.\frac{\partial^{2} V_{k}}{\partial x^{2}}\right|_{2, j}=\frac{1}{12 h_{x}^{2}}\left[10 V_{k_{1, j}}-15 V_{k_{2, j}}-4 V_{k_{3, j}}+14 V_{k_{4, j}}-6 V_{k_{5, j}}+V_{k_{6, j}}\right]+O\left(h_{x}^{4}\right),
$$

- Para $3 \leq i \leq N_{E P}-2$ :

$$
\begin{aligned}
\left.\frac{\partial^{2} V_{k}}{\partial x^{2}}\right|_{3 \leq i \leq N_{E P}-2, j}= & \frac{1}{12 h_{x}^{2}}\left[-V_{k_{i-2, j}}+16 V_{k_{i-1, j}}-30 V_{k_{i, j}}\right. \\
& \left.+16 V_{k_{i+1, j}}-V_{k_{i+2, j}}\right]+O\left(h_{x}^{4}\right),
\end{aligned}
$$


- Para $i=N_{E P}-1$ :

$$
\begin{aligned}
\left.\frac{\partial^{2} V_{k}}{\partial x^{2}}\right|_{N_{E P}-1, j}= & \frac{1}{12 h_{x}^{2}}\left[10 V_{k_{N_{E P}, j}}-15 V_{k_{N_{E P}-1, j}}-4 V_{k_{N_{E P}-2, j}}\right. \\
& \left.+14 V_{k_{N_{E P}-3, j}}-6 V_{k_{N_{E P}-4, j}}+V_{k_{N_{E P}-5, j}}\right]+O\left(h_{x}^{4}\right),
\end{aligned}
$$

em que $h_{x}$ é o espaçamento de malha e $N_{E P}$ corresponde ao número de pontos de cada subdomínio, que é resolvido em um EP, ambos na direção longitudinal;

- Na direção y deriva-se aproximações similares às apresentadas abaixo (para uma malha com espaçamento constante):

- Para $j=2$ :

$$
\left.4 \frac{\partial^{2} V_{k}}{\partial y^{2}}\right|_{i, 2}+\left.\frac{\partial^{2} V_{k}}{\partial y^{2}}\right|_{i, 3}=\frac{1}{36 h_{y}^{2}}\left[254 V_{k_{i, 1}}-432 V_{k_{i, 2}}+162 V_{k_{i, 3}}+16 V_{k_{i, 4}}\right]+O\left(h_{y}^{5}\right)
$$

- Para $3 \leq j \leq N_{y}-2$ :

$$
\begin{aligned}
\left.2 \frac{\partial^{2} V_{k}}{\partial y^{2}}\right|_{i, j-1}+\left.11 \frac{\partial^{2} V_{k}}{\partial y^{2}}\right|_{i, j}+\left.2 \frac{\partial^{2} V_{k}}{\partial y^{2}}\right|_{i, j+1}= & \frac{1}{4 h_{y}^{2}}\left[3 V_{k_{i, j-2}}+48 V_{k_{i, j-1}}-102 V_{k_{i, j}}\right. \\
& \left.+48 V_{k_{i, j+1}}+3 V_{k_{i, j+2}}\right]+O\left(h_{y}^{6}\right)
\end{aligned}
$$

- Para $j=N_{y}-1$ :

$$
\begin{aligned}
& \left.\quad \frac{\partial^{2} V_{k}}{\partial y^{2}}\right|_{i, N_{y}-1}=\frac{1}{h_{y}^{2}}\left[V_{k_{i, N_{y}-2}}-2 V_{k_{i, N_{y}-1}}+V_{k_{i, N_{y}}}\right]+O\left(h_{y}^{2}\right) \\
& -\operatorname{Para} j=N_{y}: \\
& \left.\frac{\partial^{2} V_{k}}{\partial y^{2}}\right|_{i, N_{y}}=\frac{-7 V_{k_{i, N_{y}}}+8 V_{k_{i, N_{y}-1}}-V_{k_{i, N_{y}-2}}}{2 h_{y}^{2}}+\left.\frac{3}{h_{y}} \frac{\partial V_{k}}{\partial y}\right|_{i, N_{y}}+O\left(h_{y}^{2}\right) .
\end{aligned}
$$

em que $h_{y}$ é o espaçamento de malha e $N_{y}$ corresponde ao número de pontos, ambos na direção normal à superfície. Para uma malha com espaçamento variável na direção $y$, ou seja, com estiramento nessa direção, os coeficientes das equações acima são calculados em função do fator de estiramento da malha, de acordo com Linnick e Fasel (2005). Não há necessidade de utilização de aproximações de alta ordem próximo ao contorno superior $\left(j=N_{y}\right)$, pois o 
fenômeno físico em questão ocorre próximo à superfície inferior $(j=1)$.

- Na direção $z$ a discretização já foi realizada no momento em que adotou-se o método espectral nesta direção. Portanto, para cada modo $k$ de Fourier, tem-se:

$$
\frac{\partial^{2} v}{\partial z^{2}}=-\beta_{k}^{2} V_{k} e^{-i \beta_{k} z}
$$

Com as aproximações acima é montada uma matriz pentadiagonal, que é resolvida para cada coluna do domínio (Press et al., 1992). A solução desta matriz para todas as colunas do domínio é chamada de iteração.

Como é feita a decomposição do domínio na direção $x$, foi implementada uma versão paralelizada do método multimalha. Considerando a divisão do domínio em subdomínios, que são resolvidos em EPs separados, é necessário uma atenção especial na comunicação dos valores da função $f$ entre os subdomínios. Estas comunicações são realizadas em todas as malhas do método multimalha, nos seguintes pontos:

- a cada iteração do método LSOR;

- depois de efetuada a operação de restrição;

- depois de efetuada a operação de correção.

A figura 3.7 ilustra as comunicações que ocorrem entre dois EPs consecutivos do método multimalha paralelizado implementado. Pode-se ver, nesta figura, a interseção necessária para a correta resolução da equação de Poisson entre os subdomínios. A quantidade de pontos da interseção é definida a partir da malha mais grossa $(8 h)$. 


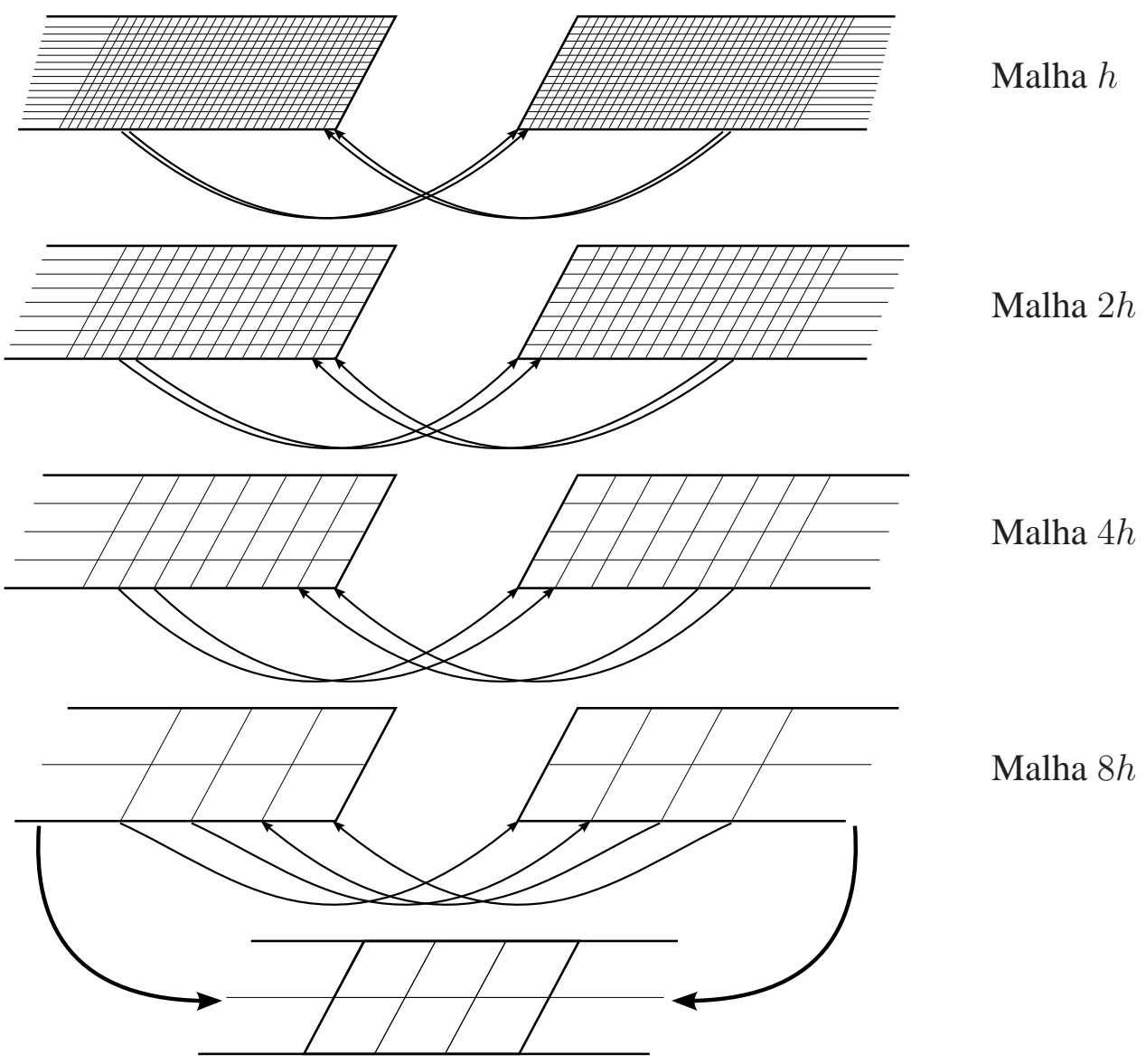

Figura 3.7: Ilustração do processo de comunicação entre dois subdomínios adjacentes.

\subsection{Cálculo da vorticidade na superfície}

Os cálculos das componentes de vorticidade na superfície $(y=0)$ são efetuados após a resolução das equações de Poisson para as componentes de velocidade. De acordo com Souza (2003), após a atualização do campo de velocidade, calcula-se os valores da variável:

$$
J_{k}(x, y=0)=\frac{\partial^{2} V_{k}}{\partial x^{2}}+\frac{\partial^{2} V_{k}}{\partial y^{2}}-\beta_{k}^{2} V_{k} .
$$

A derivada $\frac{\partial^{2} V_{k}}{\partial x^{2}}$, em $y=0$, pode ser calculada analiticamente, conforme explicado na Seção 3.11. A segunda derivada de $V_{k}$ na direção $y$ é obtida por uma aproximação descentrada de sexta ordem. Esta aproximação utiliza um estêncil de 7 pontos e seus coeficientes são obtidos de acordo com o estiramento da malha. 
A componente longitudinal da vorticidade $\Omega_{x}$ é calculada por meio da equação:

$$
\frac{\partial^{2} \Omega_{x_{k}}}{\partial x^{2}}-\beta_{k}^{2} \Omega_{x_{k}}=-i \beta_{k} J_{k}-\frac{\partial^{2} \Omega_{y_{k}}}{\partial x \partial y}
$$

Na direção normal à superfície, a componente de vorticidade é nula, devido à condição de não deslizamento.

A componente de vorticidade na direção $z$ é obtida, para cada modo $k$ de Fourier, pela integração da equação:

$$
\frac{\partial \Omega_{z_{k}}}{\partial x}=-J_{k}-i \beta_{k} \Omega_{x_{k}}
$$

\subsection{Introdução de perturbações}

Para o estudo de estabilidade linear é necessário a introdução de perturbações periódicas na superfície. A introdução destas perturbações é realizada através de sucção e injeção de massa no modo fundamental. Essas perturbações geram ondas TS que serão propagadas no escoamento.

Este método de introdução de perturbações é utilizado por vários pesquisadores (Fasel et al., 1990; Kloker, 1998; Souza, 2003) e os resultados obtidos através deste método já foram verificados e validados, provando a sua eficiência. No código implementado assume-se que, no tempo $t=0$, o escoamento é não perturbado, ou seja, é composto apenas da camada limite não perturbada sobre a superfície. Este escoamento base é obtido conforme citado na Seção 2.3. No tempo $t+\delta t$, as perturbações são inseridas na região de introdução de perturbações (do inglês disturbance strip).

Para o estudo em questão, são utilizadas perturbações temporais, com uma determinada frequência. As perturbações não estacionárias são inseridas entre os pontos $x_{1}$ e $x_{2}$, ilustrados na figura 2.1. Para se introduzir estas perturbações, utiliza-se a seguinte função para a velocidade $V_{k}$ na superfície, para cada modo $k$ de Fourier:

$$
V_{k}(x, y=0, t)=\mathcal{A}_{k} f_{p}(x) \operatorname{sen}\left(\omega_{t_{k}} t+\theta_{k}\right), \text { para } x_{1} \leq x \leq x_{2}
$$

e

$$
V_{k}(x, y=0, t)=0, \text { para } x \leq x_{1} \text { e } x \geq x_{2} .
$$


Os valores de $\mathcal{A}_{k}$ e $\theta_{k}$ são constantes reais escolhidas para ajustar os valores da amplitude e a fase da perturbação. A constante $\omega_{t_{k}}$ é a frequência adimensional. Ajustou-se os coeficientes da função $f_{p}(x)$ de tal forma que o valor da função e da sua segunda derivada fossem nulos em $x_{1}$ e $x_{2}$. Isto torna a introdução de perturbações no escoamento mais suave.

O valor da segunda derivada desta função é utilizado para cálculo das componentes de vorticidade na superfície, conforme é mostrado na Seção 3.10.

\subsection{Método numérico}

Nesta seção são descritas as etapas de cálculo para o avanço temporal da solução numérica.

Para cada passo do método de Runge-Kutta, são efetuadas as seguintes etapas:

1. cálculo das componentes intermediárias de vorticidade, sem os termos forçantes do método de fronteiras imersas;

2. cálculo dos termos forçantes do método de fronteiras imersas;

3. aplicação do filtro de Gibbs aos termos forçantes do método de fronteiras imersas;

4. aplicação do filtro espacial (somente no último passo do Runge-Kutta);

5. relaminarização do escoamentos na entrada e saída do domínio;

6. solução da equação de Poisson para $V_{k}$;

7. solução da equação de Poisson para $U_{k}$;

8. solução da equação de Poisson para $W_{k}$;

9. atualização de $\Omega_{x}$ na superfície;

10. atualização de $\Omega_{z}$ na superfície;

11. atualização das perturbações;

O código para quando o tempo final de simulação for atingido. 


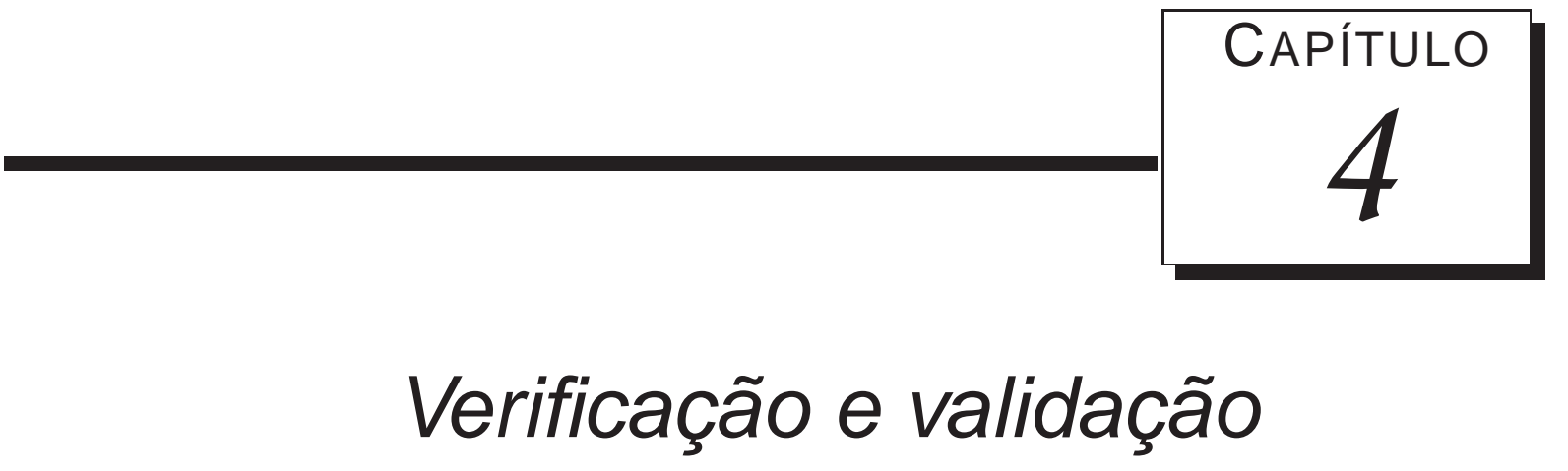

Neste capítulo são definidos os termos verificação e validação, bem como as principais diferenças entre eles. Também são apresentados resultados de ordem de convergência, que mostram a verificação do código numérico, através do Método das Soluções Manufaturadas. Por fim, é feita a validação do código DNS por meio da comparação dos resultados numéricos com resultados experimentais e da Teoria de Estabilidade Linear (LST - do inglês Linear Stability Theory).

\subsection{Verificação $X$ validação}

Os termos verificação e validação podem eventualmente ser confundidos. Esses dois procedimentos devem ser executados para checar a precisão do código numérico e a conformidade do modelo matemático em relação ao problema físico, respectivamente (Roache, 1998; Oberkampf e Trucano, 2002a).

\subsection{Verificação}

Como mencionado anteriormente, verificação é uma metodologia que identifica se o código numérico tem erros de implementação. Ela também determina se o código resolve as Equações Diferenciais Parciais (EDPs) correta e precisamente, ou seja, garante que a solução numérica se aproxima da analítica quando o espaçamento de malha tende a zero. Vale a pena ressaltar que esta metodologia não 
se preocupa se o modelo matemático é adequado para representar o problema físico (Roache, 1997; Salari e Knupp, 2000; Roy et al., 2004; Roy e Oberkampf, 2011).

A verificação também avalia se o código numérico atinge a ordem de convergência esperada pelo método numérico implementado. Além disso, pode ser feita uma estimativa da magnitude do erro do esquema numérico (Salari e Knupp, 2000; Roy, 2005). Considerando que nenhuma alteração foi feita no código numérico, o procedimento de verificação precisa ser efetuado uma única vez (Roy et al., 2004).

Os métodos mais populares para a verificação de códigos são o Método das Soluções Exatas (MES - do inglês Method of Exact Solutions) e o Método das Soluções Manufaturadas (MMS - do inglês Method of Manufactured Solutions) (Roy et al., 2004). No MES, a comparação entre as soluções exata e numérica é facilmente realizada, uma vez que a solução exata para o conjunto de equações a ser resolvido é conhecida. Porém, a solução exata pode não existir ou sua obtenção pode ser não trivial, visto que as equações governantes são, geralmente, não lineares e acopladas, além de possuírem condições de contorno complexas e serem resolvidas em domínios irregulares. Ainda, há casos em que existe uma solução analítica, mas quando isso ocorre, essa solução envolve diversas simplificações.

Por outro lado, o MMS não necessita da solução exata do problema. O método consiste na construção de uma função solução (a manufatura), que satisfaz uma versão modificada das equações governantes do problema de interesse (Salari e Knupp, 2000; Roy, 2005). O objetivo é resolver um problema similar, no qual a solução exata é conhecida. Mais detalhes são dados a seguir, na Seção 4.2.1.

\subsubsection{Método das soluções manufaturadas}

O MMS é o método mais eficiente para a verificação de códigos e tem sido amplamente utilizado na comunidade científica (Roache, 1998; Salari e Knupp, 2000; Roache, 2002; Knupp e Salari, 2003; Roy, 2005; Eça et al., 2007). A ideia de se construir soluções manufaturadas é antiga, mas só recentemente esta técnica passou a ser empregada na verificação de códigos. Shih (1985) publicou um dos primeiros artigos sobre esse assunto, contudo, somente nos trabalhos de Steinberg e Roache (1985) e Roache (1998) essa técnica foi combinada com refinamento sucessivo de malha para determinar a ordem de convergência.

A princípio não é necessário que a solução manufaturada satisfaça as EDPs em estudo. Depois que a solução manufaturada é gerada para todas as variáveis dependentes do problema, elas são subs- 
tituídas nas EDPs originais, para que as derivadas possam ser calculadas analiticamente. Então, as EDPs originais são rearranjadas e os termos excedentes são agrupados em um termo fonte, que é colocado do lado direito da equação. Logo, gera-se um problema modificado, cuja solução exata é conhecida e pode ser comparada à solução numérica.

Este método foi utilizado no presente trabalho para a verificação do código DNS. Inicialmente, verificou-se o código bidimensional, que gera o escoamento base (Seção 4.2.3). Em seguida, na Seção 4.2.4, o código DNS tridimensional foi verificado.

\subsubsection{Cálculo da ordem de convergência}

A fim de se calcular a ordem de convergência do código numérico, foram feitas simulações utilizando várias malhas, com diferentes número de pontos e espaçamentos nas duas direções. As normas $L_{1}, L_{2}$ e $L_{\infty}$ foram consideradas para o cálculo do erro das variáveis em cada malha. Os erros em cada norma são então definidos como:

$$
\begin{aligned}
& E_{1}=\|s-\bar{s}\|_{1}=\frac{1}{N} \sum_{n=1}^{N}\left|s_{n}-\bar{s}_{n}\right|, \\
& E_{2}=\|s-\bar{s}\|_{2}=\sqrt{\sum_{n=1}^{N} \frac{\left|s_{n}-\bar{s}_{n}\right|^{2}}{N}}, \\
& E_{\infty}=\|s-\bar{s}\|_{\infty}=\max \left|s_{n}-\bar{s}_{n}\right|,
\end{aligned}
$$

em que $E_{i}$ é o erro na norma $L_{i}, i=1,2, \infty ; s_{n}$ e $\bar{s}_{n}$ são as soluções numérica e exata, respectivamente, e $N$ é o número total de pontos. O índice $n$ indica que as soluções numérica e exata devem ser calculadas no mesmo ponto físico.

Calculados os erros em cada malha, a ordem de convergência observada $p^{k}$ entre duas malhas pode ser aproximada através da equação:

$$
p^{k} \approx \frac{\log \left(\frac{E_{h_{1}}}{E_{h_{2}}}\right)}{\log (r)},
$$

em que $h_{1}$ e $h_{2}$ são o espaçamento de cada malha e

$$
r=\frac{h_{1}}{h_{2}}
$$


é o fator de refinamento de malha.

De acordo com Roy (2010), um refinamento sistemático foi efetuado, para garantir consistência e uniformidade.

\subsubsection{Verificação do código base bidimensional}

Com o intuito de verificar o código DNS bidimensional, que simula o escoamento base, foi gerada uma solução manufaturada 2D. Na geração desta solução, as variáveis $u$ e $v$ são escolhidas de forma a satisfazer a equação da continuidade (equação (2.7)) e a variável $\omega_{z}$ é obtida a partir da definição de vorticidade (equação (2.3)).

A solução gerada, de acordo com as condições acima, é dada por:

$$
\begin{aligned}
u & =\operatorname{sen}(\alpha x) e^{-y}\left[P(y)-P^{\prime}(y)\right], \\
v & =\alpha \cos (\alpha x) P(y) e^{-y}, \\
\omega_{z} & =\operatorname{sen}(\alpha x) e^{-y}\left[\left(\alpha^{2}-1\right) P(y)+2 P^{\prime}(y)-P^{\prime \prime}(y)\right],
\end{aligned}
$$

em que $\alpha=0,1$, o polinômio $P(y)$ é dado por:

$$
P(y)=y^{6}-3 y^{5}+3 y^{4}-y^{3}
$$

e $P^{\prime}(y)$ e $P^{\prime \prime}(y)$ são a primeira e segunda derivadas do polinômio na direção $y$. As variáveis da solução bidimensional podem ser vistas na figura 4.1 .

Funções senoidais foram escolhidas por serem de classe $C^{\infty}$. O polinômio $P(y)$ foi adotado para garantir que a variável $v$ fosse nula nos contornos inferior (condição de impermeabilidade) e superior (decaimento exponencial da velocidade). A primeira derivada do polinômio também é nula nos contorno inferior e superior, de forma a satisfazer a equação da continuidade. A presença do termo $e^{-y}$ na solução manufaturada se deve à condição de decaimento exponencial da velocidade na direção $y$.

Termos fontes são adicionados à equação (2.11), para que as equações governantes sejam satisfeitas. Em todos os casos de verificação com MMS, um programa de manipulação algébrica foi utilizado para a obtenção dos termos fontes das equações.

Para a simulação bidimensional utilizando MMS considerou-se o domínio da figura 2.1, sem a introdução de perturbações e a rugosidade, com dimensões $[0,1] \times[0,1]$. O número de Reynolds 


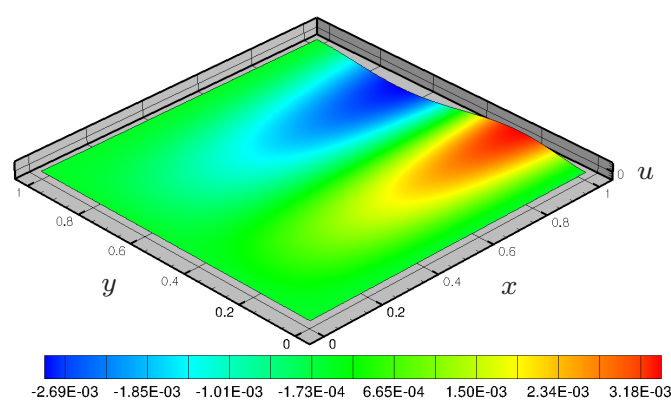

(a) Variável $u$.

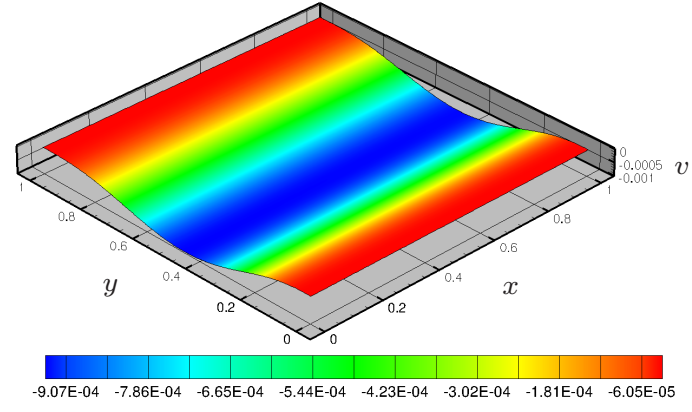

(b) Variável $v$.

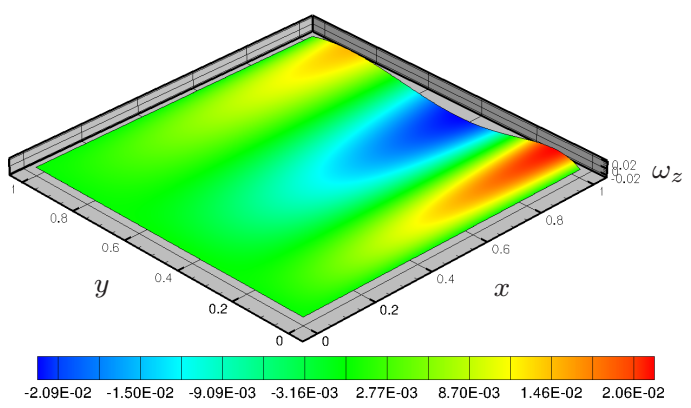

(c) Variável $\omega_{z}$.

Figura 4.1: Variáveis da solução bidimensional.

adotado é $R e=322326$. Esse número foi escolhido por ser próximo ao Re do problema físico a ser estudado. Embora a solução manufaturada não seja dependente do tempo, foi feita uma integração pseudotemporal, para atingir o estado estacionário. Para isso, foi utilizado $\delta t=10^{-4}$, integrando-se 10000 passos no tempo.

Como o intuito do código DNS é resolver escoamentos em camada limite, a necessidade de resolução próximo à superfície justifica o uso de estiramento de malha na direção $y$. A maneira mais simples de se aplicar esta técnica é considerar a variação do tamanho do espaçamento de malha como uma progressão geométrica. Entretanto, o uso de uma progressão geométrica para discretizar o domínio na direção $y$ pode acarretar variações significantes na razão entre os tamanhos do último e do primeiro espaçamentos de malha. Quanto maior esta razão, mais anisotrópica será a malha. Para as malhas utilizadas neste trabalho, se a razão entre esses espaçamentos é maior do que 3,5, aparecem instabilidades, que podem levar o código numérico adotado a divergir. Além disso, os erros para este tipo de malha são geralmente maiores, comparados aos erros de malhas sem estiramento. No entanto, nas simulações com MMS para o código base, não se notou efeito de anisotropia de malha. 
Dois conjuntos de malhas foram considerados para este teste: um composto por malhas sem estiramento na direção $y$ e um por malhas com estiramento nesta direção. Esses conjuntos de malhas são apresentados nas tabelas 4.1 e 4.2 , respectivamente. A quantidade de pontos (espaçamentos de malha) nas direções $x$ e $y$ são representadas por $N_{x}\left(h_{x}\right)$ e $N_{y}\left(h_{y}\right)$, respectivamente. Na tabela 4.2, os parâmetros $h_{y_{0}}$ e $h_{\left(N_{y}-1\right)}$ representam o primeiro e o último espaçamentos de malha (partindo do contorno inferior), respectivamente, e $s_{f}$ é o fator de estiramento. Cada malha tem um fator de estiramento diferente para garantir que as coordenadas dos pontos na direção y possam coincidir, permitindo assim o cálculo do erro no mesmo ponto físico.

Tabela 4.1: Malhas sem estiramento na direção y usadas na verificação do código base.

\begin{tabular}{|c|c|c|}
\hline Malha & $\boldsymbol{N}_{\boldsymbol{x}} \times \boldsymbol{N}_{\boldsymbol{y}}$ & $\boldsymbol{h}_{\boldsymbol{x}}=\boldsymbol{h}_{\boldsymbol{y}}$ \\
\hline 1 & $65 \times 65$ & $1,5625 \times 10^{-2}$ \\
\hline 2 & $129 \times 129$ & $7,8125 \times 10^{-3}$ \\
\hline 3 & $257 \times 257$ & $3,90625 \times 10^{-3}$ \\
\hline 4 & $513 \times 513$ & $1,953125 \times 10^{-3}$ \\
\hline
\end{tabular}

Tabela 4.2: Malhas com estiramento na direção y usadas na verificação do código base.

\begin{tabular}{|c|c|c|c|c|}
\hline Malha & $\boldsymbol{N}_{\boldsymbol{x}} \times \boldsymbol{N}_{\boldsymbol{y}}$ & $\boldsymbol{h}_{\boldsymbol{x}}=\boldsymbol{h}_{\boldsymbol{y}_{\mathbf{0}}}$ & $\boldsymbol{s}_{\boldsymbol{f}}$ & $\boldsymbol{h}_{\boldsymbol{y}_{\left(N_{\boldsymbol{y}}-1\right)}}$ \\
\hline 1 & $65 \times 33$ & $1,5625 \times 10^{-2}$ & 1,0406 & $5,5835 \times 10^{-2}$ \\
\hline 2 & $129 \times 65$ & $7,8125 \times 10^{-3}$ & 1,0201 & $2,7921 \times 10^{-2}$ \\
\hline 3 & $257 \times 129$ & $3,90625 \times 10^{-3}$ & 1,01 & $1,3960 \times 10^{-2}$ \\
\hline
\end{tabular}

A norma do erro para todas as variáveis, obtida com ambos os conjuntos de malhas, é mostrada na figura 4.2. Linhas de referência representando segunda e terceira ordens de convergência também são mostradas nesta figura. Em todos os casos, o decaimento do erro com o refinamento da malha pode ser notado. Como mencionado anteriormente, erros maiores são observados para as malhas com estiramento. Os erros para as malhas sem estiramento podem atingir uma ordem de grandeza a menos.

Na tabela 4.3 a ordem de convergência para todas as variáveis é apresentada para os dois conjuntos de malhas. Como a ordem de convergência é calculada com base no erro entre duas malhas consecutivas, não há valor de ordem de convergência para a primeira malha na tabela 4.3.

Pode-se observar, na tabela 4.3, que a ordem de convergência para todas as variáveis está entre 2,03 e 3,70 para as malhas sem estiramento e entre 1,76 e 3,63 para as malhas com estiramento.

Para aproximar as derivadas espaciais nas direções $x$ e $y$, esquemas de diferenças finitas de quarta, quinta e sexta ordem são utilizados no interior do domínio. Na fronteira superior, aproximações de 


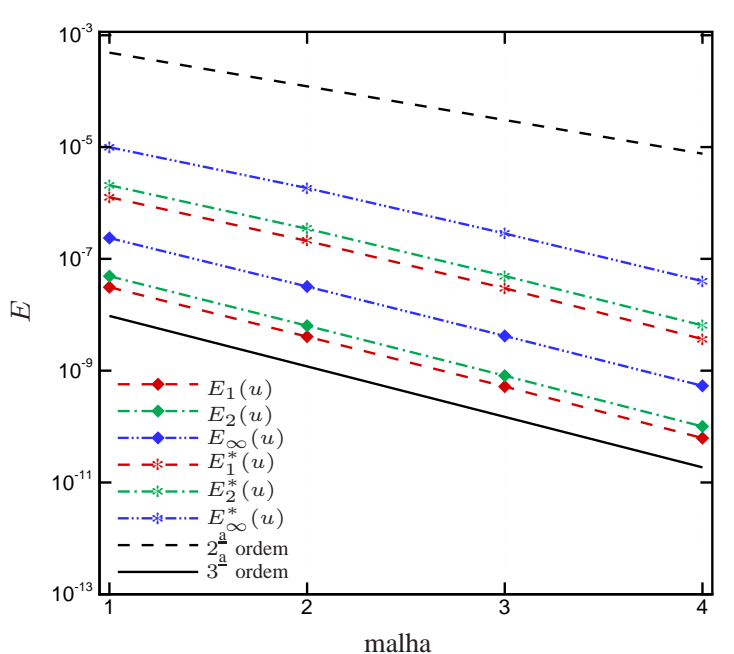

(a) Variável $u$.

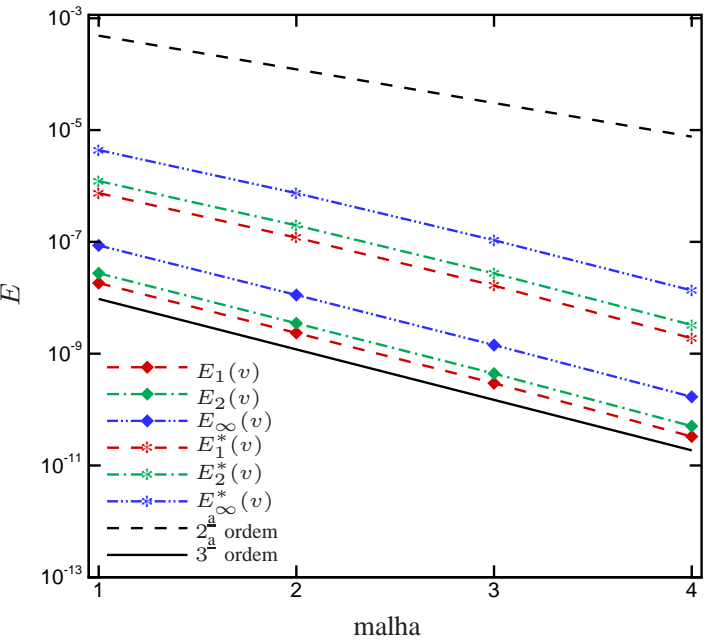

(b) Variável $v$.

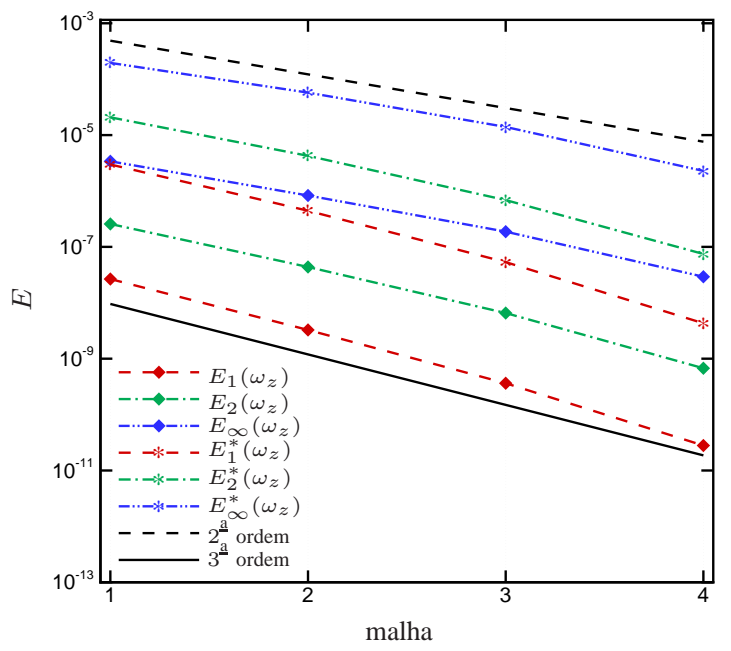

(c) Variável $\omega_{z}$.

Figura 4.2: Erro $E$ para a solução bidimensional ( $E$ - em escala logarítmica). ${ }^{*}$ representa as malhas com estiramento na direção $y$.

Tabela 4.3: Ordem de convergência para todas as variáveis calculadas com o MMS para o caso bidimensional. * representa as malhas com estiramento na direção $y$.

\begin{tabular}{|c|c|c|c|c|c|c|c|}
\hline Variável & Malha & $\boldsymbol{E}_{\mathbf{1}}$ & $\boldsymbol{E}_{\mathbf{2}}$ & $\boldsymbol{E}_{\boldsymbol{\infty}}$ & $\boldsymbol{E}_{\mathbf{1}}^{*}$ & $\boldsymbol{E}_{\mathbf{2}}^{*}$ & $\boldsymbol{E}_{\boldsymbol{\infty}}^{*}$ \\
\hline \multirow{4}{*}{$\boldsymbol{u}$} & 2 & 2,93 & 2,94 & 2,88 & 2,59 & 2,58 & 2,42 \\
\cline { 2 - 8 } & 3 & 2,96 & 2,97 & 2,93 & 2,81 & 2,80 & 2,70 \\
\cline { 2 - 8 } & 4 & 3,06 & 3,01 & 2,96 & 3,02 & 2,93 & 2,83 \\
\hline \multirow{3}{*}{$\boldsymbol{v}$} & 2 & 2,96 & 2,97 & 2,94 & 2,65 & 2,63 & 2,56 \\
\cline { 2 - 8 } & 3 & 2,98 & 2,98 & 2,97 & 2,85 & 2,84 & 2,79 \\
\cline { 2 - 8 } & 4 & 3,16 & 3,12 & 3,07 & 3,12 & 3,06 & 2,98 \\
\hline \multirow{3}{*}{$\boldsymbol{\omega}_{\boldsymbol{z}}$} & 2 & 3,02 & 2,55 & 2,03 & 2,75 & 2,28 & 1,76 \\
\cline { 2 - 8 } & 3 & 3,16 & 2,73 & 2,14 & 3,05 & 2,63 & 2,03 \\
\cline { 2 - 8 } & 4 & 3,70 & 3,28 & 2,67 & 3,63 & 3,20 & 2,61 \\
\hline
\end{tabular}


segunda ordem são usadas para calcular a solução da equação de Poisson para $v$. Essa redução na ordem da aproximação no contorno superior influenciou a ordem de convergência global para todas as componentes (Silva et al., 2010). Contudo, como a região de interesse para escoamentos em camada limite é próximo à superfície, a redução da ordem no contorno superior não afeta a solução numérica dos fenômenos físicos que se deseja estudar com o código.

Também é possível notar que o uso de estiramento na direção y reduz a ordem de convergência do método numérico. Isto se deve à diferença entre os valores do último espaçamento de malha no contorno superior, para ambos os conjuntos de malha, como mostrado na tabela 4.2. Porém, devido ao comportamento quase constante da solução de camada limite longe do contorno superior, variações na resolução da malha próximo à fronteira superior podem ser considerados desprezíveis. Por esta razão, não há influência desses erros no problema em estudo.

Uma segunda solução bidimensional também foi utilizada para testes com MMS. Para evitar repetições, os resultados obtidos com essa solução são apresentados no Apêndice A.1.

\subsubsection{Verificação do código DNS tridimensional}

Assim como foi feito com o código base, o código DNS tridimensional também foi verificado através do uso de MMS.

A seguinte solução manufaturada foi gerada para este teste:

$$
\begin{aligned}
u & =-\operatorname{sen}\left(\alpha_{1} x\right) \operatorname{sen}\left(\alpha_{2} z\right) P^{\prime}(y), \\
v & =\alpha_{1} \cos \left(\alpha_{1} x\right) \cos \left(\alpha_{2} z\right) P(y) e^{-y}, \\
w & =\frac{\alpha_{1}}{\alpha_{2}} \cos \left(\alpha_{1} x\right)\left\{\operatorname{sen}\left(\alpha_{2} z\right) e^{-y}\left[P(y)-P^{\prime}(y)\right]-\cos \left(\alpha_{2} z\right) P^{\prime}(y)\right\}, \\
\omega_{x} & =\frac{\alpha_{1}}{\alpha_{2}} \cos \left(\alpha_{1} x\right)\left\{\operatorname{sen}\left(\alpha_{2} z\right) e^{-y}\left[\left(1-\alpha_{2}^{2}\right) P(y)-2 P^{\prime}(y)+P^{\prime \prime}(y)\right]+\cos \left(\alpha_{2} z\right) P^{\prime \prime}(y)\right\}, \\
\omega_{y} & =\frac{1}{\alpha_{2}} \operatorname{sen}\left(\alpha_{1} x\right)\left\{\left[-P(y)+P^{\prime}(y)\right] e^{-y}+\left(\alpha_{1}^{2}+\alpha_{2}^{2}\right) \cos \left(\alpha_{2} z\right) P^{\prime}(y)\right\}, \\
\omega_{z} & =\operatorname{sen}\left(\alpha_{1} x\right)\left[\alpha_{1}^{2} \cos \left(\alpha_{2} z\right) P(y) e^{-y}-\operatorname{sen}\left(\alpha_{2} z\right) P^{\prime \prime}(y)\right],
\end{aligned}
$$

em que $\alpha_{1}=0,1$ e $\alpha_{2}=1$. O polinômio $P(y)$ é o mesmo usado para o caso bidimensional (equação 4.1). As variáveis $\omega_{x}, \omega_{y}$ e $\omega_{z}$ são calculadas analiticamente através das equações (2.1)-(2.3). É importante ressaltar que a solução proposta para $u, v$ e $w$ satisfazem a equação da continuidade. Além disso, todas as variáveis são periódicas na direção $z$. Ainda, termos fontes são adicionados às equações (2.4)-(2.6), para que o sistema seja satisfeito. 
Para a simulação tridimensional usando MMS foram utilizados os mesmos parâmetros das simulações bidimensionais (Seção 4.2.3), considerando a direção $z$ com dimensão $[0,2 \pi]$ e adotando 11 modos de Fourier (assumindo 32 pontos no espaço físico). Uma vez que os cálculos das derivadas na direção $z$ introduzem somente erros de arredondamento, que podem ser desprezados no presente estudo, não é necessário um refinamento de malha nesta direção.

As malhas são as mesmas utilizadas para o caso bidimensional (tabelas 4.1 e 4.2). Para o caso tridimensional, a malha 4 com estiramento apresentou problemas de anisotropia. Por isso, os resultados para essa malha não são mostrados.

Na figura 4.3 é apresentada a norma do erro para todas as variáveis, obtida com os dois conjuntos de malhas. Linhas de referência representando segunda e quarta ordens de convergência são também apresentadas na figura 4.3. Assim como no caso bidimensional, pode-se observar o decaimento do erro com o refinamento da malha, bem como a diferença entre o erro nas malhas sem e com estiramento.

Na tabela 4.4 são mostradas as ordens de convergência para todas as variáveis em ambos os conjuntos de malhas. Novamente, não há ordem de convergência para a primeira malha.

Tabela 4.4: Ordem de convergência para todas as variáveis calculadas com o MMS para o caso tridimensional. ${ }^{*}$ representa as malhas com estiramento na direção $y$.

\begin{tabular}{|c|c|c|c|c|c|c|c|}
\hline Variável & Malha & $\boldsymbol{E}_{\mathbf{1}}$ & $\boldsymbol{E}_{\mathbf{2}}$ & $\boldsymbol{E}_{\boldsymbol{\infty}}$ & $\boldsymbol{E}_{\mathbf{1}}^{*}$ & $\boldsymbol{E}_{\mathbf{2}}^{*}$ & $\boldsymbol{E}_{\boldsymbol{\infty}}^{*}$ \\
\hline \multirow{4}{*}{$\boldsymbol{u}$} & 2 & 3,05 & 2,58 & 2,09 & 2,63 & 2,19 & 1,73 \\
\cline { 2 - 8 } & 3 & 6,07 & 5,90 & 5,32 & 2,58 & 2,08 & 1,52 \\
\cline { 2 - 8 } & 4 & 4,08 & 3,91 & 3,42 & - & - & - \\
\hline \multirow{4}{*}{$\boldsymbol{v}$} & 2 & 3,03 & 3,04 & 3,05 & 2,64 & 2,65 & 2,62 \\
\cline { 2 - 8 } & 3 & 5,37 & 5,39 & 5,47 & 2,72 & 2,68 & 2,59 \\
\cline { 2 - 8 } & 4 & 3,87 & 3,88 & 3,91 & - & - & - \\
\hline \multirow{4}{*}{$\boldsymbol{w}$} & 2 & 3,02 & 2,56 & 2,07 & 2,62 & 2,21 & 1,72 \\
\cline { 2 - 8 } & 3 & 5,30 & 4,79 & 4,31 & 2,62 & 2,16 & 1,67 \\
\cline { 2 - 8 } & 4 & 3,87 & 3,39 & 2,89 & - & - & - \\
\hline \multirow{4}{*}{} & 2 & 3,41 & 2,88 & 2,42 & 2,87 & 2,42 & 1,93 \\
\cline { 2 - 8 } & 3 & 5,55 & 5,39 & 4,91 & 3,22 & 3,06 & 2,60 \\
\cline { 2 - 8 } & 4 & 4,37 & 4,48 & 4,32 & - & - & - \\
\hline \multirow{4}{*}{} & 2 & 3,02 & 3,03 & 2,99 & 2,61 & 2,66 & 2,79 \\
\cline { 2 - 8 } & 3 & 5,46 & 5,31 & 4,75 & 2,76 & 2,74 & 2,71 \\
\cline { 2 - 8 } & 4 & 3,97 & 3,90 & 3,78 & - & - & - \\
\hline \multirow{3}{*}{$\boldsymbol{\omega}_{\boldsymbol{z}}$} & 2 & 3,28 & 2,77 & 2,26 & 2,88 & 2,43 & 1,88 \\
\cline { 2 - 8 } & 3 & 5,81 & 5,50 & 4,68 & 3,37 & 3,06 & 2,28 \\
\cline { 2 - 8 } & 4 & 4,48 & 4,44 & 3,51 & - & - & - \\
\hline
\end{tabular}




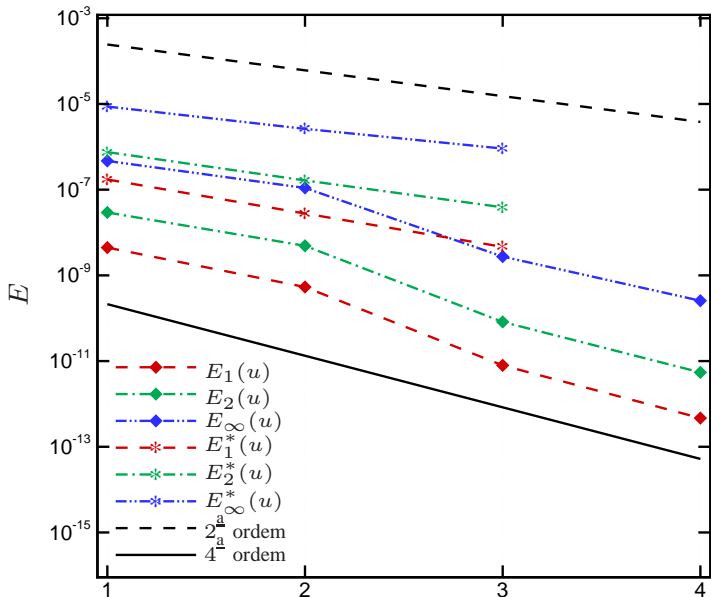

malha

(a) Variável $u$.

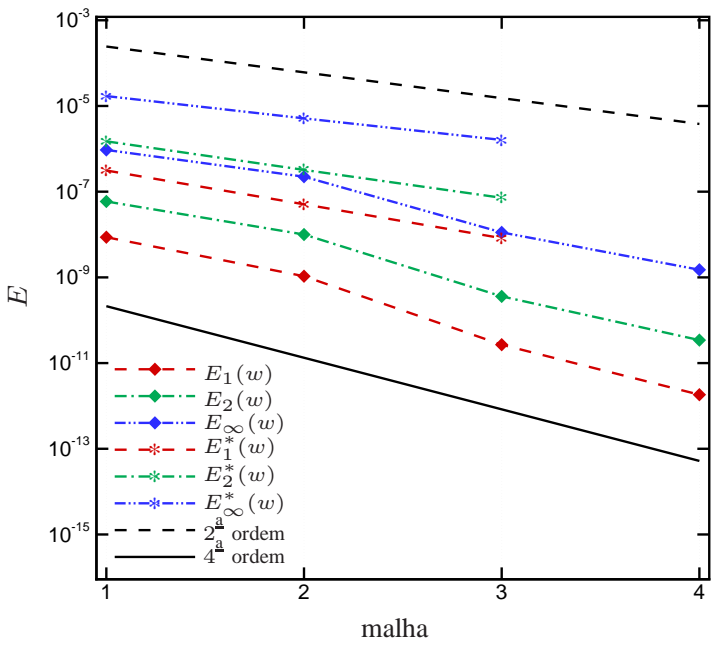

(c) Variável $w$.

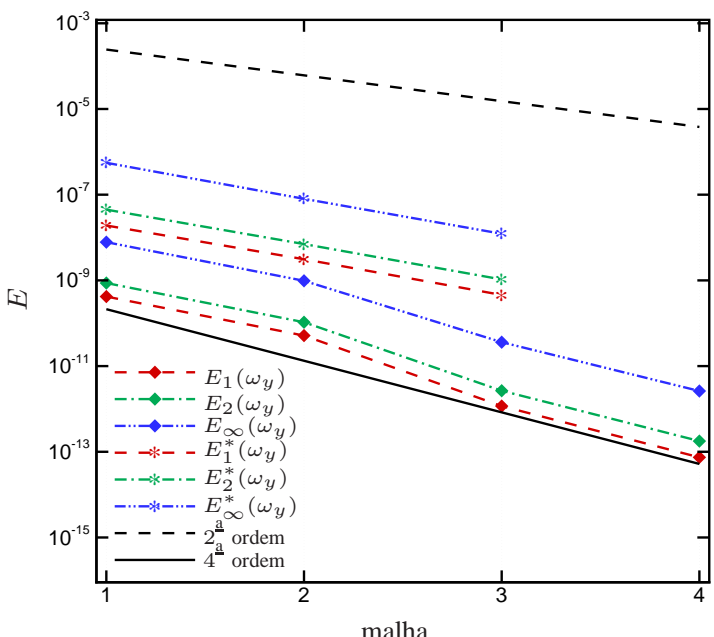

(e) Variável $\omega_{y}$.

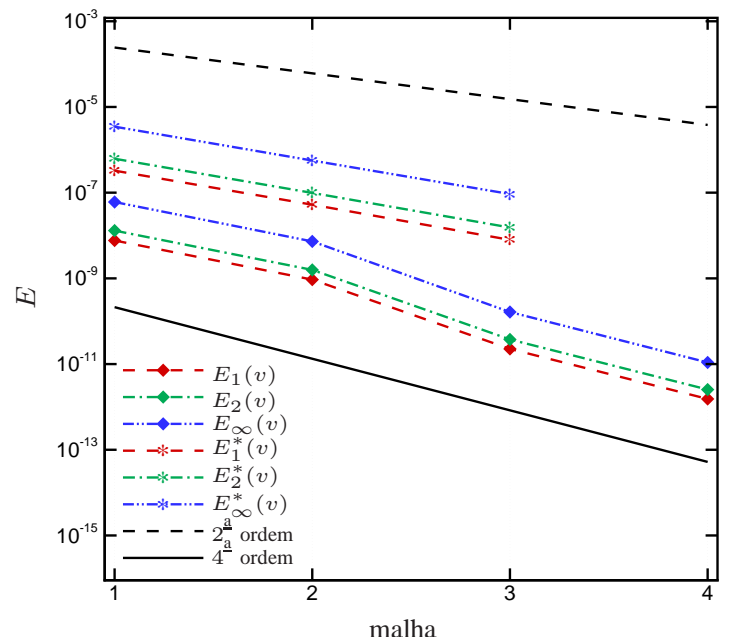

(b) Variável $v$.

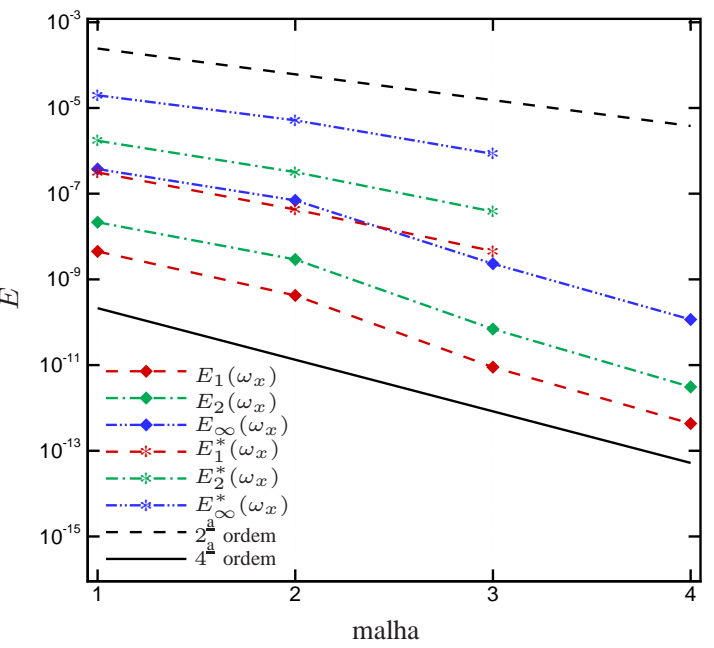

(d) Variável $\omega_{x}$.

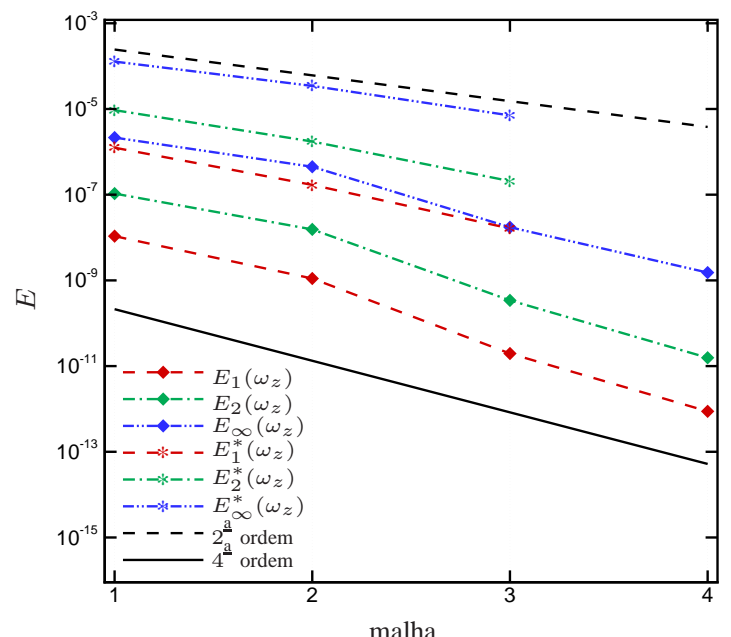

(f) Variável $\omega_{z}$.

Figura 4.3: Erro $E$ para a solução tridimensional ( $E$ - em escala logarítmica). ${ }^{*}$ representa as malhas com estiramento na direção $y$. 
Os resultados apresentados na tabela 4.4 mostram que a ordem de convergência para todas as variáveis está entre 2,07 e 6,07 para as malhas do primeiro conjunto e entre 1,52 e 3,37 para as do segundo.

Também para este caso, nota-se a redução na ordem de convergência devido à baixa ordem na aproximação da derivada no contorno superior. Ressalta-se novamente que essa redução na ordem não influencia o escoamento de interesse, como explicado anteriormente.

Com base nos resultados apresentados, pode-se considerar os códigos DNS bi e tridimensional verificados, através do uso do MMS e da análise da ordem de convergência.

Outras quatro soluções manufaturadas foram também testadas com o MMS. Os resultados desses testes são apresentados no Apêndice A.2.

\subsection{Validação}

Validação é o processo de estimar quão bem um modelo matemático representa um problema físico (Salari e Knupp, 2000; Roy e Oberkampf, 2011). Um código numérico só pode ser validado para a classe de problemas que satisfaça as hipóteses do modelo adotado (Roache, 1997; Slater, 2008).

O procedimento clássico para a validação é a comparação gráfica de resultados computacionais com dados experimentais. Na maioria dos casos, se a comparação é satisfatória, o código é considerado validado (Oberkampf e Trucano, 2002b). Ou seja, o parâmetro de medida é o dado experimental, a nossa melhor representação da realidade. Isto não significa dizer que os dados experimentais são mais precisos do que os computacionais, eles apenas fornecem informações confiáveis sobre o mundo real (Oberkampf e Trucano, 2002b).

A seguir, são apresentados os resultados de validação do código numérico. Os resultados experimentais e da Teoria de Estabilidade Linear utilizados nas seções subsequentes foram concedidos pelo aluno de doutorado Dipl.-Ing. Benjamin Plogmann e pelo professor Dr.-Ing. Werner Würz da Universidade de Stuttgart, durante o estágio da doutoranda no exterior. Esses resultados foram obtidos no túnel de vento laminar do Instituto de Aerodinâmica e Dinâmica dos Gases (Institut für Aerodynamik und Gasdynamik - IAG) da Universidade de Stuttgart, Alemanha (Plogmann et al., 2012).

\subsubsection{Características da camada limite}

Nesta seção, características da camada limite sobre um aerofólio, obtidas experimental e numericamente, são comparadas, no intuito de validar o código numérico. As características da camada 
limite consideradas aqui foram: velocidade na fronteira da camada limite $u_{e}$, espessura de deslocamento $\delta_{1}$ (do inglês displacement thickness), espessura de deslocamento da quantidade de movimento $\delta_{2}$ (do inglês momentum thickness) e fator de forma $H_{12}$ (do inglês shape factor). As características integrais são definidas como:

- espessura de deslocamento:

$$
\delta_{1}=\int_{\tilde{y}=0}^{\infty}\left(1-\frac{\tilde{u}}{\tilde{U}_{\infty}}\right) d \tilde{y}
$$

- espessura de deslocamento da quantidade de movimento:

$$
\delta_{2}=\int_{\tilde{y}=0}^{\infty}\left[\frac{\tilde{u}}{\tilde{U}_{\infty}}\left(1-\frac{\tilde{u}}{\tilde{U}_{\infty}}\right)\right] d \tilde{y}
$$

- fator de forma:

$$
H_{12}=\frac{\delta_{1}}{\delta_{2}}
$$

O cálculo destas características foi efetuado com o código DNS bidimensional, considerando os seguintes parâmetros: velocidade de referência $\tilde{U}_{\infty}=31,1288 \mathrm{~m} / \mathrm{s}$; comprimento de referência $\tilde{L}=0,18 \mathrm{~m}$; viscosidade cinemática $\tilde{\nu}=1,56 \times 10^{-5} \mathrm{~m}^{2} / \mathrm{s}$; número de Reynolds $R e=359178,462$; domínio com $1.177 \times 177$ pontos nas direções do escoamento e normal à superfície, respectivamente; e espaçamento de malha $h_{x}=3,125 \times 10^{-3}$ e $h_{y_{0}}=1,8 \times 10^{-4}$ nas direções do escoamento e normal à superfície, respectivamente, com estiramento de malha de $1 \%\left(s_{f}=1,01\right)$ na direção normal à superfície. O comprimento do domínio computacional na direção longitudinal, adimensionalizado pelo diâmetro da rugosidade, é 33. A altura do domínio computacional tem pelo menos três vezes a espessura da camada limite $(\delta)$ na posição do centro da rugosidade.

Na figura 4.4 as características da camada limite são comparadas através de dados experimentais e do código DNS-2D. O desvio máximo (em \%) dos resultados numéricos em relação aos dados experimentais, para cada característica da camada limite, é mostrado na tabela 4.5.

Para a concordância dos resultados com os dados experimentais, adotou-se a posição zero do eixo das abscissas como sendo a posição equivalente ao centro da rugosidade e adimensionalizou-se a coordenada na direção longitudinal $s$ pelo diâmetro da rugosidade $d_{r}=0,02 \mathrm{~m}$. O comprimento do 
domínio computacional na direção longitudinal, adimensionalizado pelo diâmetro da rugosidade, é 42. A altura do domínio computacional tem pelo menos três vezes a espessura da camada limite $(\delta)$ na posição $s / d_{r}=0$.

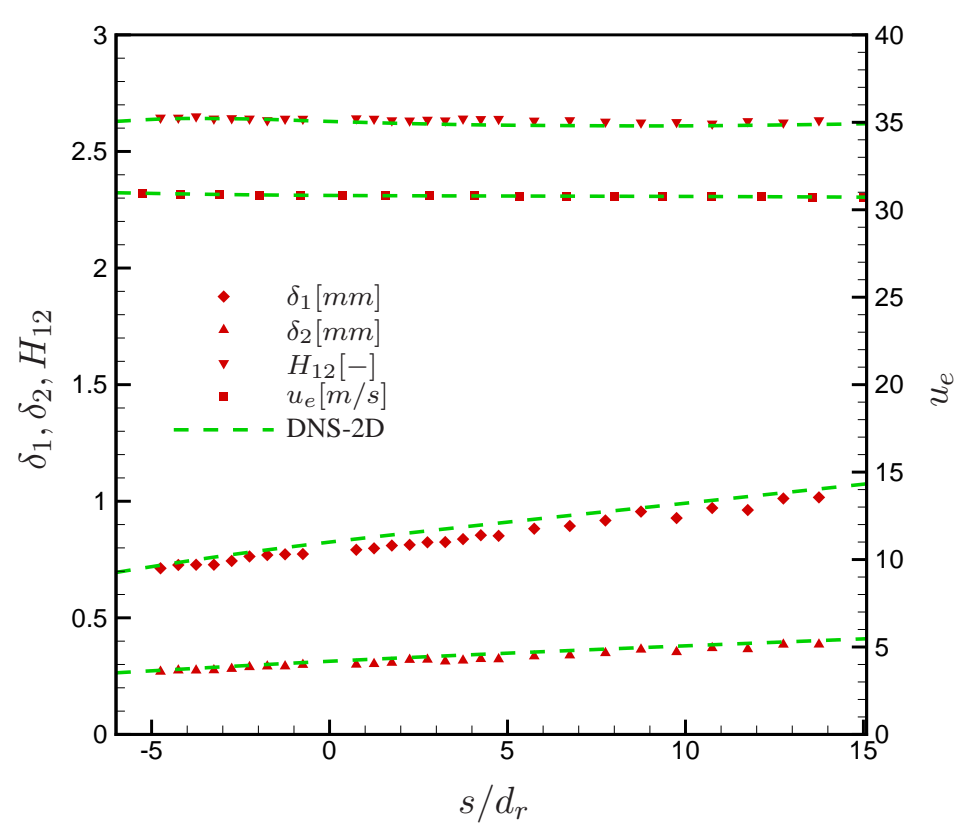

Figura 4.4: Características da camada limite.

Tabela 4.5: Desvio máximo (em \%) entre os resultados numéricos e os dados experimentais.

\begin{tabular}{|c|c|c|c|c|}
\hline Característica & $\delta_{1}$ & $\delta_{2}$ & $H_{12}$ & $u_{e}$ \\
\hline Desvio máximo (em \%) & 6,4336 & 7,0787 & 0,9912 & 0,13 \\
\hline
\end{tabular}

É possível notar, na figura 4.4, que os resultados numéricos para o perfil de velocidade e os parâmetros integrais da camada limite estão próximos aos dados experimentais. Os resultados da tabela 4.5 indicam que o código DNS-2D é capaz de simular escoamentos de camada limite em conformidade com resultados experimentais, uma vez que o desvio máximo é menor do que $10 \%$. Isto permite a validação deste código numérico.

Os dados experimentais foram obtidos utilizando diferentes gradientes de pressão. Para evitar repetições, somente um caso foi apresentado nesta seção. Este caso corresponde ao resultado com gradiente de pressão adverso. Os resultados dos demais casos, com gradiente de pressão próximo de zero e com gradiente de pressão favorável, são apresentados no Apêndice B.1. 


\subsubsection{Desenvolvimento da amplitude de perturbação}

As comparações apresentadas na seção anterior mostraram que o código numérico bidimensional foi validado para a simulação do escoamento base em camada limite. Nesta seção será efetuado um teste de estabilidade linear, utilizando o código numérico tridimensional.

Para este teste, perturbações periódicas de amplitude infinitesimal são introduzidas via sucção e injeção de massa na região localizada entre os pontos $x_{1}$ e $x_{2}$ do domínio da figura 2.1. Estas perturbações são introduzidas no modo fundamental e geram ondas TS bidimensionais. A evolução espacial dessas ondas é medida e comparada com resultados de LST e experimentais. A amplitude das ondas TS é pequena o suficiente para garantir que os produtos não lineares possam ser negligenciados.

Define-se amplitude como:

$$
a m p=\max _{y}\left(u^{\prime}\right)
$$

em que $u^{\prime}$ é a perturbação da componente de velocidade na direção do escoamento, obtida pela análise temporal de Fourier.

Os parâmetros considerados para esta simulação tridimensional são os mesmos utilizados na simulação 2D do escoamento base da Seção 4.3.1. As ondas TS foram estudadas com comprimento de onda na direção transversal $\lambda_{z}=0,4 \mathrm{~m}$ e 2 modos de Fourier (assumindo 4 pontos no espaço físico). Além disso, três frequências de perturbação foram adotadas: $F=396 \mathrm{~Hz}, 549 \mathrm{~Hz}$ e $701 \mathrm{~Hz}$. Na figura 4.5 apresenta-se a variação na amplitude de perturbação $u^{\prime}$ na direção longitudinal, para as três frequências.

Pode-se ver que os resultados do código DNS-3D estão em concordância com os resultados experimentais e de LST. Essas comparações indicam que o código numérico é capaz de simular o desenvolvimento espacial de ondas TS adequadamente.

O resultado experimental apresentado nesta seção também corresponde ao caso com gradiente de pressão adverso, por ser o que possui mais dados para comparação. Há ainda um resultado com gradiente de pressão próximo de zero com frequência de perturbação $F=549 \mathrm{~Hz}$, apresentado no Apêndice B.2, a título de resultado complementar. 


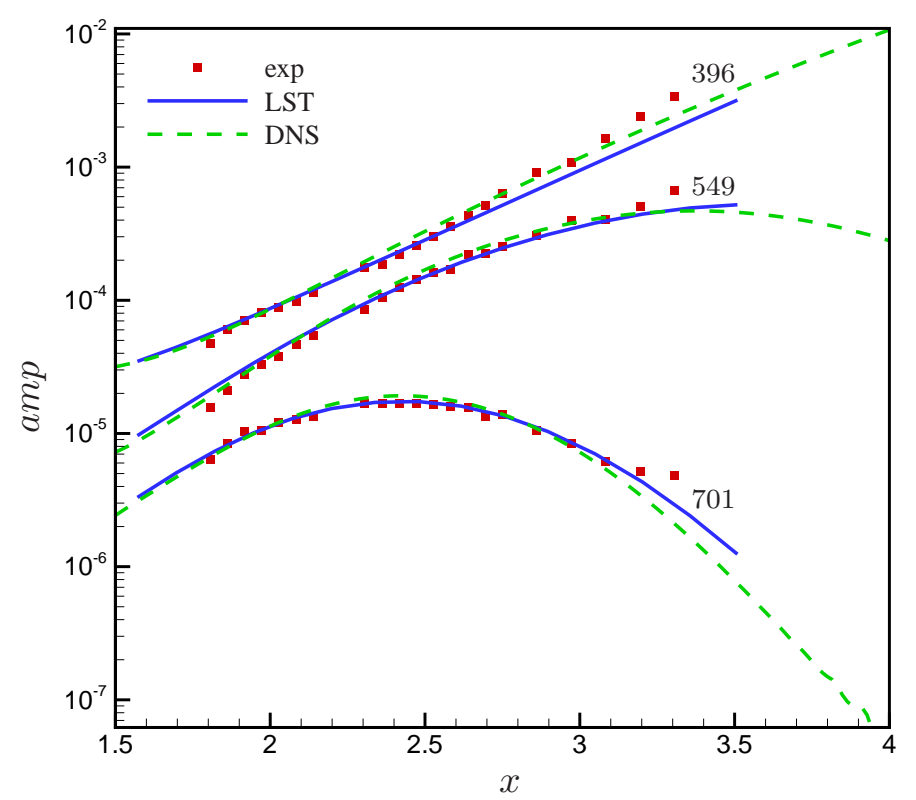

Figura 4.5: Amplitude de $u^{\prime}$ na direção $x$ ( $a m p$ - em escala logarítmica). Três diferentes frequências de perturbação são consideradas: $F=396 \mathrm{~Hz}, 549 \mathrm{~Hz}$ e $701 \mathrm{~Hz}$.

\subsection{Conclusão}

Os resultados gerados utilizando o MMS (Seção 4.2.1) mostraram que o código DNS apresenta a ordem de convergência esperada. Esta ordem é influenciada pelo uso de aproximações de segunda ordem no contorno superior e de estiramento de malha na direção $y$. Contudo, como o fenômeno físico ocorre próximo ao contorno inferior e o escoamento é quase constante fora da camada limite, a redução na ordem de convergência no contorno superior não tem influência na simulação numérica do problema investigado.

Também foi mostrado, na Seção 4.3.1, que os dados experimentais e a solução numérica estão em concordância na previsão das características da camada limite sobre um aerofólio. Além do mais, o desenvolvimento espacial de ondas TS na camada limite usando o código DNS-3D está em conformidade com os resultados experimentais e de LST. Neste sentido, pode-se considerar que o código DNS foi verificado e validado. 


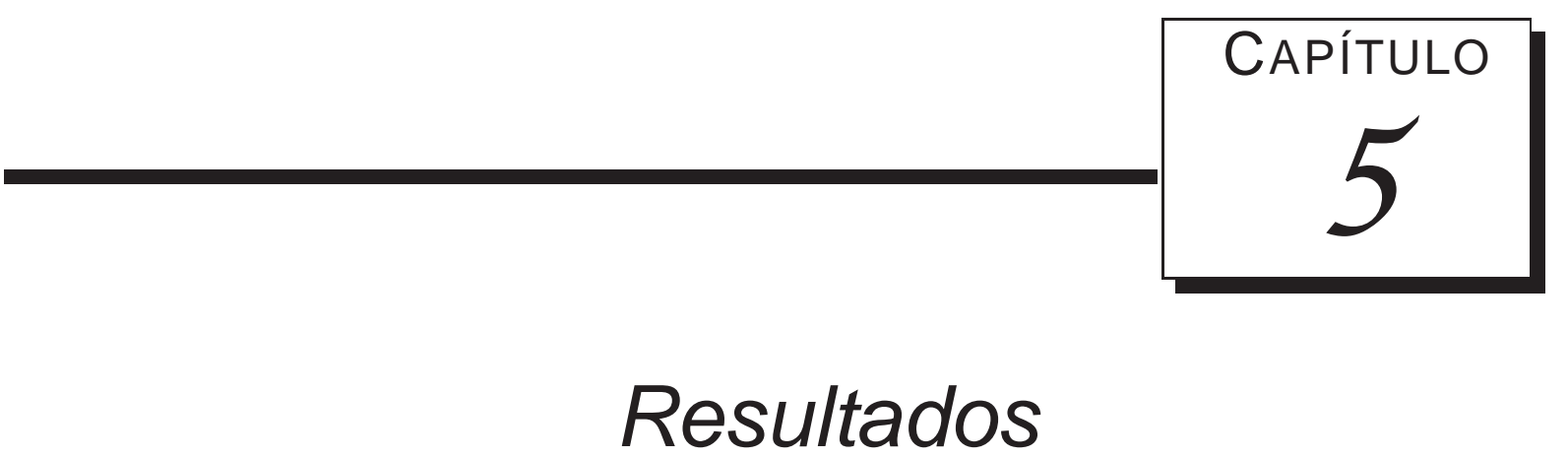

Neste capítulo são apresentados os resultados obtidos com simulações do código DNS tridimensional sobre uma superfície contendo uma rugosidade isolada.

\subsection{Escoamento contendo rugosidade}

Para as simulações numéricas aqui apresentadas, foram adotados três casos com diferentes gradientes de pressão, definidos a partir do gradiente de velocidade na fronteira da camada limite. Esses casos serão denominados como:

P0. escoamento com gradiente de pressão próximo de zero;

PA. escoamento com gradiente de pressão adverso (escoamento desacelerado);

PF. escoamento com gradiente de pressão favorável (escoamento acelerado).

O domínio computacional é o domínio mostrado na figura 2.1. Foram utilizados os seguintes parâmetros: comprimento de referência $\tilde{L}=0,18 \mathrm{~m}$; viscosidade cinemática $\tilde{\nu}=1,56 \times 10^{-5} \mathrm{~m}^{2} / \mathrm{s}$; diâmetro da rugosidade $d_{r}=0,02 \mathrm{~m}$; domínio com $1049 \times 321$ pontos nas direções longitudinal e normal à superfície, respectivamente; 43 modos de Fourier (assumindo 128 pontos para o espaço físico, para satisfazer a regra de 1/3); espaçamento de malha $h_{x}=3,125 \times 10^{-3}, h_{y_{0}}=4,5 \times 10^{-5} \mathrm{e}$ $h_{z}=6,076 \times 10^{-3}$ nas direções longitudinal, normal à superfície e transversal, respectivamente, com 
estiramento de malha de $0,5 \%$ na direção $y\left(s_{f}=1,005\right)$; e fator de relaxação do método de fronteiras imersas $r_{f}=-R e / 10$.

A velocidade de referência depende do gradiente de pressão, sendo: $\tilde{U}_{\infty}=29,8094 \mathrm{~m} / \mathrm{s}$ para o caso P0, $\tilde{U}_{\infty}=30,4925 \mathrm{~m} / \mathrm{s}$ para o caso PA e $\tilde{U}_{\infty}=29,395 \mathrm{~m} / \mathrm{s}$ para o caso PF. O passo de tempo é calculado em função da velocidade de referência, por isso os seguintes valores foram considerados: $\delta t=2,355 \times 10^{-6}$ para o caso $\mathrm{P} 0, \delta t=2,409 \times 10^{-6}$ para o caso PA e $\delta t=2,323 \times 10^{-6}$ para o caso PF.

A altura da rugosidade $h_{r}$ é calculada como uma porcentagem da espessura de deslocamento da camada limite na posição longitudinal do centro da rugosidade, que é $\delta_{1}=4 \times 10^{-3}$. Diferentes alturas de rugosidade foram consideradas para cada caso.

Ainda, as variáveis foram adimensionalizadas da seguinte maneira: coordenadas $x$ e $z$ pelo diâmetro da rugosidade $d_{r}$; coordenada $y$ pela espessura de deslocamento da camada limite $\delta_{1}$; velocidades $u, v$ e $w$ pela velocidade de referência $\tilde{U}_{\infty}, \operatorname{com} v$ também adimensionalizada por $\sqrt{R e}$. Além disso, as coordenadas $x$ e $z$ foram deslocadas para que o centro da rugosidade na superfície estivesse na posição $(x, y, z)=(0,0,0)$. O comprimento do domínio computacional nas direções longitudinal e transversal, adimensionalizado pelo diâmetro da rugosidade, é 30 e 7 , respectivamente. A altura do domínio computacional tem pelo menos três vezes a espessura da camada limite $(\delta)$ na posição do centro da rugosidade.

As simulações numéricas deste capítulo foram executadas em um cluster com três tipos de computadores: Intel Xeon E5430 de 2,66 GHz com 32 GB de RAM com 8 núcleos de processamento; Intel Xeon E5690 de 3,46 GHz com 32 GB de RAM com 12 núcleos de processamento; Intel Xeon E5-2690 de 2,90 GHz com 64 GB de RAM com 16 núcleos de processamento. Para estas simulações foram utilizados 8 EPs. Neste caso, cada EP é um núcleo de processamento de um nó do cluster. As simulações foram executadas por 6 meses, alternando-se entre os nós citados. Devido à diferença na velocidade de processamento de cada nó, diferentes números de passos de tempo foram simulados para cada caso.

Os resultados são apresentados da seguinte forma, para cada altura de rugosidade:

- distribuições das componentes de velocidade $v$ e $w$ como vetores, em diversas posições longitudinais, com a rugosidade, quando presente, sendo representada por um retângulo cinza;

- distribuições das componentes de velocidade $u$ e $w$ como vetores são apresentadas em cortes 


\section{1 - Escoamento contendo rugosidade}

em diversas posições normais à superfície. A rugosidade é representada por um círculo cinza;

- distribuições das componentes de velocidade $u$ e $v$ como vetores são apresentadas na posição transversal $z=0$. É feito um enfoque no escoamento nas partes anterior e posterior à rugosidade, com a mesma sendo representada por um retângulo cinza;

- perfis de $u$ na direção normal à superfície, em corte na posição transversal $z=0$. Os perfis são apresentados nas seguintes posições longitudinais: $x=0,55 ; 0,60 ; 0,65 ; 0,71 ; 0,76 ; 0,82 ; 0,88$; 0,$93 ; 0,99 ; 1,04 ; 1,10 ; 1,15 ; 1,21 ; 1,27 ; 1,32 ; 1,38 ; 1,44 ; 1,50 ; 1,55 ; 1,60$. Além disso, os perfis de $u$ são deslocados de 1, para melhor visualização. Para os casos em que a altura da rugosidade é $h_{r}=0,1 \delta_{1}$ ou $h_{r}=0,2 \delta_{1}$ são mostrados apenas os dez primeiros perfis de velocidade (até $x=0,99)$.

Nas figuras com perfis de velocidade, dois perfis de $u$ são mostrados: o perfil obtido na simulação tridimensional com a rugosidade (linhas sólidas vermelhas) e o perfil de uma simulação tridimensional de escoamento em camada limite sem a rugosidade (pontilhados pretos). Isso permite visualizar a deformação no perfil de velocidade ocasionado pela rugosidade.

Nas figuras que mostram os vetores de velocidade, um vetor de referência (em vermelho) informa a escala de velocidade de cada caso.

Nas seções seguintes são apresentados os resultados para os três casos considerados.

\subsubsection{Caso P0 - escoamento com gradiente de pressão próximo de zero}

Para o escoamento com gradiente de pressão próximo de zero foram consideradas dez alturas de rugosidade: $0,1 \delta_{1}, 0,2 \delta_{1}, 0,3 \delta_{1}, 0,4 \delta_{1}, 0,5 \delta_{1}, 0,6 \delta_{1}, 0,7 \delta_{1}, 0,8 \delta_{1}, 0,9 \delta_{1}$ e $1,0 \delta_{1}$. Na direção longitudinal, o centro da rugosidade está localizado a 8 diâmetros da região de relaminarização no início do domínio e a 16 diâmetros da região de relaminarização na saída do domínio.

A seguir, são apresentados os resultados para cada altura de rugosidade.

\subsubsection{Rugosidade com altura $h_{r}=0,1 \delta_{1}$}

Os resultados obtidos com altura de rugosidade igual a $10 \%$ da espessura de deslocamento da camada limite $\left(\delta_{1}\right)$ são mostrados nas figuras de 5.1 a 5.4. Para este caso, foram rodados 65280 passos no tempo. 
A distribuição de $v$ e $w$ como vetores em um corte no centro da rugosidade $(x=0)$ é mostrado na figura 5.1a. O deslocamento de fluido ocasionado pela rugosidade gera o surgimento de dois vórtices longitudinais contrarrotativos acima da protuberância, em $y \approx 0,5$, com centro nas posições $z \approx \pm 0,5$. O vórtice centrado em $z \approx-0,5$ gira no sentido horário, enquanto que o vórtice centrado em $z \approx 0,5$ gira no sentido anti-horário. Para simplicidade de notação, esse par de vórtices será denominado VLCRP (Vórtices Longitudinais Contrarrotativos Primários). Influenciado pelo aumento da velocidade nas laterais da rugosidade e pela tendência do fluido em ocupar a região de baixa velocidade a jusante da protuberância, pode-se ver, na figura 5.1b, que os VLCRP se tornam mais evidentes. Nas figuras 5.1c e 5.1d é possível ver que os VLCRP continuam se propagando no escoamento. Também é possível notar que eles vão se aproximando entre si, na direção transversal. Porém, sua influência é reduzida, uma vez que a velocidade nessa região é da ordem de $10^{-3}$ (vide velocidade de referência).

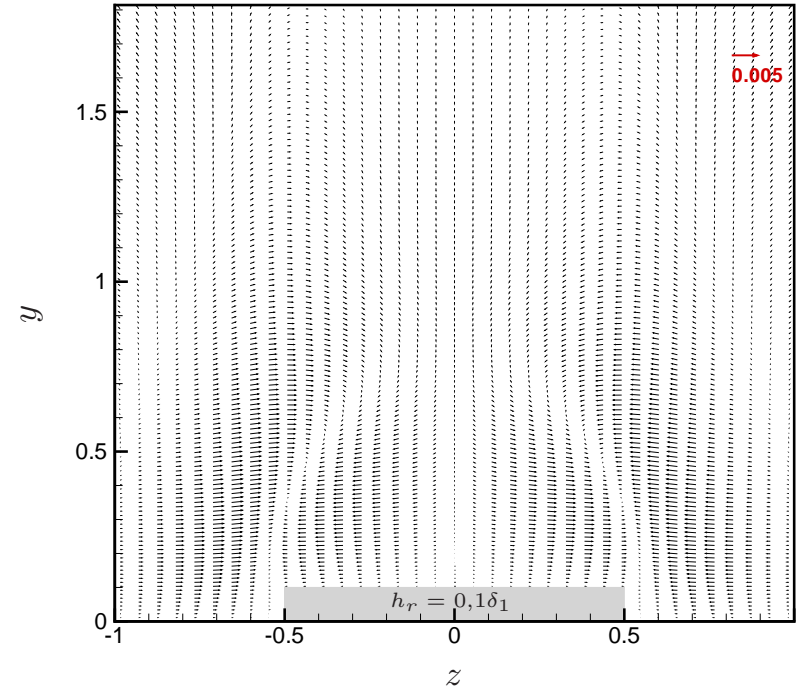

(a) $x=0,0$

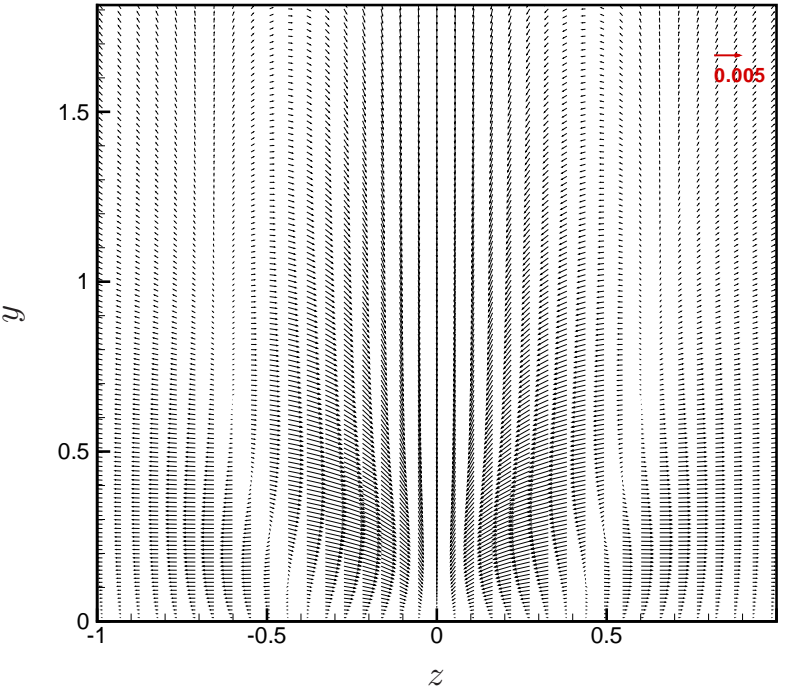

(b) $x=0,6$

Figura 5.1: Distribuição de $v$ e $w$ como vetores, em diferentes posições $x$, para o caso P0 com $h_{r}=0,1 \delta_{1}$.

A distribuição de $u$ e $w$ como vetores pode ser vista na figura 5.2. Nesta figura, pode-se notar a redução da velocidade nas proximidades da protuberância. Também é possível observar a mudança no sentido do escoamento, contornando a rugosidade a montante e ocupando a região de baixa velocidade a jusante da protuberância.

Na figura 5.3 é mostrada a distribuição de $u$ e $v$ como vetores. Fica evidente, na figura 5.3a, a redução na velocidade a montante da rugosidade. Na figura 5.3b é possível observar a região de baixa velocidade a jusante da protuberância. 


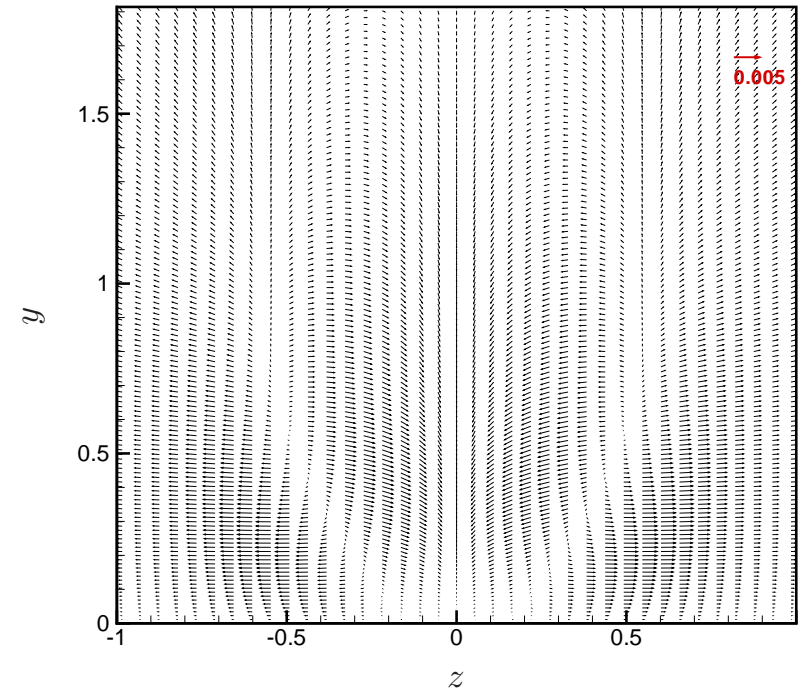

(c) $x=0,7$

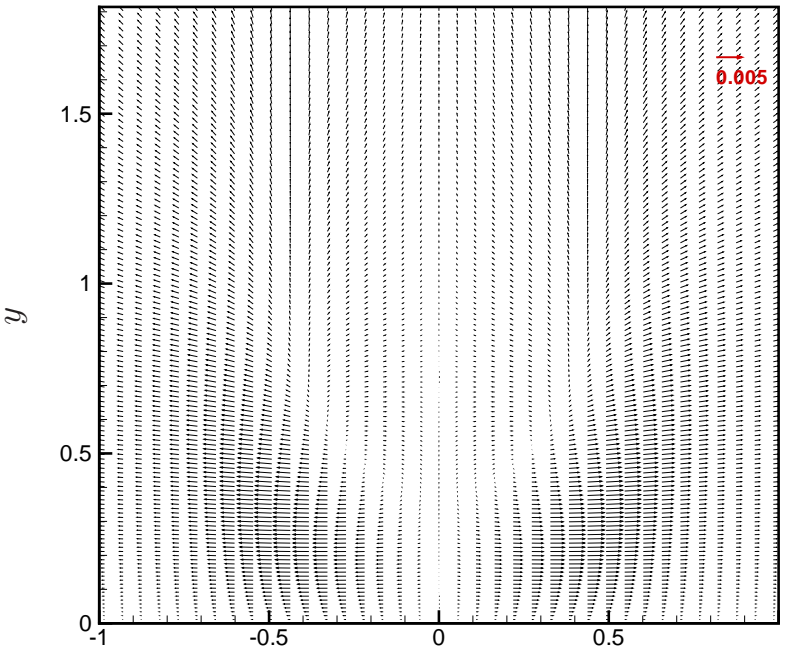

(d) $x=0,8$

Figura 5.1: Distribuição de $v$ e $w$ como vetores, em diferentes posições $x$, para o caso P0 com $h_{r}=0,1 \delta_{1}$ (cont.).

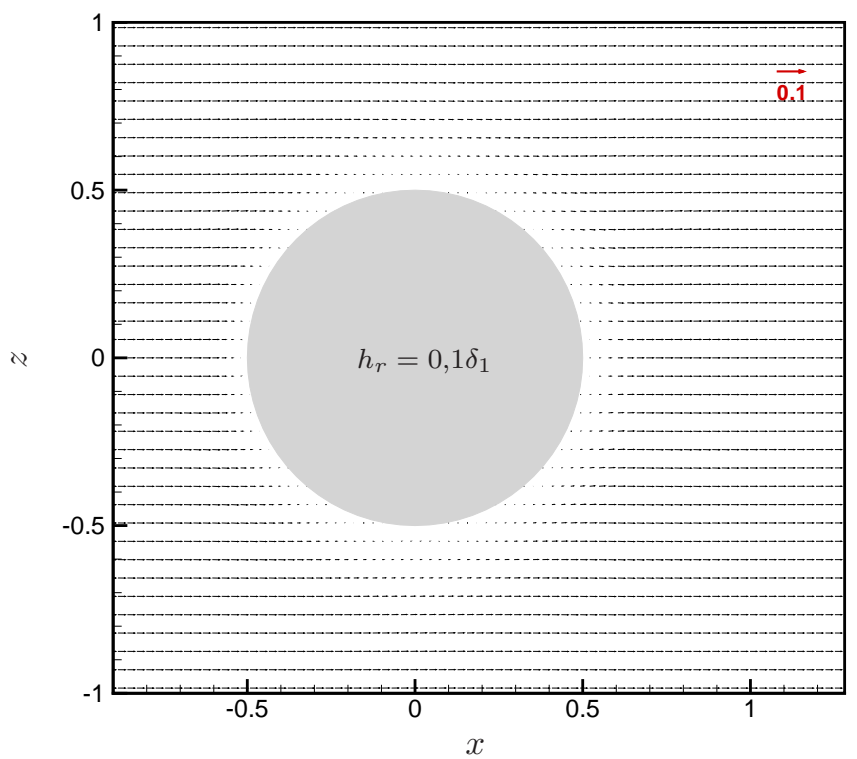

Figura 5.2: Distribuição de $u$ e $w$ como vetores, em $y=0,05$, para o caso P0 com $h_{r}=0,1 \delta_{1}$. 


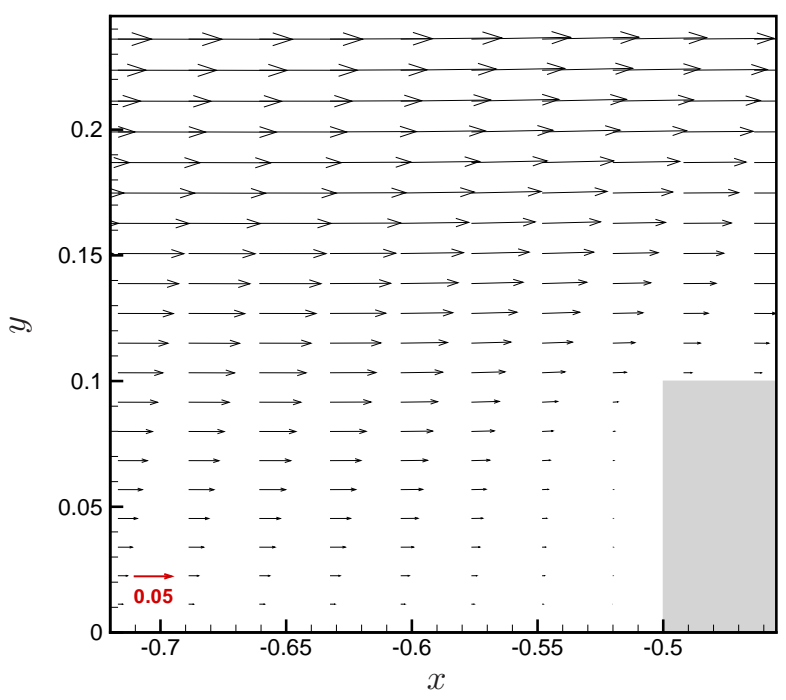

(a) A montante da rugosidade.

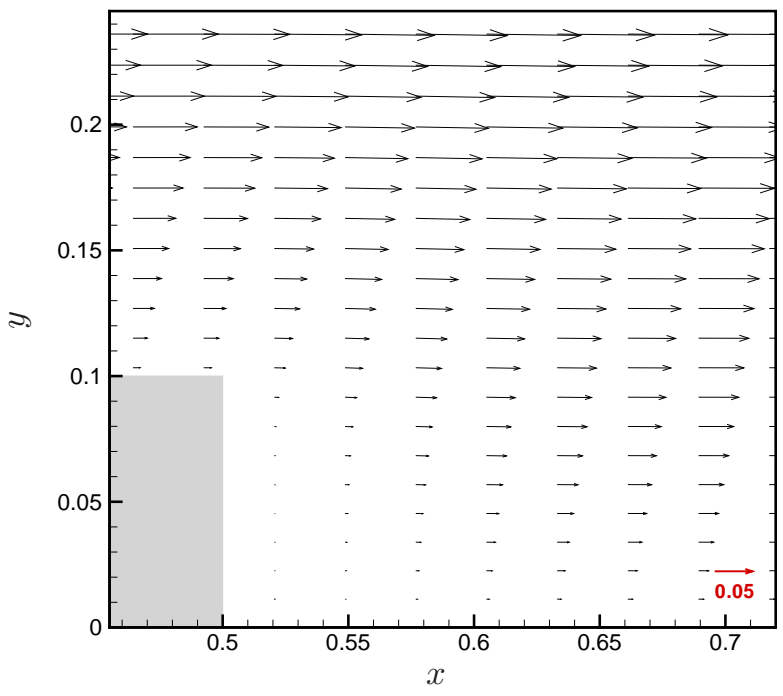

(b) A jusante da rugosidade.

Figura 5.3: Distribuição de $u$ e $v$ como vetores, em $z=0$, para o caso P0 com $h_{r}=0,1 \delta_{1}$.

O perfil de $u$ normal à superfície, em $z=0,0$, é mostrado na figura 5.4. É possível notar, nesta figura, que o perfil de velocidade sofre pequena deformação, próximo à superfície, devido à presença da rugosidade. A região de baixa velocidade a jusante da protuberância pode ser vista em $x=0,55$. A partir de $x \approx 0,65$ o perfil de velocidade volta ao estado não perturbado.

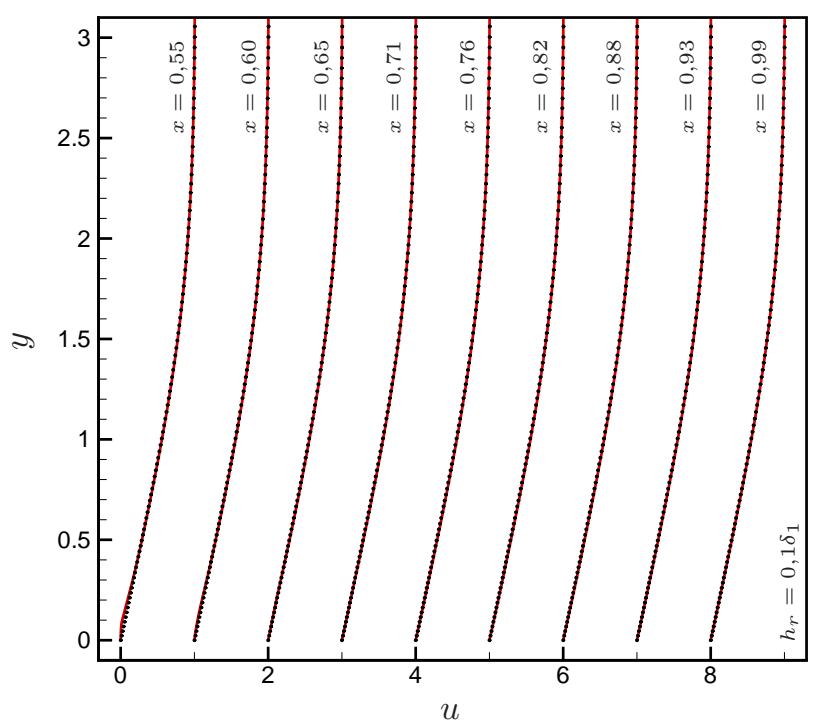

Figura 5.4: Perfil de $u$ normal à superfície, em $z=0$, para o caso P0 com $h_{r}=0,1 \delta_{1}$.

De modo geral, os efeitos da presença de uma rugosidade com altura $h_{r}=0,1 \delta_{1}$ no escoamento são apenas locais. As perturbações são rapidamente amortecidas e o escoamento volta ao estado não perturbado. 


\subsubsection{Rugosidade com altura $h_{r}=0,2 \delta_{1}$}

Os resultados para a rugosidade com altura $h_{r}=0,2 \delta_{1}$ são apresentados nas figuras de 5.5 a 5.8 . Para este caso, foram rodados 75520 passos no tempo.

Assim como no caso anterior, a formação dos VLCRP pode ser vista na figura 5.5a, através da distribuição de $v$ e $w$ como vetores em um corte no centro da rugosidade. Nota-se que esses vórtices estão mais próximos entre si, em comparação com a figura $5.1 \mathrm{a}$, com seus centros em $z \approx \pm 0,35$. Os VLCRP ficam evidentes a jusante da rugosidade, como mostrado na figura 5.5b. Comparando-se as figuras 5.1d e 5.5c, pode-se notar que os VLCRP estão mais próximos à superfície para o caso com maior altura de rugosidade. Também é possível observar que a velocidade para este caso é maior (vide velocidade de referência). Conforme afasta-se da rugosidade, no sentido do escoamento, os VLCRP vão se aproximando entre si, até se aglutinarem, como pode ser visto na figura $5.5 \mathrm{~d}$. Na figura $5.5 \mathrm{e}$, pode-se ver a formação de um segundo par de vórtices longitudinais contrarrotativos, em $y \approx 0,6 \mathrm{e}$ centrado em $z \approx \pm 0,7$. Esses vórtices são gerados pelos VLCRP e giram no sentido oposto.

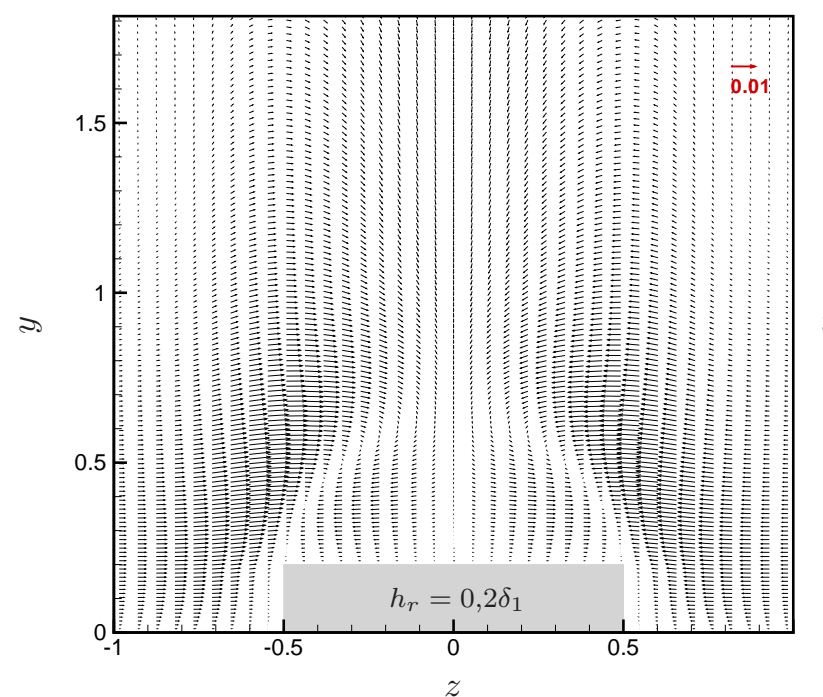

(a) $x=0,0$

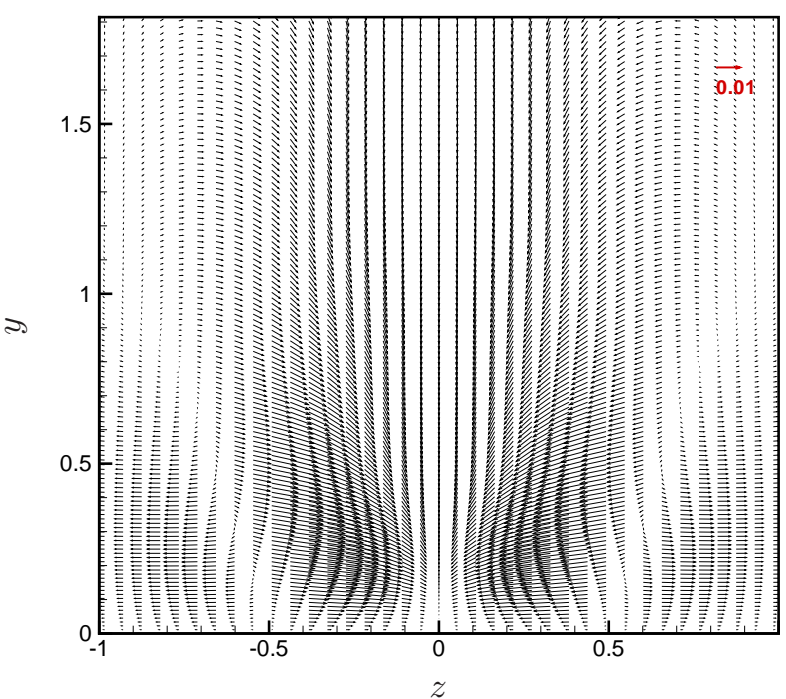

(b) $x=0,6$

Figura 5.5: Distribuição de $v$ e $w$ como vetores, em diferentes posições $x$, para o caso $\mathrm{P} 0$ com $h_{r}=0,2 \delta_{1}$.

Através da distribuição de $u$ e $w$ como vetores, mostrada na figura 5.6, é possível ver que a região de influência da rugosidade no escoamento é local. A redução na velocidade ao redor da protuberância é semelhante à observada no caso com altura $h_{r}=0,1 \delta_{1}$, na figura 5.2, em que se percebe o deslocamento de fluido a jusante da rugosidade.

Nas figuras 5.7a e 5.7b a distribuição de $u$ e $v$ como vetores mostra as regiões de baixa velocidade 


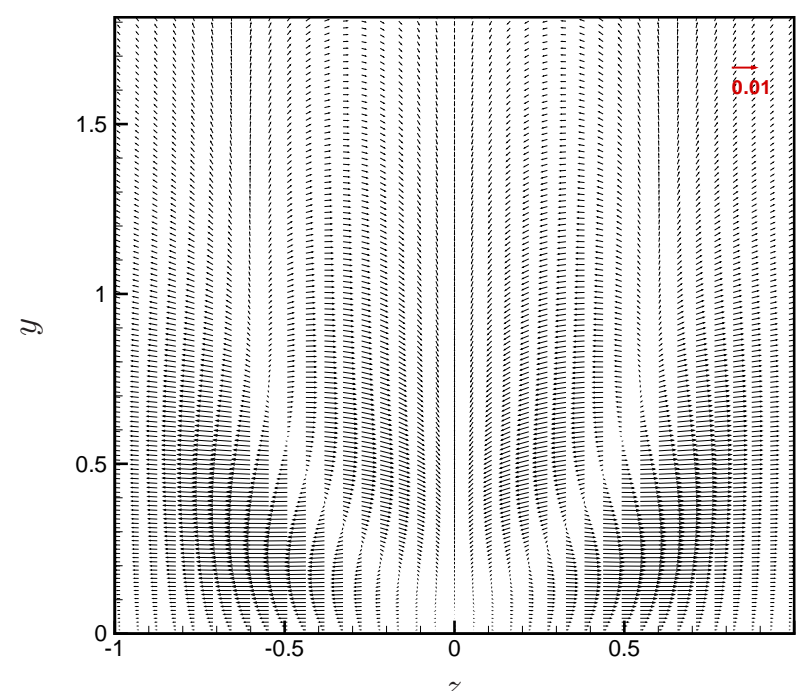

(c) $x=0,8$

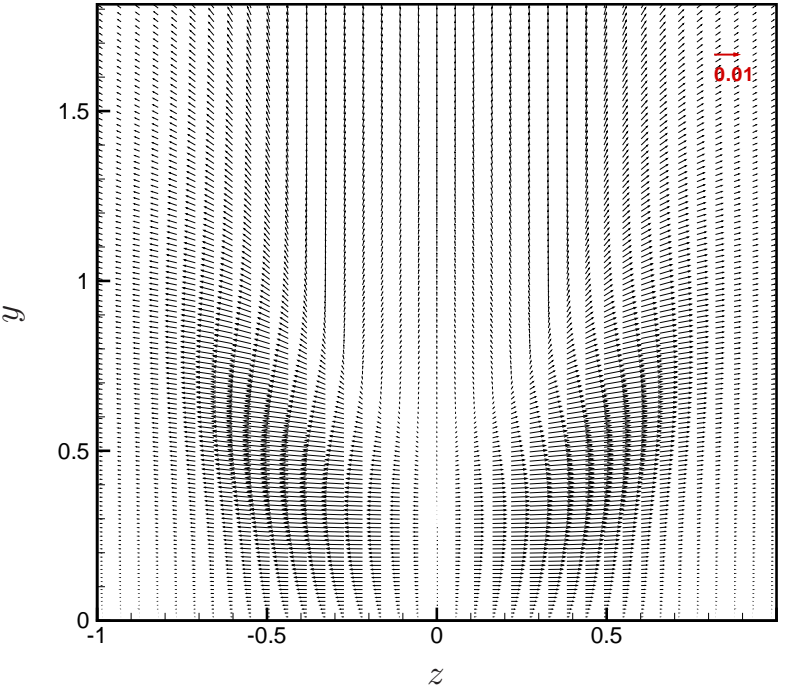

(d) $x=1,0$

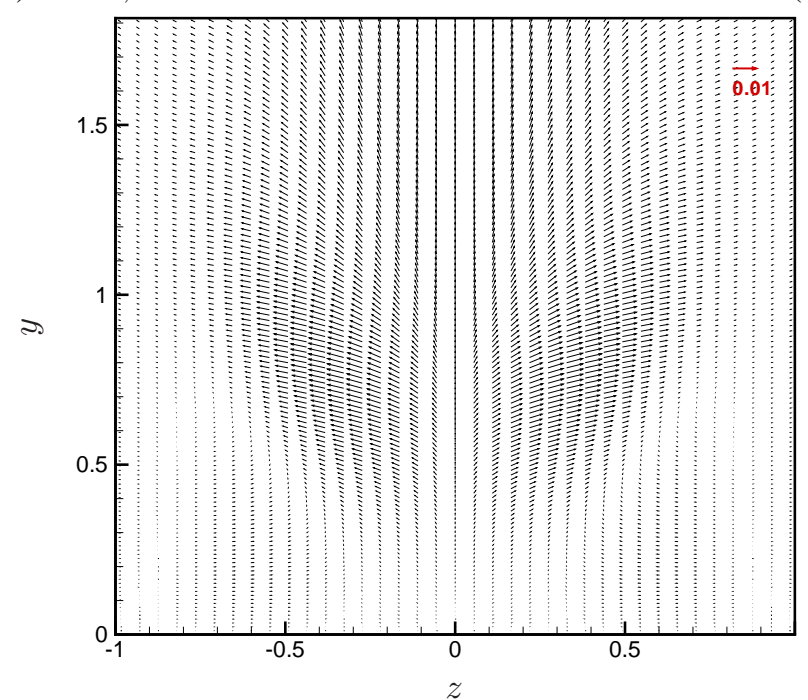

(e) $x=1,2$

Figura 5.5: Distribuição de $v$ e $w$ como vetores, em diferentes posições $x$, para o caso P0 com $h_{r}=0,2 \delta_{1}$ (cont.). 


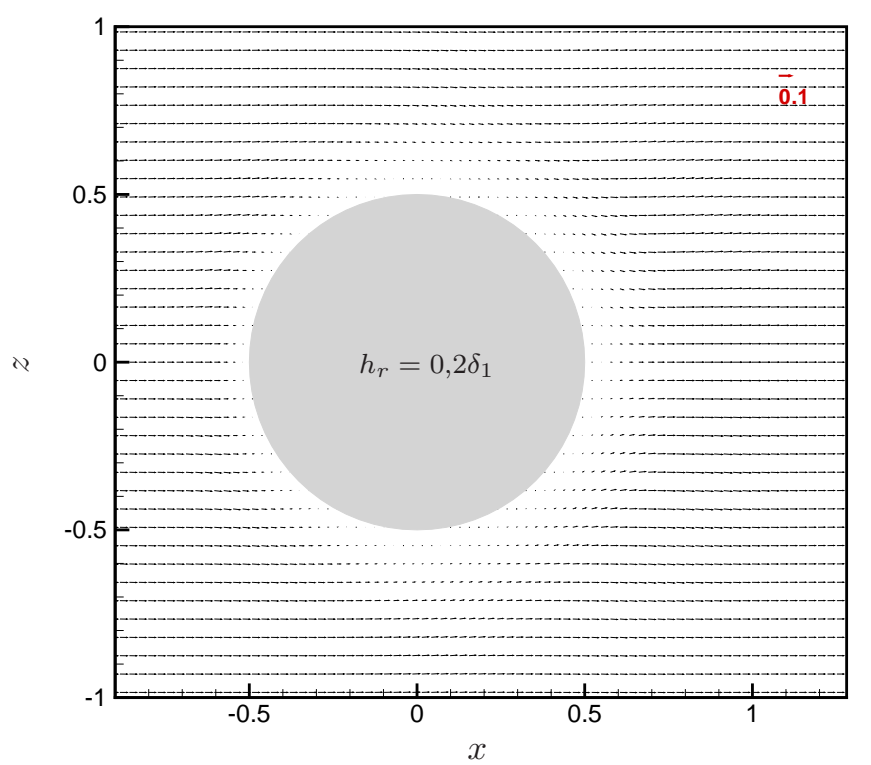

Figura 5.6: Distribuição de $u$ e $w$ como vetores, em $y=0,1$, para o caso P0 com $h_{r}=0,2 \delta_{1}$.

a montante e a jusante da rugosidade, respectivamente. Nota-se, em comparação com o caso anterior (figura 5.3b), um aumento nas direções longitudinal e normal à superfície da região de redução de velocidade a jusante da protuberância.

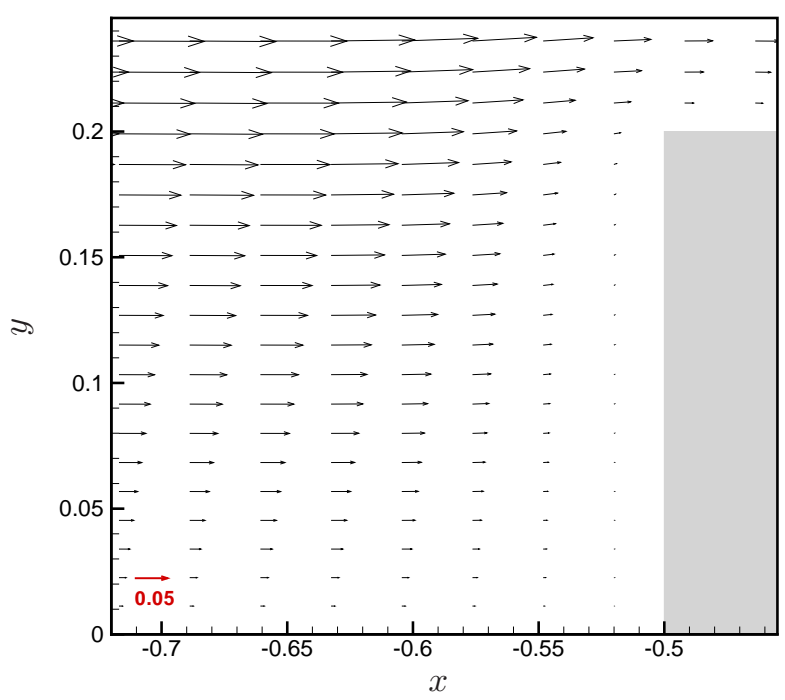

(a) A montante da rugosidade.

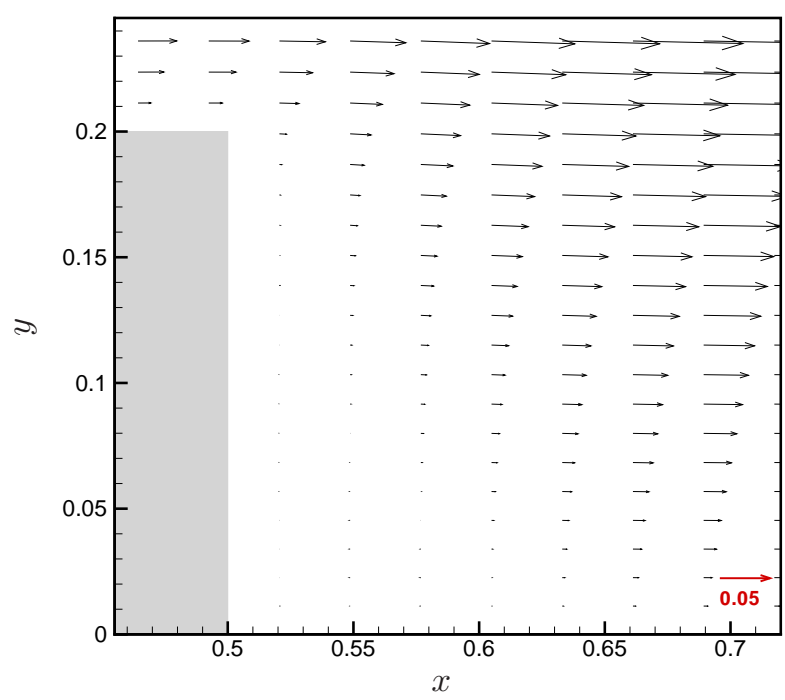

(b) A jusante da rugosidade.

Figura 5.7: Distribuição de $u$ e $v$ como vetores em $z=0$, para o caso P0 com $h_{r}=0,2 \delta_{1}$.

Esse aumento na região de baixa velocidade também fica visível na figura 5.8, em que a deformação no perfil de $u$ próximo à superfície se estende até a posição $x \approx 0,65$. Também é possível observar, na figura 5.8, um pequeno aumento da velocidade a partir de $y \approx 0,7$, em $x=0,55$. Esse aumento de velocidade se propaga na direção longitudinal e se mantém abaixo de $y \approx 2,0$. 


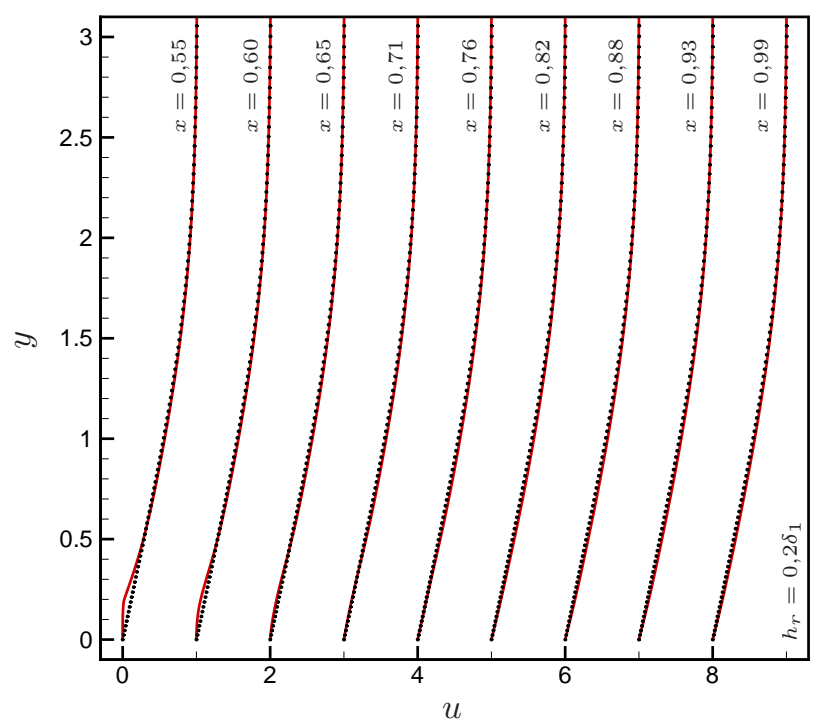

Figura 5.8: Perfil de $u$ normal à superfície em $z=0$, para o caso $\mathrm{P} 0$ com $h_{r}=0,2 \delta_{1}$.

Assim como no caso anterior, a presença de uma rugosidade com altura $h_{r}=0,2 \delta_{1}$ ocasiona uma perturbação local no escoamento. Devido à baixa velocidade, essa perturbação é amortecida, permitindo que o escoamento volte ao seu estado não perturbado.

\subsubsection{Rugosidade com altura $h_{r}=0,3 \delta_{1}$}

Na presente seção são apresentados os resultados obtidos com $h_{r}=0,3 \delta_{1}$. Esses resultados são mostrados nas figuras de 5.9 a 5.12. Para este caso, foram rodados 108800 passos no tempo.

A distribuição de $v$ e $w$ como vetores é mostrada na figura 5.9. Como o perfil de velocidade é um perfil de camada limite, a velocidade no topo da rugosidade é maior para este caso do que para os casos anteriores. Isso pode ser percebido na figura 5.9a, em que a velocidade do escoamento vindo das laterais da protuberância, em direção ao centro da rugosidade, não permite a formação dos VLCRP como nos casos anteriores. Esses vórtices aparecem muito menores, nas quinas da protuberância. Na figura 5.9b pode-se ver a presença de dois pares de vórtices longitudinais contrarrotativos. O maior desses pares está em $y \approx 0,4$, com centros em $z \approx \pm 0,9$, e gira no mesmo sentido dos VLCRP. Para simplicidade de notação, esses vórtices serão denominados VLCRS (Vórtices Longitudinais Contrarrotativos Secundários). O segundo par de vórtices observado está em $y \approx 0,5$, com centros em $z \approx \pm 0,1$. Esses vórtices são gerados pelos VLCRS e serão denominados VLCRT (Vórtices Longitudinais Contrarrotativos Terciários). Os VLCRT giram no sentido oposto ao dos VLCRS e possuem menor intensidade.

Nas figuras 5.9c, 5.9d e 5.9e vê-se que os VLCRS aproximam-se entre si e se afastam da su- 

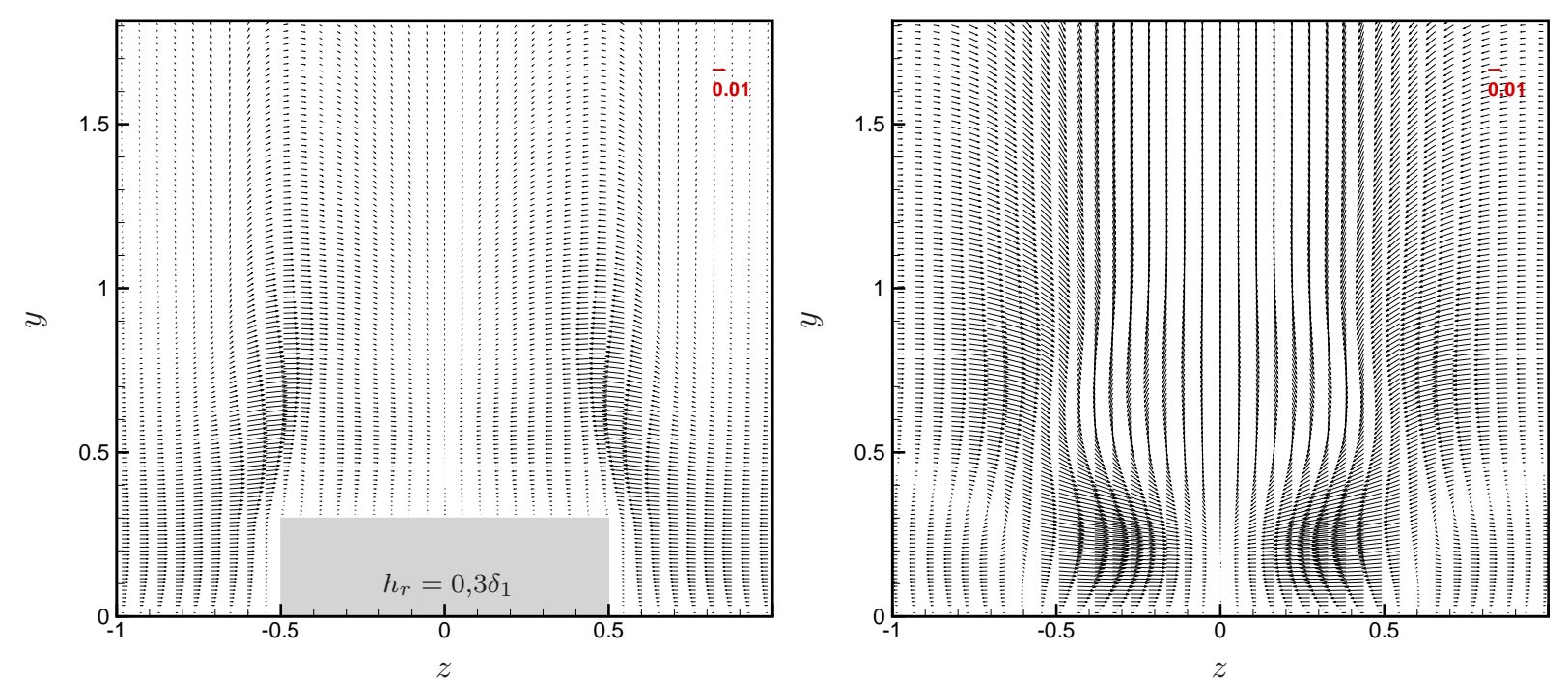

(a) $x=0,0$

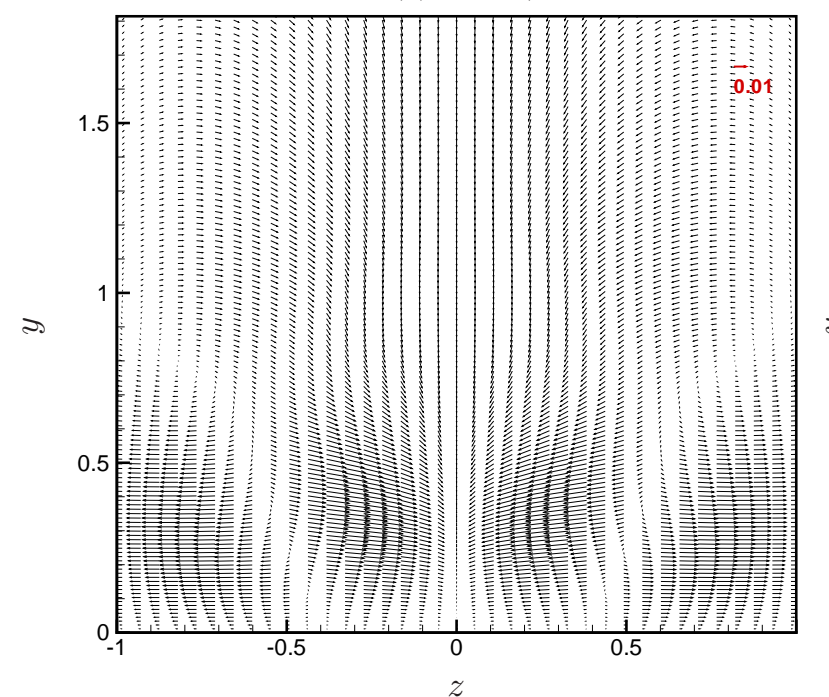

(b) $x=0,6$

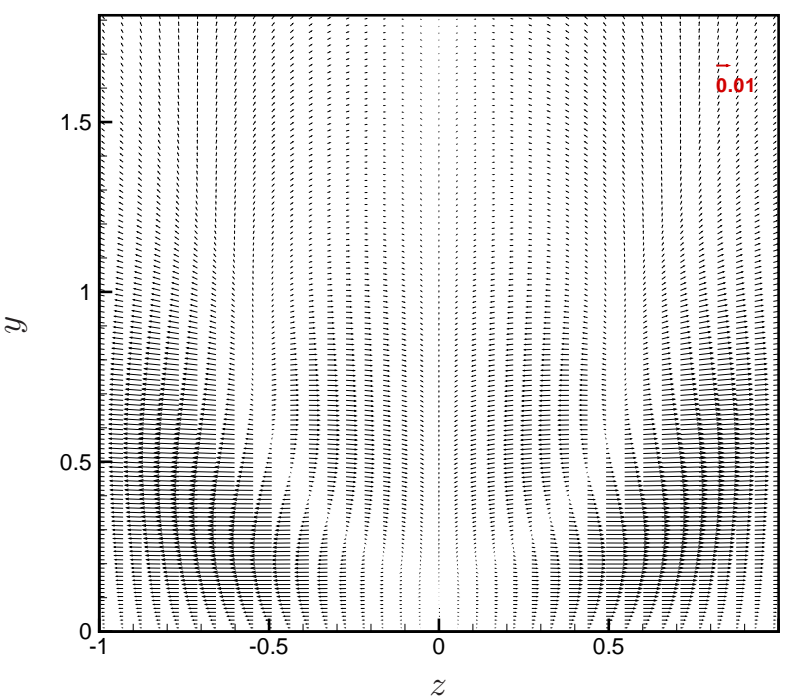

(c) $x=0,8$

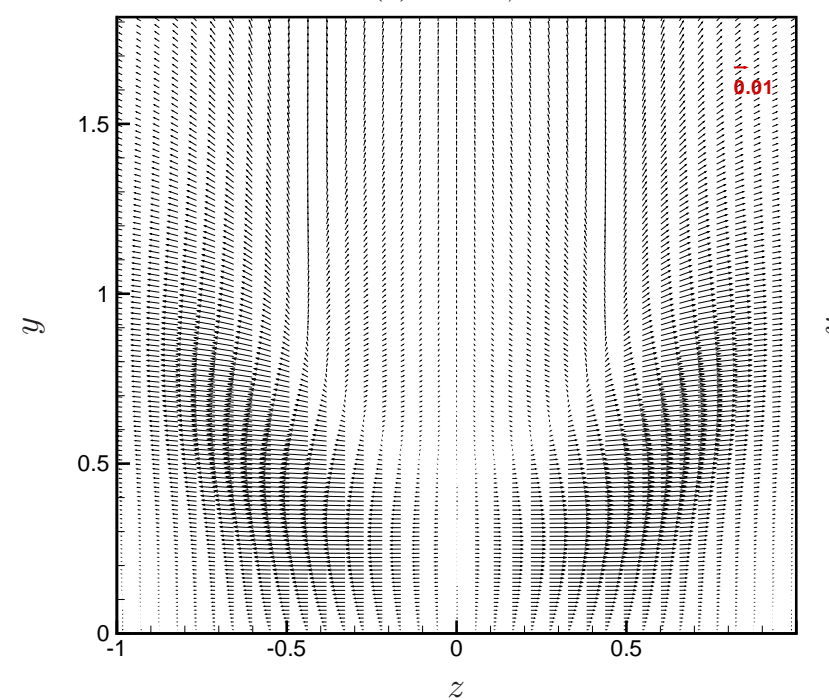

(d) $x=1,0$

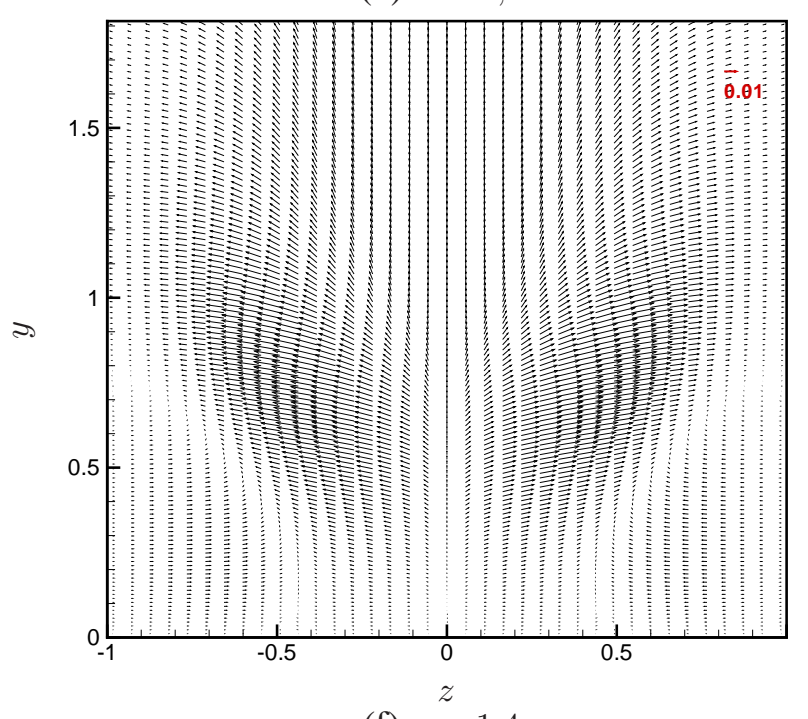

(e) $x=1,2$

(f) $x=1,4$

Figura 5.9: Distribuição de $v$ e $w$ como vetores, em diferentes posições $x$, para o caso $\mathrm{P} 0$ com $h_{r}=0,3 \delta_{1}$. 


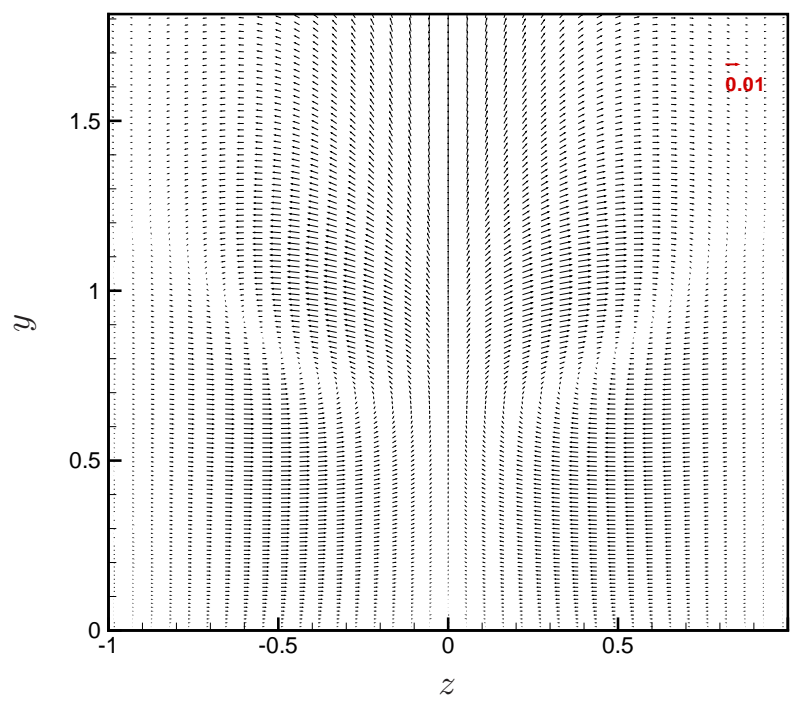

(g) $x=1,6$

Figura 5.9: Distribuição de $v$ e $w$ como vetores, em diferentes posições $x$, para o caso P0 com $h_{r}=0,3 \delta_{1}$ (cont.).

perfície. Os VLCRT perdem força e são absorvidos pelo escoamento. Um segundo par de VLCRT, também formado a partir dos VLCRS, pode ser visto na figura 5.9f. Esses vórtices estão em $y \approx 0,6$, com centros em $z \approx \pm 0,9$. Assim como os VLCRS, o segundo par de VLCRT se propaga na direção longitudinal, se afastando da superfície e se aproximando um do outro, como pode ser visto na figura $5.9 \mathrm{~g}$.

O aumento na altura da rugosidade gera um aumento na modificação do escoamento ao redor da protuberância, como mostra a distribuição de $u$ e $w$ com vetores, na figura 5.10, em comparação com a figura 5.6. Contudo, esse aumento não é suficiente para que as perturbações se propaguem para longe da rugosidade.

Assim como nos casos anteriores, há a formação de uma região de redução de velocidade a montante da protuberância, como pode ser visto na figura 5.11a. A partir da altura de rugosidade $h_{r}=0,3 \delta_{1}$, nota-se a formação de uma bolha de separação a jusante da rugosidade, causada pela redução da velocidade nesta região. Para simplicidade de notação, essa bolha será denominada BSJR (Bolha de Separação a Jusante da Rugosidade). A BSJR gira no sentido horário e está localizada em $x \approx 0,6$, com $y \approx 0,15$ e pode ser vista na figura $5.11 \mathrm{~b}$.

$\mathrm{O}$ efeito da BSJR no perfil de velocidade pode ser percebido na figura 5.12, entre $x \approx 0,55 \mathrm{e}$ $x \approx 0,71$. Nesta figura também pode-se notar uma deformação longitudinal no perfil de $u$, indicando que houve um aumento da quantidade de movimento, provavelmente devido aos vórtices longitudinal 


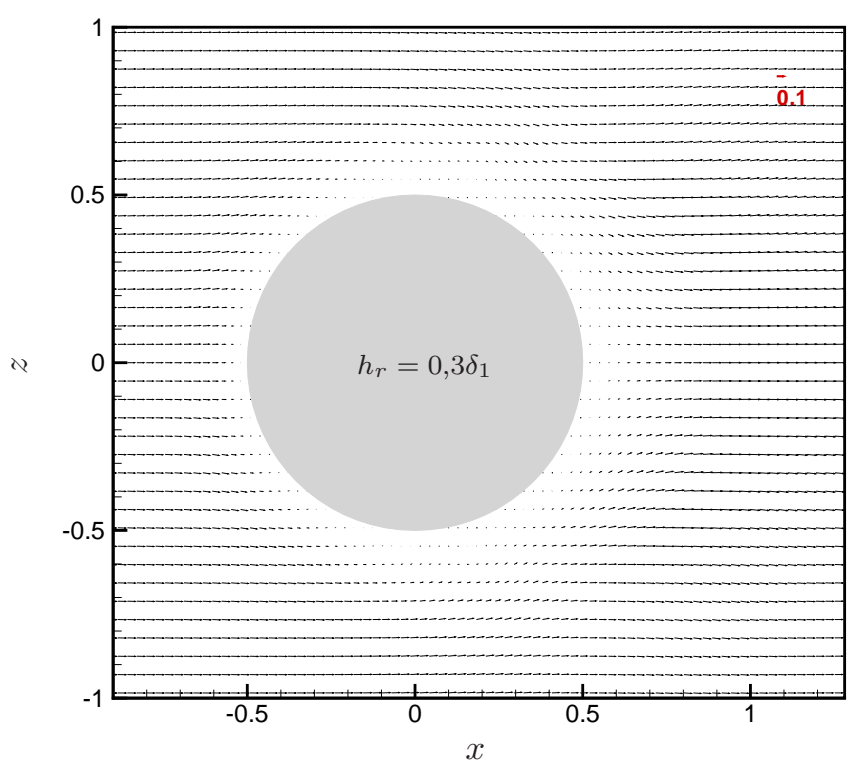

Figura 5.10: Distribuição de $u$ e $w$ como vetores em $y=0,2$, para o caso P0 com $h_{r}=0,3 \delta_{1}$.

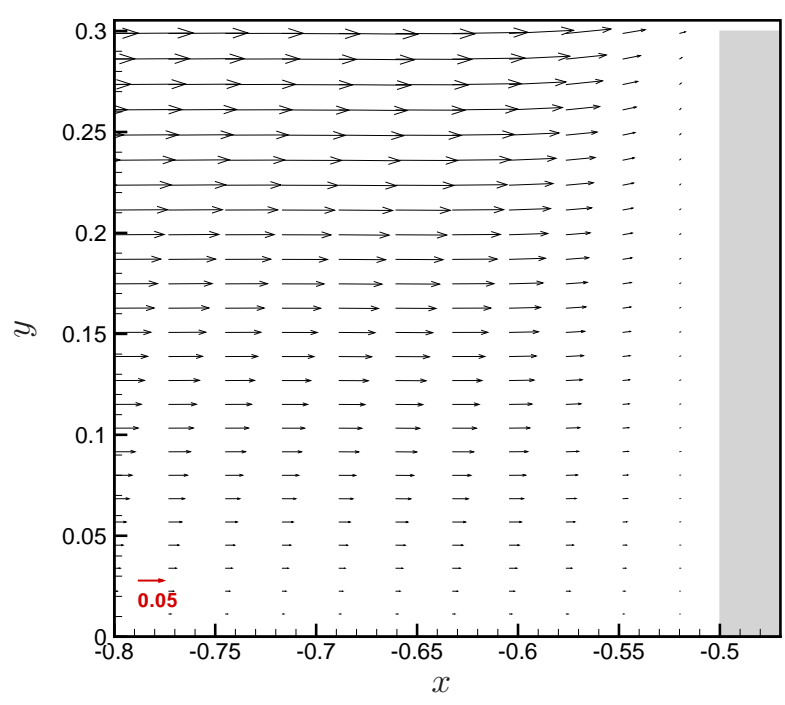

(a) A montante da rugosidade.

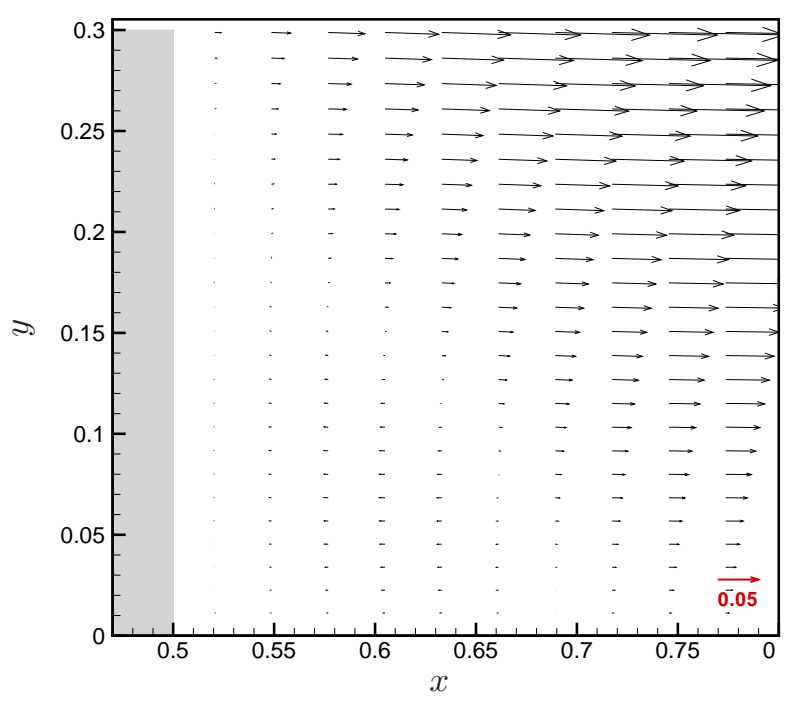

(b) A jusante da rugosidade.

Figura 5.11: Distribuição de $u$ e $v$ como vetores em $z=0$, para o caso P0 com $h_{r}=0,3 \delta_{1}$. 
contrarrotativos.

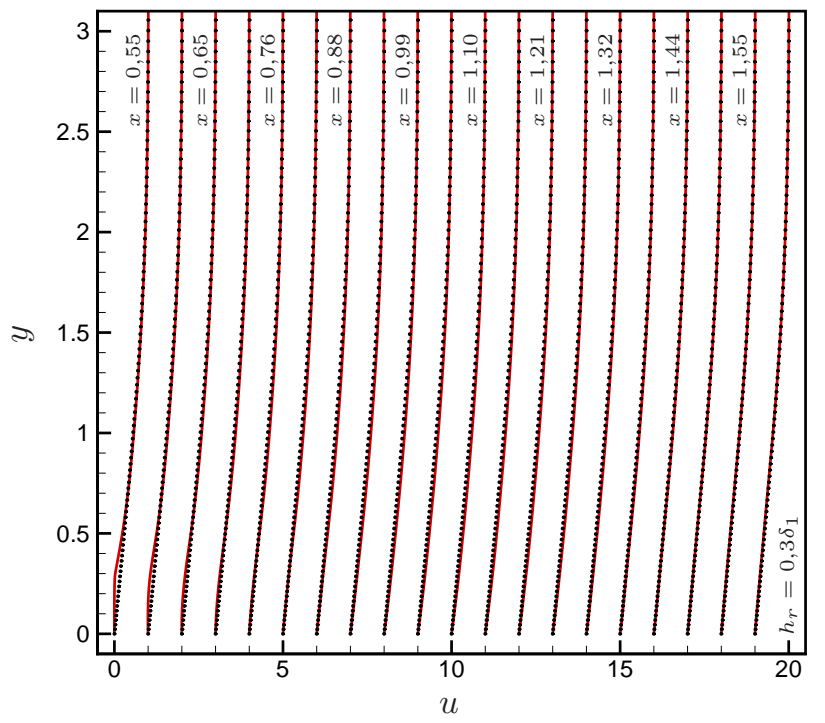

Figura 5.12: Perfil de $u$ normal à superfície em $z=0$, para o caso P0 com $h_{r}=0,3 \delta_{1}$.

Os efeitos causados por uma rugosidade com altura $h_{r}=0,3 \delta_{1}$ se estendem por uma região um pouco maior do que para protuberâncias mais baixas. No entanto, a perturbação causada por este tipo de rugosidade no escoamento ainda é pequena.

\subsubsection{Rugosidade com altura $h_{r}=0,4 \delta_{1}$}

Nesta seção são apresentados os resultados obtidos com $h_{r}=0,4 \delta_{1}$. Esses resultados são mostrados nas figuras de 5.13 a 5.16. Para este caso, foram rodados 138240 passos no tempo.

A distribuição de $v$ e $w$ como vetores mostra, na figura 5.13a, a presença dos VLCRP acima da rugosidade. Vê-se também nessa figura, a presença de um par de VLCRT que gira no sentido oposto ao dos VLCRP, em $y \approx 0,5$ e $z \approx \pm 0,7$. A jusante da rugosidade, observa-se um aumento na velocidade em $y \approx 0,7 \mathrm{e} z \approx \pm 0,5$, como mostrado na figura 5.13b. Em $y \approx 0,7$, entre $z \approx-0,5 \mathrm{e}$ $z \approx 0,5$, nota-se uma redução na velocidade. Isso sugere uma influência da BSJR, não permitindo a formação bem definida dos VLCRS. Esses vórtices conseguem ser identificados a partir de $x \approx 0,8$, conforme diminui a influência da BSJR, como pode ser visto na figura 5.13c. Nesta figura, os VLCRS aparecem em $y \approx 0,4 \mathrm{e} z \approx \pm 0,8$. Na figura 5.13d esses vórtices aparecem mais afastados da superfície, em $y \approx 0,75$, e com menor intensidade. Nas figuras 5.13e 5.13f e 5.13g nota-se que os VLCRS se aproximam entre si, conforme se deslocam na direção do escoamento, até se aglutinarem, a partir de $x \approx 1,6$. Na figura 5.13 g pode-se ver a formação de VLCRT, em $y \approx 0,5 \mathrm{e} z \approx \pm 0,8$. Porém, esses vórtices são bem menores do que os demais. 

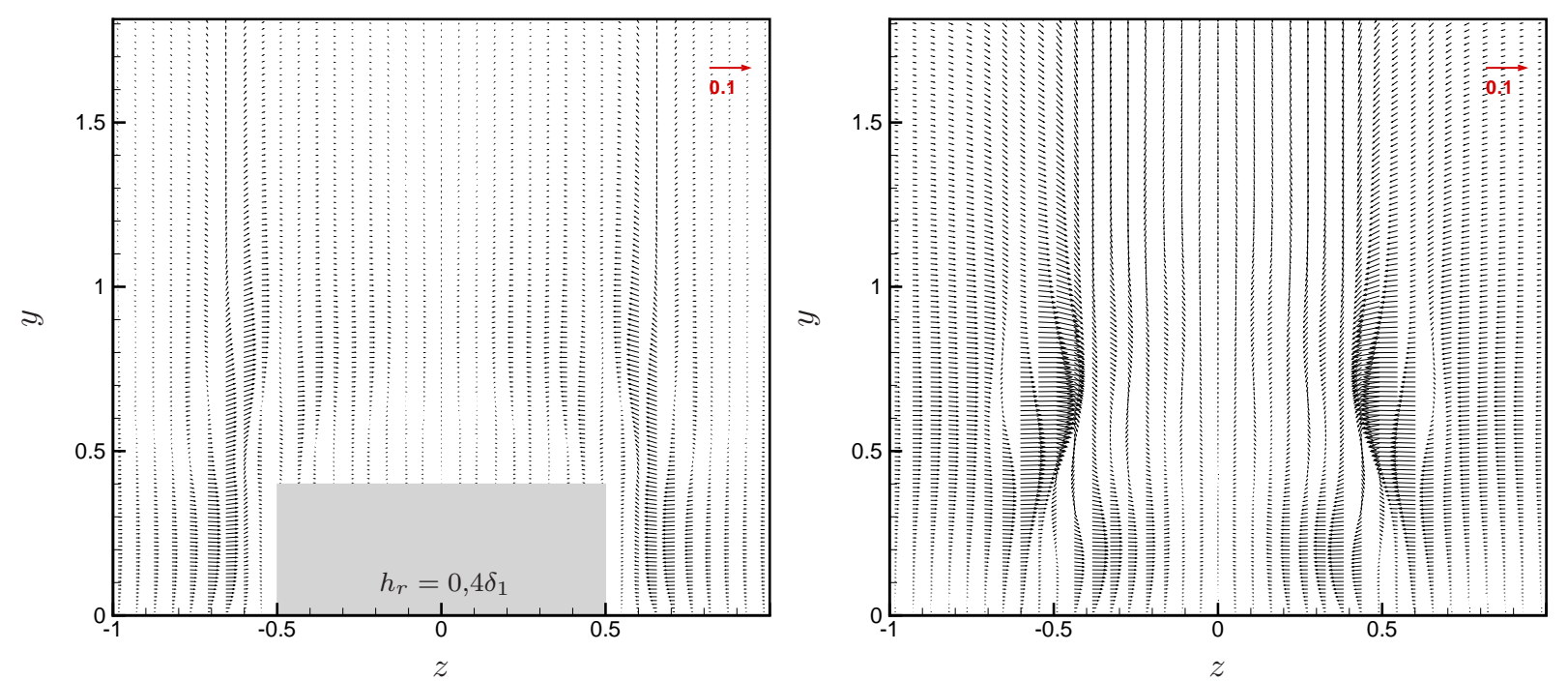

(a) $x=0,0$
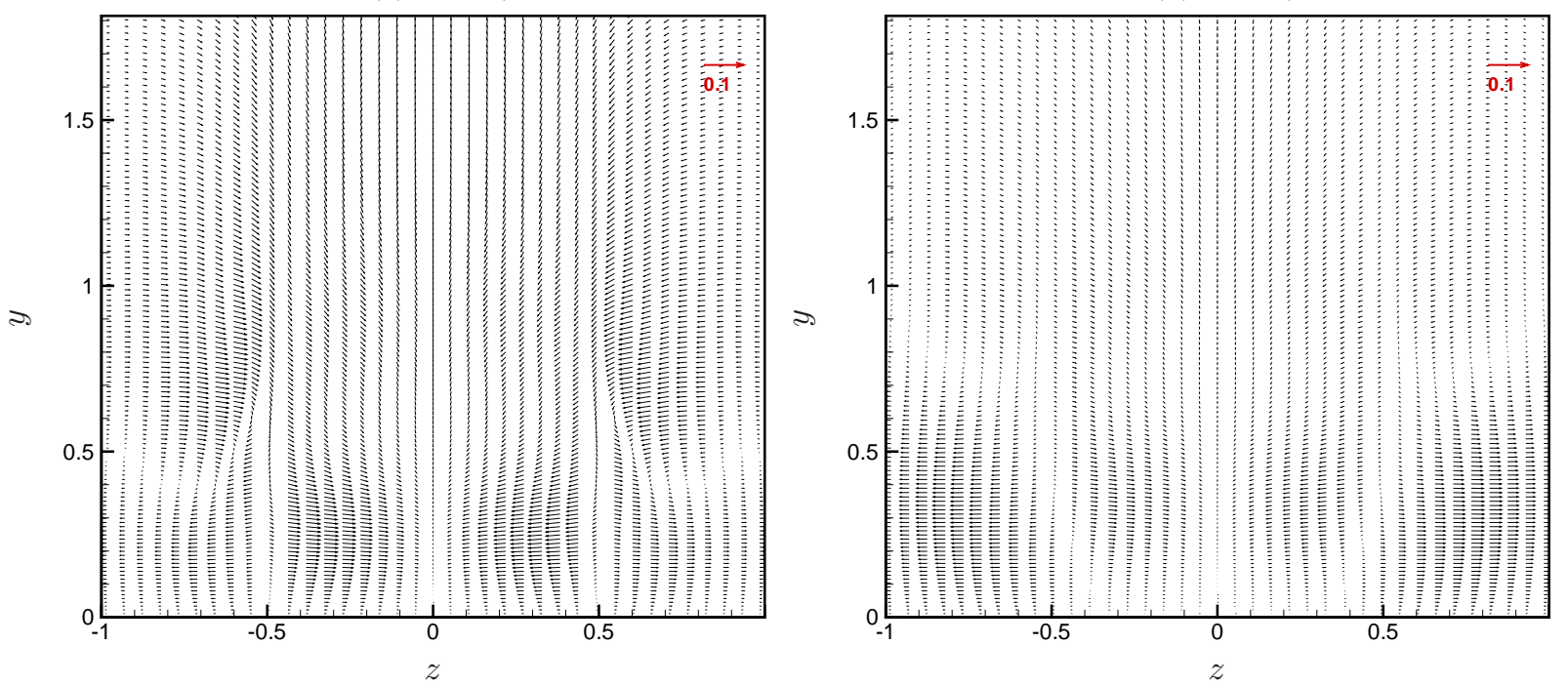

(c) $x=0,8$

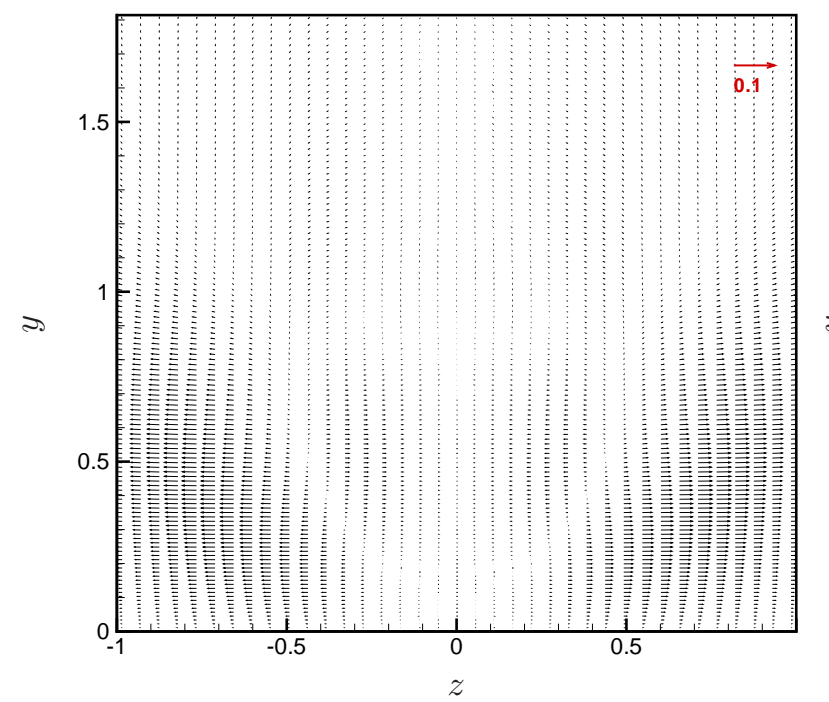

(e) $x=1,2$ (d) $x=1,0$

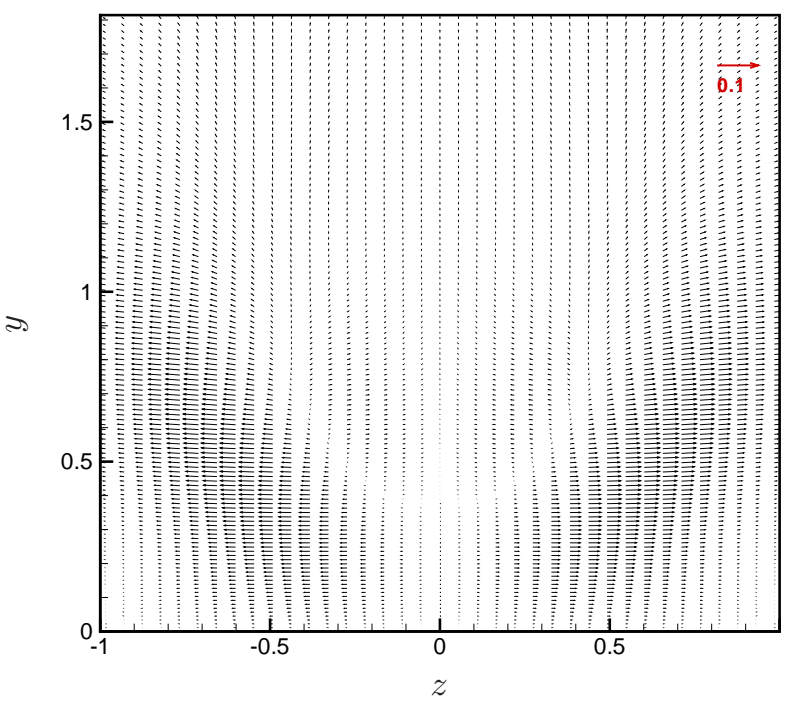

(f) $x=1,4$

Figura 5.13: Distribuição de $v$ e $w$ como vetores, em diferentes posições $x$, para o caso $\mathrm{P} 0$ com $h_{r}=0,4 \delta_{1}$. 


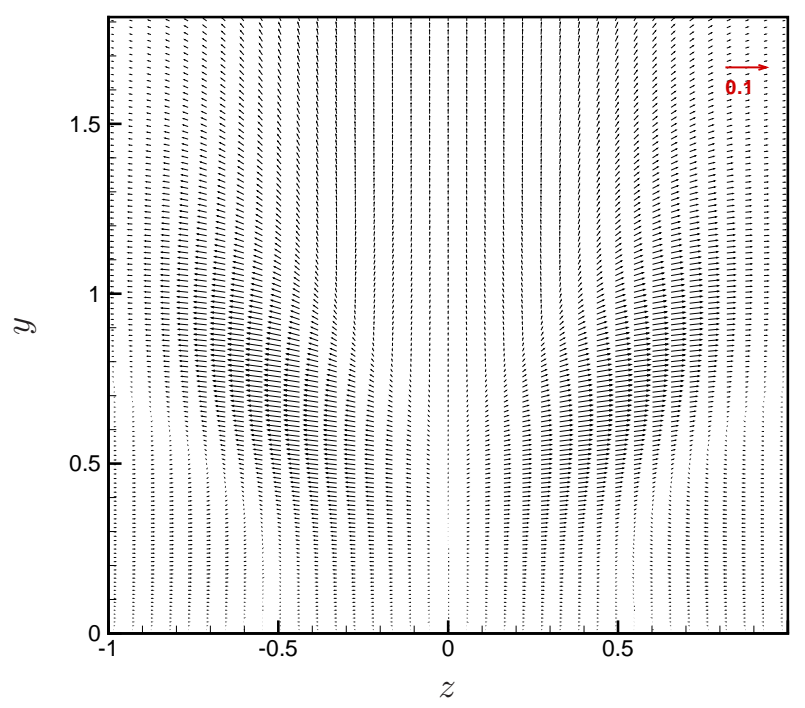

(g) $x=1,6$

Figura 5.13: Distribuição de $v$ e $w$ como vetores, em diferentes posições $x$, para o caso P0 com $h_{r}=0,4 \delta_{1}$ (cont.).

$\mathrm{Na}$ figura 5.14 fica evidente o movimento feito pelo fluido ao redor da protuberância, com a redução da velocidade na vizinhança da mesma. Pode-se ver também os escoamentos laterais se juntando a jusante da rugosidade. Além disso, pode-se observar oscilações dos vetores a partir de $x \approx 0,0$. Novamente, isso sugere uma interação da BSJR com os VLCRS, formados a partir do escoamento vindo das laterais da rugosidade, em direção ao centro do domínio na direção transversal.

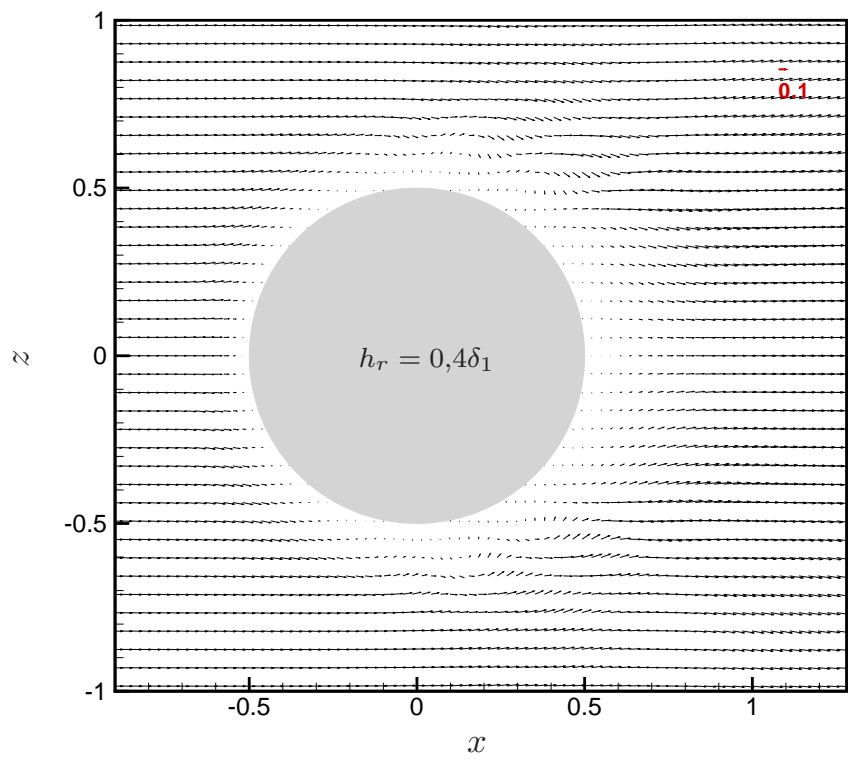

Figura 5.14: Distribuição de $u$ e $w$ como vetores em $y=0,3$, para o caso P0 com $h_{r}=0,4 \delta_{1}$.

A região de baixa velocidade a montante da rugosidade pode ser vista na figura 5.15a. Pode-se notar que em $x \approx 0,69$ a redução na velocidade é mais acentuada. Nesta figura nota-se também o 


\section{1 - Escoamento contendo rugosidade}

movimento do fluido para cima, contornando a protuberância. Na figura 5.15b pode-se ver a formação da BSJR, em $y \approx 0,22$ e $x \approx 0,66$. Essa bolha se estende até $x \approx 0,9$. Para essa altura de rugosidade, a BSJR é maior do que no caso anterior, com $h_{r}=0,3 \delta_{1}$.

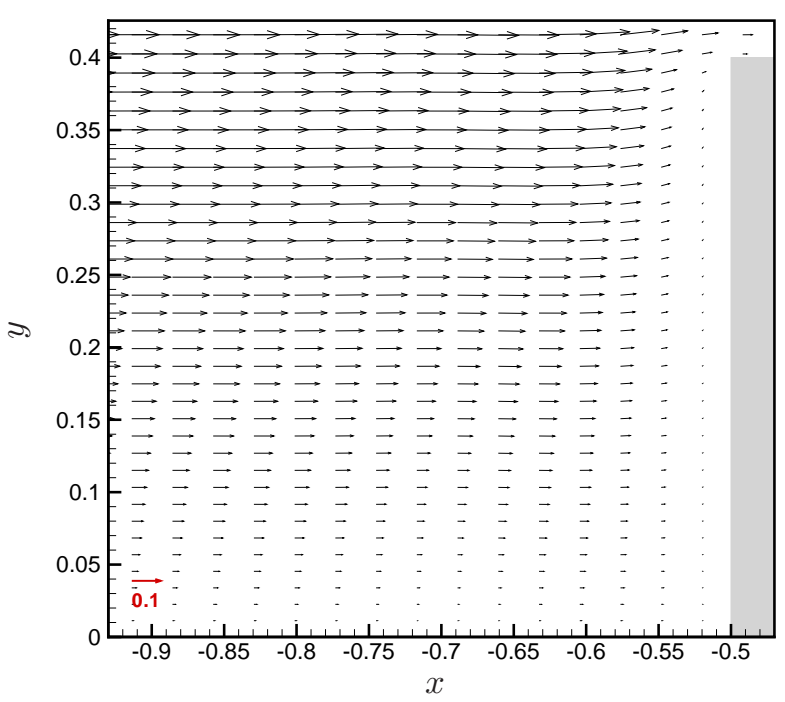

(a) A montante da rugosidade.

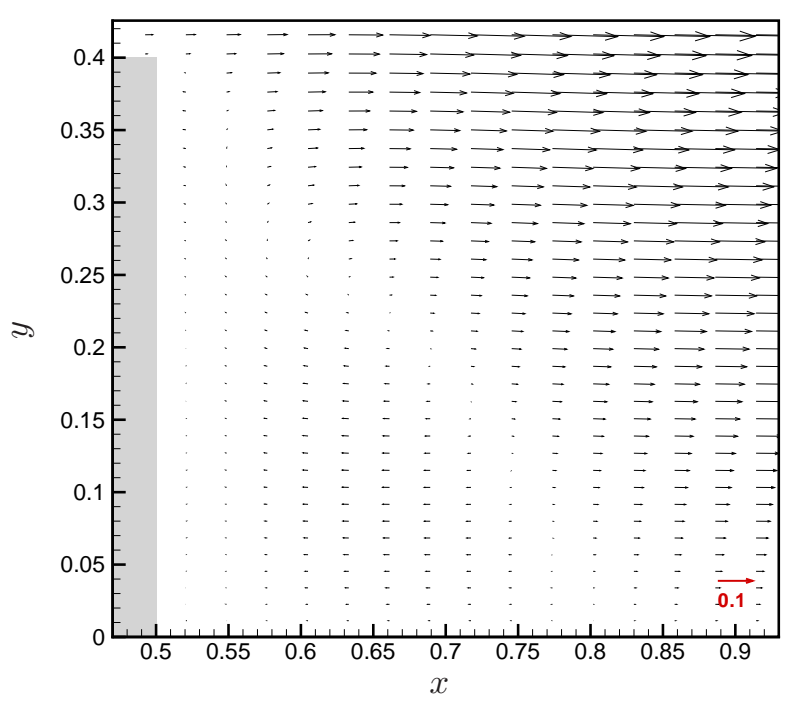

(b) A jusante da rugosidade.

Figura 5.15: Distribuição de $u$ e $v$ como vetores em $z=0$, para o caso $\mathrm{P} 0$ com $h_{r}=0,4 \delta_{1}$.

A deformação do perfil de velocidade, mostrado na figura 5.16, também ilustra a presença da BSJR, se estendendo até $x \approx 0,88$. Novamente, é possível observar um aumento na quantidade de movimento na direção do escoamento. Esse aumento é mais evidente em $x \approx 1,10$, entre $y \approx 0,0 \mathrm{e}$ $y \approx 2,0$.

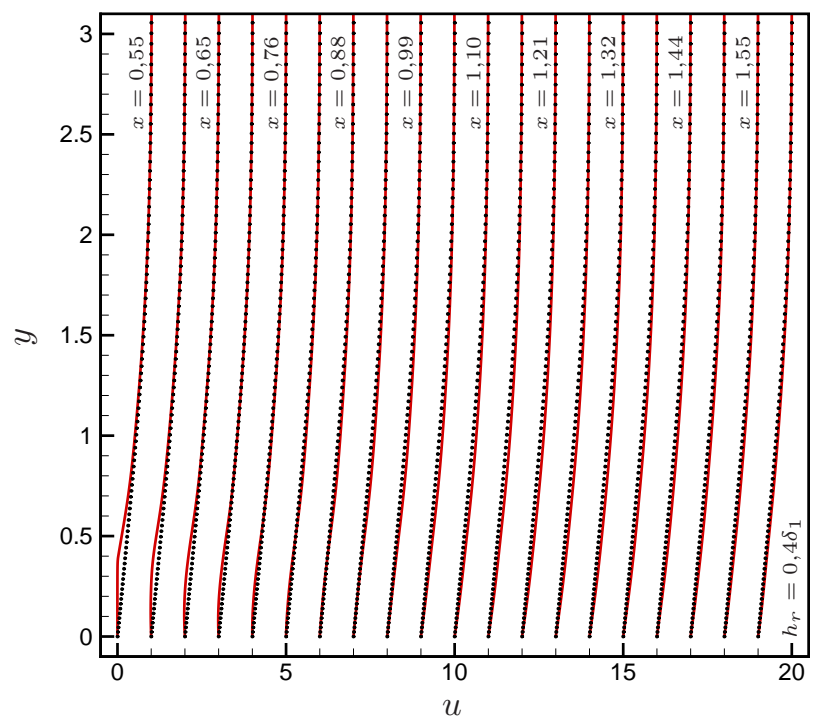

Figura 5.16: Perfil de $u$ normal à superfície em $z=0$, para o caso $\mathrm{P} 0$ com $h_{r}=0,4 \delta_{1}$.

Para este caso, com altura de rugosidade $h_{r}=0,4 \delta_{1}$, as perturbações no escoamento geradas pela 
presença da protuberância são maiores do que nos casos anteriores. Porém, essas perturbações não são suficientes para levar o escoamento a transição do escoamento do regime laminar para o turbulento.

\subsubsection{Rugosidade com altura $h_{r}=0,5 \delta_{1}$}

Os resultados obtidos com $h_{r}=0,5 \delta_{1}$ são mostrados nas figuras de 5.17 a 5.20. Para este caso, foram rodados 174080 passos no tempo.

A partir dessa altura de rugosidade o escoamento não atingiu um estágio estacionário, quando existente. Isso se deve ao alto custo computacional das simulações numéricas.

Na figura 5.17a é apresentada a distribuição de $v$ e $w$ como vetores. Nesta figura, pode-se ver a formação dos VLCRP, em $z \approx \pm 0,6$ e $y \approx 0,8$. Um par de VLCRT de menor intensidade também pode ser visto, em $y \approx 0,5$ e $z \approx \pm 0,8$. Devido ao perfil de velocidade da camada limite, quanto maior a altura da rugosidade, maior será a velocidade no topo da protuberância, fazendo com que os efeitos nesta região se tornem mais evidentes. Assim como observado no caso anterior, as estruturas do escoamento começam a interagir entre si, dificultando a identificação de cada uma separadamente. Nas figuras de 5.17 b a $5.17 \mathrm{~g}$, pode-se observar que os vórtices não estão bem definidos, como nos casos com menor altura de rugosidade. O fato de o escoamento ser transiente também dificulta a identificação das estruturas.

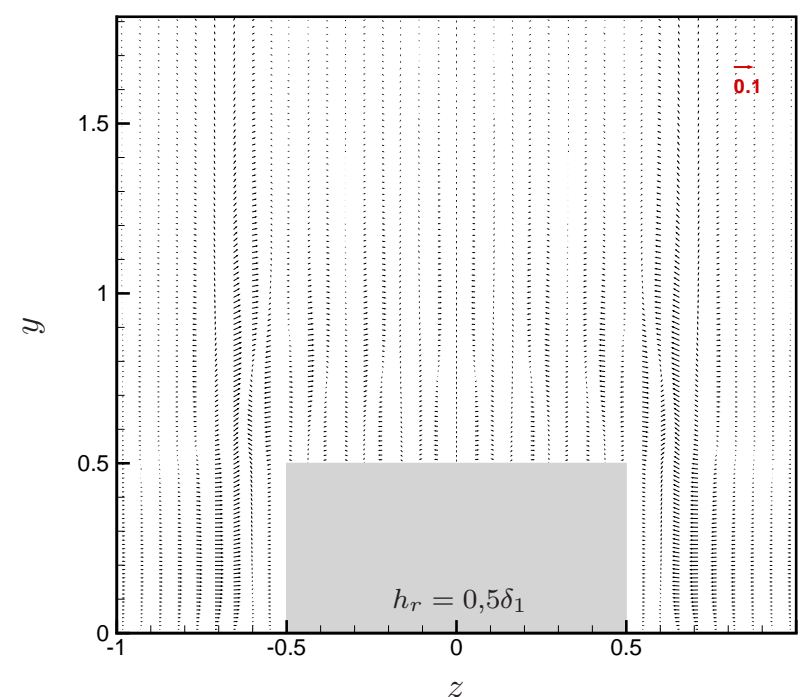

(a) $x=0,0$

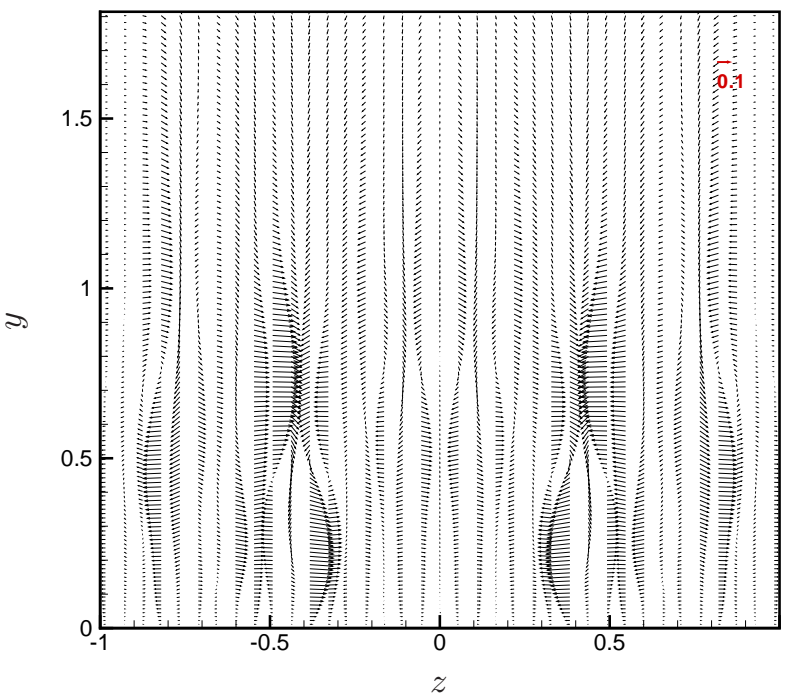

(b) $x=0,6$

Figura 5.17: Distribuição de $v$ e $w$ como vetores, em diferentes posições $x$, para o caso P0 com $h_{r}=0,5 \delta_{1}$.

A partir da altura de rugosidade $h_{r}=0,5 \delta_{1}$, efeitos tridimensionais mais fortes começam a aparecer no escoamento. Esses efeitos podem ser observados na figura 5.18. Nesta figura é possível ver 


\section{1 - Escoamento contendo rugosidade}

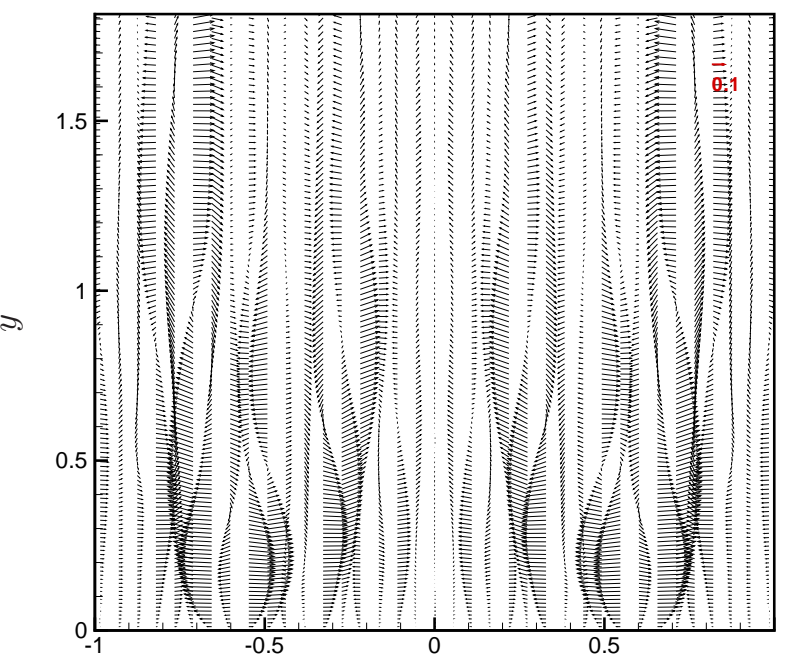

(c) $\stackrel{z}{x=0,8}$

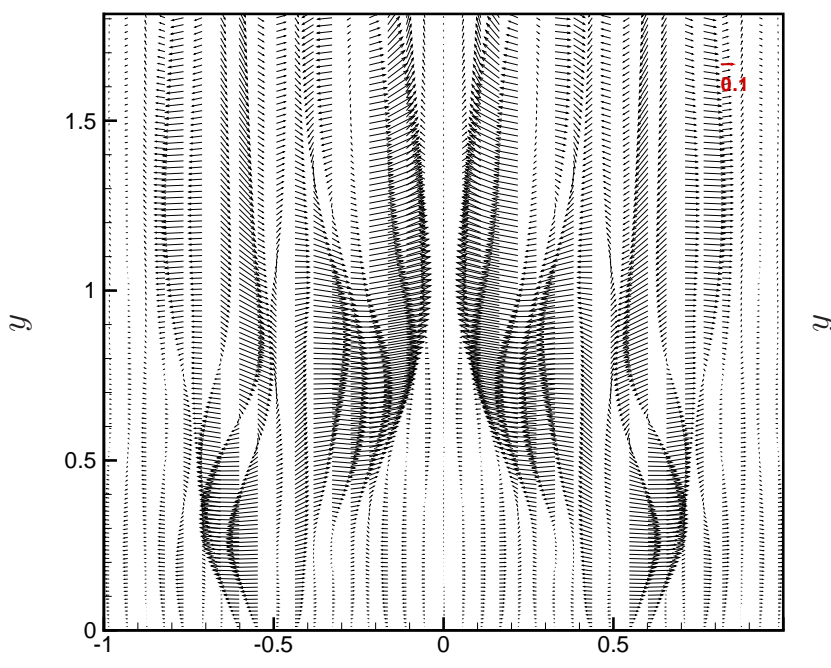

(e) $x=1,2$

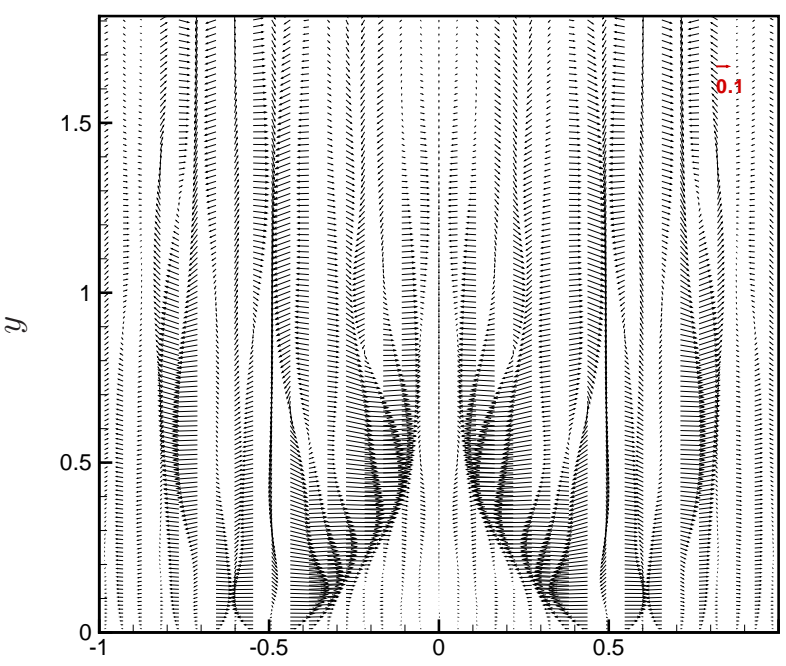

(d) $\stackrel{z}{x=1,0}$

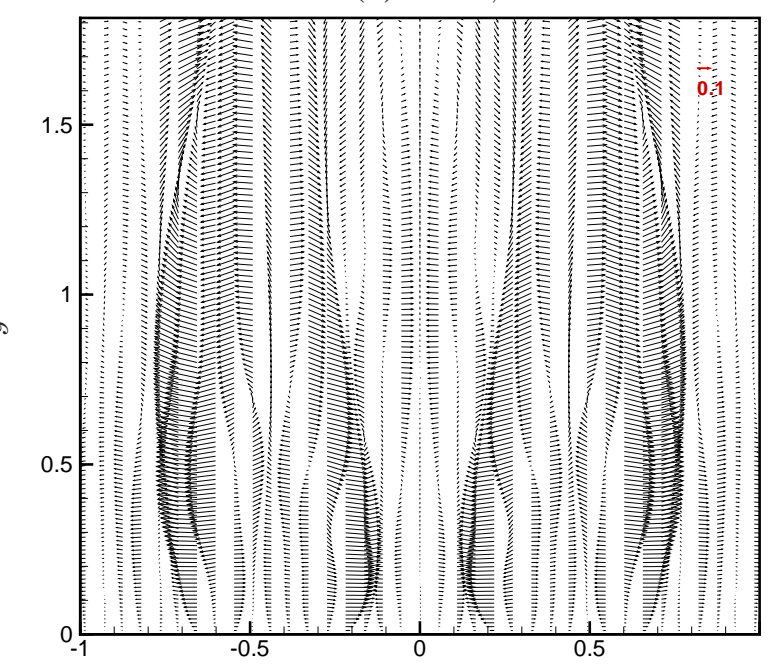

(f) $x=1,4$

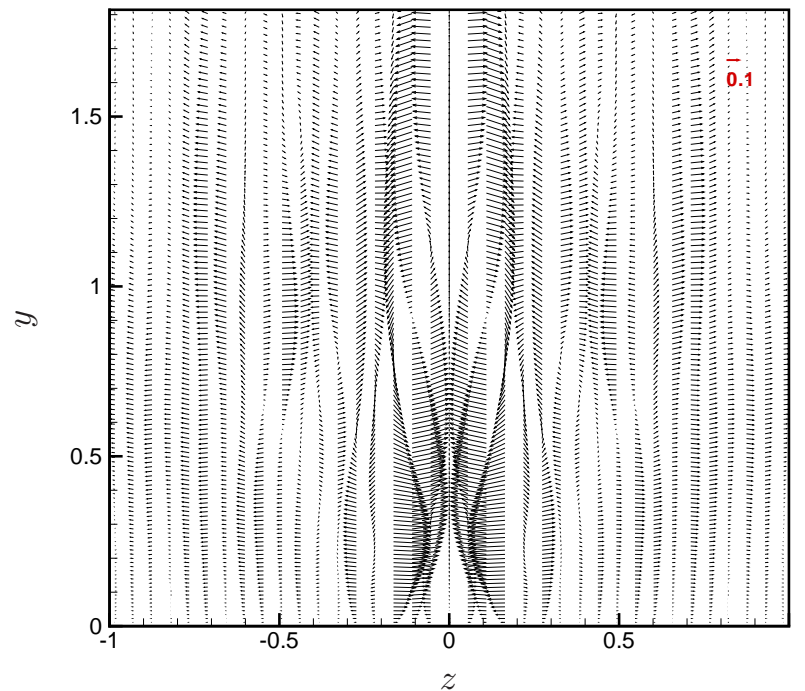

(g) $\stackrel{z}{x=1,6}$

Figura 5.17: Distribuição de $v$ e $w$ como vetores, em diferentes posições $x$, para o caso P0 com $h_{r}=0,5 \delta_{1}$ (cont.). 
um comportamento oscilatório do escoamento nas laterais da rugosidade, semelhante ao mostrado na figura 1.2. Também é possível observar na figura 5.18 a redução da velocidade na vizinhança da protuberância.

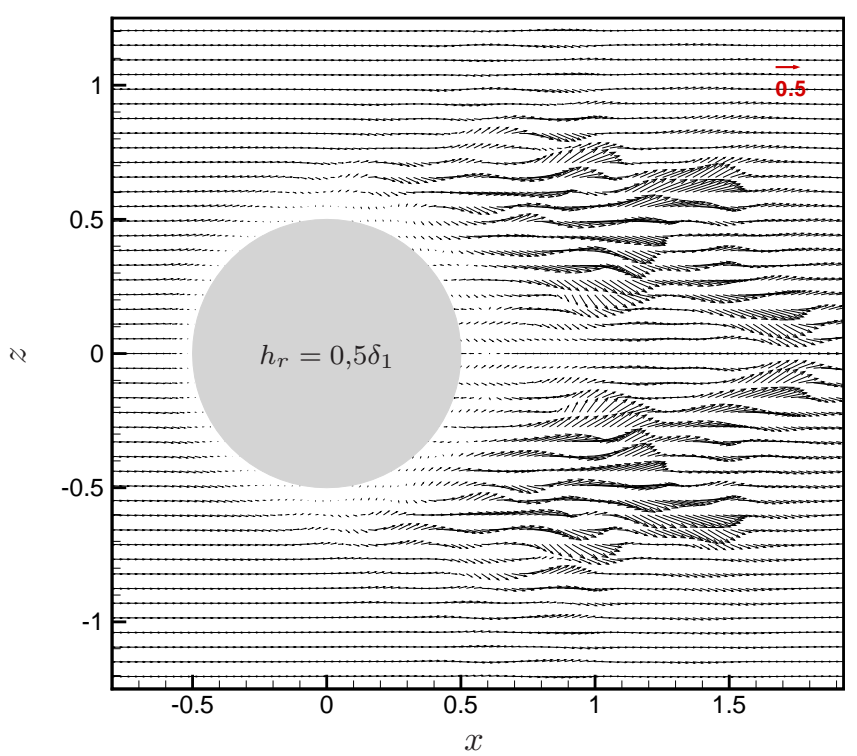

Figura 5.18: Distribuição de $u$ e $w$ como vetores em $y=0,4$, para o caso P0 com $h_{r}=0,5 \delta_{1}$.

Na figura 5.19a nota-se a região de baixa velocidade a montante da rugosidade. Em particular, na figura 5.19a, pode-se observar uma maior redução de velocidade em $x \approx-0,69$. Isso sugere que, a partir dessa altura de rugosidade, formar-se-á um vórtice do tipo ferradura a montante da rugosidade, como mostrado na figura 1.3. Para facilitar a notação, esse vórtice será denominado VTFMR (Vórtice Tipo Ferradura a Montante da Rugosidade).

A BSJR pode ser observada na figura 5.19b. Esta bolha está centrada em $x \approx 0,66$ e $y \approx 0,28 \mathrm{e}$ se estende até a posição $x \approx 0,76$. O comprimento longitudinal desta bolha aumentou até a altura de rugosidade $h_{r}=0,4 \delta_{1}$. Ainda, na figura $5.19 \mathrm{~b}$, pode-se notar a formação de uma segunda bolha, em $x \approx 0,91$ e $y \approx 0,03$. No entanto, essa segunda bolha faz parte do transiente do escoamento, e será convectada por ele.

Os efeitos das BSJRs formadas a jusante da protuberância no perfil de velocidade podem ser vistos na figura 5.20. Além disso, há a influência da formação de um vórtice transversal no topo da rugosidade, a jusante da mesma. A deformação no perfil de $u$ para este caso é muito maior, mostrando a influência da altura da rugosidade no escoamento.

A presença de uma protuberância com altura $h_{r}=0,5 \delta_{1}$ gera perturbações não estacionárias no escoamento. Essas perturbações não levam o escoamento a transicionar para o regime turbulento, 


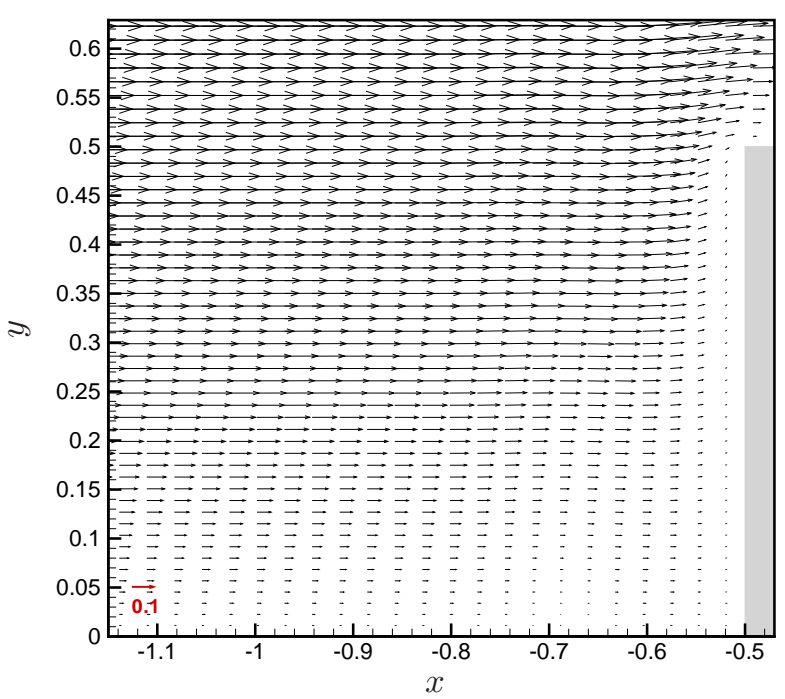

(a) A montante da rugosidade.

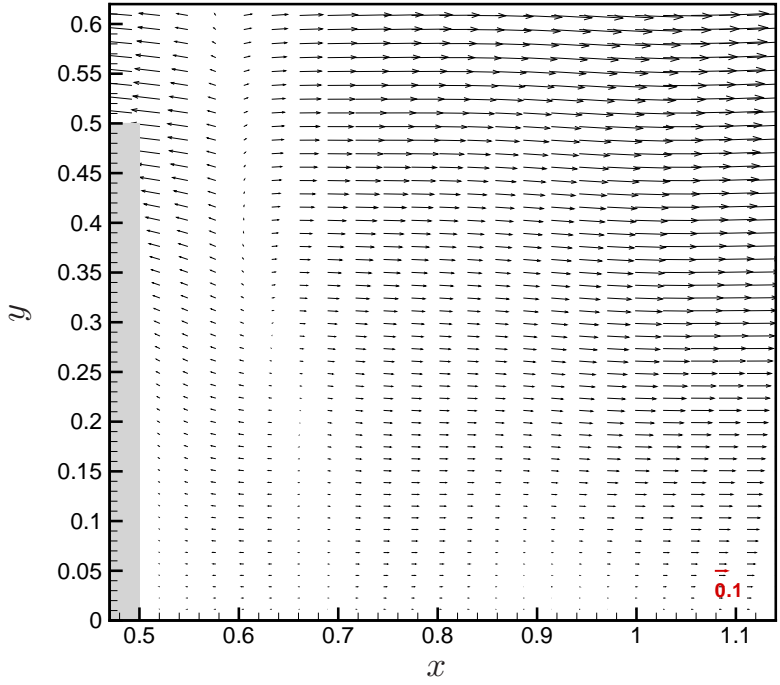

(b) A jusante da rugosidade.

Figura 5.19: Distribuição de $u$ e $v$ como vetores em $z=0$, para o caso P0 com $h_{r}=0,5 \delta_{1}$.

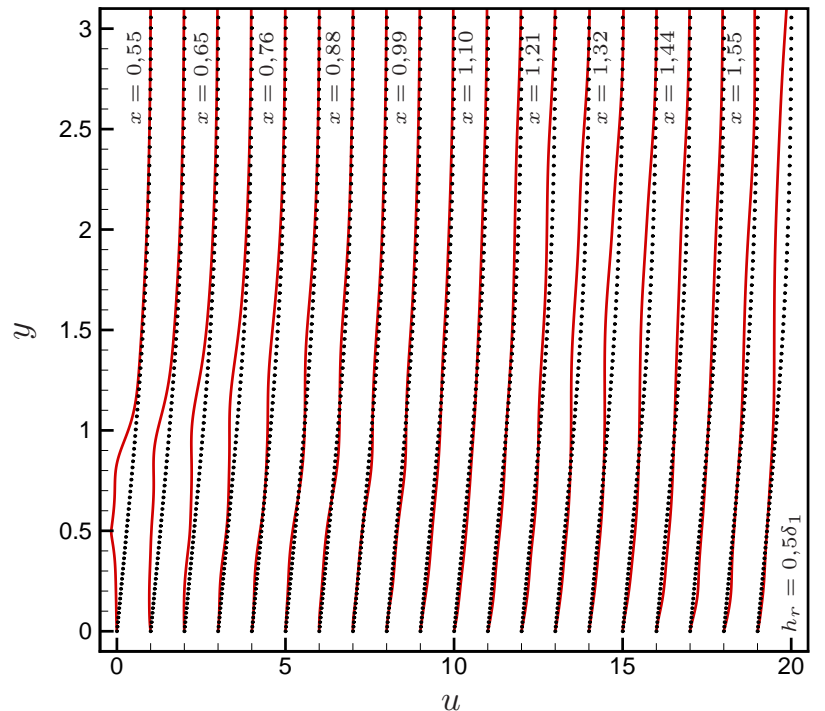

Figura 5.20: Perfil de $u$ normal à superfície em $z=0$, para o caso $\mathrm{P} 0$ com $h_{r}=0,5 \delta_{1}$. 
porém, são capazes de afetá-lo significativamente.

\subsubsection{Rugosidade com altura $h_{r}=0,6 \delta_{1}$}

Nesta seção são apresentados os resultados obtidos com $h_{r}=0,6 \delta_{1}$ são mostrados nas figuras de 5.21 a 5.24. Para este caso, foram rodados 139520 passos no tempo.

Apesar do menor tempo de simulação, os fenômenos observados para a rugosidade com altura $h_{r}=0,6$ são semelhantes aos observados com $h_{r}=0,5$.

Na figura 5.21 pode-se observar que a interação entre os vórtices longitudinais contrarrotativos e as BSJRs deixa as estruturas tridimensionais mais evidentes, dificultando o reconhecimento de cada estrutura separadamente.

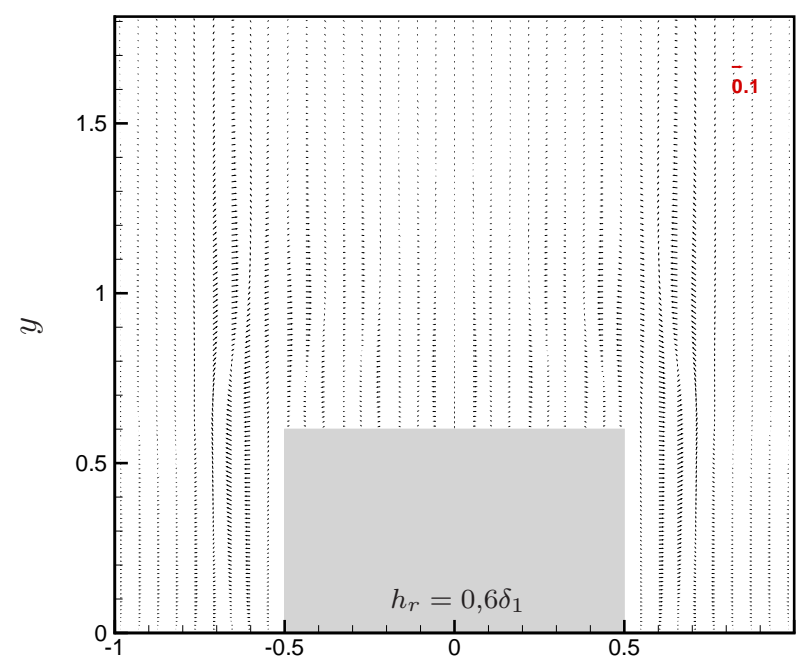

(a) $\stackrel{z}{x}=0,0$

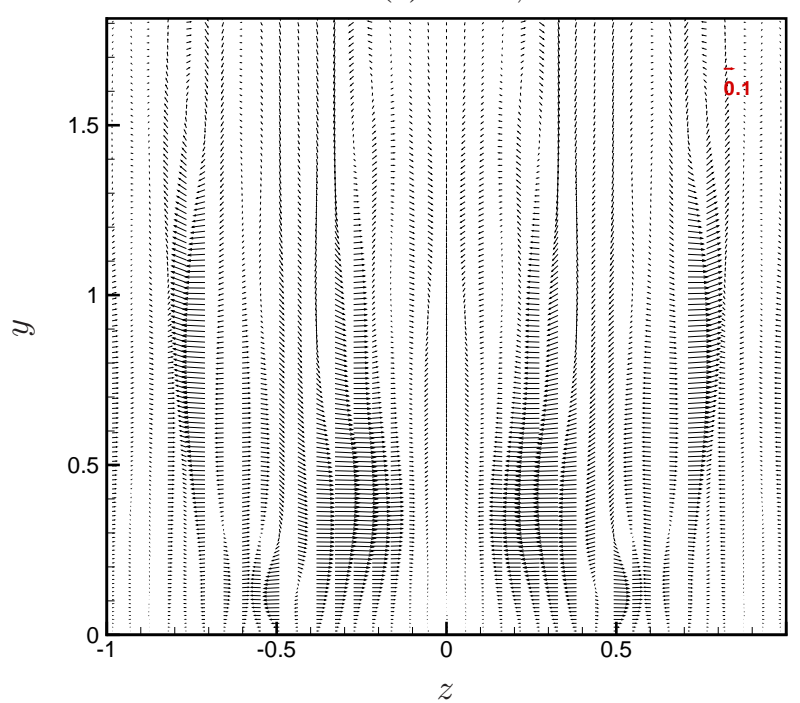

(c) $x=0,8$

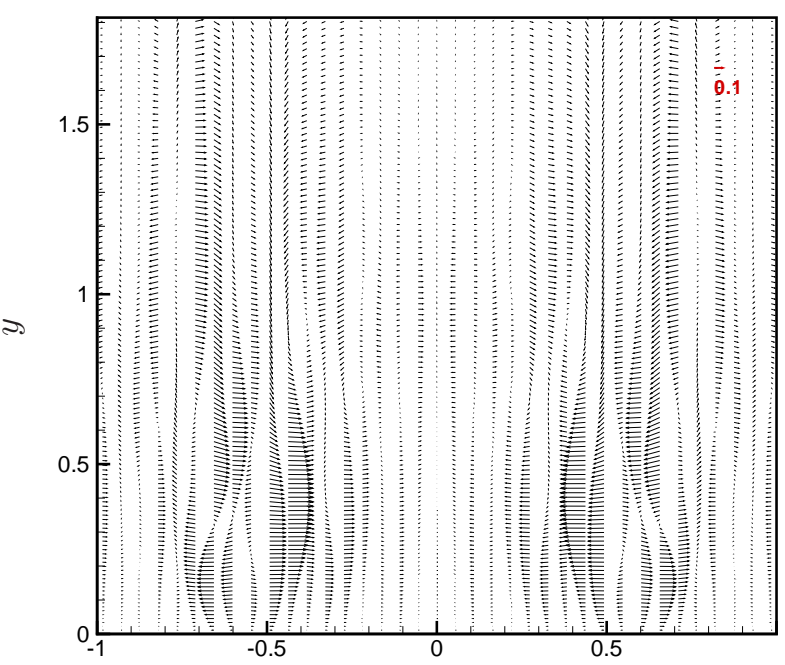

(b) $\stackrel{z}{x}=0,6$

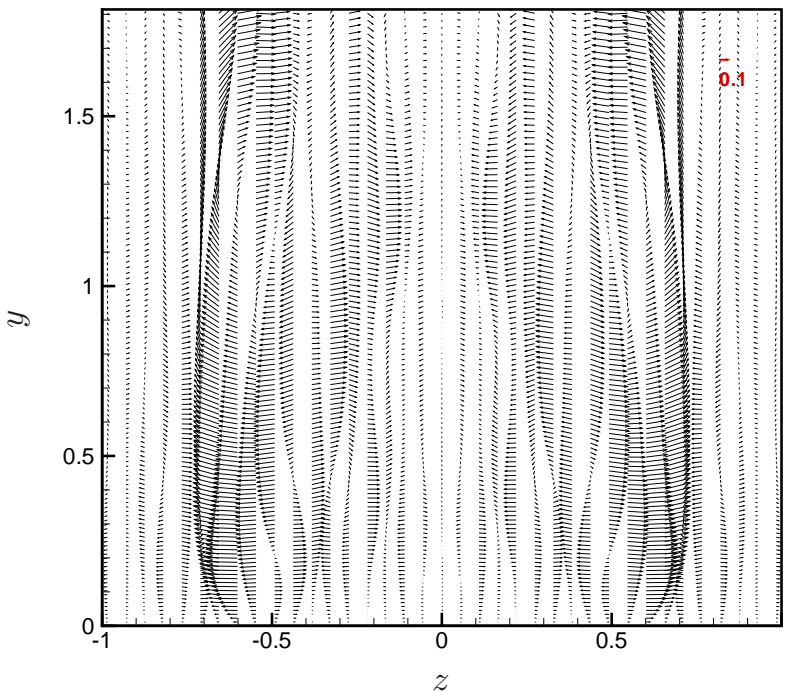

(d) $x=1,0$

Figura 5.21: Distribuição de $v$ e $w$ como vetores, em diferentes posições $x$, para o caso P0 com $h_{r}=0,6 \delta_{1}$. 


\section{1 - Escoamento contendo rugosidade}

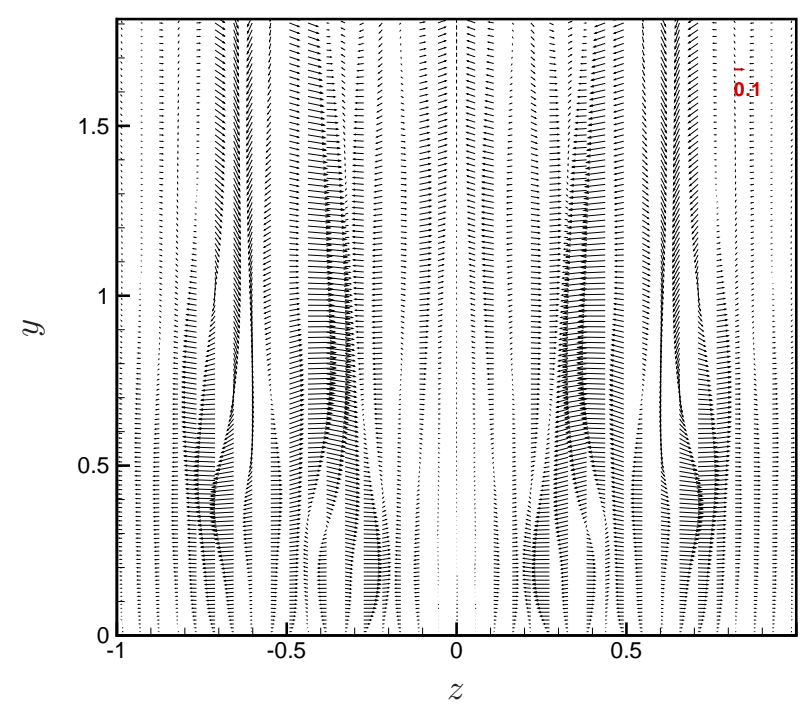

(e) $x=1,2$

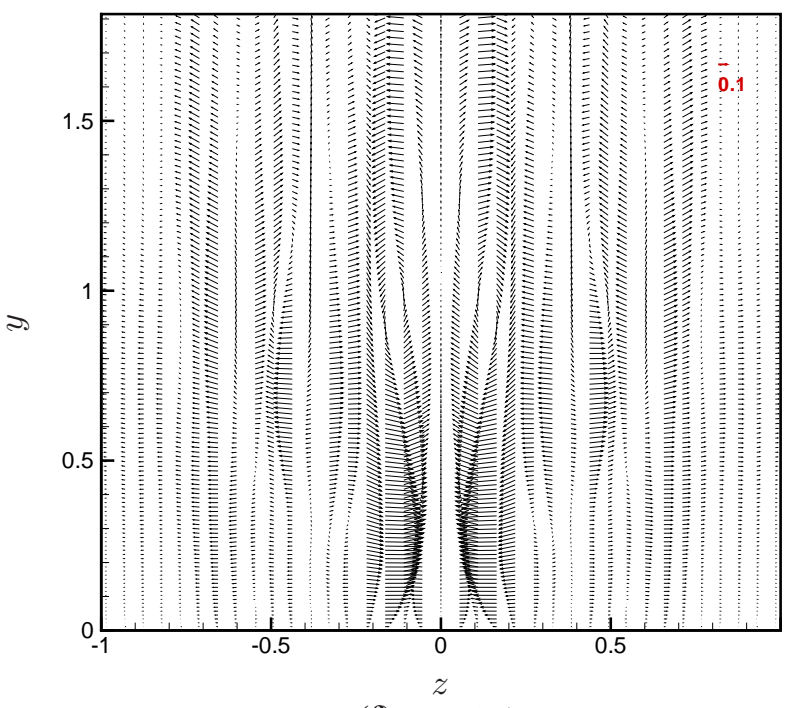

(f) $x=1,4$

Figura 5.21: Distribuição de $v$ e $w$ como vetores, em diferentes posições $x$, para o caso P0 com $h_{r}=0,6 \delta_{1}$ (cont.).

Na figura 5.22 pode-se ver a redução da velocidade nas proximidades da rugosidade. Novamente, como no caso com $h_{r}=0,5 \delta_{1}$, o comportamento oscilatório do escoamento a partir de $x \approx 0,0$ no entorno da protuberância pode ser visto na figura 5.22.

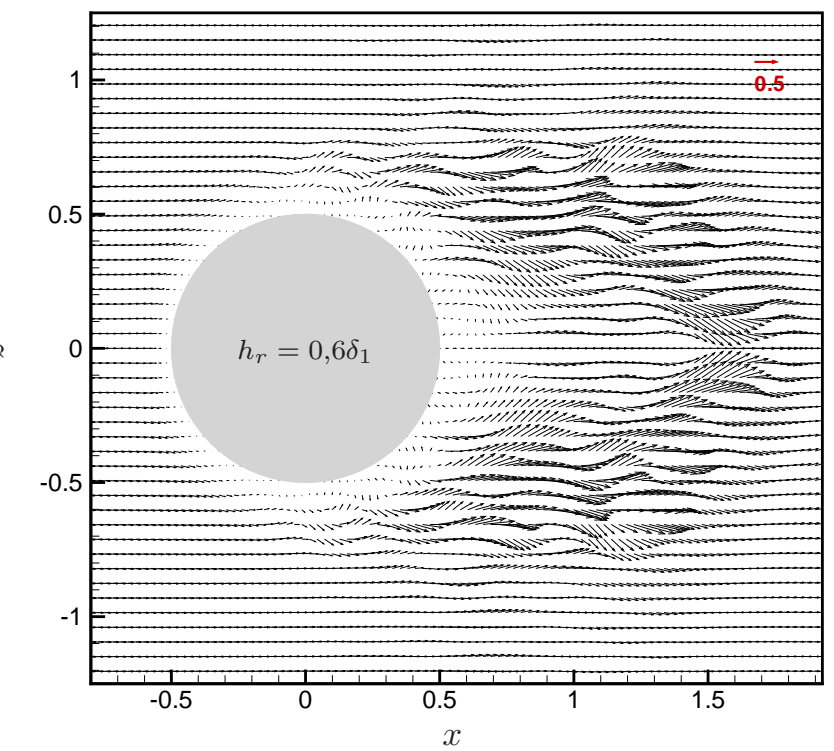

Figura 5.22: Distribuição de $u$ e $w$ como vetores em $y=0,5$, para o caso P0 com $h_{r}=0,6 \delta_{1}$.

Pode-se notar, na figura 5.23a, a formação do VTFMR, em $x \approx 0,67$ e $y=0,05$, girando no sentido horário. A BSJR pode ser vista na figura 5.23b, centrada em $x \approx 0,75$ e $y \approx 0,27$, se estendendo até $x \approx 0,9$.

Os efeitos da BSJR e do escoamento sobre a rugosidade no perfil de velocidade podem ser ob- 


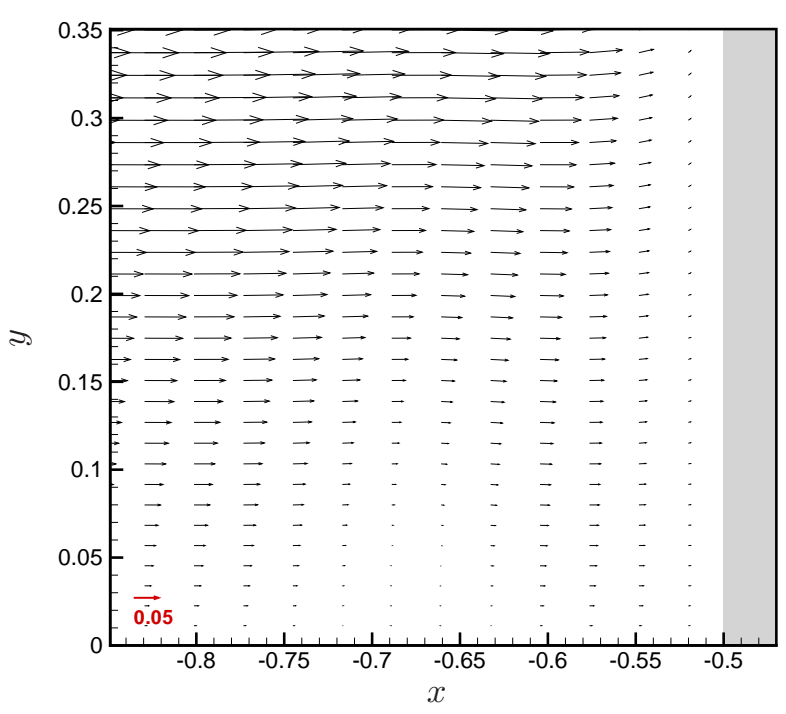

(a) A montante da rugosidade.

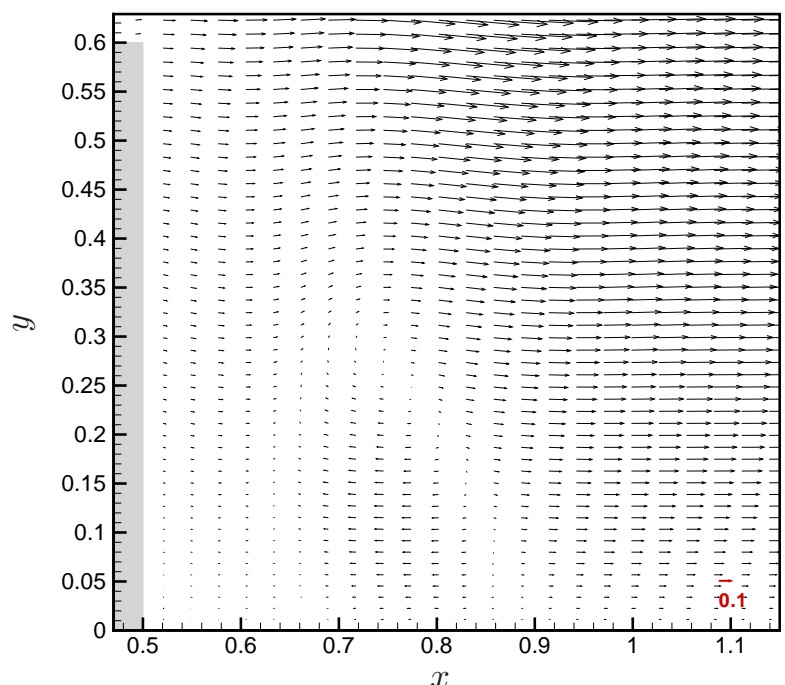

(b) A jusante da rugosidade.

Figura 5.23: Distribuição de $u$ e $v$ como vetores em $z=0$, para o caso P0 com $h_{r}=0,6 \delta_{1}$.

servados na figura 5.24. Assim como no caso anterior, as deformações no perfil de $u$ ficam mais evidentes com o aumento na altura da rugosidade.

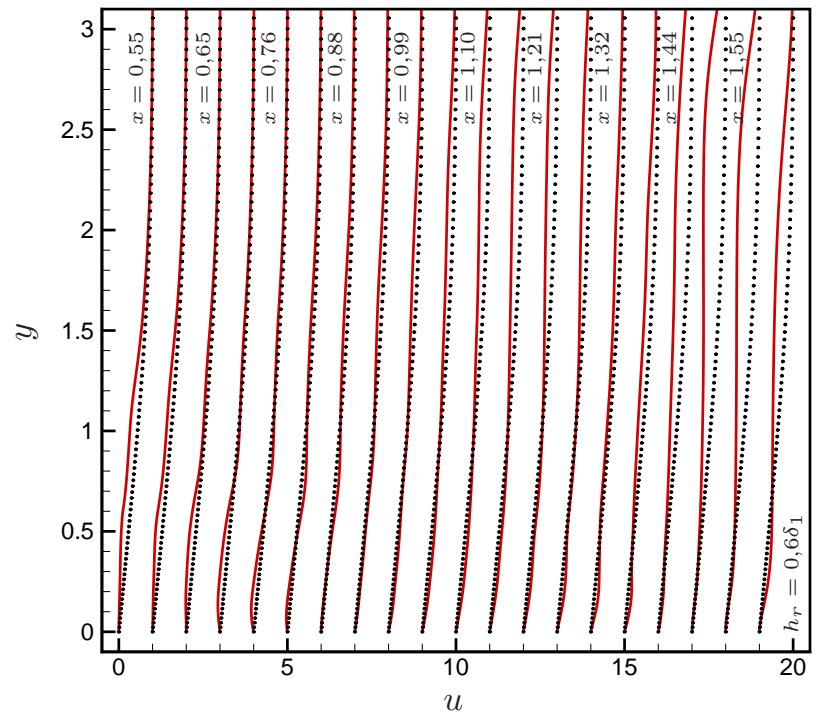

Figura 5.24: Perfil de $u$ normal à superfície em $z=0$, para o caso P0 com $h_{r}=0,6 \delta_{1}$.

Como mencionado anteriormente, os resultados para a altura de rugosidade $h_{r}=0,6 \delta_{1}$ são muito semelhantes aos resultados do caso com $h_{r}=0,5 \delta_{1}$. Novamente, a presença da protuberância provoca perturbações significativas no escoamento. Contudo, essas perturbações não são suficientes para a transição do escoamento. 


\subsubsection{Rugosidade com altura $h_{r}=0,7 \delta_{1}$}

Nesta seção são apresentados os resultados obtidos com $h_{r}=0,7 \delta_{1}$. Esses resultados são mostrados nas figuras de 5.25 a 5.28. Para este caso, foram rodados 144640 passos no tempo.

Novamente, tem-se uma semelhança no comportamento deste escoamento com os de altura $h_{r}=$ $0,5 \delta_{1}$ e $h_{r}=0,6 \delta_{1}$.

$\mathrm{O}$ aumento dos fortes efeitos tridimensionais pode ser observado na figura 5.25. As interações entre as estruturas causa oscilações no escoamento e essas oscilações são maiores perto da altura da rugosidade, uma vez que nesta região a velocidade é maior do que na superfície e há a formação de mais estruturas vorticais.

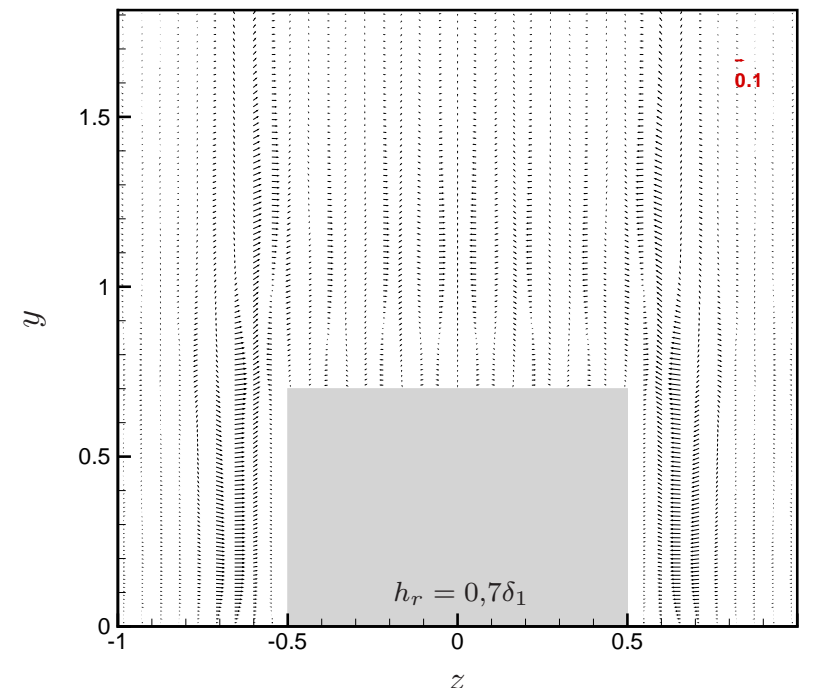

(a) $x=0,0$

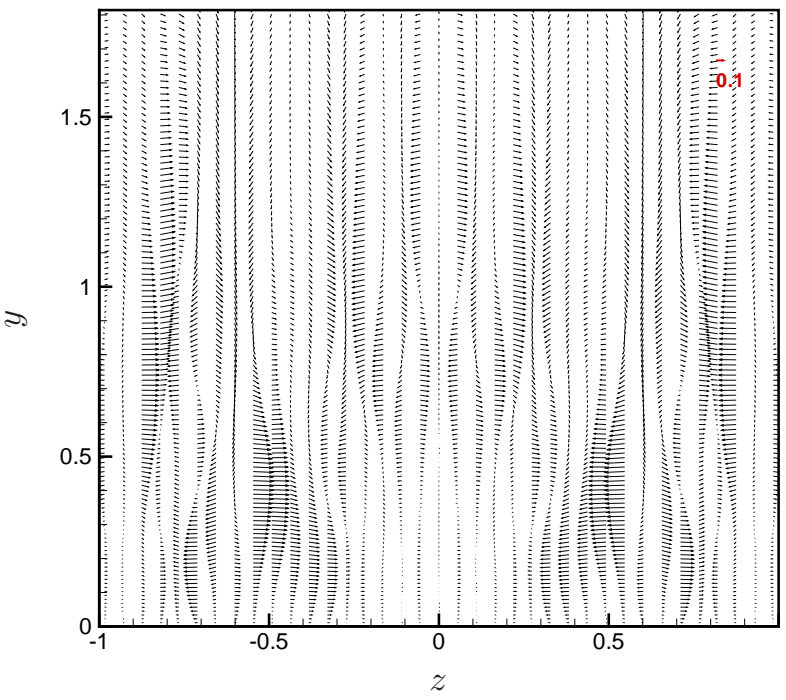

(b) $x=0,6$

Figura 5.25: Distribuição de $v$ e $w$ como vetores, em diferentes posições $x$, para o caso $\mathrm{P} 0$ com $h_{r}=0,7 \delta_{1}$.

As oscilações causadas pelos efeitos tridimensionais do escoamento ficam mais evidentes para esta altura de rugosidade, como pode ser visto na figura 5.26. Pode-se ver, nesta figura, que as oscilações começam a partir de $x \approx-0,2$ e se estendem por uma área maior a jusante da protuberância.

O VTFMR pode ser visto na figura 5.27a. Este vórtice está centrado em $x \approx 0,66 \mathrm{e} y \approx 0,12 \mathrm{e}$ gira no sentido horário. Esse vórtice contorna a rugosidade, juntando-se aos VLCR, como pode ser visto na figura 1.3 .

Na figura 5.27b é possível notar a presença da BSJR, com centro em $x \approx 0,9$ e $y \approx 0,25$, se estendendo até $x \approx 1,0$. Ainda nesta figura, pode-se ver a formação de um vórtice transversal no topo da rugosidade, com centro em $x \approx 0,57$ e $y \approx 0,7$. 


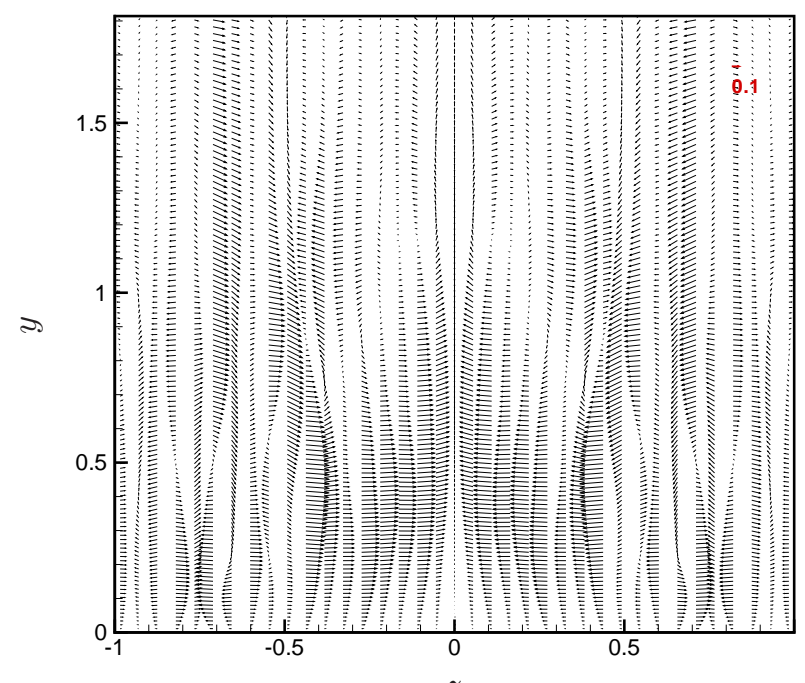

(c) $x=0,8$

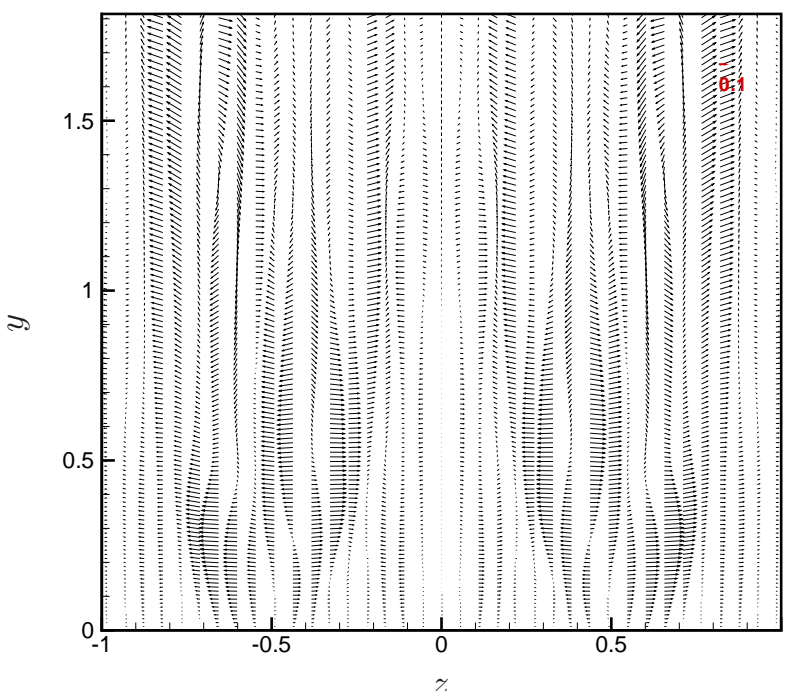

(e) $x=1,2$

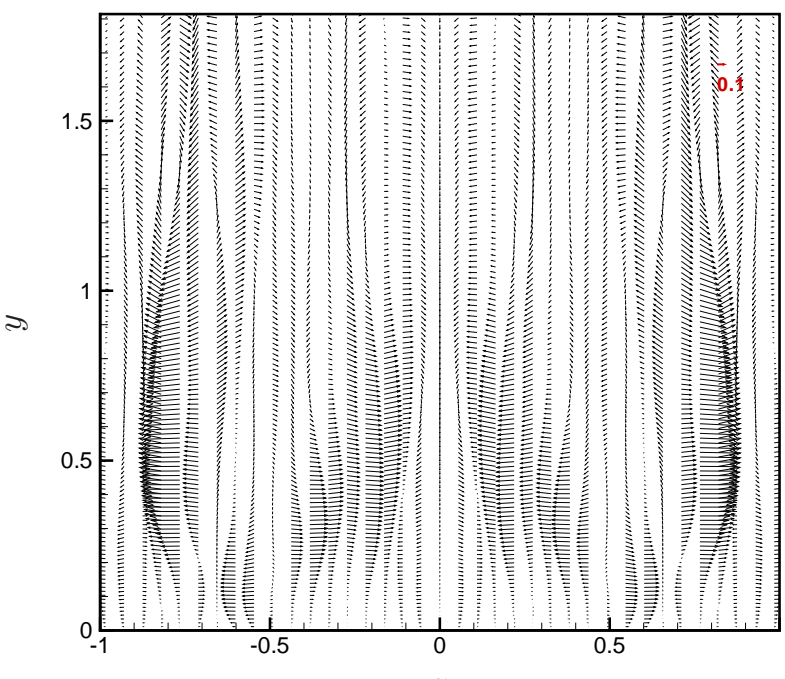

(d) $x=1,0$

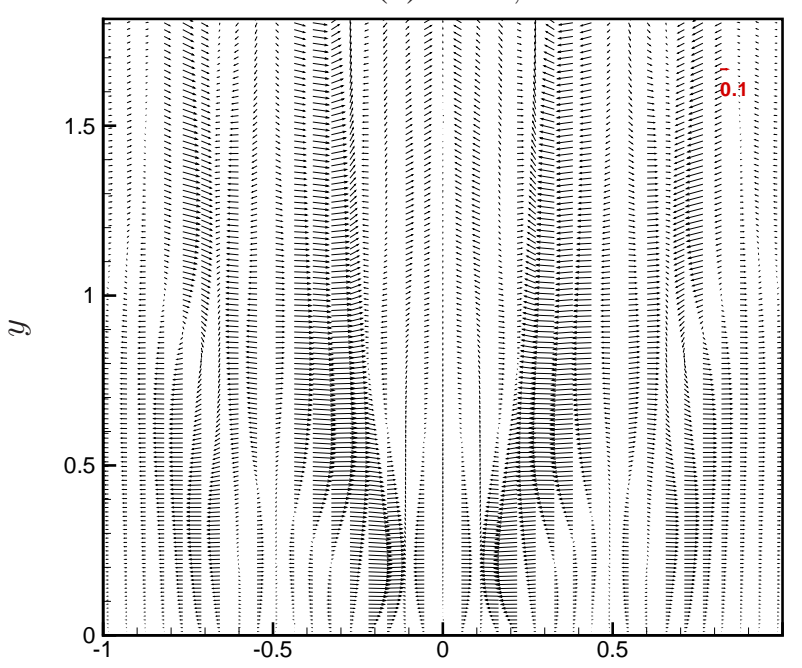

(f) $x=1,4$

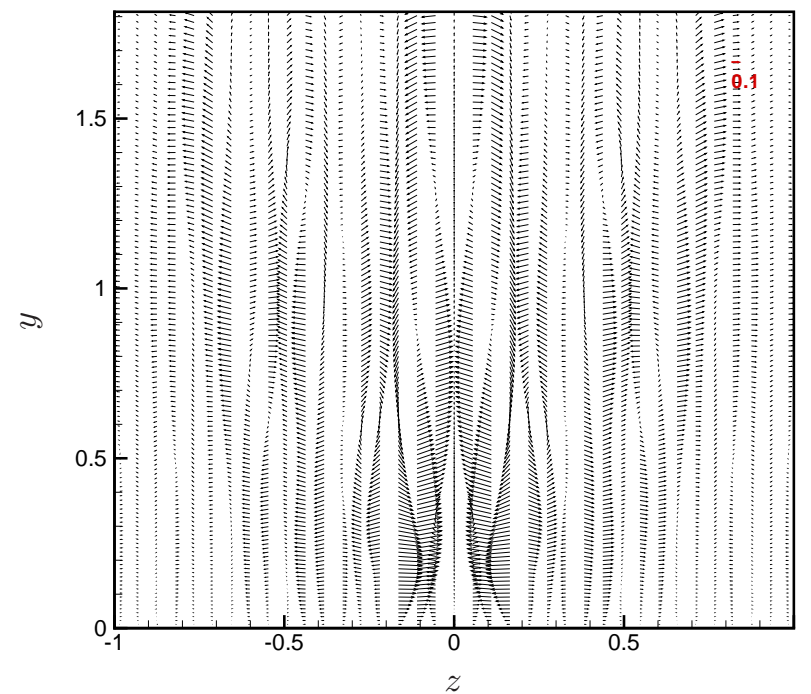

(g) $x=1,6$

Figura 5.25: Distribuição de $v$ e $w$ como vetores, em diferentes posições $x$, para o caso P0 com $h_{r}=0,7 \delta_{1}$ (cont.). 


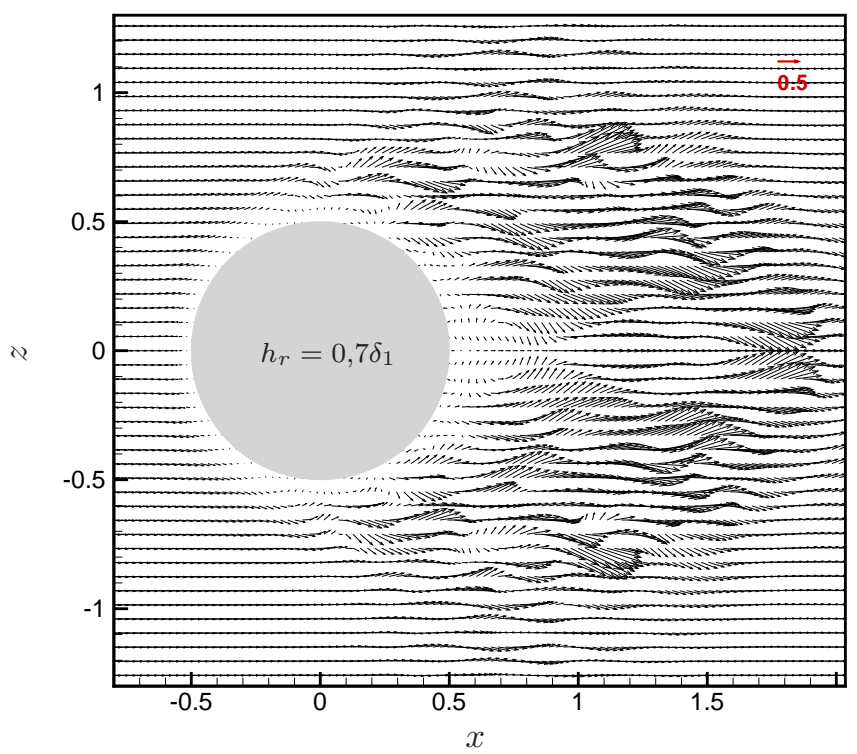

Figura 5.26: Distribuição de $u$ e $w$ como vetores em $y=0,6$, para o caso P0 com $h_{r}=0,7 \delta_{1}$.

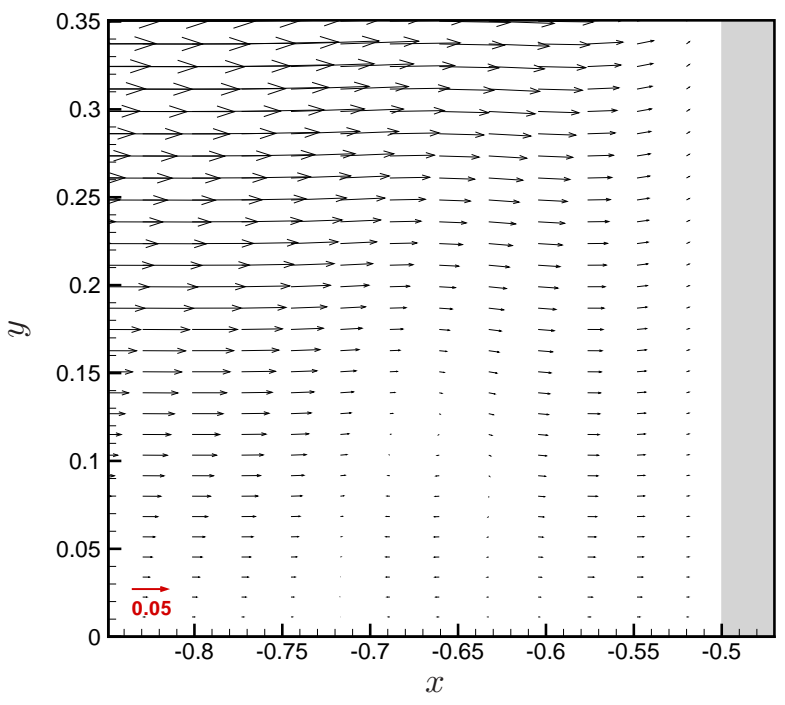

(a) A montante da rugosidade.

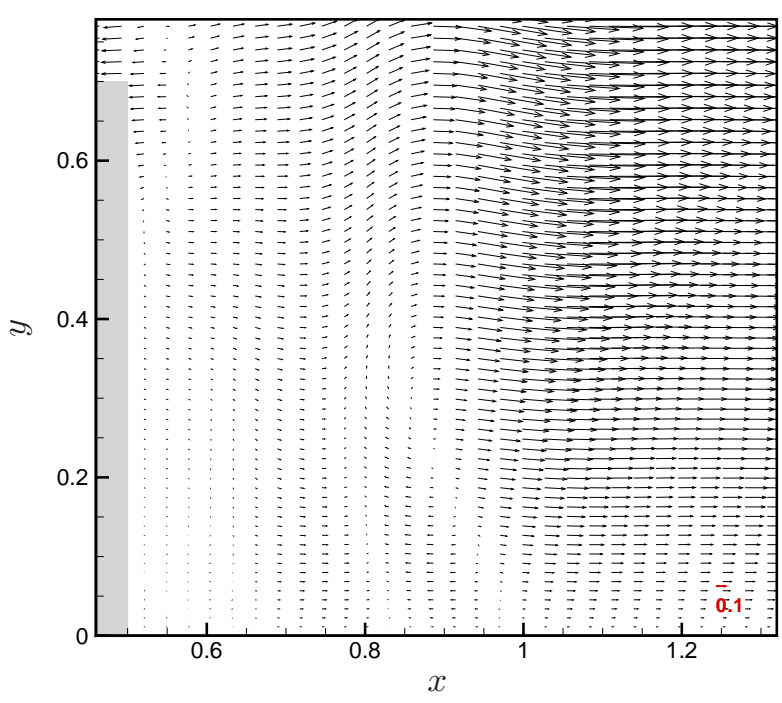

(b) A jusante da rugosidade.

Figura 5.27: Distribuição de $u$ e $v$ como vetores em $z=0$, para o caso P0 com $h_{r}=0,7 \delta_{1}$. 
A BSJR e o vórtice transversal do topo da rugosidade provocam deformações maiores sobre o perfil de velocidade, como mostrado na figura 5.28.

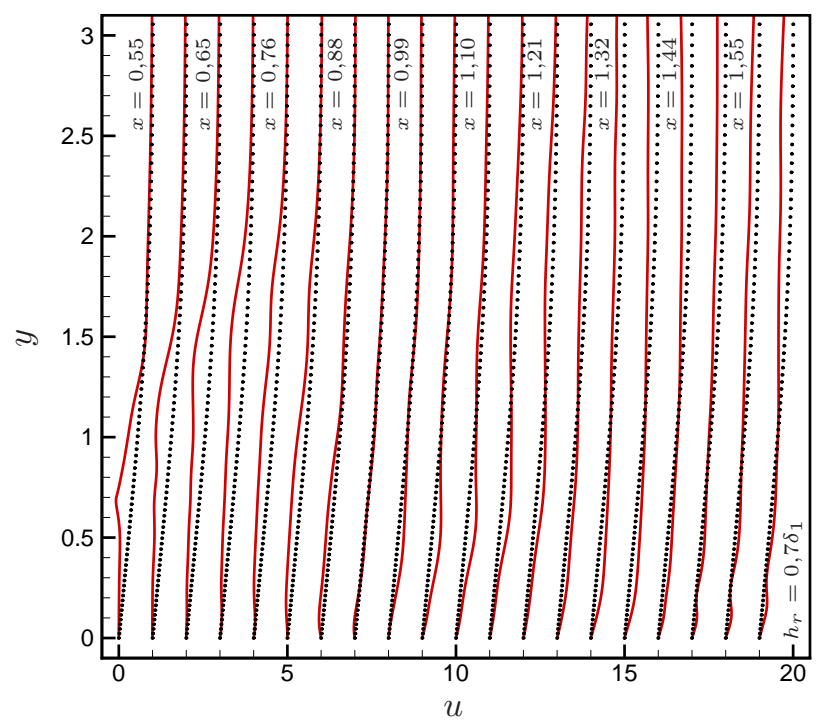

Figura 5.28: Perfil de $u$ normal à superfície em $z=0$, para o caso $\mathrm{P} 0$ com $h_{r}=0,7 \delta_{1}$.

Apesar dos fortes efeitos tridimensionais e da considerável perturbação no escoamento, não há transição para este caso. Contudo, a presença de uma rugosidade com altura $h_{r} \geq 0,7 \delta_{1}$ podem ser considerada crítica para o escoamento.

\subsubsection{Rugosidade com altura $h_{r}=0,8 \delta_{1}$}

Nesta seção são apresentados os resultados obtidos com $h_{r}=0,8 \delta_{1}$. Esses resultados são mostrados nas figuras de 5.29 a 5.32. Para este caso, foram rodados 142080 passos no tempo.

Neste caso, os efeitos oscilatórios estão muito mais evidentes, uma vez que o escoamento para esta altura de rugosidade começa a ficar instável. Na figura 5.29a observa-se a formação dos VLCRP e dos VLCRS. O primeiro está centrado em $y \approx 1,1$ e $z \approx \pm 0,45$ e o segundo em $y \approx 1,1$ e $z \approx$ $\pm 0,6$. A jusante da rugosidade a interação das estruturas vorticais aumenta, levando o escoamento a transicionar, como pode ser visto nas figura de 5.29c a 5.29f.

$\mathrm{O}$ aumento dos efeitos tridimensionais também pode ser visto na figura 5.30. Nota-se a semelhança com a figura 1.2. Além disso, é possível ver a formação de um par de vórtices espiral, normal à superfície. Esses vórtices estão centrados em $x \approx 0,5 \mathrm{e} z \approx \pm 0,5$, em que o vórtice com centro em $z \approx-0,5$ gira no sentido horário e o com centro em $z \approx 0,5$ no sentido anti-horário.

Na figura 5.31a pode-se ver a formação do VTFMR, com centro em $x \approx 0,66$ e $y \approx 0,2$, girando no sentido horário. A posição $x$ deste vórtice se mantém, comparado ao caso anterior. Contudo, ele 

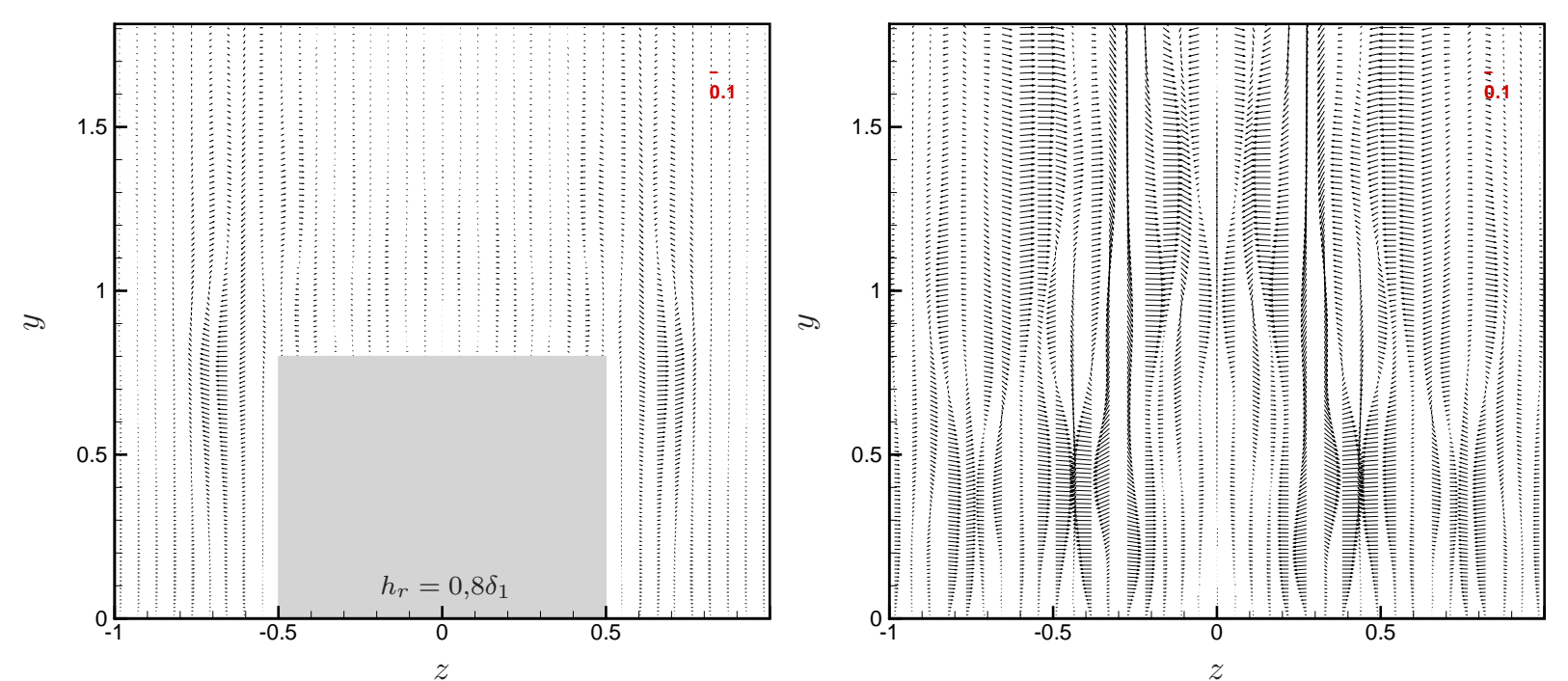

(a) $x=0,0$
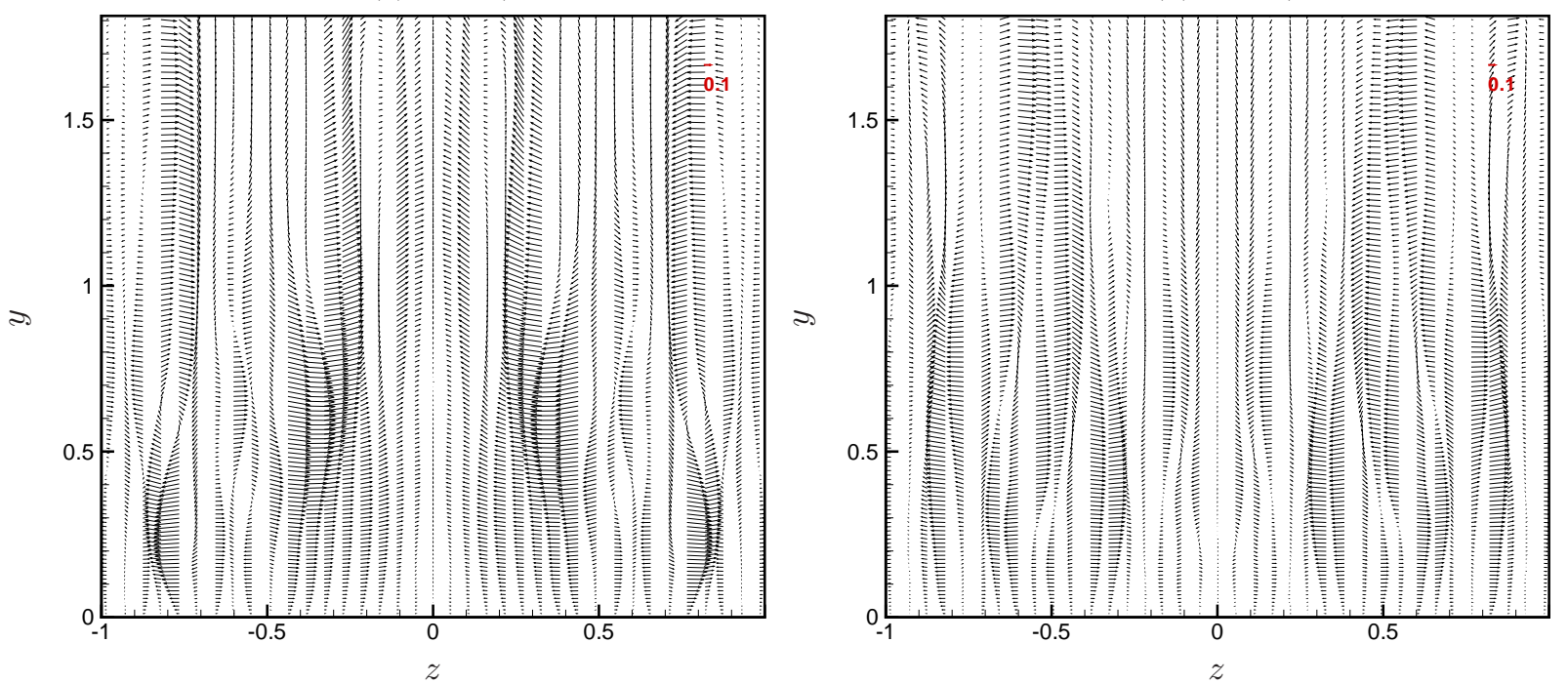

(c) $x=0,8$

(d) $x=1,0$

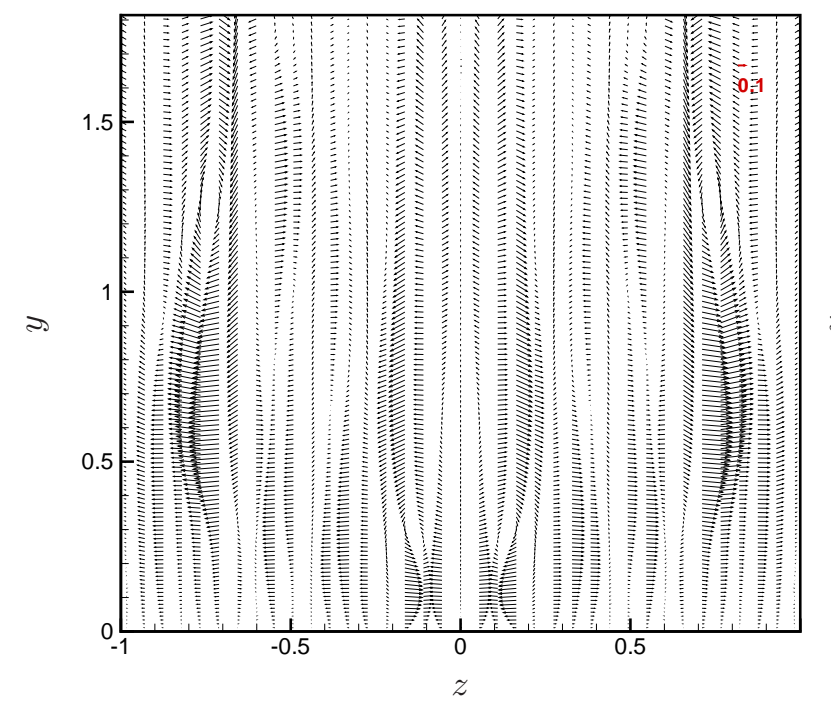

(e) $x=1,2$

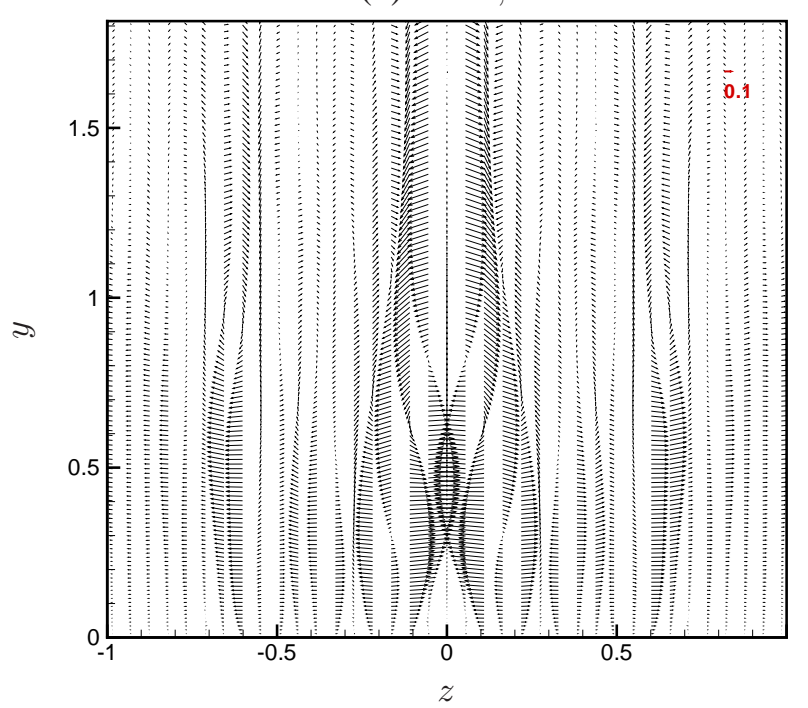

(f) $x=1,4$

Figura 5.29: Distribuição de $v$ e $w$ como vetores, em diferentes posições $x$, para o caso P0 com $h_{r}=0,8 \delta_{1}$. 


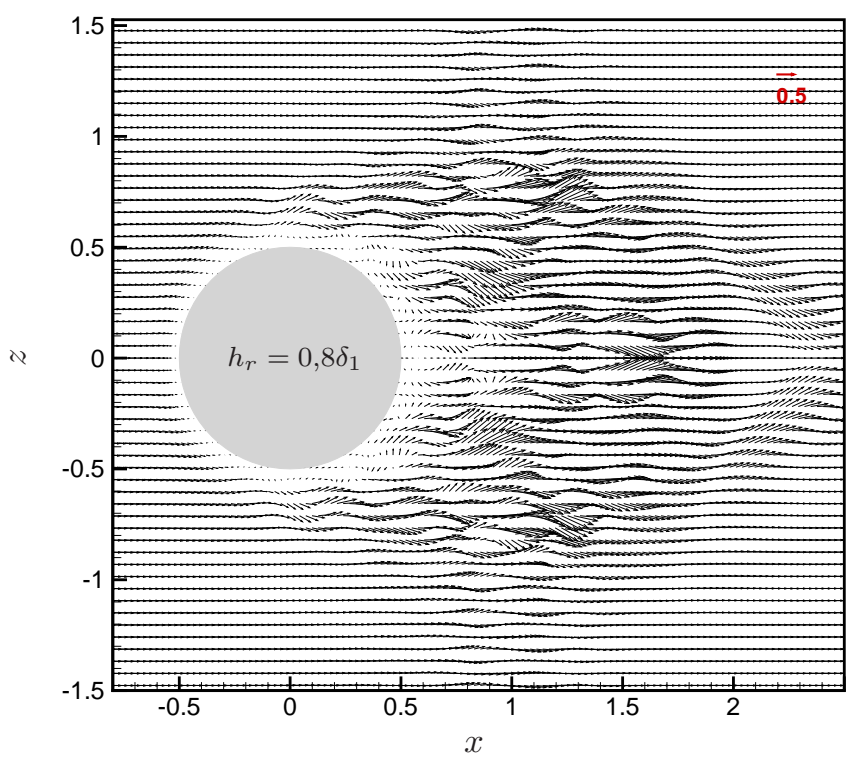

Figura 5.30: Distribuição de $u$ e $w$ como vetores em $y=0,7$, para o caso P0 com $h_{r}=0,8 \delta_{1}$.

se afasta da superfície, passando de $y \approx 0,12$, no caso com $h_{r}=0,7 \delta_{1}$ (figura 5.27a), para $y \approx 0,2$, no caso com $h_{r}=0,8 \delta_{1}$.

A BSJR, centrada em $x \approx 0,81$ e $y \approx 0,5$, pode ser vista na figura 5.31b. Em comparação com o caso anterior, essa bolha está mais próxima da rugosidade e mais afastada da superfície. O vórtice transversal formado no topo da rugosidade, com centro em $x \approx 0,45$ e $y \approx 0,73$, também pode ser visto na figura 5.31b. Porém, devido ao estado transiente do escoamento, estas estruturas não têm mais posição fixa.

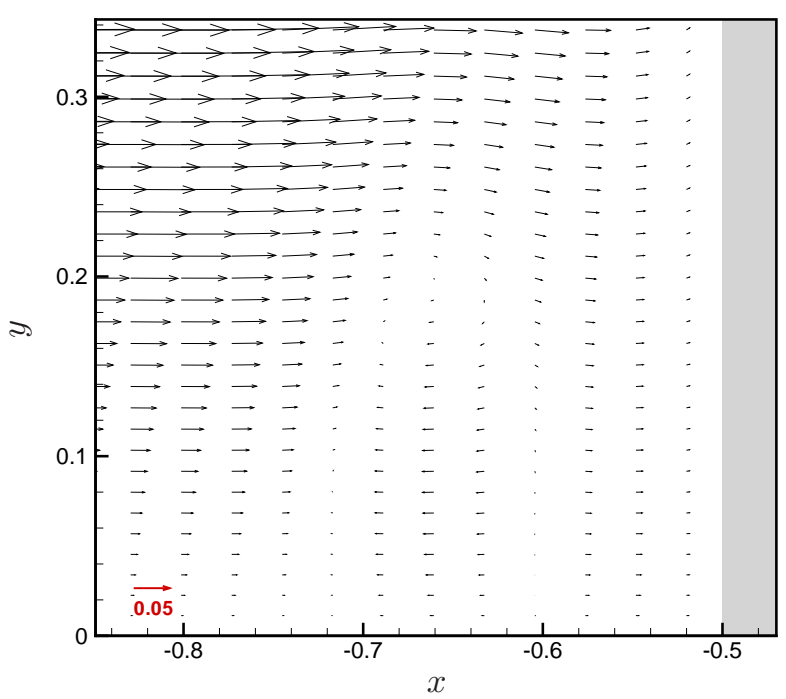

(a) A montante da rugosidade.

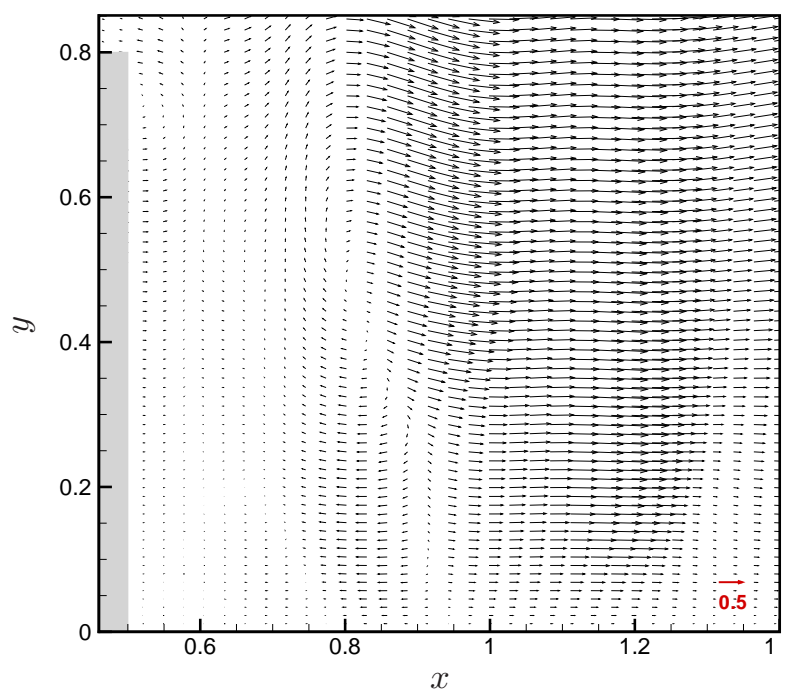

(b) A jusante da rugosidade.

Figura 5.31: Distribuição de $u$ e $v$ como vetores em $z=0$, para o caso P0 com $h_{r}=0,8 \delta_{1}$. 


\section{1 - Escoamento contendo rugosidade}

Os efeitos das estruturas do escoamento sobre o perfil de velocidade é mais evidente, como mostrado na figura 5.32. Esse efeito se estende tanto na direção longitudinal quanto na direção normal à superfície.

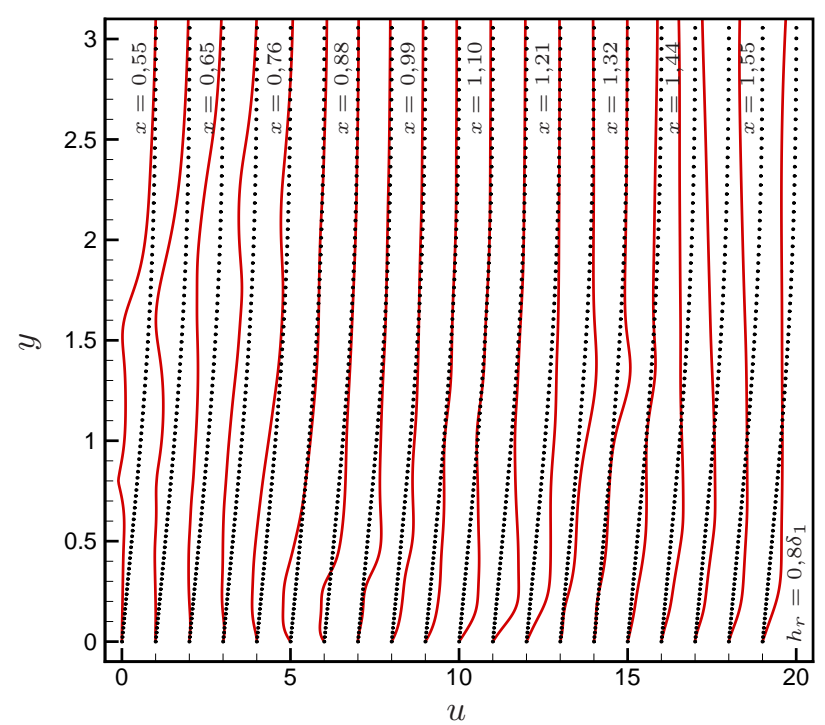

Figura 5.32: Perfil de $u$ normal à superfície em $z=0$, para o caso $\mathrm{P} 0 \operatorname{com} h_{r}=0,8 \delta_{1}$.

Os resultados das simulações com altura de rugosidade $h_{r}=0,8 \delta_{1}$ mostram que a protuberância exerce grande influência no escoamento, gerando perturbações mais intensas, que levam o escoamento a transicionar.

\subsubsection{Rugosidade com altura $h_{r}=0,9 \delta_{1}$}

Nesta seção são apresentados os resultados obtidos com $h_{r}=0,9 \delta_{1}$. Esses resultados são mostrados nas figuras de 5.33 a 5.36. Para este caso, foram rodados 154880 passos no tempo.

Para esta altura de rugosidade, pode-se perceber que o escoamento está transicionando. Já não se consegue mais identificar as estruturas vorticais separadamente, como pode ser observado na figura 5.33. Devido ao maior tempo de simulação, comparado ao caso anterior, com $h_{r}=0,8 \delta_{1}$, pode-se notar que as estruturas se estendem por uma distância maior na direção longitudinal.

A figura 5.34 também mostra o aumento das oscilações no escoamento. Essas oscilações se propagam nas direções longitudinal e transversal.

$\mathrm{Na}$ figura $5.35 \mathrm{a}$ pode-se ver o VTFMR, com centro em $x \approx 0,66$ e $y \approx 0,26$. Novamente, a posição $x$ desse vórtice se mantém a mesma do caso anterior e a posição $y$ é maior do que no caso $\operatorname{com} h_{r}=0,8 \delta_{1}$.

A BSJR pode ser notada na figura 5.35b, com centro em $x \approx 0,75 \mathrm{e} y \approx 0,3 \mathrm{e}$ girando no sentido 

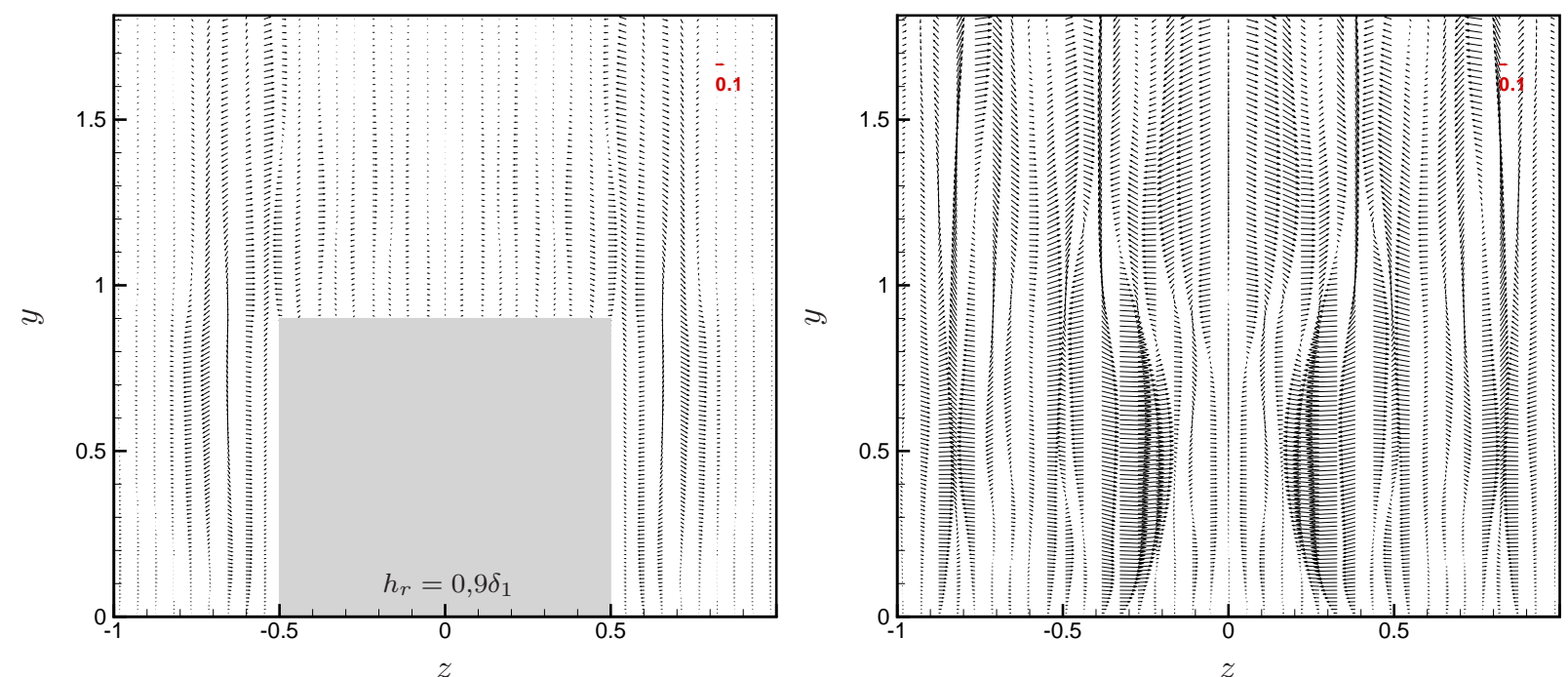

(a) $x=0,0$

(b) $x=0,6$
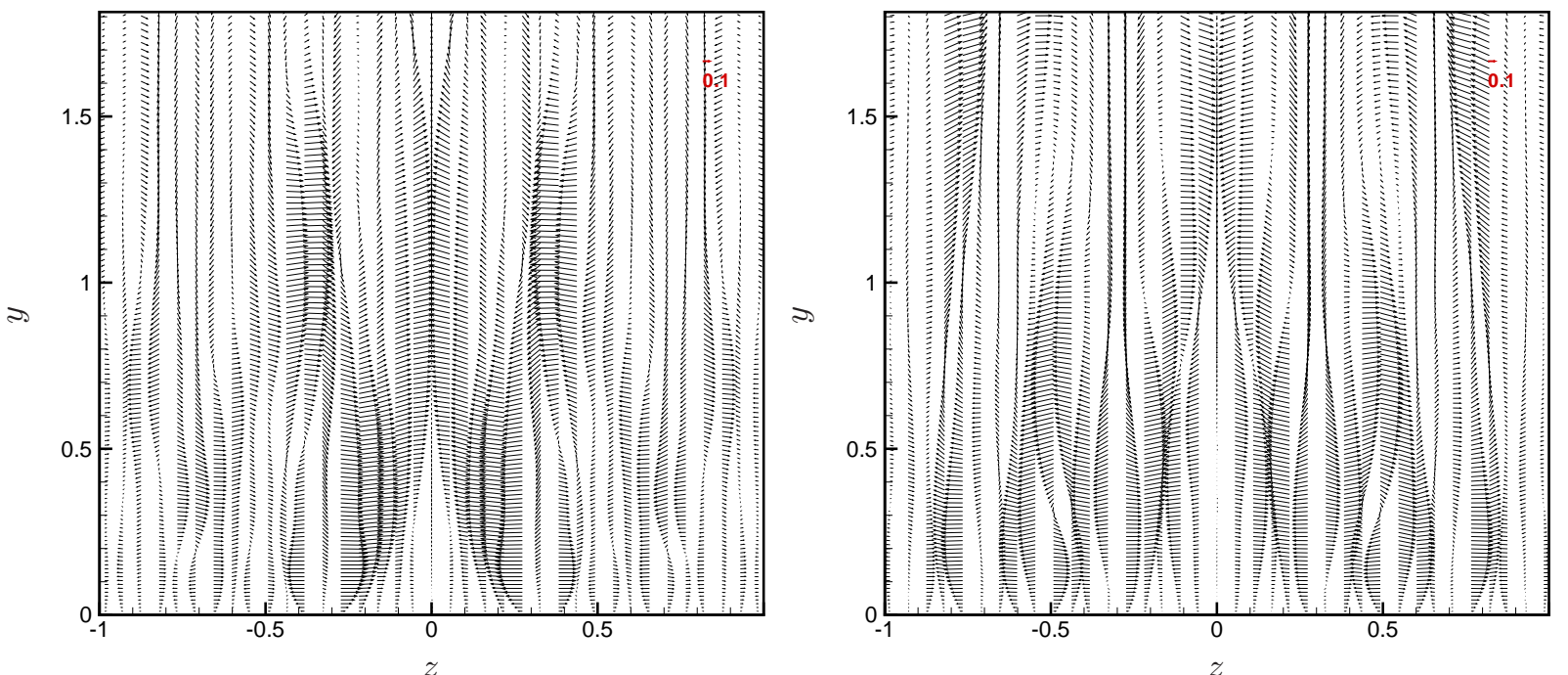

(c) $x=0,8$

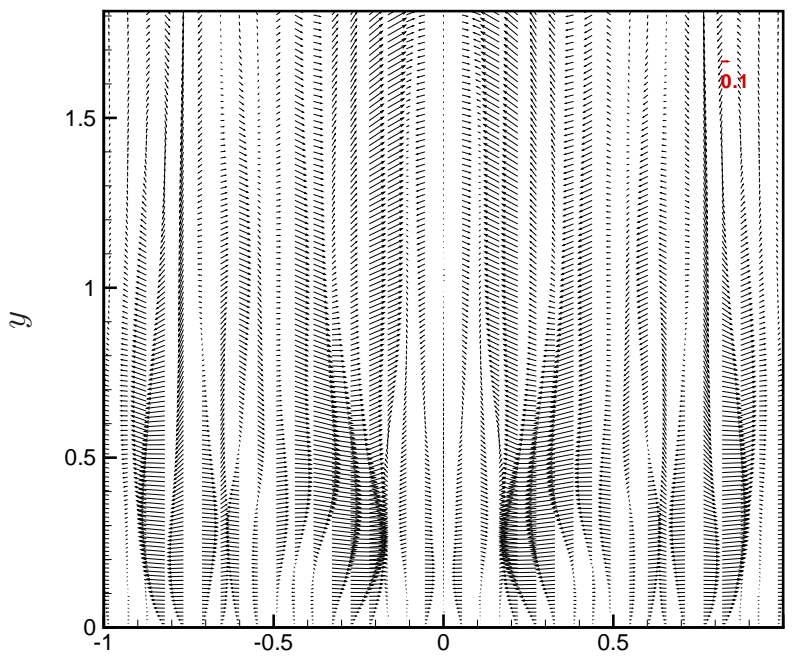

(d) $x=1,0$

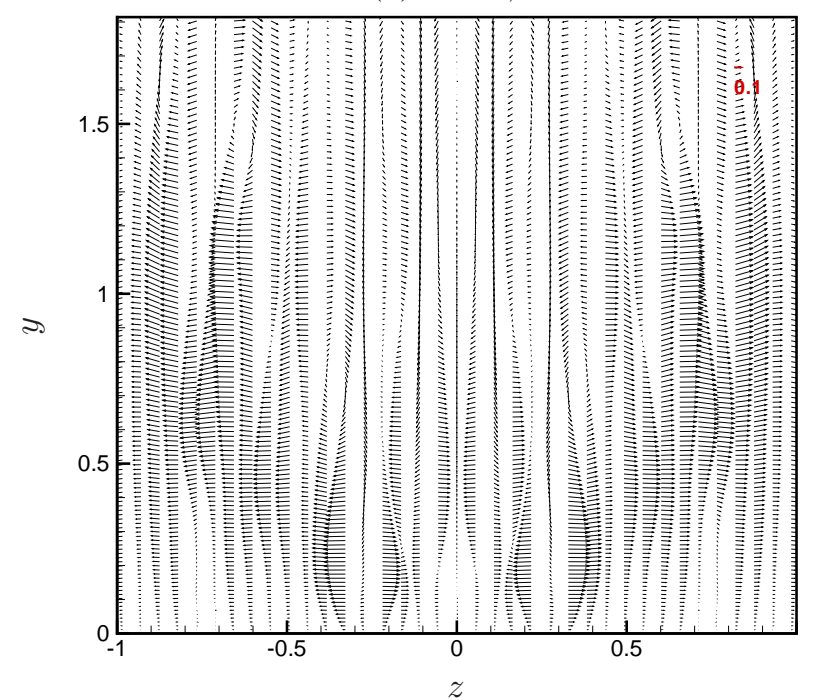

(e) $x=1,2$

(f) $x=1,4$

Figura 5.33: Distribuição de $v$ e $w$ como vetores, em diferentes posições $x$, para o caso P0 com $h_{r}=0,9 \delta_{1}$. 


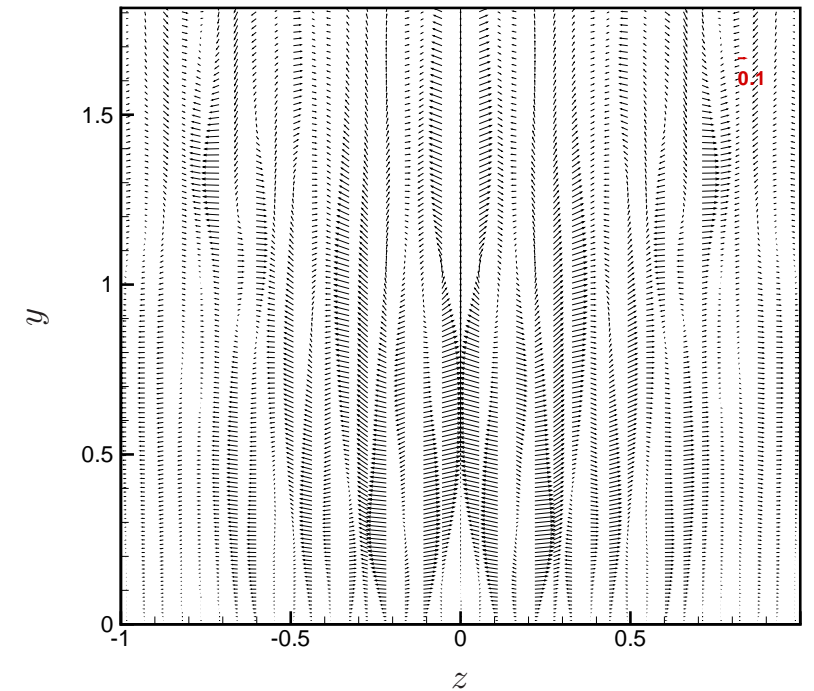

(g) $x=1,6$

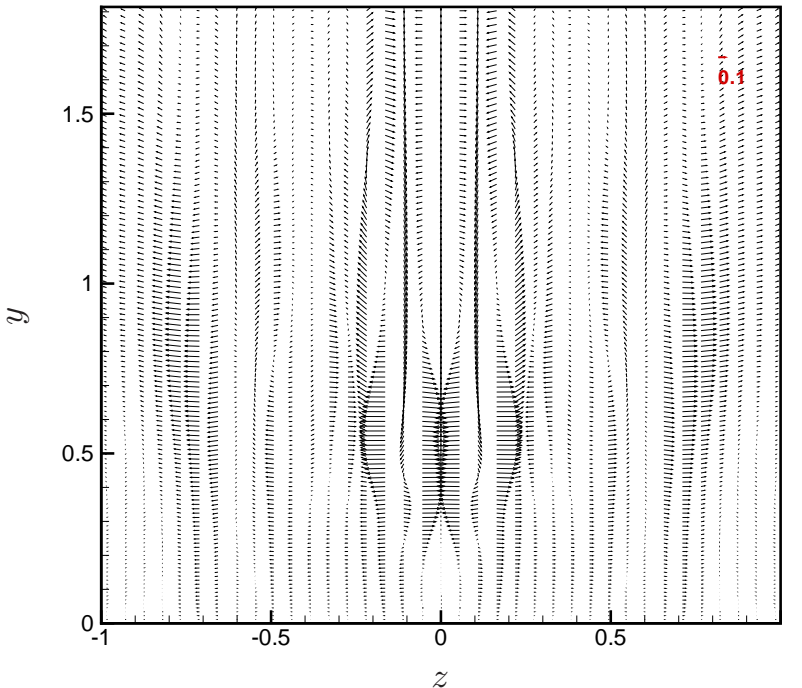

(h) $x=1,8$

Figura 5.33: Distribuição de $v$ e $w$ como vetores, em diferentes posições $x$, para o caso $\mathrm{P} 0$ com $h_{r}=0,9 \delta_{1}$ (cont.).

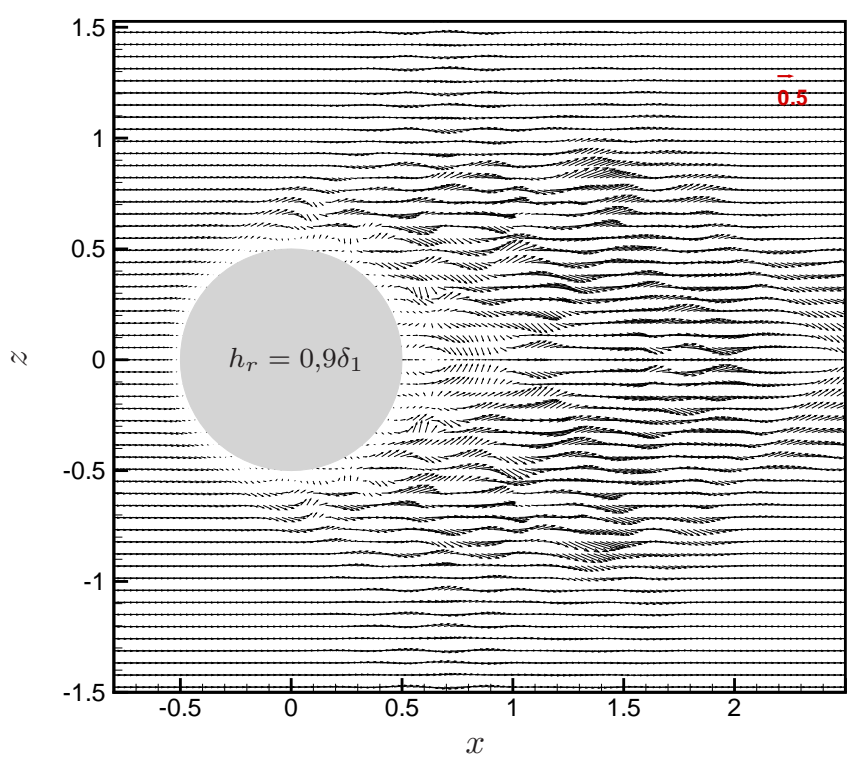

Figura 5.34: Distribuição de $u$ e $w$ como vetores em $y=0,8$, para o caso P0 com $h_{r}=0,9 \delta_{1}$. 
horário. Esta bolha está mais próxima da rugosidade e da superfície, comparada ao caso anterior.

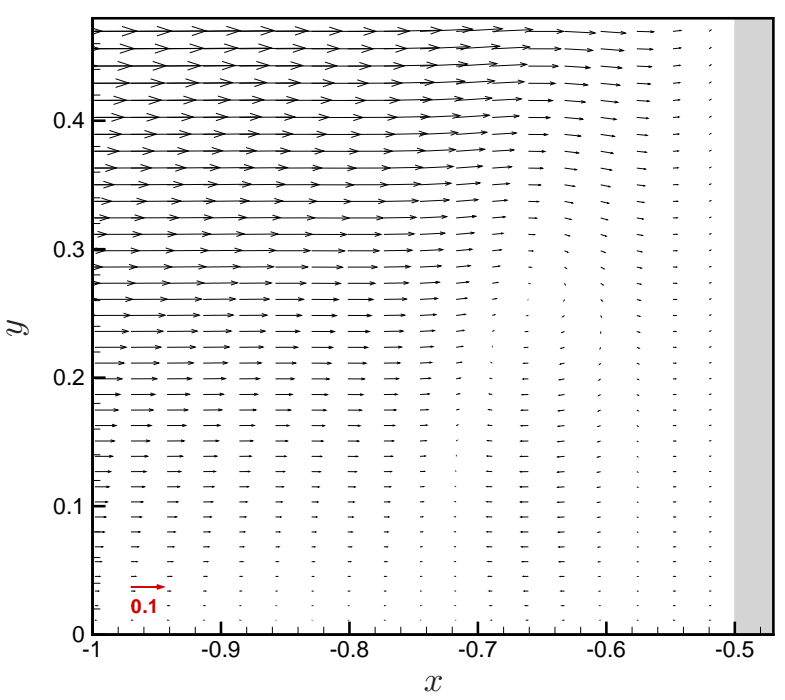

(a) A montante da rugosidade.

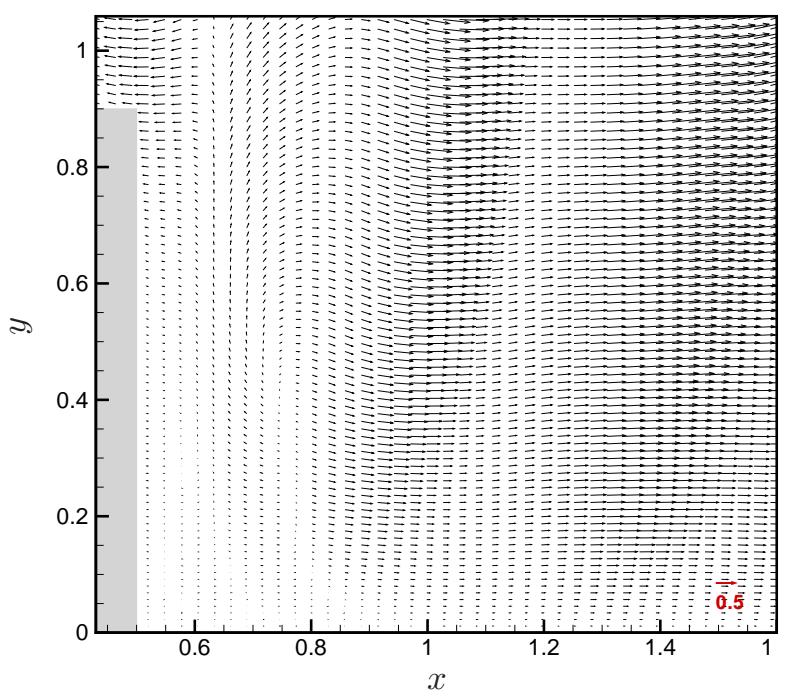

(b) A jusante da rugosidade.

Figura 5.35: Distribuição de $u$ e $v$ como vetores em $z=0$, para o caso P0 com $h_{r}=0,9 \delta_{1}$.

Na figura 5.36 são mostrados os efeitos das perturbações causadas pela presença da rugosidade no perfil de $u$. Pode-se notar que o perfil de velocidade está bem diferente do perfil do escoamento base (linha pontilhada), apresentando perfis inflexionais.

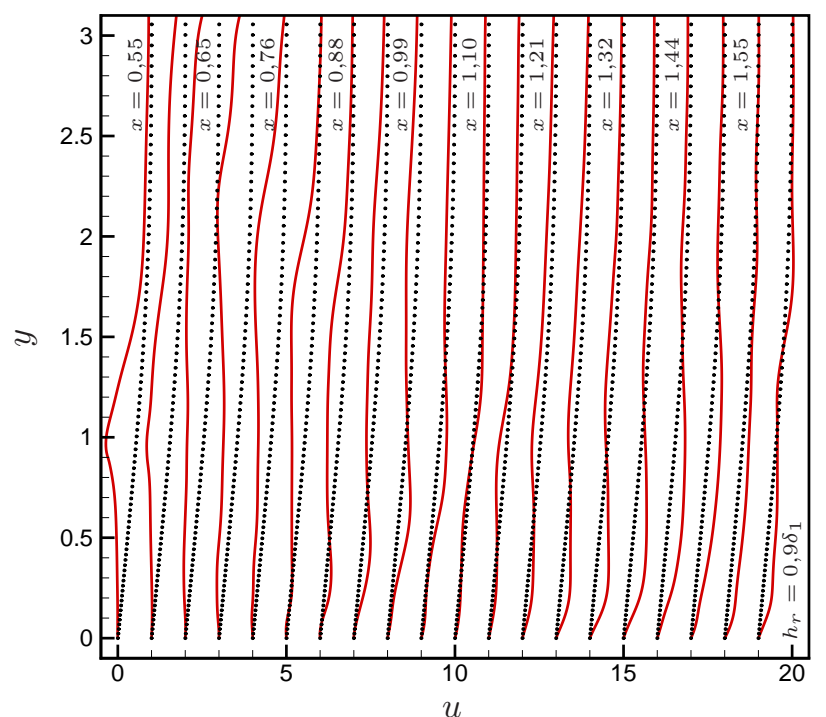

Figura 5.36: Perfil de $u$ normal à superfície em $z=0$, para o caso P0 com $h_{r}=0,9 \delta_{1}$.

$\mathrm{O}$ aumento na altura da rugosidade gera um aumento nas perturbações no escoamento, levando-o a transicionar para o regime turbulento. Tal fato, acontece para rugosidade com altura $h_{r}=0,9 \delta_{1}$. 


\subsubsection{Rugosidade com altura $h_{r}=1,0 \delta_{1}$}

Nesta seção são apresentados os resultados obtidos com $h_{r}=1,0 \delta_{1}$. Esses resultados são mostrados nas figuras de 5.37 a 5.40. Para este caso, foram rodados 167680 passos no tempo.

Assim como no caso anterior, com $h_{r}=0,9$, o escoamento está passando de laminar para turbulento. Isso pode ser visto na figura 5.37. Nesta figura, não se pode mais identificar separadamente as estruturas vorticais.

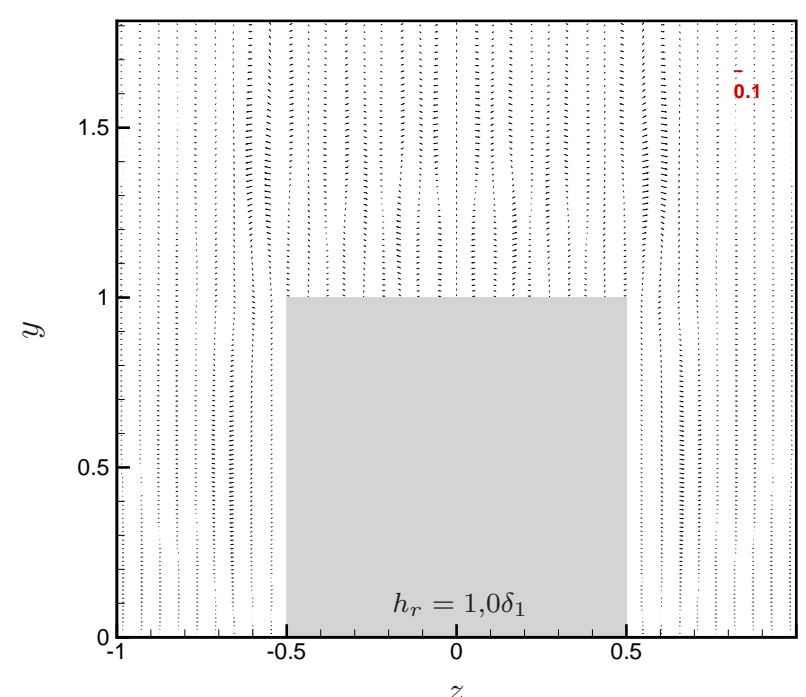

(a) $x=0,0$

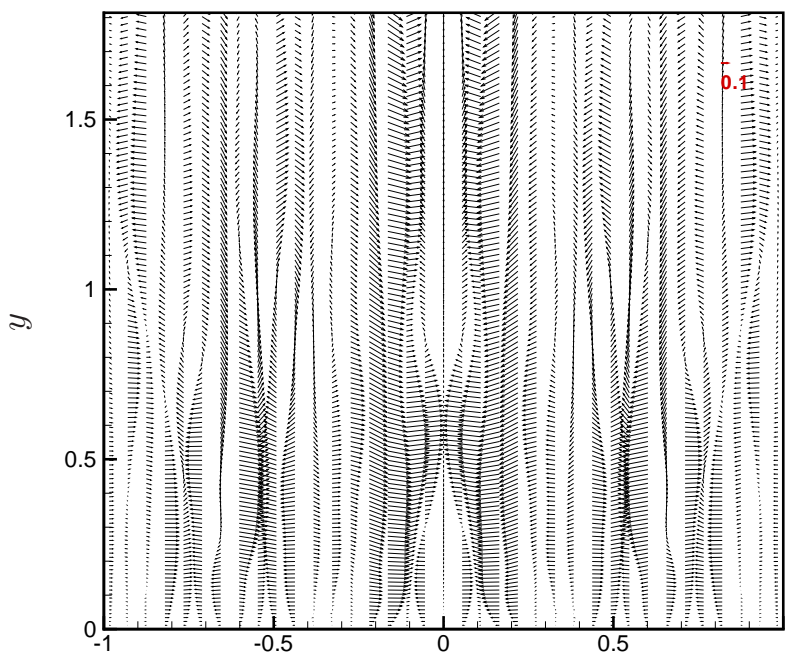

(c) $x=0,8$

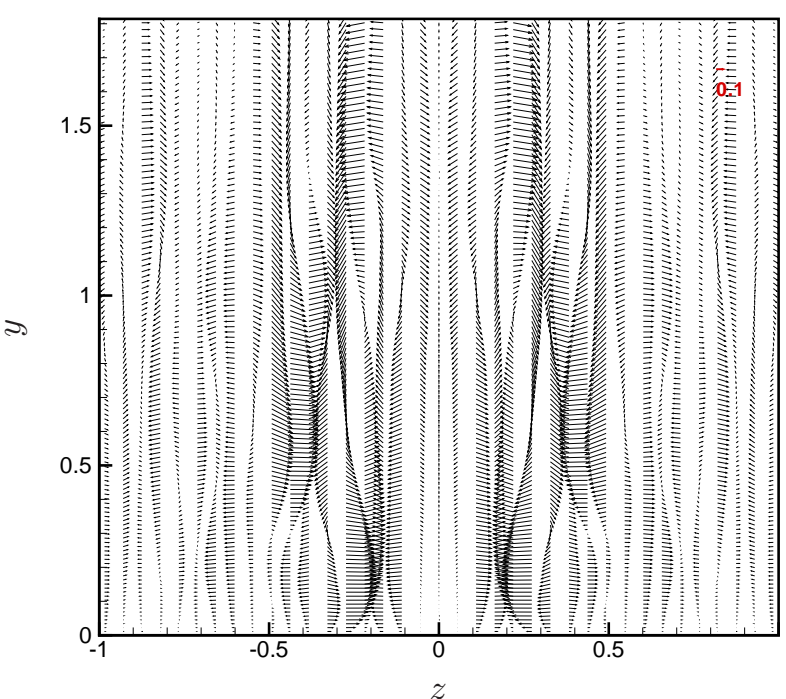

(b) $x=0,6$

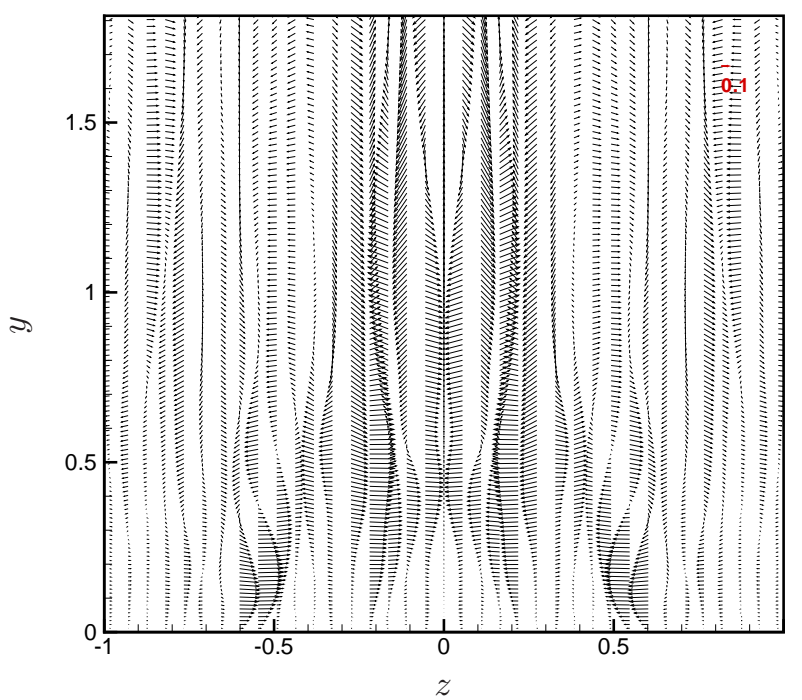

(d) $x=1,0$

Figura 5.37: Distribuição de $v$ e $w$ como vetores, em diferentes posições $x$, para o caso $\mathrm{P} 0$ com $h_{r}=1,0 \delta_{1}$.

Na figura 5.38 pode-se ver que a área afetada a partir da protuberância é maior do que nos casos anteriores. Pode-se também notar a semelhança com o que ocorre na figura 1.2.

As únicas estruturas que ainda podem ser identificadas são o VTFMR e a BSJR, que podem 


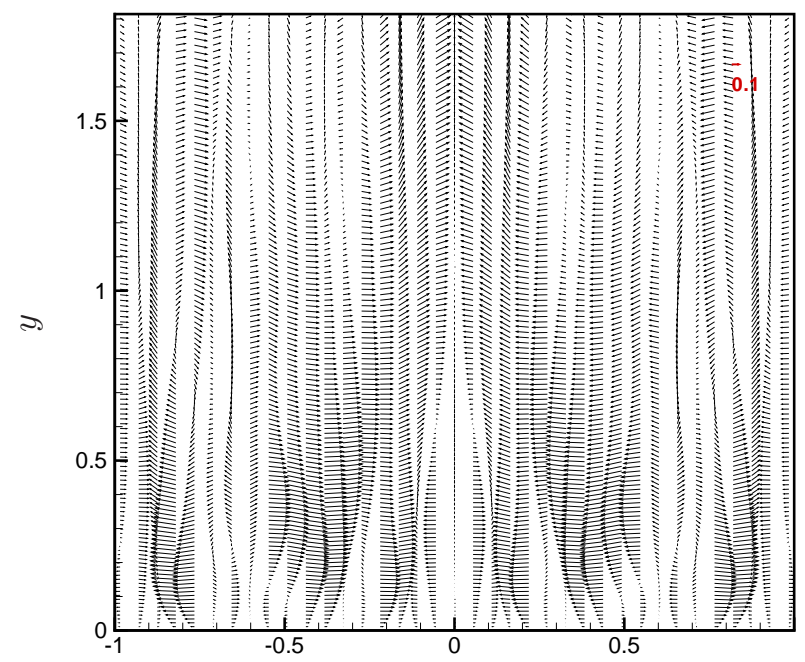

(e) $\stackrel{z}{x=1,2}$

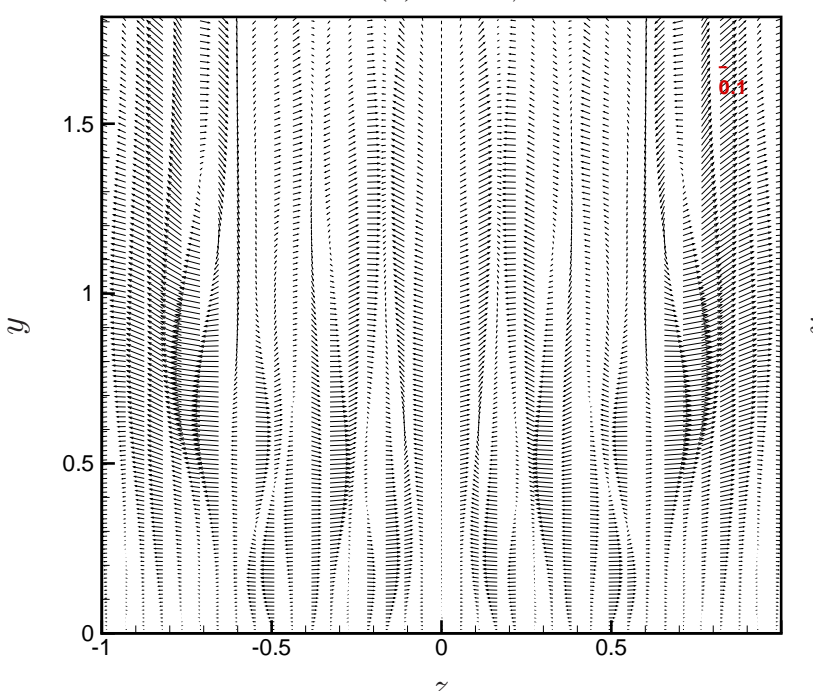

(g) $x=1,6$

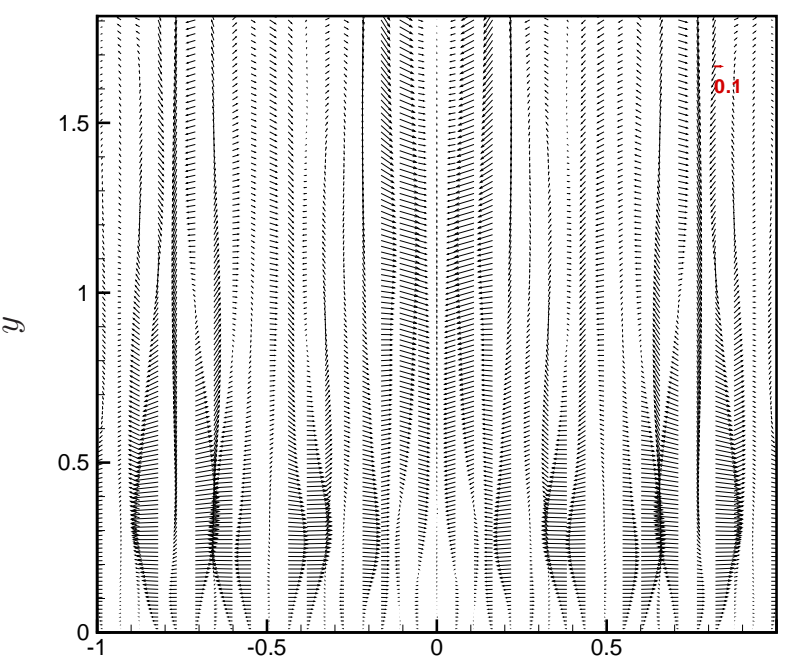

(f) $x=1,4$

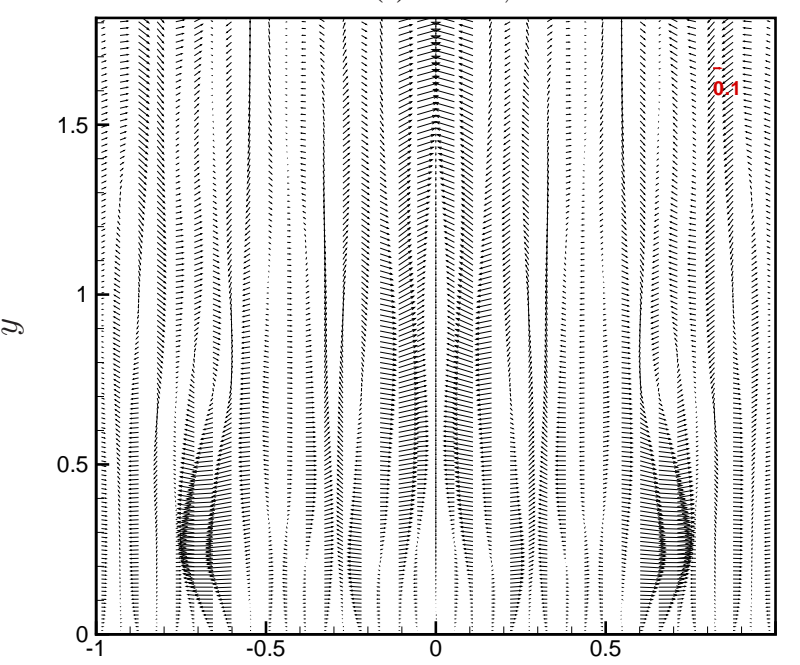

(h) $x=1,8$

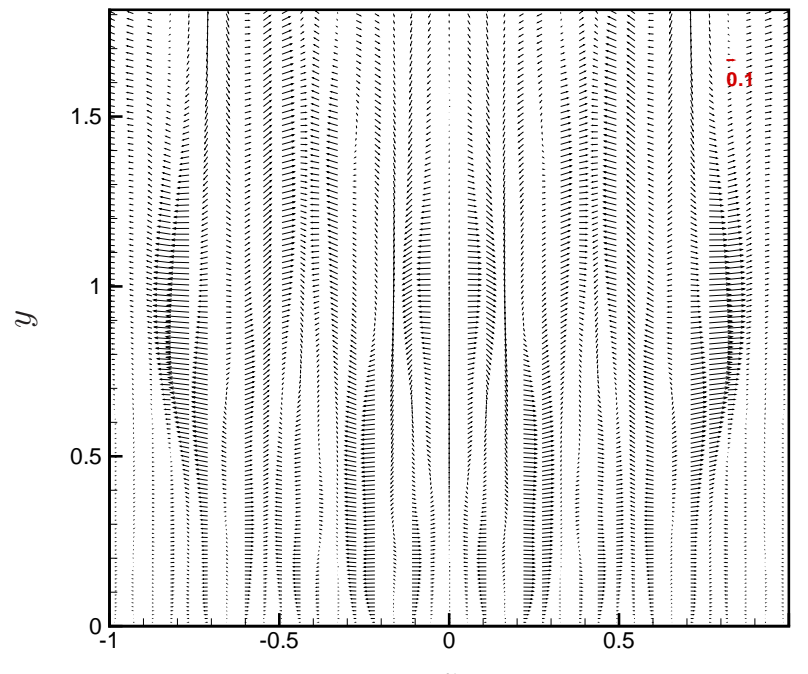

(i) $\stackrel{z}{=} 2,0$

Figura 5.37: Distribuição de $v$ e $w$ como vetores, em diferentes posições $x$, para o caso P0 com $h_{r}=1,0 \delta_{1}$ (cont.). 


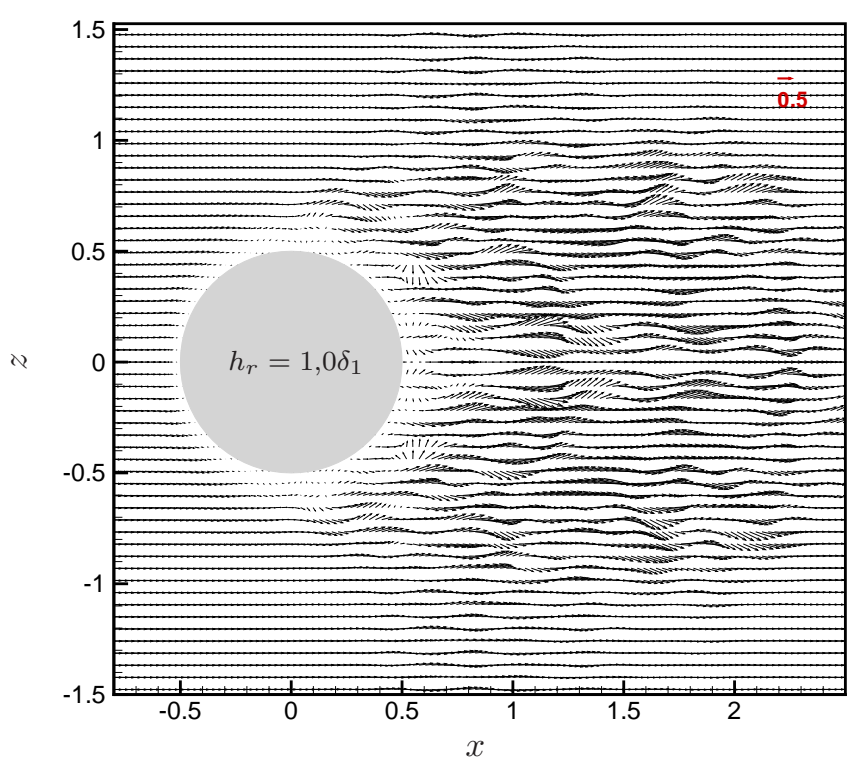

Figura 5.38: Distribuição de $u$ e $w$ como vetores em $y=0,9$, para o caso P0 com $h_{r}=1,0 \delta_{1}$.

ser vistas nas figuras 5.39a e 5.39b, respectivamente. O VTFMR mantém a distância em relação à rugosidade, aumentando a distância em relação à superfície para $y \approx 0,32$. Na figura 5.39a pode-se também notar a redução da velocidade a montante do VTFMR, em $x \approx-0,82$. Isso sugere a formação de um segundo VTFMR. A BSJR está em $x \approx 0,63$ e $y \approx 0,45$. Em comparação com o caso anterior, essa bolha está mais próxima da rugosidade e mais afastada da superfície.

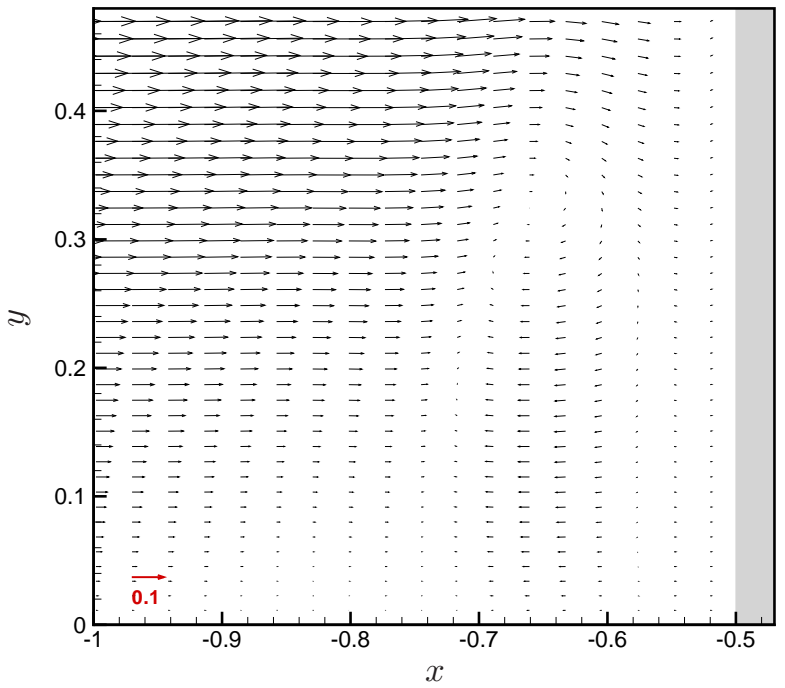

(a) A montante da rugosidade.

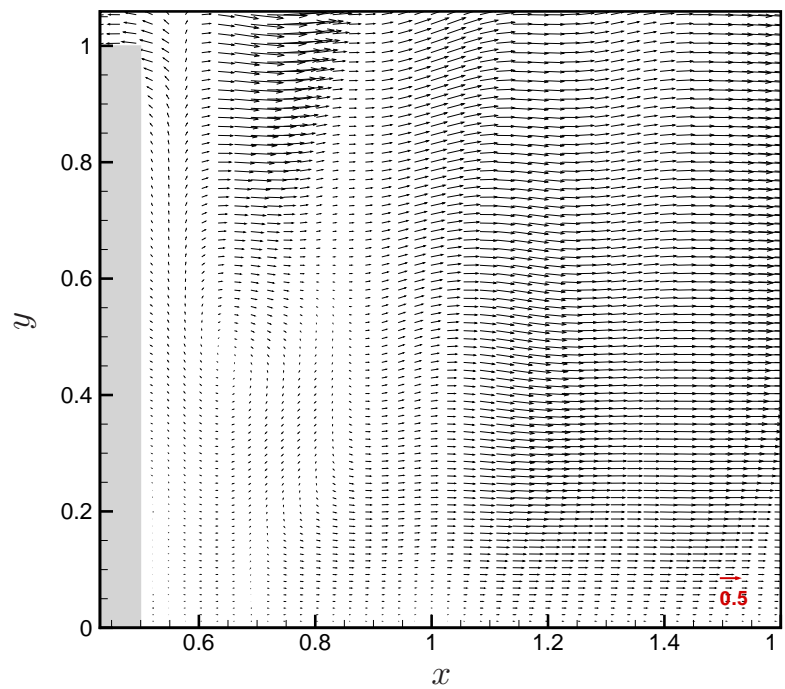

(b) A jusante da rugosidade.

Figura 5.39: Distribuição de $u$ e $v$ como vetores em $z=0$, para o caso P0 com $h_{r}=1,0 \delta_{1}$.

Os efeitos das estruturas vorticais no perfil de velocidade não estão mais bem definidos e podem ser vistos na figura 5.40. Pode-se notar que o perfil apresenta inflexões, o que caracteriza a transição 
para o regime turbulento.

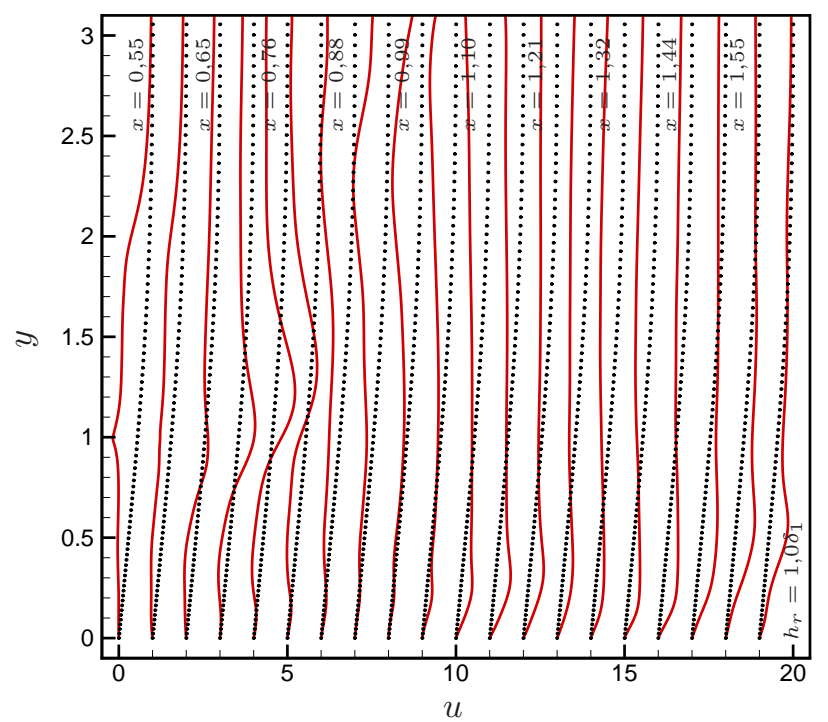

Figura 5.40: Perfil de $u$ normal à superfície em $z=0$, para o caso P0 com $h_{r}=1,0 \delta_{1}$.

A altura de rugosidade $h_{r}=1,0$ é uma altura crítica, capaz de levar o escoamento a transicionar para a turbulência.

\subsubsection{Caso PA - escoamento com gradiente de pressão adverso}

Para o escoamento com gradiente de pressão adverso foram consideradas três alturas de rugosidade: $0,4 \delta_{1}, 0,5 \delta_{1}$ e $0,6 \delta_{1}$. Na direção longitudinal, o centro da rugosidade está localizado a 6 (18) diâmetros da região de relaminarização do início (saída) do domínio.

Os resultados são mostradas nas seções a seguir, para cada altura de rugosidade.

\subsubsection{Rugosidade com altura $h_{r}=0,4 \delta_{1}$}

Nesta seção são apresentados os resultados obtidos com $h_{r}=0,4 \delta_{1}$. Esses resultados são mostrados nas figuras de 5.41 a 5.44. Para este caso, foram rodados 145920 passos no tempo.

Comparando-se os resultados deste caso com os resultados do caso P0, com $h_{r}=0,4 \delta_{1}$, pode-se notar, nas figuras 5.13 e 5.41, que as estruturas vorticais do caso PA são mais evidentes. Isso se deve ao efeito do gradiente de pressão, que deixa o escoamento mais instável.

O aumento na instabilidade do escoamento do caso PA, em relação ao caso P0, também pode ser observada na figura 5.42. Nesta figura, as oscilações laterais a jusante da rugosidade são mais evidentes.

Assim como no caso P0 com mesma altura de rugosidade, pode-se ver, na figura 5.43a, a redução 

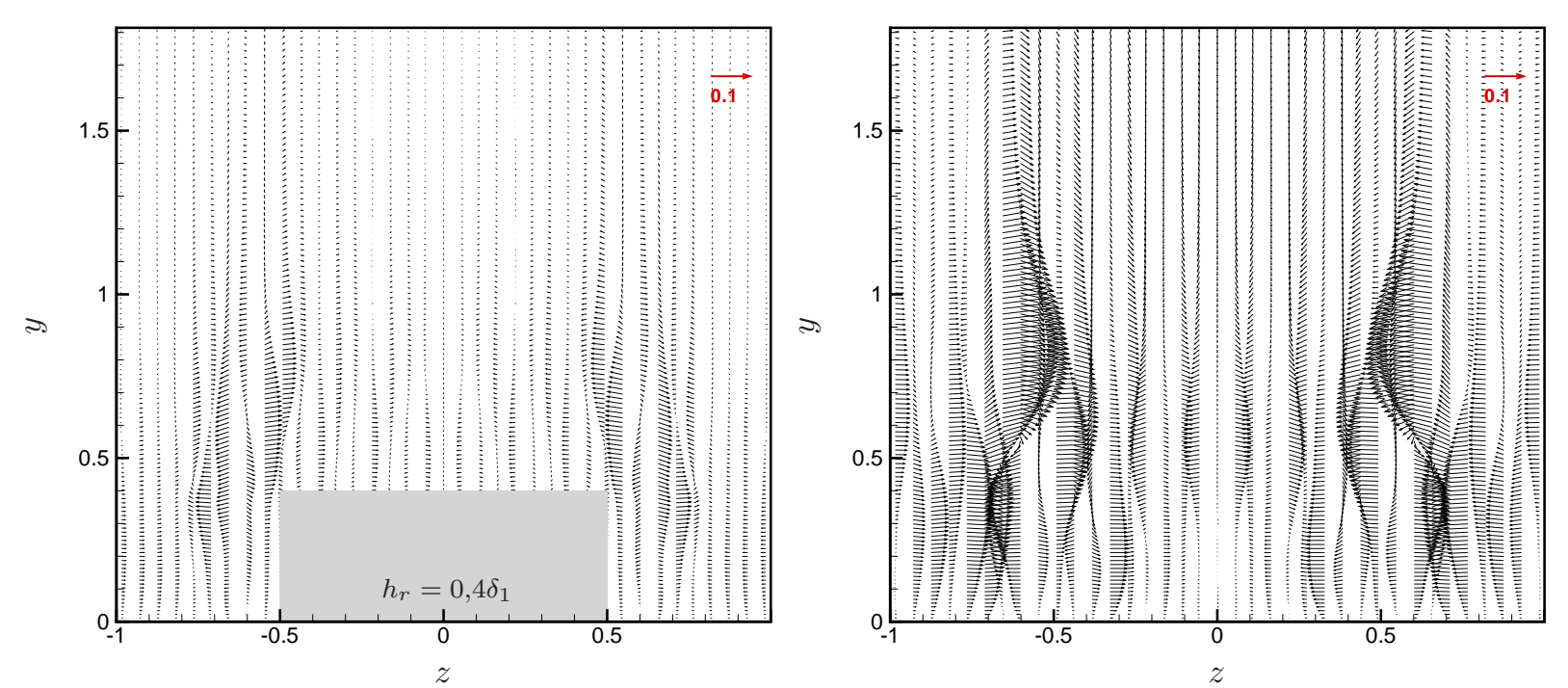

(a) $x=0,0$

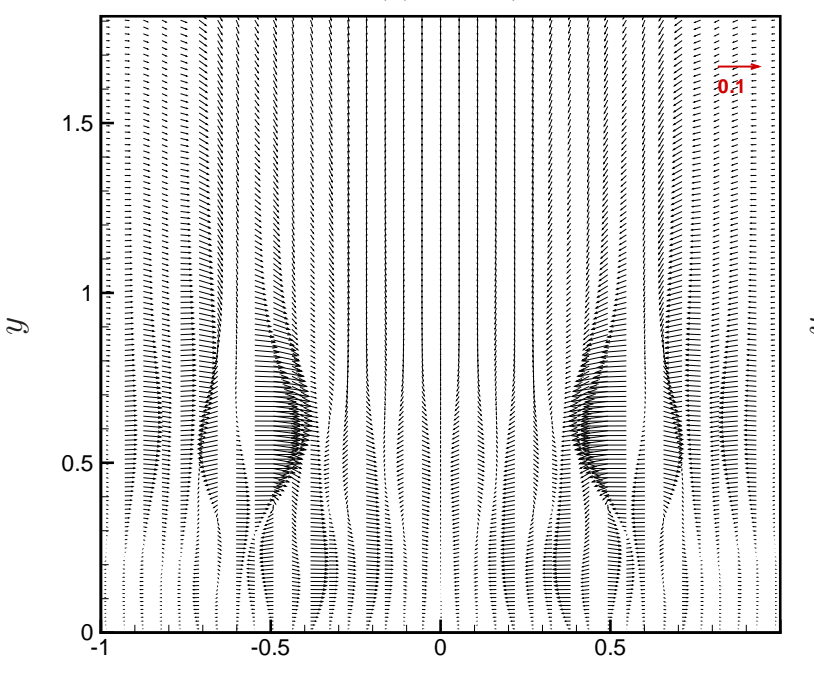

(b) $x=0,6$

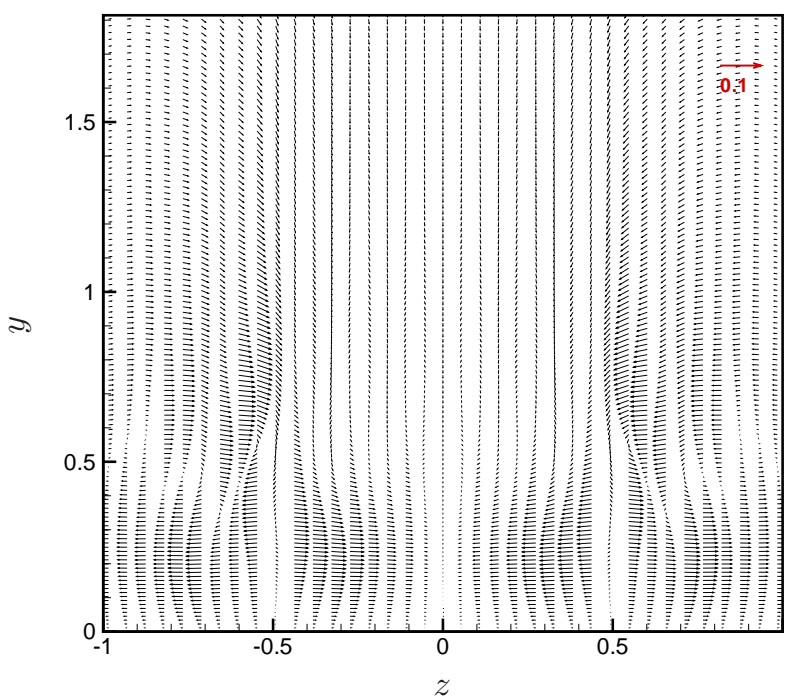

(c) $x=0,8$

(d) $x=1,0$

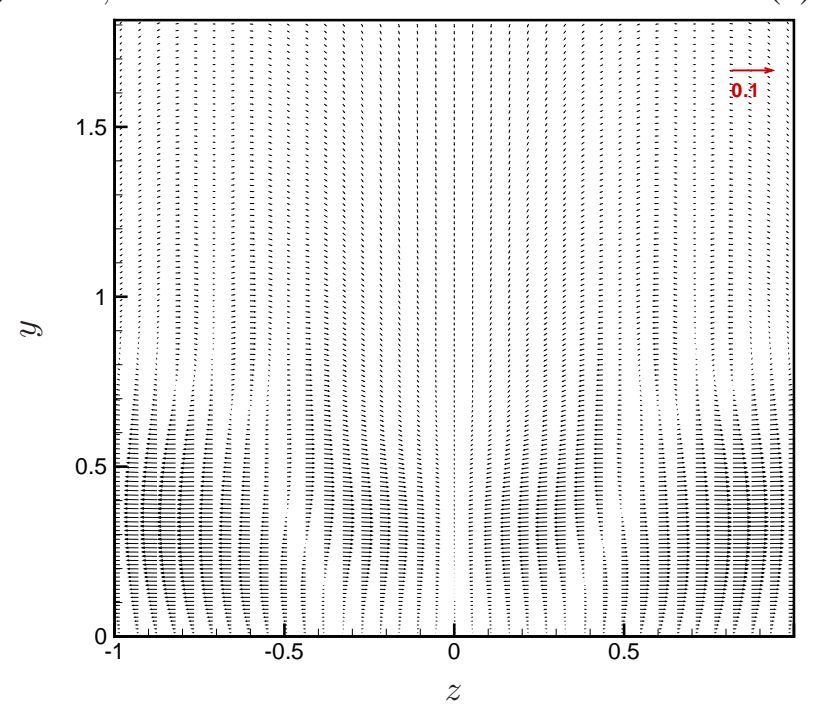

(e) $x=1,2$

Figura 5.41: Distribuição de $v$ e $w$ como vetores, em diferentes posições $x$, para o caso PA com $h_{r}=0,4 \delta_{1}$. 


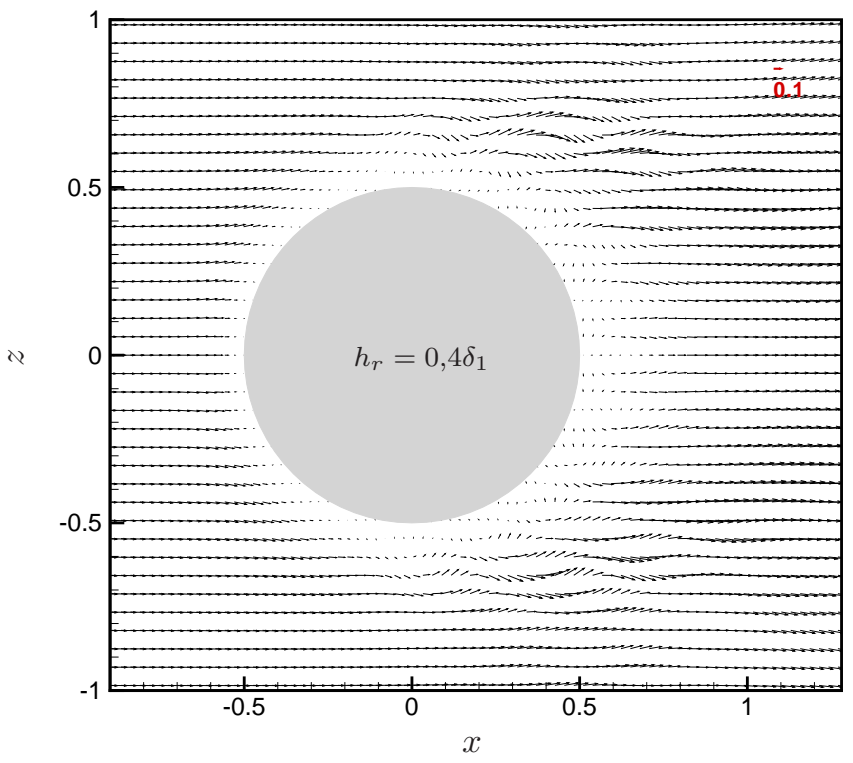

Figura 5.42: Distribuição de $u$ e $w$ como vetores em $y=0,3$, para o caso PA com $h_{r}=0,4 \delta_{1}$.

da velocidade a montante da rugosidade, em $x \approx 0,69$. Essa região é semelhante nos dois casos.

Para este caso, não se nota a formação da BSJR, como pode ser visto nas figura 5.43b. O comportamento do fluido a jusante da rugosidade sugere a presença mais forte do escoamento de maior velocidade que vem das laterais da protuberância, em direção ao centro do domínio na direção transversal.

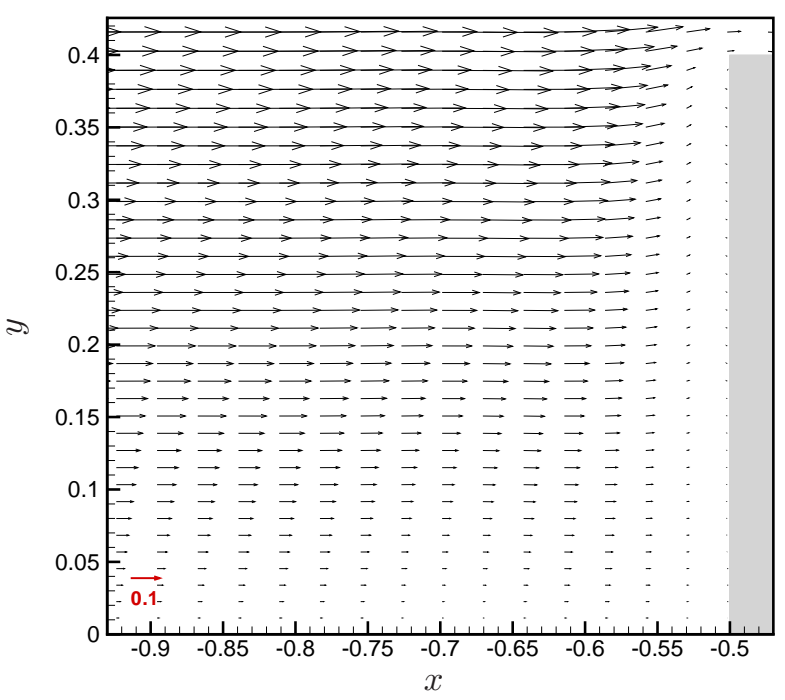

(a) A montante da rugosidade.

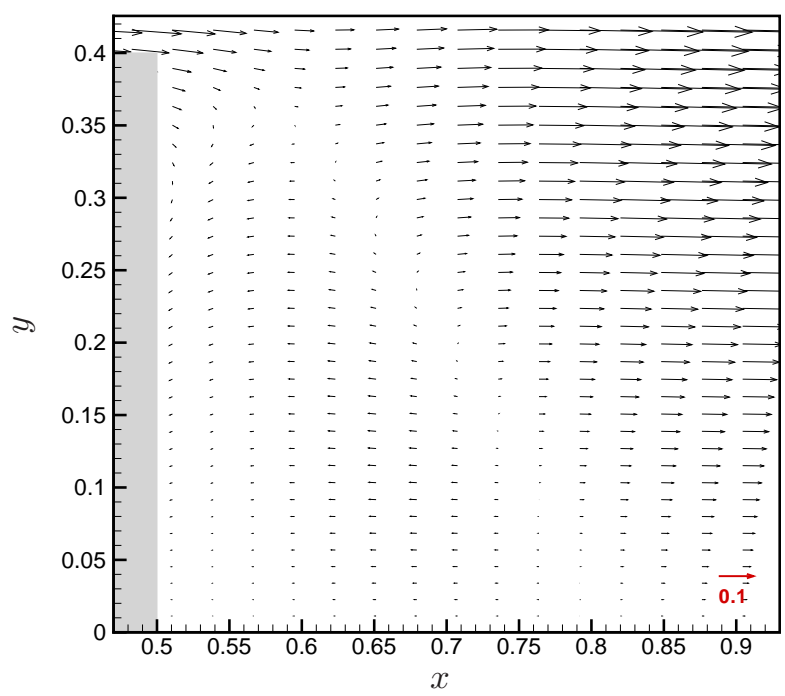

(b) A jusante da rugosidade.

Figura 5.43: Distribuição de $u$ e $v$ como vetores em $z=0$, para o caso PA com $h_{r}=0,4 \delta_{1}$.

A deformação do perfil de velocidade, mostrada na figura 5.44, é maior para o caso PA, em comparação com o caso P0. Essa deformação se estende por uma altura maior em relação à superfície 
e uma distância maior em relação à rugosidade.

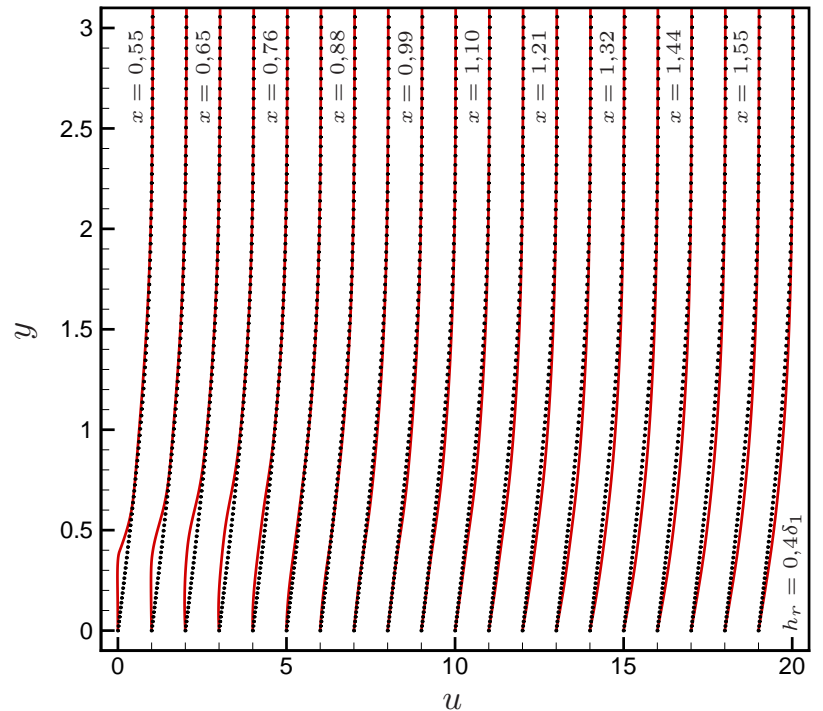

Figura 5.44: Perfil de $u$ normal à superfície em $z=0$, para o caso PA com $h_{r}=0,4 \delta_{1}$.

Os resultados deste caso mostram que o efeito do gradiente de pressão pode ser comparado ao efeito de se aumentar a altura da protuberância, deixando assim o escoamento mais instável.

\subsubsection{Rugosidade com altura $h_{r}=0,5 \delta_{1}$}

Nesta seção são apresentados os resultados obtidos com $h_{r}=0,5 \delta_{1}$. Esses resultados são mostrados nas figuras de 5.45 a 5.48. Para este caso, foram rodados 170240 passos no tempo.

Comparando a figura $5.45 \mathrm{com}$ a figura 5.41, do caso com $h_{r}=0,4 \delta_{1}$, nota-se que as estruturas vorticais são semelhantes. Contudo, as velocidades para a altura de rugosidade $h_{r}=0,5 \delta_{1}$ são maiores. Em comparação com os resultados do caso P0, com mesma altura de rugosidade (figura 5.17), nota-se um aumento das perturbações no escoamento. Novamente, tal fato é atribuído ao efeito desestabilizante do gradiente de pressão adverso. Outro efeito do gradiente de pressão é a redução da velocidade no escoamento. Isso pode ser percebido na figura 5.45, em que os vetores são menores, comparados aos da figura 5.17.

Pode-se perceber também, na figura 5.46, que os efeitos tridimensionais são mais fortes do que no caso anterior (figura 5.42). Com relação ao caso P0, com altura $h_{r}=0,5 \delta_{1}$ (figura 5.18), nota-se uma redução na velocidade (vetores menores) e um aumento nas oscilações .

A redução de velocidade a montante da rugosidade, vista na figura 5.47a, é semelhante à do caso P0 com mesma altura de rugosidade (figura 5.19a) e está na mesma região do caso PA com altura $h_{r}=0,4 \delta_{1}$ (figura 5.43a). 

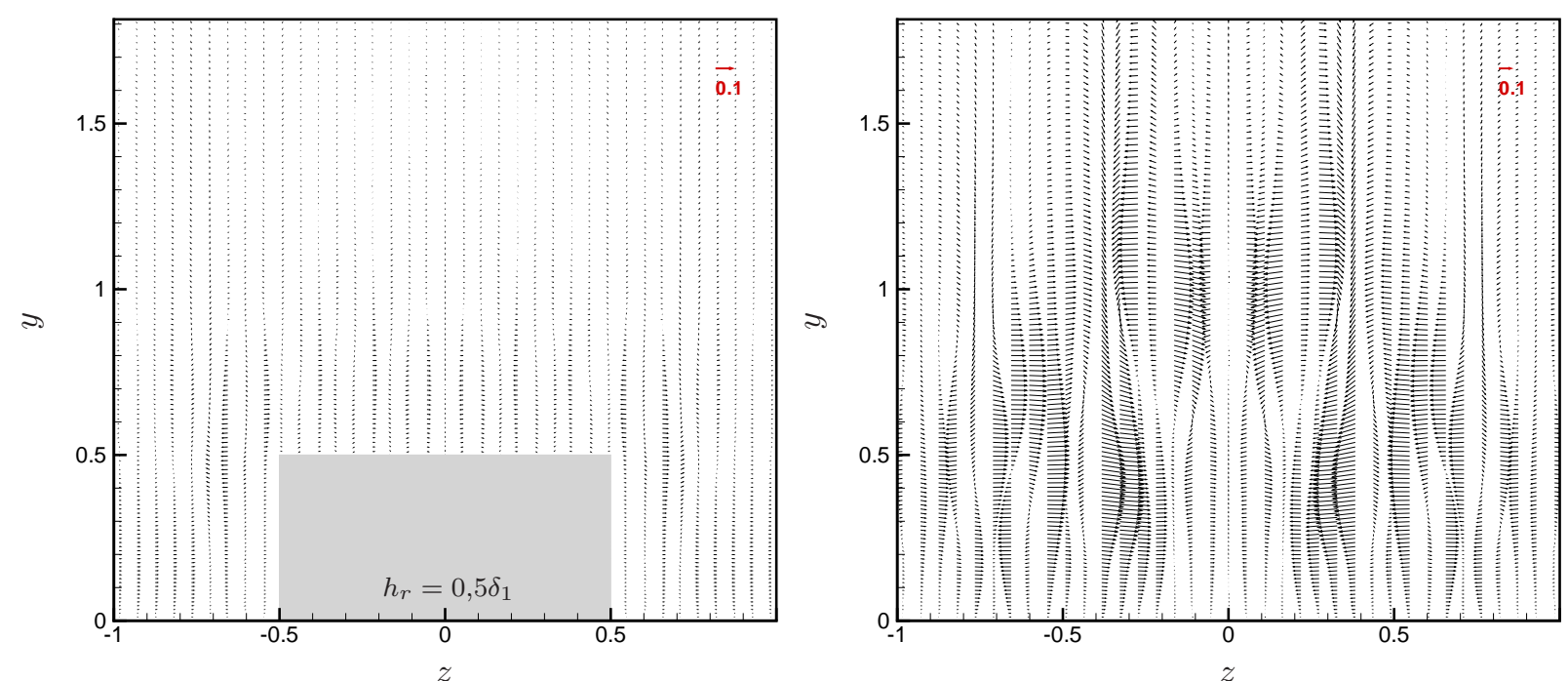

(a) $x=0,0$

(b) $x=0,6$
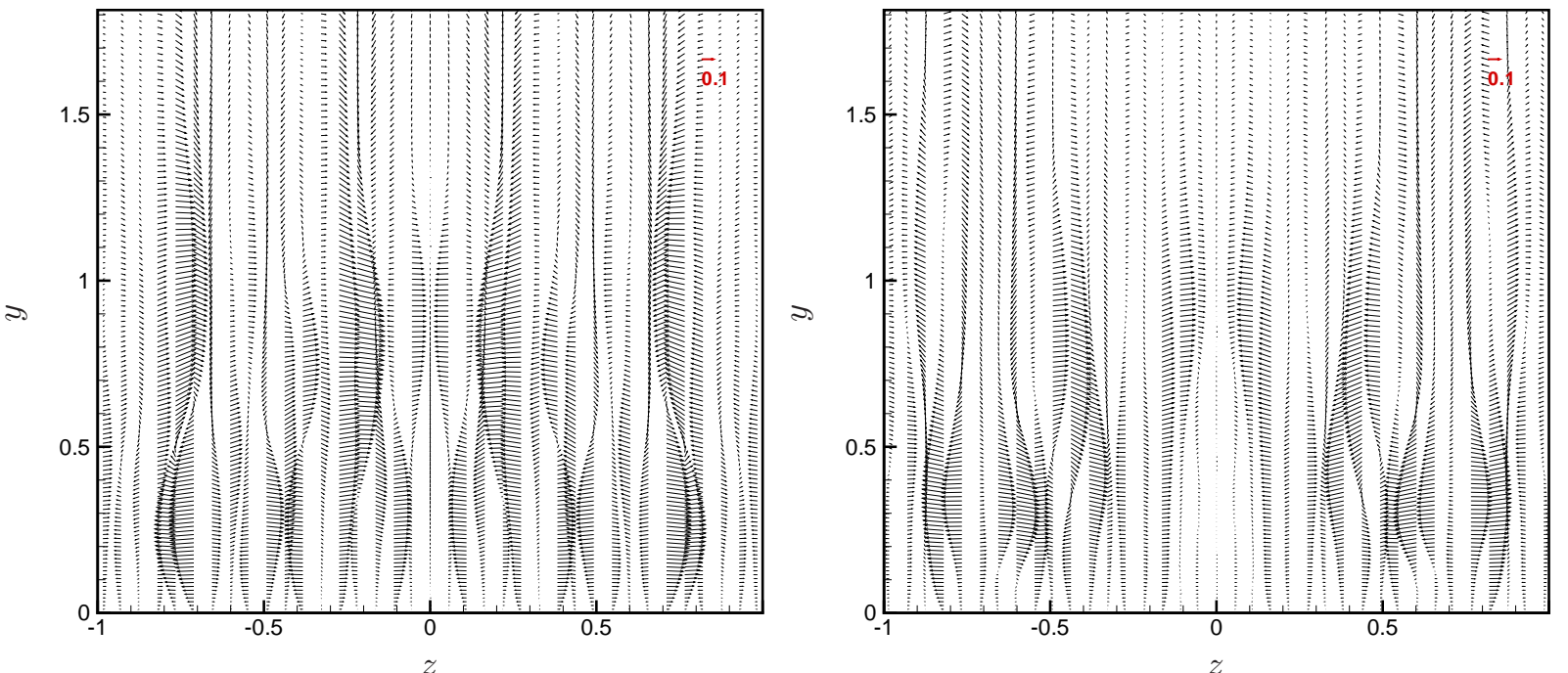

(c) $x=0,8$

(d) $x=1,0$
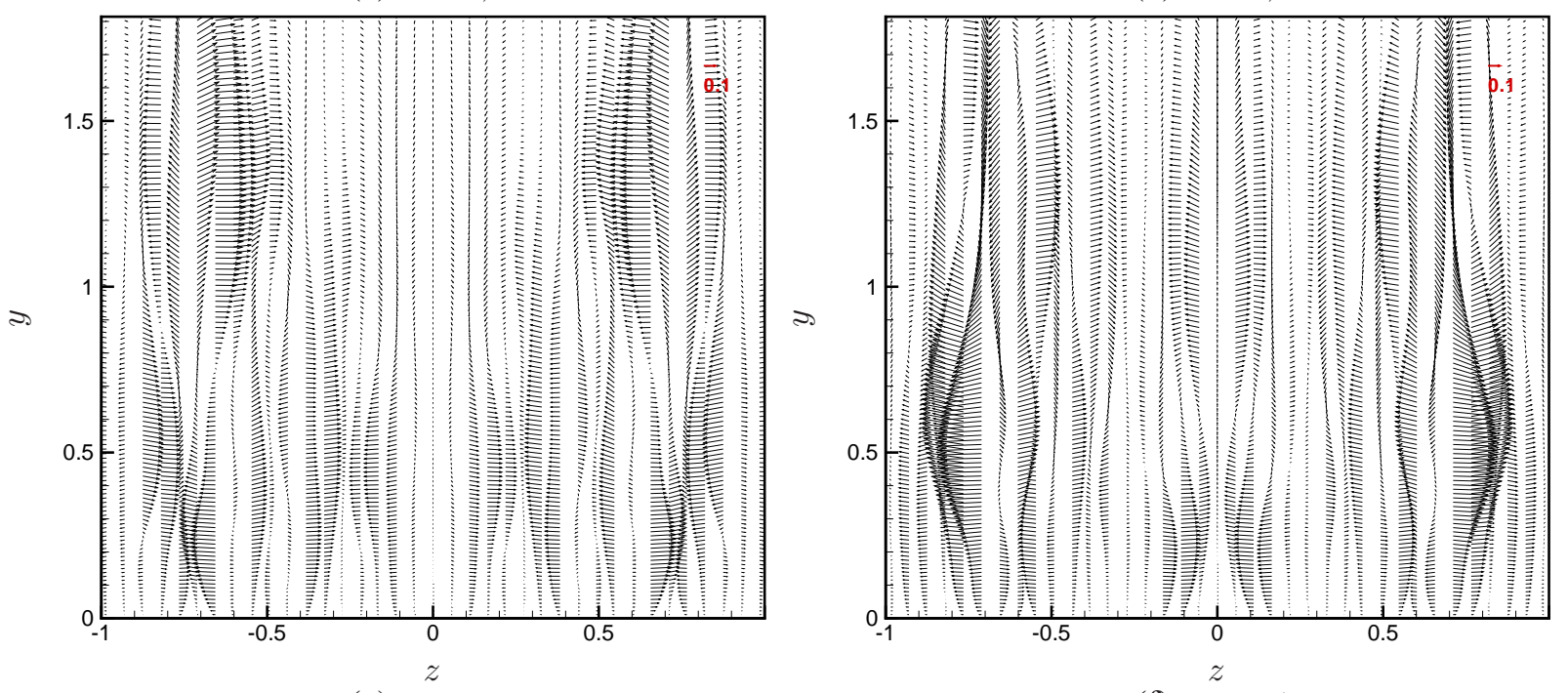

(e) $x=1,2$

(f) $x=1,4$

Figura 5.45: Distribuição de $v$ e $w$ como vetores, em diferentes posições $x$, para o caso PA com $h_{r}=0,5 \delta_{1}$. 


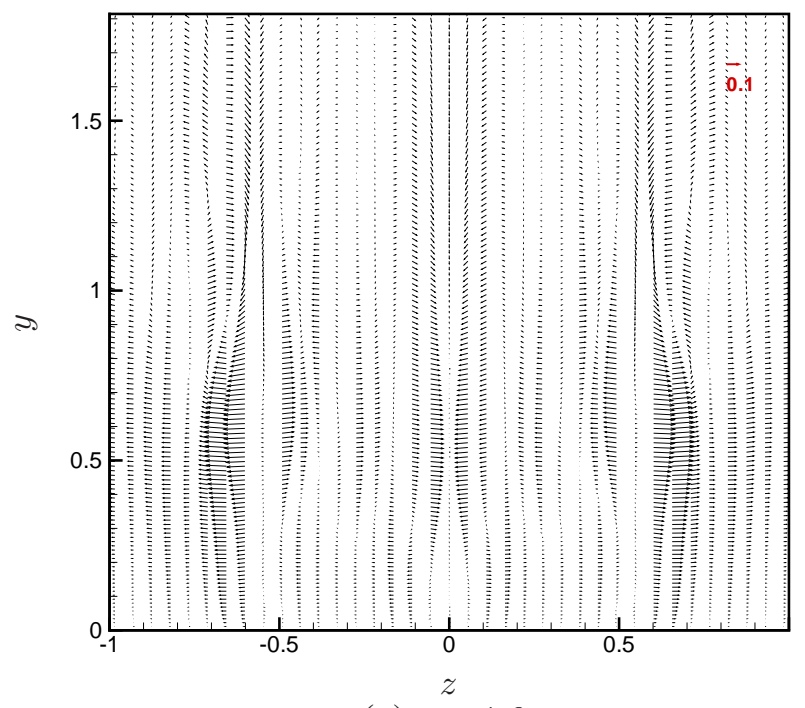

(g) $x=1,6$

Figura 5.45: Distribuição de $v$ e $w$ como vetores, em diferentes posições $x$, para o caso PA com $h_{r}=0,5 \delta_{1}$ (cont.).

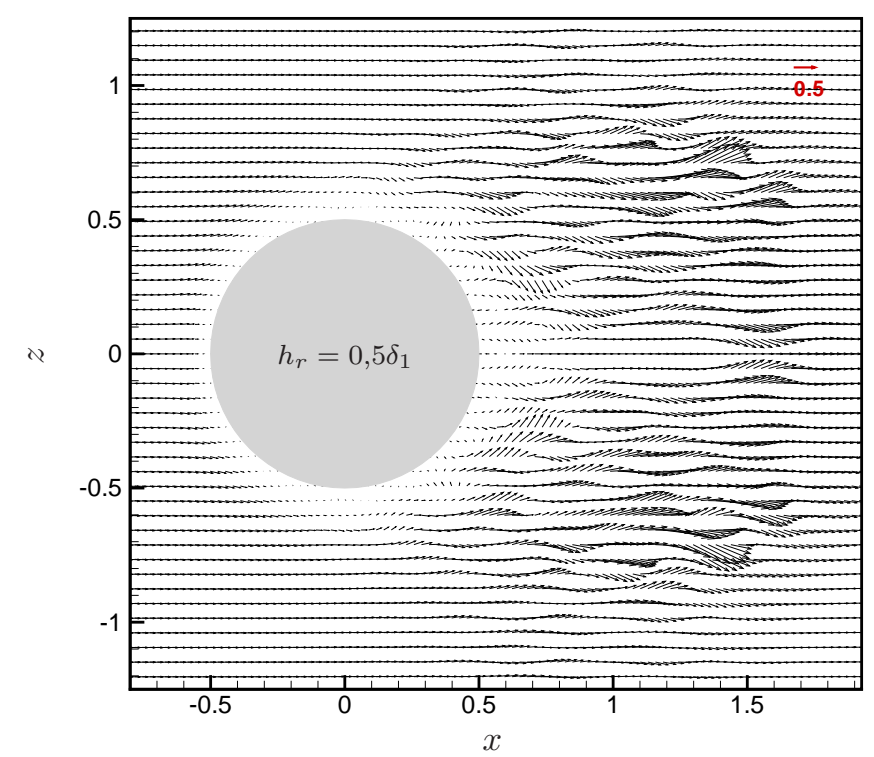

Figura 5.46: Distribuição de $u$ e $w$ como vetores em $y=0,4$, para o caso PA com $h_{r}=0,5 \delta_{1}$. 
Como mostrado na figura 5.47b, a BSJR está centrada em $x \approx 0,7$ e $y \approx 0,2$ e se estende até $x \approx 0,9$. Em comparação com o caso $\mathrm{P} 0$ com mesma altura de rugosidade, esta bolha está mais distante da protuberância e mais afastada da superfície, se estendendo por uma região maior.

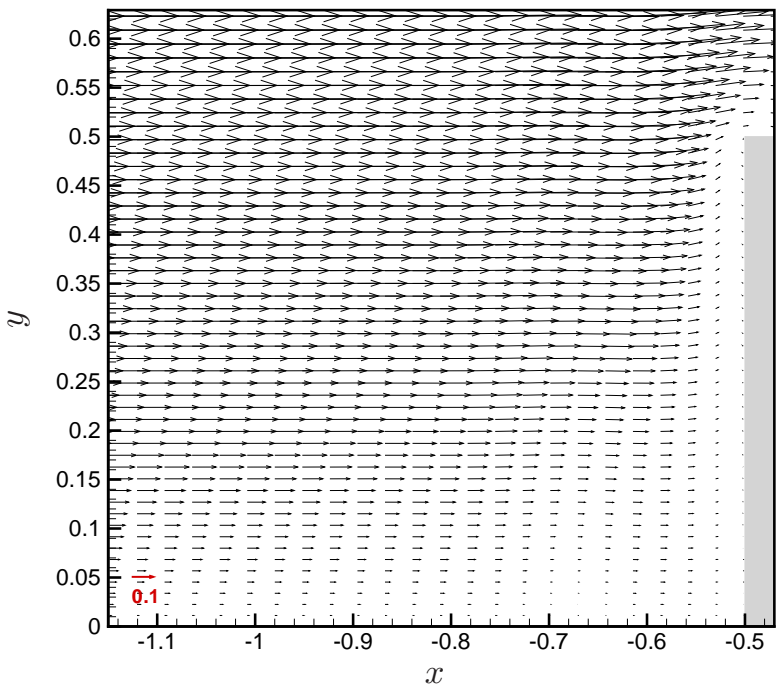

(a) A montante da rugosidade.

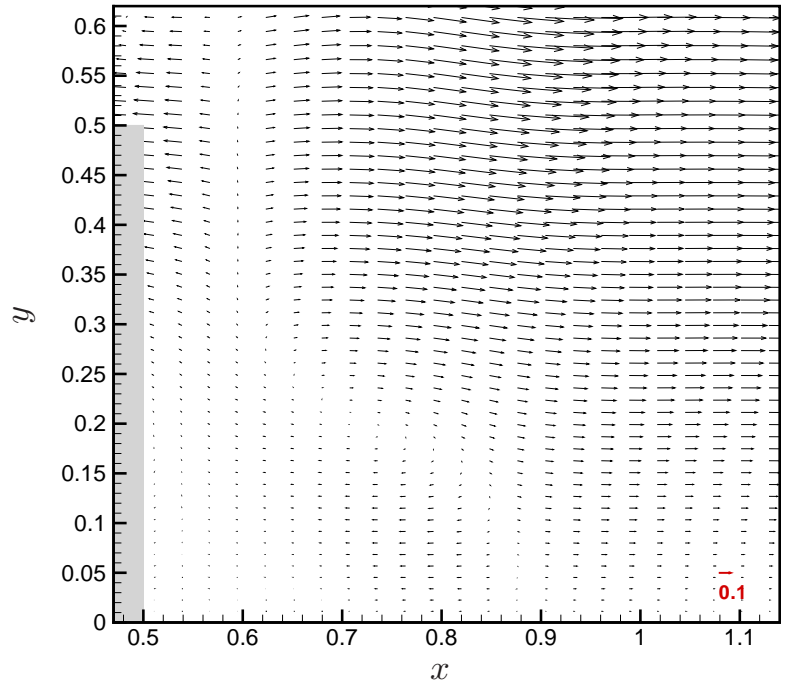

(b) A jusante da rugosidade.

Figura 5.47: Distribuição de $u$ e $v$ como vetores em $z=0$, para o caso PA com $h_{r}=0,5 \delta_{1}$.

Na figura 5.48 a deformação dos perfis de velocidade são maiores, comparadas aos do caso PA com altura $h_{r}=0,4 \delta_{1}$ (figura 5.44) e aos do caso P0 com mesma altura de rugosidade.

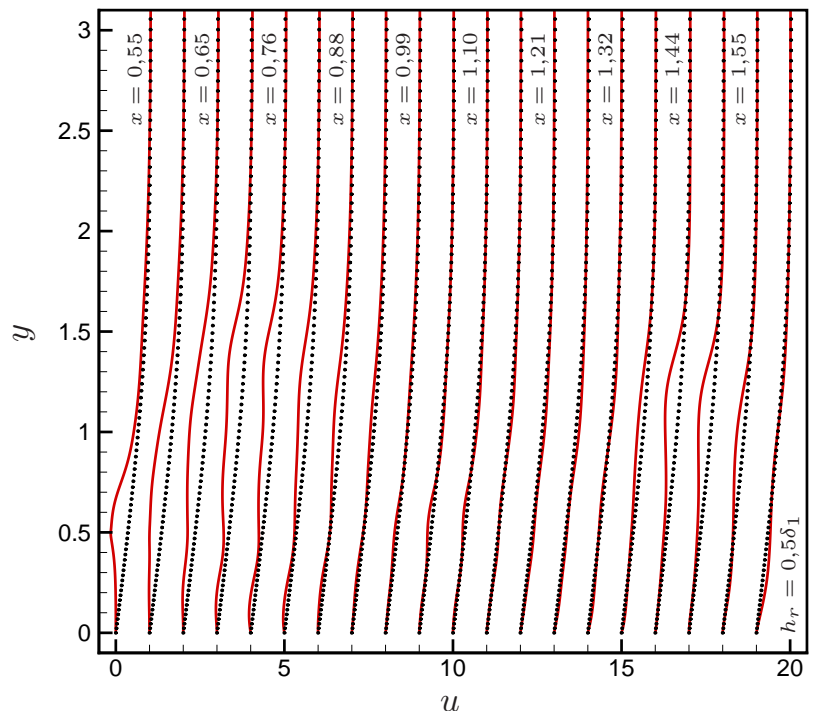

Figura 5.48: Perfil de $u$ normal à superfície em $z=0$, para o caso PA com $h_{r}=0,5 \delta_{1}$.

Os resultados deste caso mostram novamente os efeitos do gradiente de pressão adverso no escoamento. Apesar da velocidade ser menor, o escoamento se torna mais instável, comparado ao caso com gradiente de pressão próximo de zero. 


\subsubsection{Rugosidade com altura $h_{r}=0,6 \delta_{1}$}

Nesta seção são apresentados os resultados obtidos com $h_{r}=0,6 \delta_{1}$. Esses resultados são mostrados nas figuras de 5.49 a 5.52. Para este caso, foram rodados 135680 passos no tempo.

Assim como nos casos anteriores, o aumento nos efeitos tridimensionais torna difícil identificar as estruturas vorticais separadamente, como pode ser visto na figura 5.49. Também nessa figura pode-se ver a semelhança entre este escoamento e os escoamentos dos casos P0 com mesma altura de rugosidade (figura 5.21) e PA com $h_{r}=0,5 \delta_{1}$ (figura 5.45). Nota-se ainda que as perturbações para este caso são maiores do que para os outros dois.

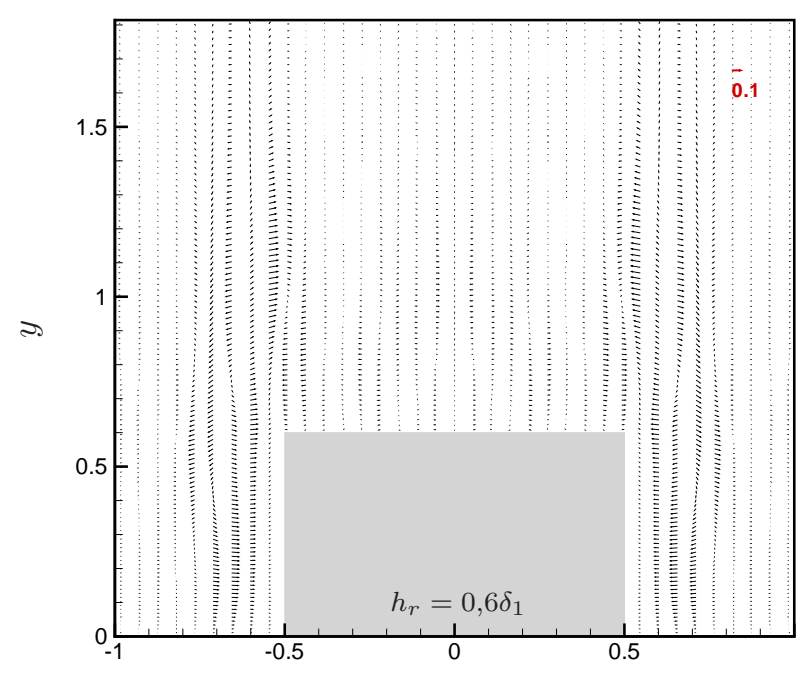

(a) $x=0,0$

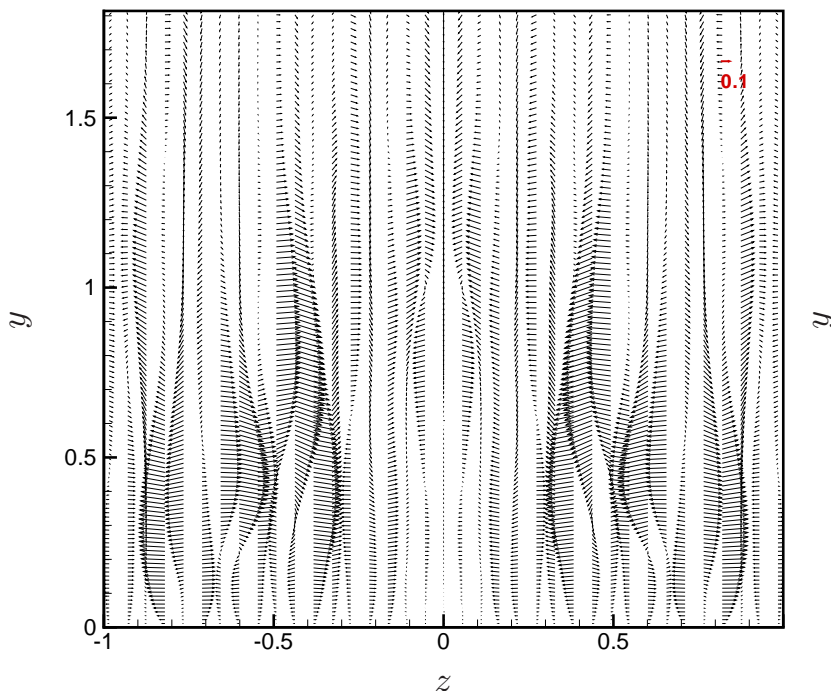

(c) $x=0,8$

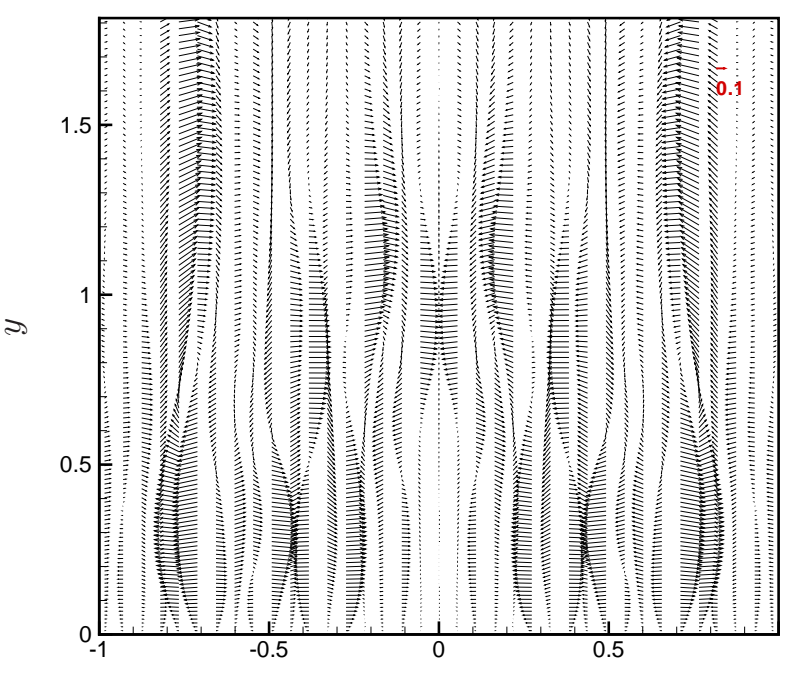

(b) $x=0,6$

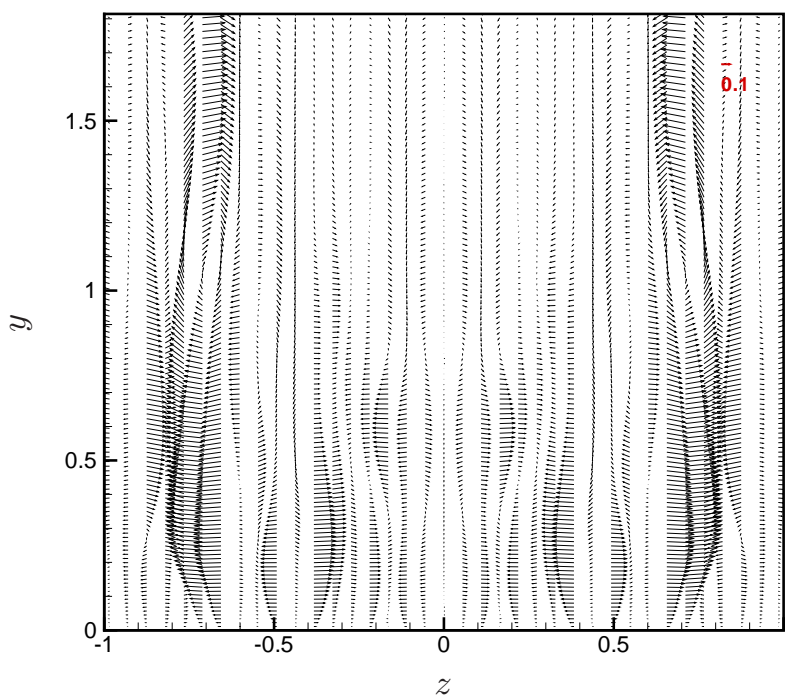

(d) $x=1,0$

Figura 5.49: Distribuição de $v$ e $w$ como vetores, em diferentes posições $x$, para o caso PA com $h_{r}=0,6 \delta_{1}$.

Na figura 5.50 pode-se ver as oscilações do escoamento a jusante da protuberância. Em compara- 


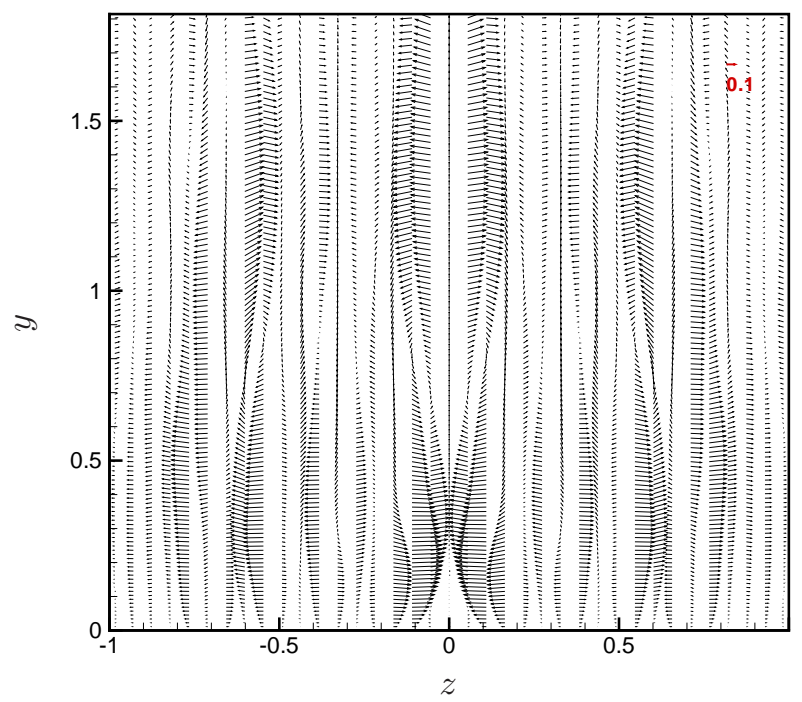

(e) $x=1,2$

Figura 5.49: Distribuição de $v$ e $w$ como vetores, em diferentes posições $x$, para o caso PA com $h_{r}=0,6 \delta_{1}$ (cont.).

ção com o caso P0 com mesma altura de rugosidade (figura 5.22), nota-se um aumento das oscilações, apesar de ambas se iniciarem em posições longitudinais semelhantes $(x \approx-0,2)$. O aumento nas oscilações também é observado em relação ao caso PA com altura $h_{r}=0,5 \delta_{1}$. Porém, no caso com menor altura de rugosidade, as oscilações começam em $x \approx 0,0$.

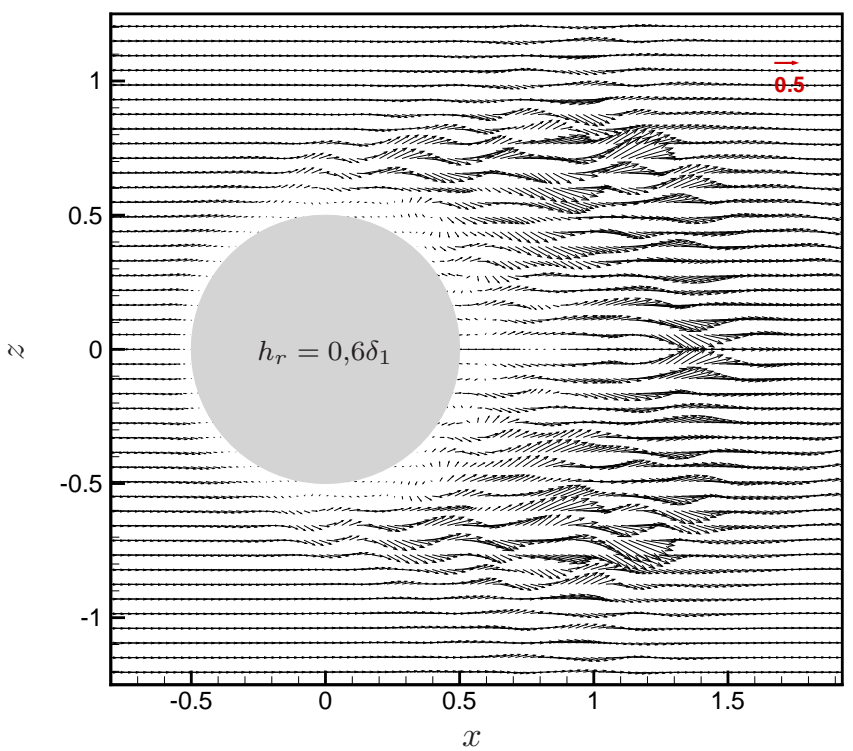

Figura 5.50: Distribuição de $u$ e $w$ como vetores em $y=0,5$, para o caso PA com $h_{r}=0,6 \delta_{1}$.

A formação do VTFMR pode ser vista na figura 5.51a. Este vórtice está centrado em $x \approx-0,67$ e $y \approx 0,07$ e gira no sentido horário. Este vórtice está mais afastado da superfície, comparado ao do caso P0 com mesma altura de rugosidade. 


\section{1 - Escoamento contendo rugosidade}

Para este caso, na figura 5.51b, nota-se o aumento dos efeitos tridimensionais entre as estruturas vorticais, dificultando sua identificação. Esse fato indica que o escoamento está transicionando para o regime turbulento.

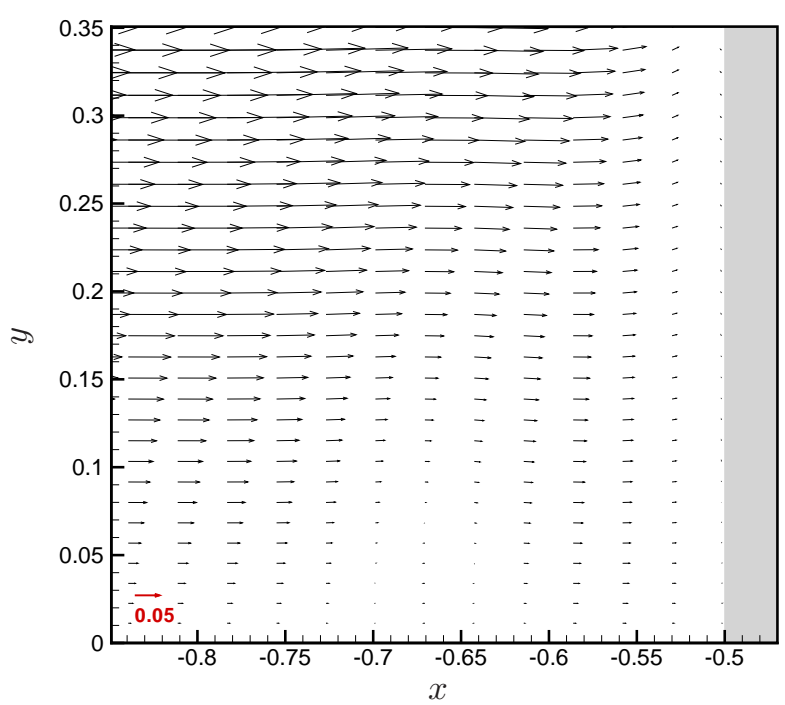

(a) A montante da rugosidade.

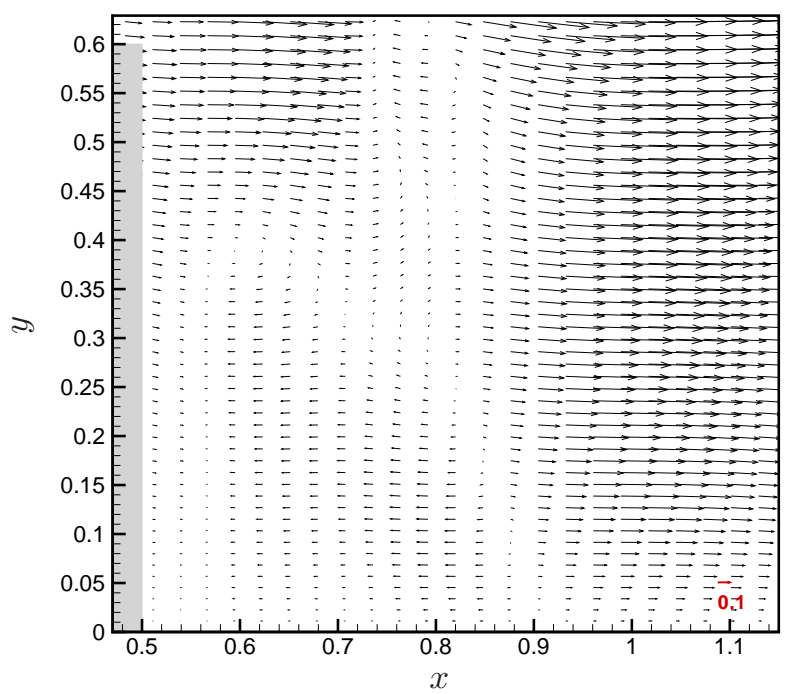

(b) A jusante da rugosidade.

Figura 5.51: Distribuição de $u$ e $v$ como vetores em $z=0$, para o caso PA com $h_{r}=0,6 \delta_{1}$.

$\mathrm{Na}$ figura 5.52 nota-se a presença de perfis inflexionais de velocidade, o que contribui para a transição do escoamento. Ainda, em comparação com os casos P0 com mesma altura de rugosidade e PA com altura $h_{r}=0,5 \delta_{1}$, vê-se um aumento nas deformações do perfil.

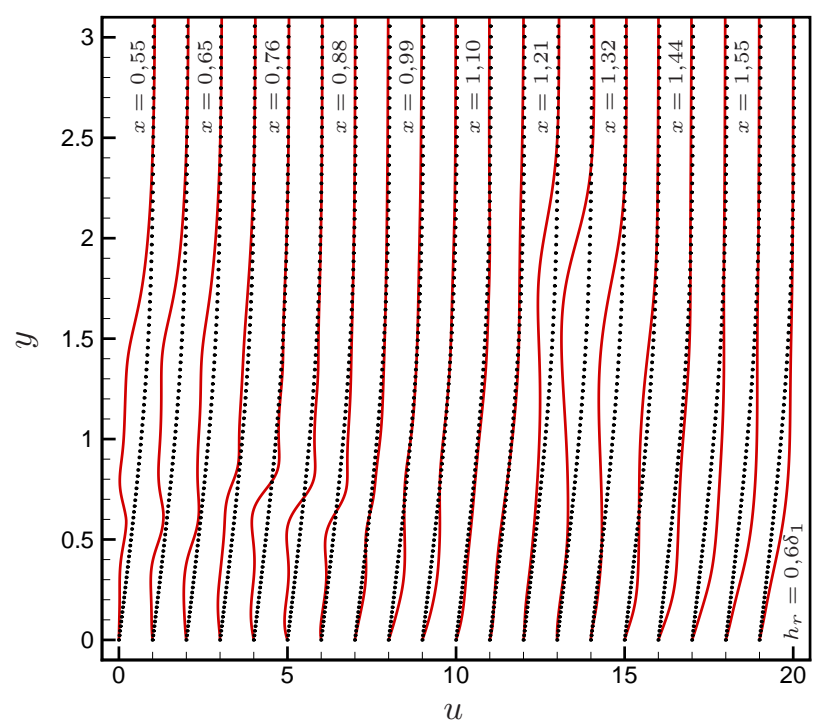

Figura 5.52: Perfil de $u$ normal à superfície em $z=0$, para o caso PA com $h_{r}=0,6 \delta_{1}$.

A presença de uma rugosidade em um escoamento com gradiente de pressão adverso é mais eficiente para seu processo de transição, uma vez que este tipo de escoamento é mais instável do que 
o escoamento com gradiente de pressão próximo de zero.

\subsubsection{Caso PF - escoamento com gradiente de pressão favorável}

Para o escoamento com gradiente de pressão favorável foram consideradas duas alturas de rugosidade: $0,5 \delta_{1}$ e $0,6 \delta_{1}$. Na direção longitudinal, o centro da rugosidade está localizado a 10 (14) diâmetros da região de relaminarização do início (saída) do domínio.

Os resultados são mostrados, para as duas alturas de rugosidade, nas a seguir.

\subsubsection{Rugosidade com altura $h_{r}=0,5 \delta_{1}$}

Nesta seção são apresentados os resultados obtidos com $h_{r}=0,5 \delta_{1}$. Esses resultados são mostrados nas figuras de 5.53 a 5.56. Para este caso, foram rodados 166400 passos no tempo.

Assim como nos casos anteriores, com mesma altura de rugosidade, pode-se observar os efeitos tridimensionais das estruturas vorticais na figura 5.53, não permitindo a distinção exata de cada uma delas.

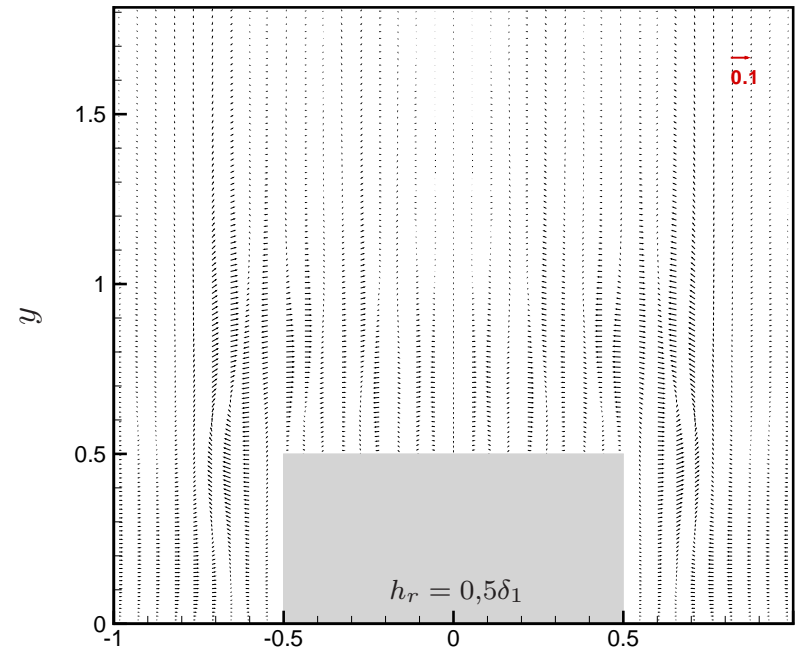

(a) $x=0,0$

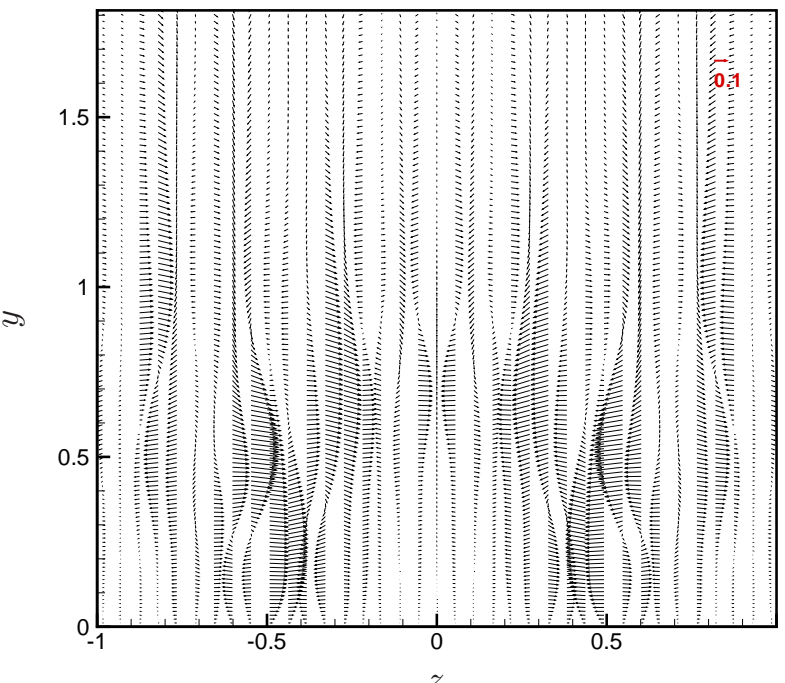

(b) $x=0,6$

Figura 5.53: Distribuição de $v$ e $w$ como vetores, em diferentes posições $x$, para o caso PF com $h_{r}=0,5 \delta_{1}$ (cont.).

As oscilações causadas pelos efeitos tridimensionais podem ser vistas na figura 5.54. Apesar da maior velocidade, esses efeitos são mais amenos neste caso, em comparação com os casos com $h_{r}=0,5$ (figuras 5.18 e 5.46). Este é o efeito do gradiente de pressão favorável, que tende a estabilizar o escoamento.

A região de baixa velocidade a montante da rugosidade, em $x \approx 0,65$ é menor do que a observada 


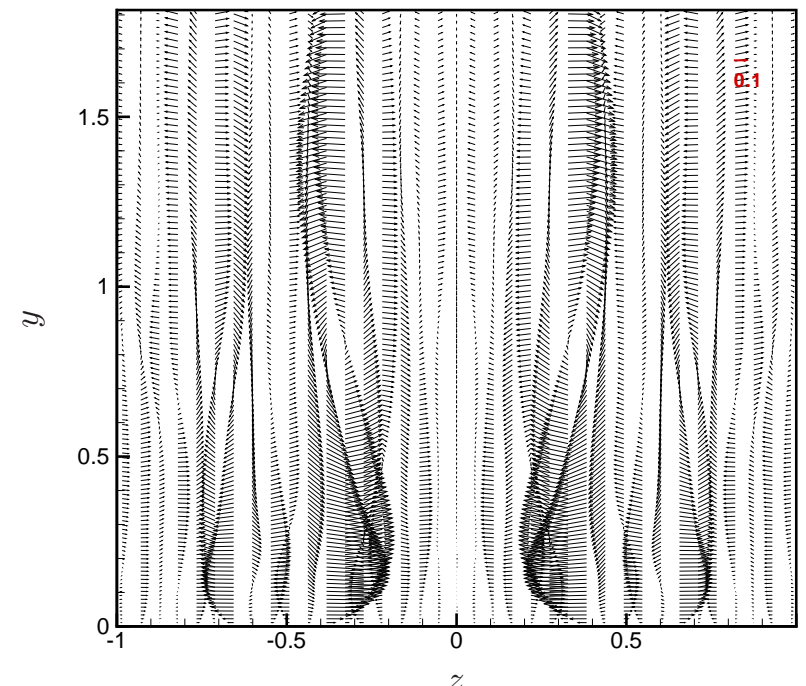

(c) $x=0,8$

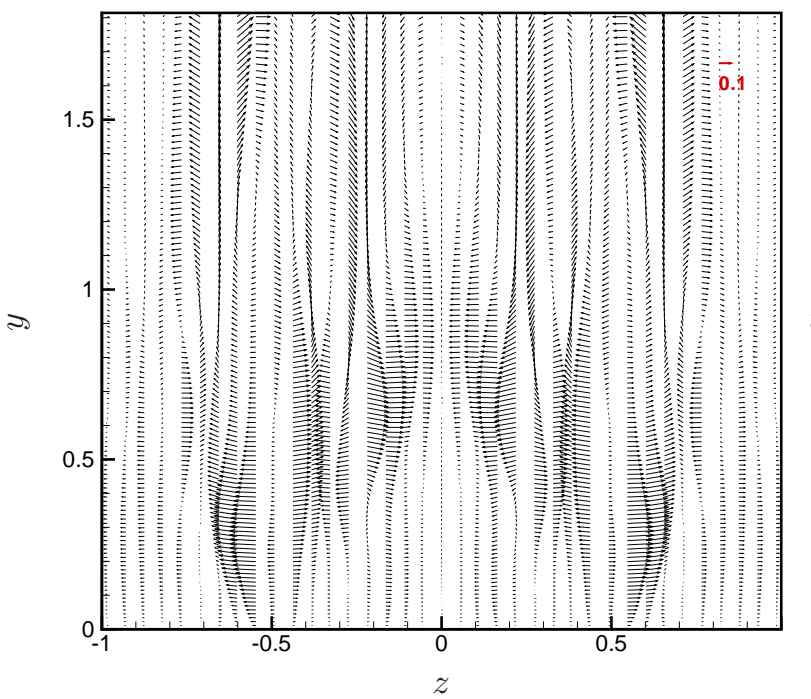

(e) $x=1,2$

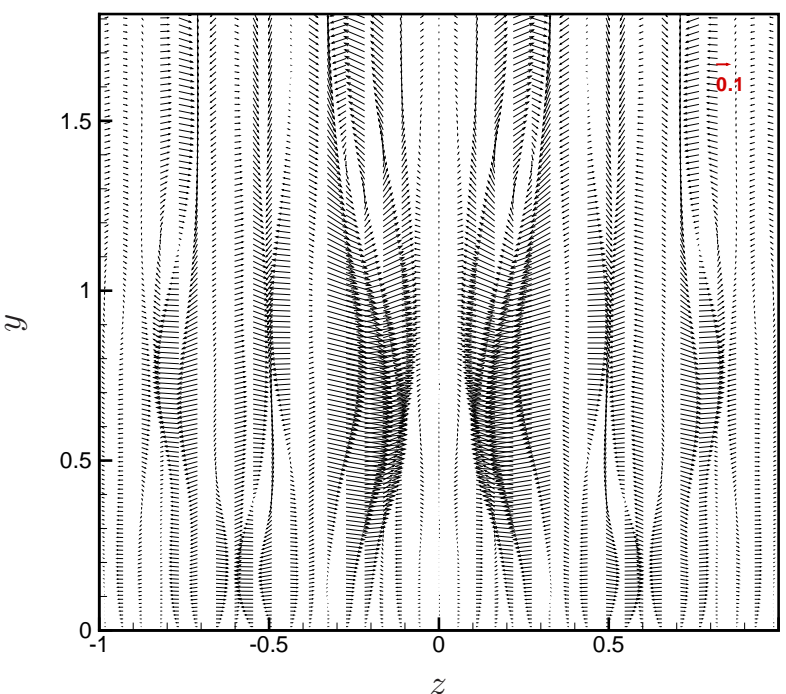

(d) $x=1,0$

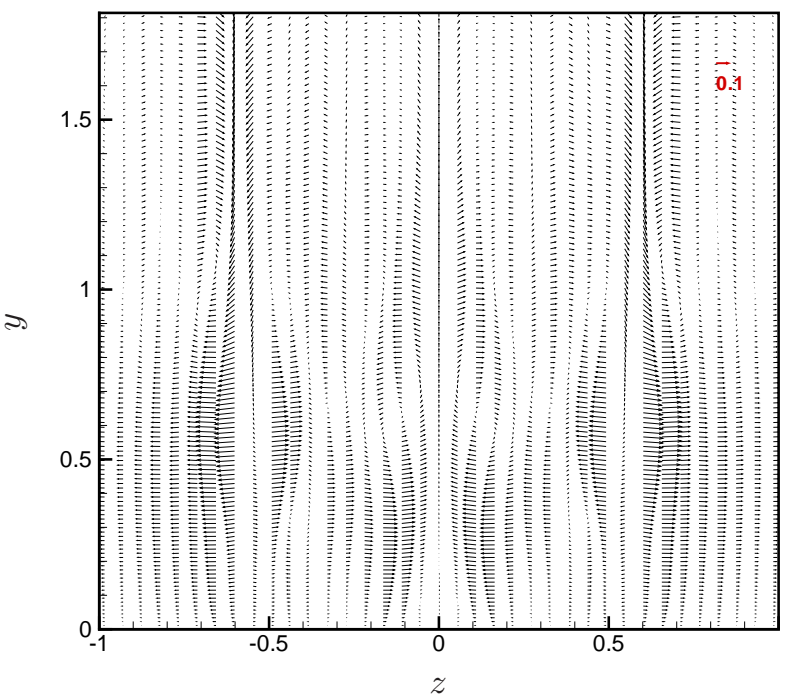

(f) $x=1,4$

Figura 5.53: Distribuição de $v$ e $w$ como vetores, em diferentes posições $x$, para o caso PF com $h_{r}=0,5 \delta_{1}$. 


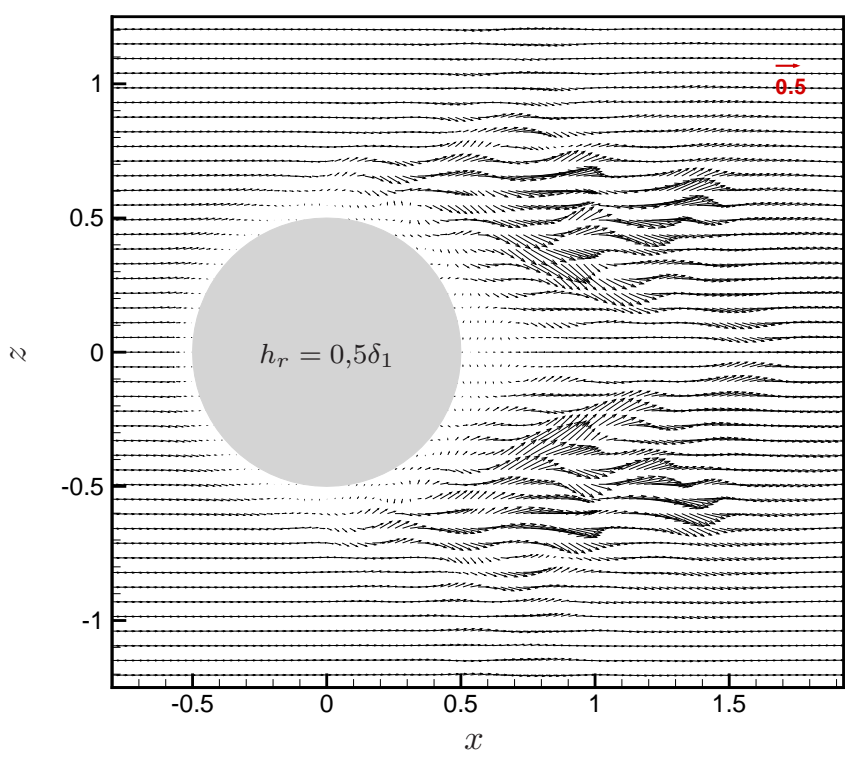

Figura 5.54: Distribuição de $u$ e $w$ como vetores em $y=0,4$, para o caso PF com $h_{r}=0,5 \delta_{1}$.

para os casos P0 e PA com mesma altura de rugosidade, como pode ser visto nas figuras 5.55a, 5.19a e $5.47 \mathrm{a}$.

A jusante da protuberância pode-se ver a formação da BSJR, centrada em $x \approx 0,74$ e $y \approx 0,17$. Essa bolha é semelhante à do caso PA, de acordo com as figuras 5.55b e 5.47b. Ela se estende até $x \approx 0,9$.

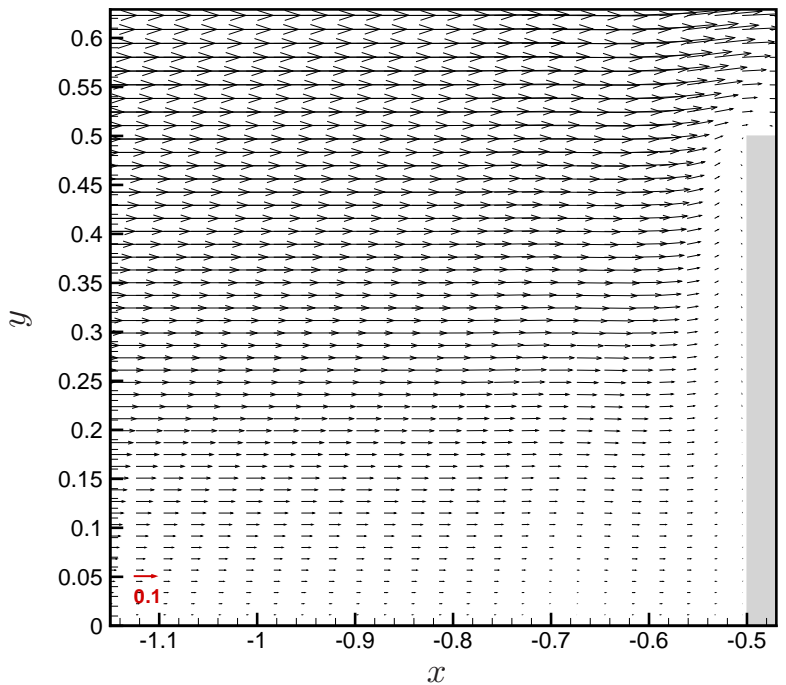

(a) A montante da rugosidade.

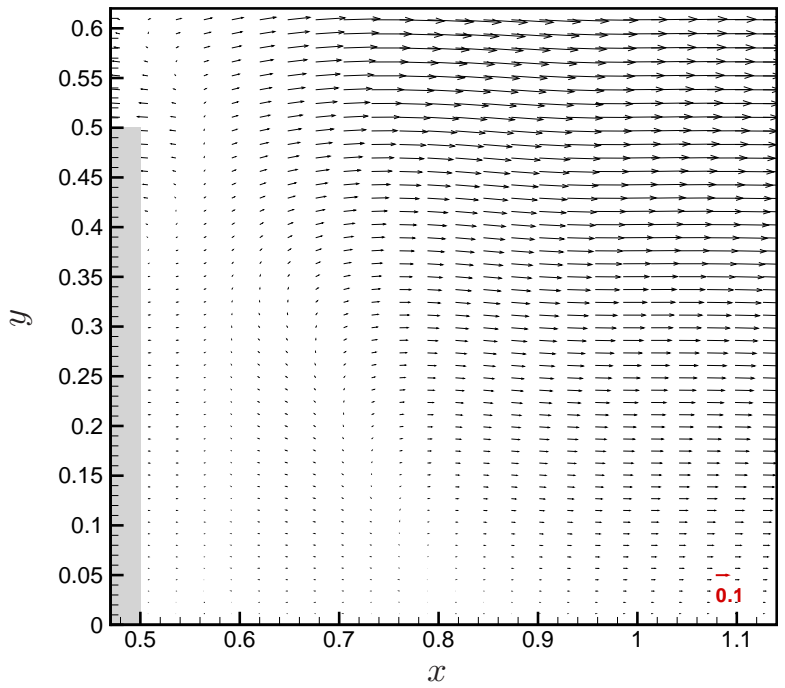

(b) A jusante da rugosidade.

Figura 5.55: Distribuição de $u$ e $v$ como vetores em $z=0$, para o caso PF com $h_{r}=0,5 \delta_{1}$.

A deformação do perfil de $u$ pode ser vista na figura 5.56. Essa deformação é mais acentuada próximo à rugosidade, se estendendo na direção normal à superfície. A partir de $x \approx 0,88$ as defor- 
mações ficam mais amenas, comparado aos demais casos com mesma altura de rugosidade (figuras 5.20 e 5.48$)$.

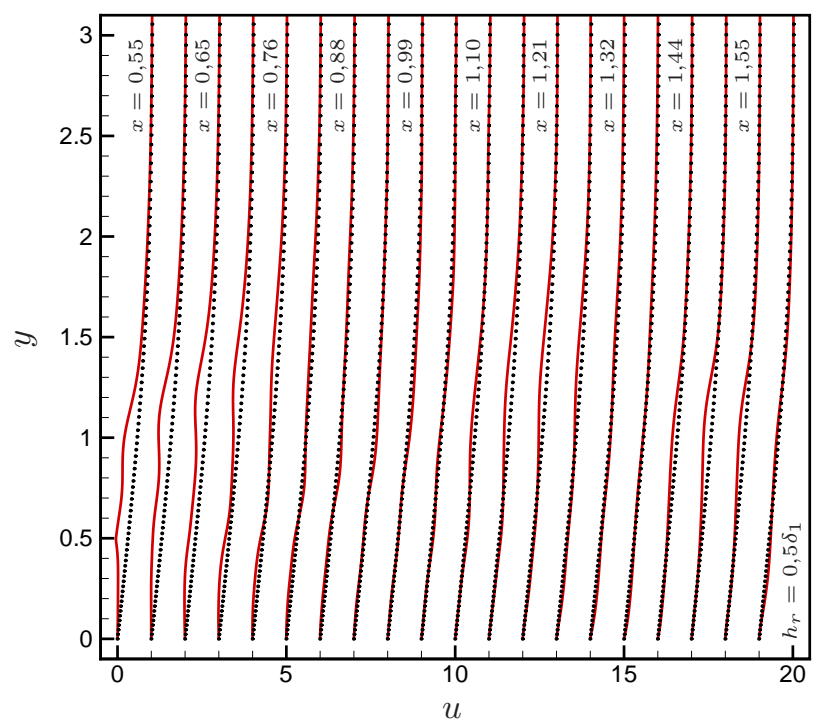

Figura 5.56: Perfil de $u$ normal à superfície em $z=0$, para o caso PF com $h_{r}=0,5 \delta_{1}$.

Os resultados desse caso se mostraram mais estáveis do que os resultados dos casos P0 e PA com altura $h_{r}=0,5 \delta_{1}$. Tal fato se deve à influência do gradiente de pressão favorável no escoamento.

\subsubsection{Rugosidade com altura $h_{r}=0,6 \delta_{1}$}

Nesta seção são apresentados os resultados obtidos com $h_{r}=0,6 \delta_{1}$. Esses resultados são mostrados nas figuras de 5.57 a 5.60. Para este caso, foram rodados 144640 passos no tempo.

As estruturas vorticais mostradas na figura 5.57 são semelhantes às dos casos P0 e PA com mesma altura de rugosidade (figuras 5.21 e 5.49). Novamente, a interação entre estruturas torna difícil sua identificação separadamente.

Na figura 5.58 pode-se ver que velocidade do escoamento é maior, comparada aos casos P0 com altura $h_{r}=0,6 \delta_{1}$ (figura 5.22), PA com altura $h_{r}=0,6 \delta_{1}$ (figura 5.50) e PF com altura $h_{r}=$ 0,5 $\delta_{1}$ (figura 5.54). As oscilações são semelhantes à do caso P0 com mesma altura de rugosidade. Em relação ao caso PA com mesma altura, nota-se que as oscilações se espalham menos na direção transversal. E como esperado, as oscilação são maiores do que as do caso PF com altura $h_{r}=0,5 \delta_{1}$.

Da mesma forma que nos casos anteriores, a formação do VTFMR pode ser vista na figura 5.59a, com centro em $x \approx-0,67 y \approx 0,05$. Este vórtice é muito semelhante ao observado no caso P0 com mesma altura de rugosidade. O VTFMR do caso PA com mesma altura localiza-se na mesma posição longitudinal, porém, mais afastado da superfície. 

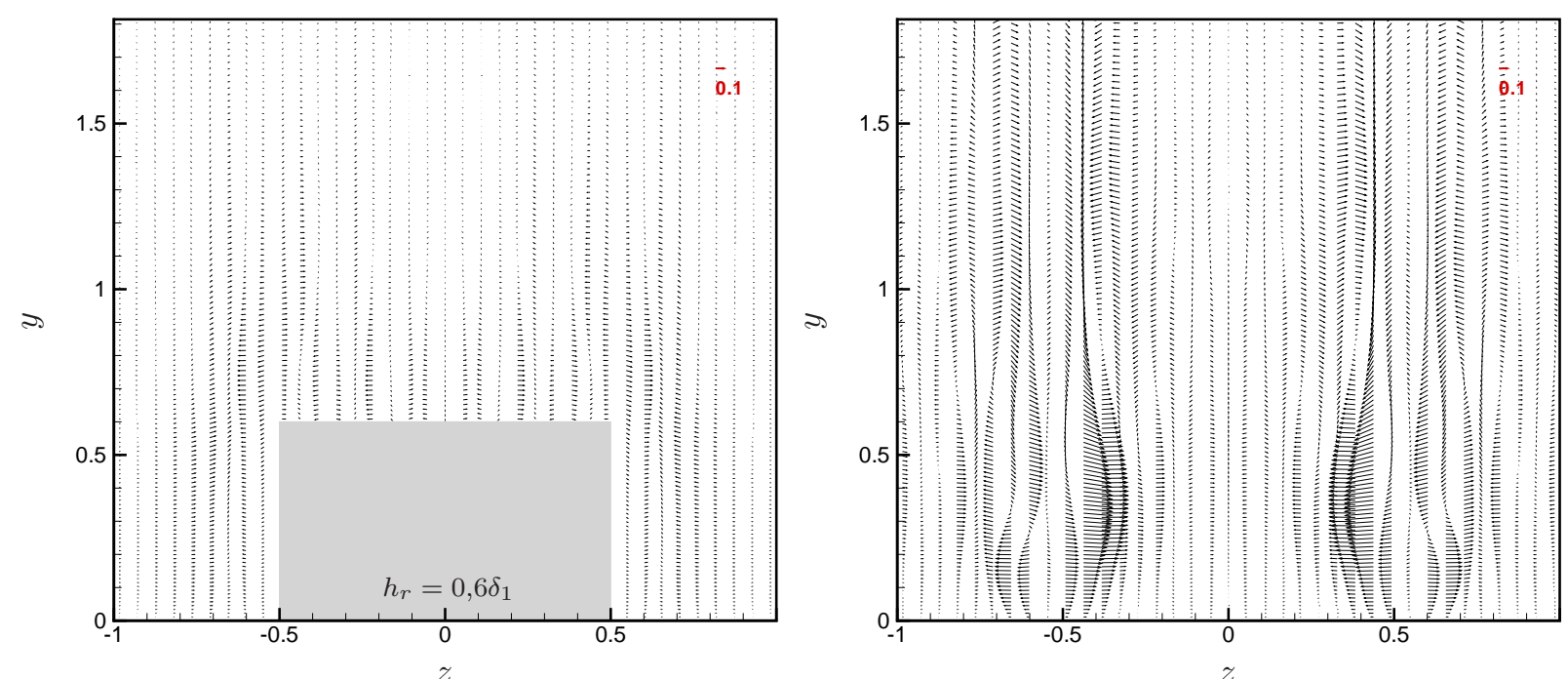

(a) $x=0,0$

(b) $x=0,6$
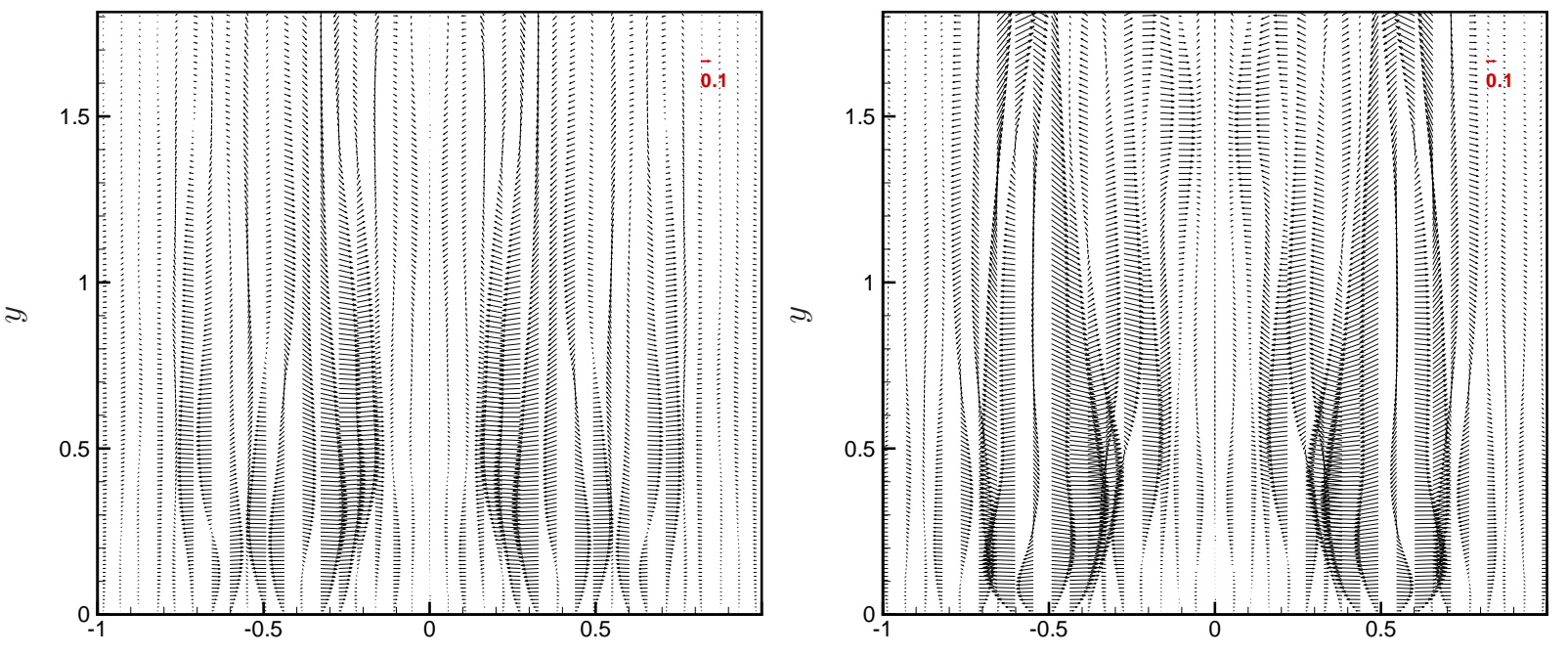

(c) $x=0,8$

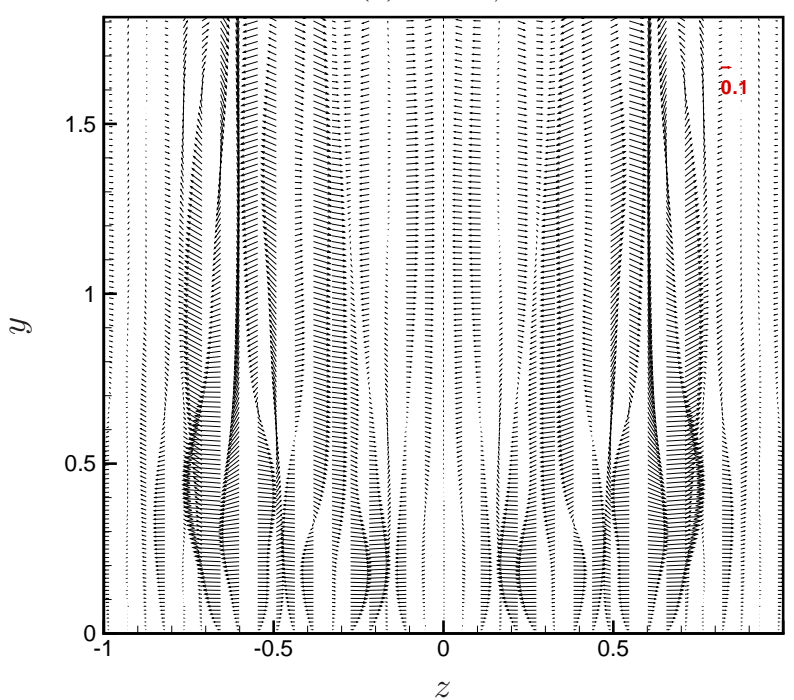

(d) $x=1,0$

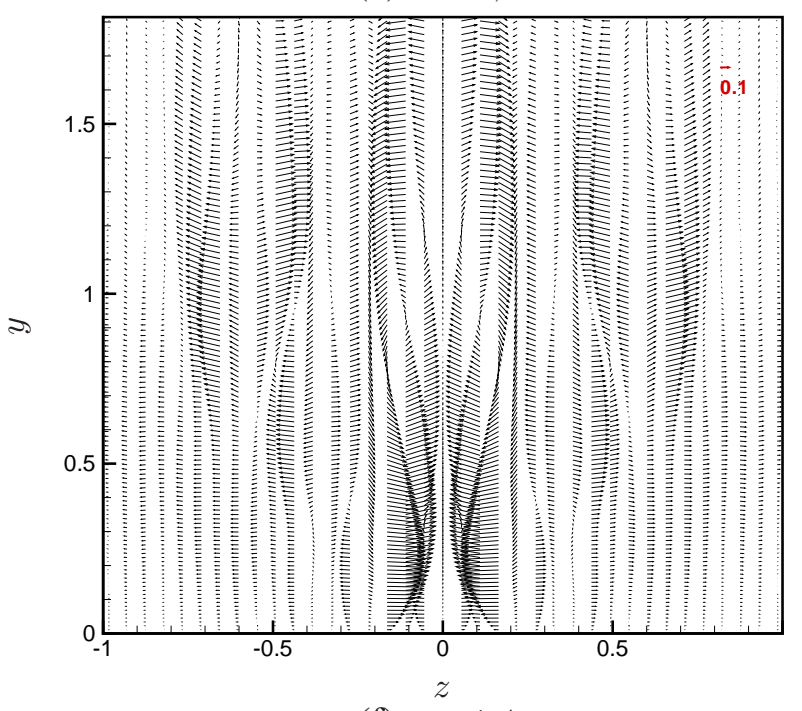

(e) $x=1,2$

(f) $x=1,4$

Figura 5.57: Distribuição de $v$ e $w$ como vetores, em diferentes posições $x$, para o caso PF com $h_{r}=0,6 \delta_{1}$. 


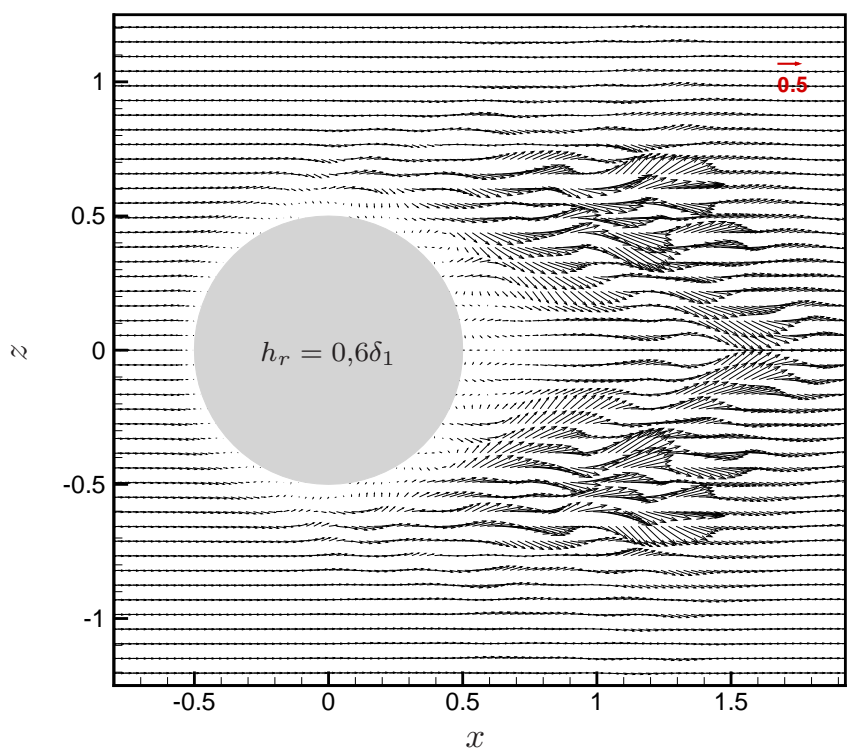

Figura 5.58: Distribuição de $u$ e $w$ como vetores em $y=0,5$, para o caso PF com $h_{r}=0,6 \delta_{1}$.

Neste caso, como no caso P0 com mesma altura de rugosidade, ocorre a formação da BSJR, apresentando comportamentos semelhantes para ambos os casos, como mostrado nas figuras 5.59b e $5.23 \mathrm{~b}$, respectivamente. Para os dois casos a bolha está na mesma posição longitudinal e se estende até $x \approx 0,9$. Contudo, para este caso, a bolha está mais afastada da superfície, em $y \approx 0,37$.

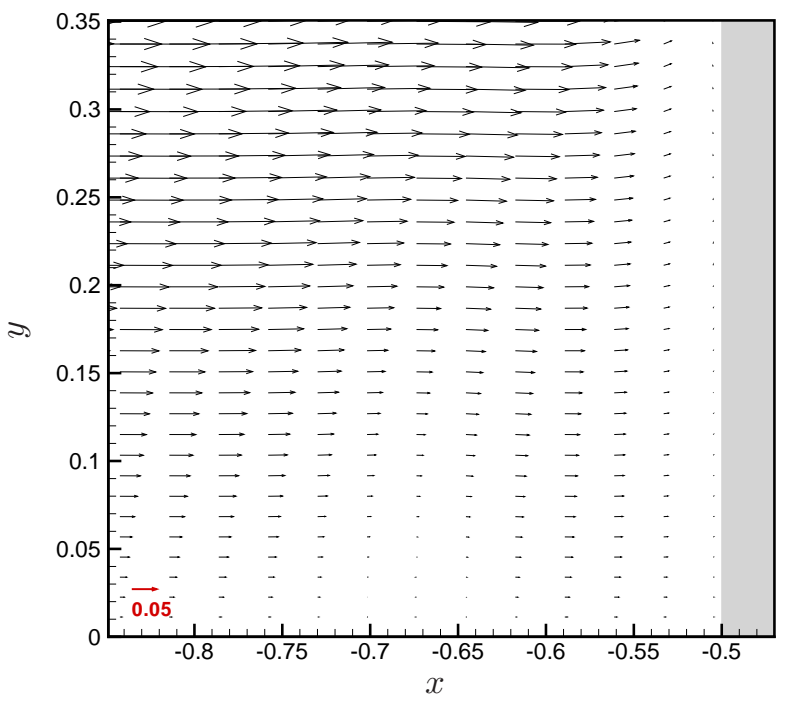

(a) A montante da rugosidade.

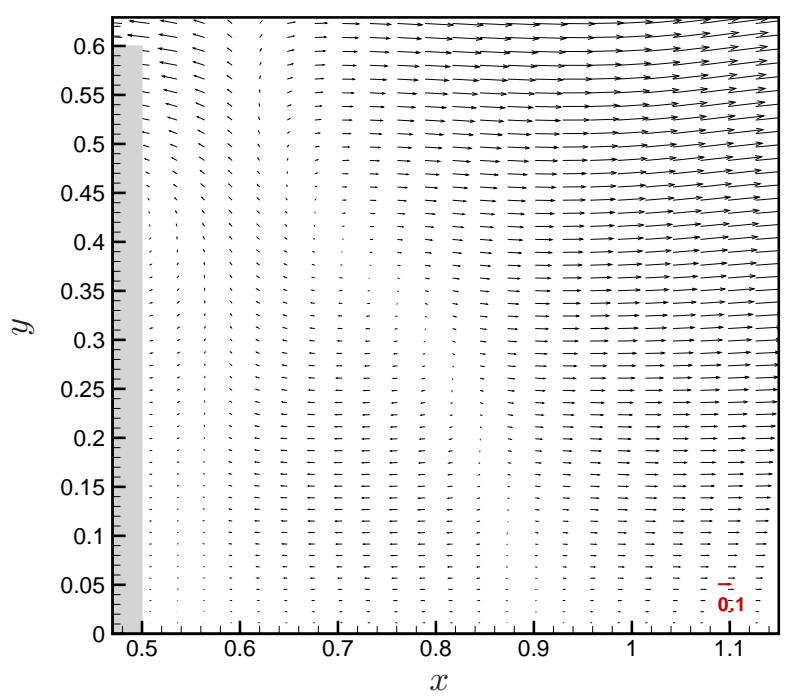

(b) A jusante da rugosidade.

Figura 5.59: Distribuição de $u$ e $v$ como vetores em $z=0$, para o caso PA com $h_{r}=0,6 \delta_{1}$.

Os efeitos das estruturas vorticais sobre o perfil de velocidade pode ser visto na figura 5.60. As deformações são semelhantes às do caso PF com altura $h_{r}=0,5 \delta_{1}$, sendo um pouco mais acentuadas para o presente caso. 


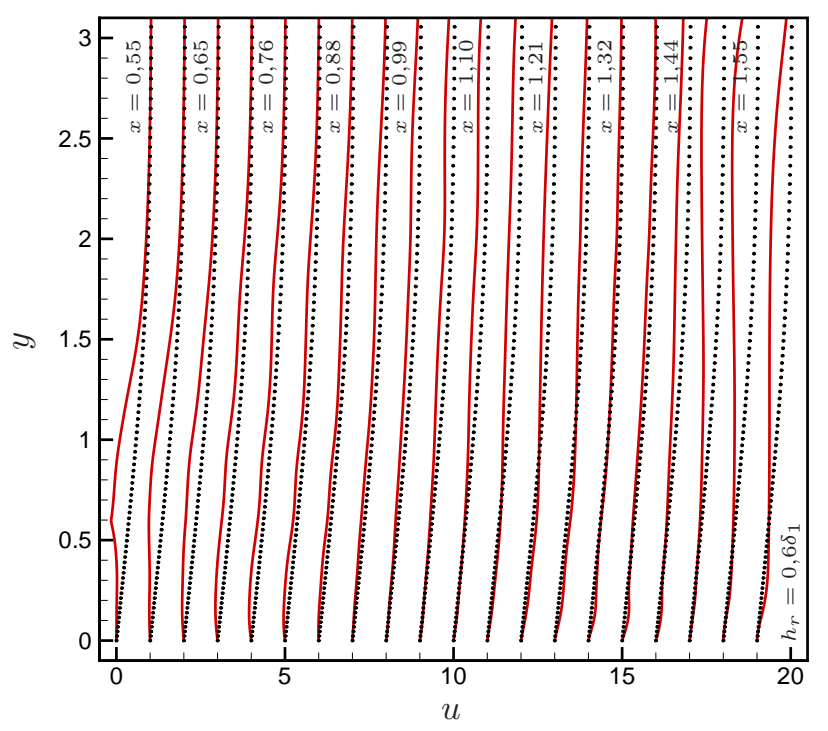

Figura 5.60: Perfil de $u$ normal à superfície em $z=0$, para o caso PF com $h_{r}=0,6 \delta_{1}$.

Os resultados deste caso são semelhantes aos resultados do caso P0, apresentando contudo, maior estabilidade, devido à presença do gradiente de pressão favorável.

\subsection{Conclusão}

Neste capítulo foram apresentados os resultados da simulação numérica de um escoamento incompressível tridimensional em uma superfície contendo uma rugosidade isolada.

De acordo com os resultados apresentados, notou-se que, para rugosidades com altura até $30 \%$ da espessura de deslocamento da camada limite, a influência da protuberância sobre o escoamento é mínima, isto é, a perturbação causada por ela é amortecida rapidamente.

Em todos os casos, para rugosidades com alturas entre $0,4 \delta_{1}$ e $0,5 \delta_{1}$ percebe-se a presença de uma região de baixa velocidade a montante da protuberância, que dará origem a um vórtice tipo ferradura nesta região, a partir de $h_{r}=0,6 \delta_{1}$. Para rugosidades com altura superior ou igual a $60 \% \delta_{1}$, este vórtice contorna a rugosidade e se junta aos vórtices formados em suas laterais. Observou-se também que a região de influência desse vórtice aumenta, nas direções longitudinal e normal à superfície, conforme o aumento na altura da protuberância.

Para o caso com gradiente de pressão próximo de zero, com alturas acima de $h_{r}=0,3 \delta_{1}$, o caso com gradiente de pressão adverso, com alturas acima de $h_{r}=0,4 \delta_{1}$, e para o caso com gradiente de pressão favorável, com altura acima de $h_{r}=0,5 \delta_{1}$, observou-se a formação de uma bolha de separação a jusante da rugosidade, que gira no sentido horário. 
Para os casos com altura de rugosidade até $h_{r}=0,3 \delta_{1}$, os resultados mostraram o aparecimento bem definido de pares de vórtices longitudinais contrarrotativos, no qual o vórtice da esquerda gira no sentido horário e o da direita no sentido anti-horário. Esses pares de vórtices são formados pelo aumento de velocidade no topo e ao redor da rugosidade. Observou-se nos resultados apresentados, que a intensidade desses vórtices cresce com o aumento da altura da protuberância.

A presença de oscilações e o aumento dos efeitos tridimensionais ao redor da protuberância foi observado para os escoamentos contendo rugosidades com altura superior ou igual a $h_{r}=0,4 \delta_{1}$, para todos os casos. Conforme aumenta-se a altura da protuberância, mais fortes são os efeitos e maiores as oscilações.

Para rugosidades com altura a partir de $h_{r}=0,8 \delta_{1}$ as interações entre as estruturas vorticais levam o escoamento a transicionar para o regime turbulento. 


\section{CAPÍTULO 6 \\ Conclusões}

Neste capítulo é feita uma síntese do trabalho. Além disso, são apresentadas considerações finais e as contribuições ao estado da arte do estudo de transição em camada limite. Ao final, são sugeridas propostas de trabalhos futuros.

\subsection{Síntese do trabalho}

Durante o desenvolvimento do código, foi necessário lidar com diversos problemas. Nesta seção, são abordadas as dificuldades enfrentadas durante este processo, bem como as contribuições deste trabalho.

Um código numérico já existente foi utilizado como base para o desenvolvimento do código utilizado neste trabalho. Primeiramente, foram feitos teste de paralelização neste código. Estes foram feitos em conjunto com o aluno de doutorado Josuel Kruppa Rogenski e envolviam técnicas de paralelização para a solução de sistemas lineares e comparação de desempenho de métodos do tipo multimalha. Os resultados destes testes foram publicados em Rogenski et al. (2015).

Em seguida, como mencionado na Seção 3.5, o método de interfaces imersas, proposto por Linnick e Fasel (2005), foi implementado. Porém, em testes com casos bidimensionais, este método apresentou problemas de convergência para altos números de Reynolds. Em contato com os autores do método, identificou-se que a estabilidade só era garantida para escoamentos com números de 
Reynolds reduzido. Apesar de não poder ser utilizado para o presente estudo, este método está sendo usado por outros membros do grupo, para problemas com baixo número de Reynolds e tem fornecido bons resultados.

Pelo fato de o MII não ser estável para escoamentos com altos números de Reynolds, optou-se pelo método de fronteiras imersas proposto por Góis (2007), por ser mais robusto para simulação deste tipo de escoamento, apesar da menor ordem de precisão. Este método foi então adaptado para o código tridimensional.

Na sequência, percebeu-se a necessidade da utilização de estiramento de malha na direção normal à superfície, uma vez que a região de interesse está próxima à superfície. Outra vantagem desta técnica é a redução da quantidade de pontos nesta direção. Os coeficientes para o cálculo das derivadas nesta direção foram implementados de acordo com os propostos por Linnick e Fasel (2005). Após a verificação da correta geração dos coeficientes, as rotinas que envolviam o uso dos mesmos foram alteradas e checadas. Este trabalho também foi feito em conjunto com o aluno de doutorado Josuel K. Rogenski.

Durante o estágio na Universidade de Stuttgart, percebeu-se a necessidade de incluir dados experimentais como condição de contorno no código numérico. Isso foi necessário para permitir a comparação dos resultados numéricos com os experimentais, obtidos no túnel de vento.

Para garantir a representação apropriada da rugosidade com a utilização do método espectral, foi feito um estudo a respeito do número de modos de Fourier necessários para aproximá-la adequadamente. Neste estudo, notou-se que seriam necessários pelo menos 43 modos de Fourier (assumindo 128 pontos no espaço físico), o que ocasionou o aumento no número total de pontos no domínio, acarretando um aumento no tempo necessário para as simulações.

Como consequência da utilização do método espectral com o método de fronteiras imersas, identificou-se o aparecimento do fenômeno de Gibbs após a aplicação das transformadas de Fourier. Em estudos feitos sobre o fenômeno, notou-se a necessidade da utilização de filtros para eliminar as oscilações. Cinco filtros foram implementados e testados, inicialmente para um escoamento bidimensional. Dentre esses filtros, os três melhores foram implementados e testados para o caso tridimensional. A partir destes testes, optou-se pelo uso do filtro exponencial, por apresentar os melhores resultados. Parte desse estudos foi desenvolvida em conjunto com o aluno de iniciação científica João Henrique Ribeiro Dainezi, que recebeu prêmio de um dos melhores trabalhos apresentados no SIICUSP (Simpósio Internacional de Iniciação Científica e Tecnológica da USP). 
Ainda em relação ao uso de filtros para o tratamento do fenômeno de Gibbs, observou-se interação entre o filtro e o integrador temporal. Foi então implementado o método de Runge-Kutta proposto por Xu e Wang (2006), que diferencia a forma como os termos forçantes do método de fronteiras imersas são tratados na integração temporal.

Depois de solucionados os problemas de instabilidade numérica, o código foi verificado, através do método de soluções manufaturadas. A ordem de convergência do código numérico foi estimada e se mostrou dentro da ordem esperada. Este trabalho foi feito em conjunto com os alunos de doutorado Patrícia Sartori e Josuel K. Rogenski e seus resultados foram aceitos para publicação no Computer Methods in Applied Mechanics and Engineering.

Além disso, foi feita a validação do código DNS, comparando seus resultados com dados experimentais e de LST. Essas comparações mostraram que o código é capaz de prever a formação da camada limite e o correto desenvolvimento de ondas TS no escoamento.

\subsection{Considerações finais sobre os resultados}

Esse código verificado e validado foi então utilizado para simulações de escoamentos em camada limite contendo rugosidade. Os resultados dessas simulações forneceram informações relevantes a respeito da influência da rugosidade neste tipo de escoamento. Pode-se notar que quanto maior a rugosidade, maior é a deformação causada no perfil de velocidade. A partir de certa altura de rugosidade, o escoamento não consegue amortecer as perturbações e acaba transicionando. Observou-se também que o ponto de transição se aproxima da rugosidade, com o aumento na altura da mesma.

\subsection{Trabalhos futuros}

Nesta seção, propõe-se algumas sugestões de trabalhos futuros, para a compreensão do fenômeno estudado. Os temas propostos são:

- implementar estiramento de malha na direção longitudinal, de forma a ter uma malha mais refinada próximo à rugosidade e para eliminar as regiões de relaminarização;

- simular o escoamento com rugosidades de diferentes diâmetros, a fim de estabelecer uma relação altura-diâmetro entre os fenômenos;

- estudar a interação da perturbação ocasionada pela rugosidade com ondas TS bi e tridimensionais. 


\section{Referências Bibliográficas}

Adam, Y., 1977. Highly accurate compact implicit methods and boundary conditions. Journal of Computational Physics, vol. 24, pp. 10-22.

Babucke, A. \& Kloker, M. J., 2009. Accuracy analysis of finite-difference methods on non-uniform grids. Technical report, Institut für Aerodynamik und Gasdynamik.

Blasius, H., 1908. Grenzschichten in Flüssigkeiten mit kleiner Reibung. Zeitschrift für Mathematik und Physik, vol. 56, n. 1.

Boltze, E., 1908. Grenzschichten an Rotationskörpern in Flüssigkeiten mit kleiner Reibung. PhD thesis, Georg-August-Universität zu Göttingen.

Bonfigli, G., 2005. Numerical simulation of transition and early turbulence in a 3-D boundary layer perturbed by superposed stationary and traveling crossflow vortices. $\mathrm{PhD}$ thesis, Universität Stuttgart.

Briggs, W. L., Henson, V. E., \& McCormick, S. F., 1986. A multigrid tutorial. Society for Industrial and Applied Mathematics.

Brynjell-Rahkola, M., Schlatter, P., Hanifi, A., \& Henningson, D. S., 2014. Global stability analysis of a roughness wake in a Falkner-Skan-Cooke boundary layer. In Proceedings of the 8th Symposium on Laminar Turbulent Transition.

Canuto, C., Hussaini, M. Y., Quarteroni, A., \& Zang, T. A., 1988. Spectral methods in fluid dynamics. Springer-Verlag. 
Canuto, C., Hussaini, M. Y., Quarteroni, A., \& Zang, T. A., 2007. Spectral methods - evolution to complex geometries and applications to fluid dynamics. Springer-Verlag.

Citro, V., Giannetti, F., Luchini, P., \& Auteri, F., 2014. Boundary-layer flows past an hemispherical roughness element: DNS, global stability and sensitivity analysis. In Proceedings of the 8th Symposium on Laminar Turbulent Transition.

Codina, R. \& Baiges, J., 2009. Approximate imposition of boundary conditions in immersed boundary methods. International Journal for Numerical Methods in Engineering, vol. 80, pp. $1379-1405$.

Collatz, L., 1966. The numerical treatment of differential equations. Springer-Verlag.

Crow, S. C., 1970. Stability theory for a pair of trailing vortices. AIAA Journal, vol. 12, pp. 2171-2179.

Delery, J. M., 2001. Robert Legendre and Henri Werlé: Toward the elucidation of three-dimensional separation. Annual Review of Fluid Mechanics, vol. 33, pp. 129-154.

Dyke, M. V., 1982. An album of fluid motion. The Parabolic Press.

Eça, L., Hoekstra, M., Hay, A., \& Pelletier, D., 2007. Verification of RANS solvers with manufactured solutions. Engineering with Computers, vol. 23, pp. 253-270.

Falkner, V. M. \& Skan, S. W., 1931. LXXXV. Solutions of the boundary-layer equations. Philosophical Magazine Series 7, vol. 12, n. 80, pp. 865-896.

Fasel, H. F., Rist, U., \& Konzelmann, U., 1990. Numerical investigation of the three-dimensional development in boundary-layer transition. AIAA Journal, vol. 28, pp. 29-37.

Girault, V. \& Glowinski, R., 1995. Error analysis of a fictitious domain method applied to a Dirichlet problem. Japan Journal of Industrial and Applied Mathematics, vol. 12, pp. 487-514.

Glowinski, R., Pan, T.-W., Hesla, T., \& Joseph, D., 1999. A distributed Lagrange multiplier/fictitious domain method for particulate flows. International Journal of Multiphase Flow, vol. 25, pp. $755-794$. 
Glowinski, R., Pan, T.-W., \& Periaux, J., 1994. A fictitious domain method for Dirichlet problems and applications. Computer Methods in Applied Mechanics and Engineering, vol. 111, pp. 283-303.

Goldstein, D., Handler, R., \& Sirovich, L., 1993. Modeling a no-slip flow boundary with an external force field. Journal of Computational Physics, vol. 105, n. 2, pp. 354-366.

Gregory, M. A. N. \& Walker, W. S., 1951. The effect on transition of isolated surface excrescences in the boundary layer. Technical report, Aeronautical Research Council.

Gupta, A. K., 1980. Some observations in the wake of a small vertical cylinder attached to a flat plate. Physics of Fluids, vol. 23, pp. 221-223.

Gupta, M. M., Kouatchou, J., \& Zhang, J., 1997. Comparison of second and fourth order discretizations for multigrid Poisson solvers. Journal of Computational Physics, vol. 132, pp. 226-232.

Góis, E. R. C., 2007. Simulação numérica do escoamento em torno de um cilindro utilizando o método das fronteiras imersas. Master's thesis, Universidade de São Paulo.

Hirsh, R. S., 1975. Higher order accurate difference solutions of fluid mechanics problems by a compact differencing technique. Journal of Computational Physics, vol. 19, n. 1, pp. 90 - 109.

Husain, S. Z. \& Floryan, J. M., 2008. Immersed boundary conditions method for unsteady flow problems described by the Laplace operator. International Journal for Numerical Methods in Fluids, vol. 56, pp. 1765-1786.

Klebanoff, P. S. Tidstrom, K. D. \& Sargent, L. M., 1962. The three-dimensional nature of boundary-layer instability. Journal of Fluid Mechanics, vol. 12, pp. 1-34.

Klebanoff, P. S., Cleveland, W. G., \& Tidstrom, K. D., 1992. On the evolution of a turbulent boundary layer induced by a three-dimensional roughness element. Journal of Fluid Mechanics, vol. 237, pp. 101-187.

Klebanoff, P. S., Schubauer, G. B., \& Tidstrom, D. K., 1955. Measurements of the effect of two-dimensional and three-dimensional roughness elements on boundary layer transition. Journal of the Aeronautical Sciences, vol. 22, pp. 803-804. 
Klebanoff, P. S. \& Tidstrom, K. D., 1959. Evolution of amplified waves leading to transition in a boundary layer with zero pressure gradient. Technical report, NASA.

Kloker, M. J., 1998. A robust high-resolution split-type compact FD-scheme for spatial direct numerical simulation of boundary-layer transition. Applied Scientific Research, vol. 59, n. 4, pp. $353-377$.

Kloker, M. J., Konzelmann, U., \& Fasel, H. F., 1993. Outflow boundary conditions for spacial Navier-Stokes simulations of transition boundary layers. AIAA Journal, vol. 31, pp. 620-628.

Knupp, P. \& Salari, K., 2003. Verification of computer codes in computational science and engineering. Chapman \& Hall/CRC.

Kopal, Z., 1961. Numerical analysis, with emphasis on the application of numerical techniques to problems of infinitesimal calculus in single variable. Chapman \& Hall.

Kozlov, V. V., Gorev, V. N., \& Tolkachev, S. N., 2014. Investigation of cross-flow vortices and its secondary instability after the roughness element on the leading edge of swept wing. In Proceedings of the 8th Symposium on Laminar Turbulent Transition.

Kundu, P. K., 1990. Fluid mechanics. Academic Press.

Lai, M.-C. \& Peskin, C., 2000. An immersed boundary method with formal second-order accuracy and reduced numerical viscosity. Journal of Computational Physics, vol. 160, pp. 705-719.

Lee, C., 2003. Stability characteristics of the virtual boundary method in three-dimensional applications. Journal of Computational Physics, vol. 184, pp. 559-591.

Lee, L. \& LeVeque, R., 2003. An immersed interface method for incompressible Navier-Stokes equations. SIAM Journal on Scientific Computing, vol. 25, pp. 832-856.

Lele, S. K., 1992. Compact finite difference schemes with spectral-like resolution. Journal of Computational Physics, vol. 103, pp. 16-42.

LeVeque, R. J. \& Li, Z., 1994. The immersed interface method for elliptic equations with discontinuous coefficients and singular sources. SIAM Journal on Numerical Analysis, vol. 31, pp. 1019-1044. 
Lew, A. \& Buscaglia, G., 2008. A discontinuous-Galerkin-based immersed boundary method. International Journal for Numerical Methods in Engineering, vol. 76, pp. 427-454.

Lima e Silva, A., Silveira-Neto, A., \& Damasceno, J. J. R., 2003. Numerical simulation of two-dimensional flows over a circular cylinder using the immersed boundary method. Journal of Computational Physics, vol. 189, pp. 351-370.

Linnick, M. N. \& Fasel, H. F., 2005. A high-order immersed interface method for simulating unsteady incompressible flows on irregular domains. Journal of Computational Physics, vol. 204, pp. $157-192$.

Mahesh, K., 1998. A family of high order finite difference schemes with good spectral resolution. Journal of Computational Physics, vol. 145, pp. 332-358.

Medeiros, M. A. F., 2000. Laminar-turbulent transition: effect of modulations on the evolution of waves in boundary layers. In Proceedings of the 8th Brazilian Congress of Thermal Engineering and Sciences, Porto Alegre - RS.

Medeiros, M. A. F. \& Mendonça, M. T. d., 2000. On subharmonic and fundamental instability modes in boundary layer. In Proceedings of the 8th Brazilian Congress of Thermal Engineering and Sciences, Porto Alegre - RS.

Meitz, H. L., 1996. Numerical investigation of suction in a transitional flat-plate boundary layer. Master's thesis, University of Arizona.

Meitz, H. L. \& Fasel, H. F., 2000. A compact-difference scheme for the Navier-Stokes equations in vorticity-velocity formulation. Journal of Computational Physics, vol. 157, pp. 371-403.

Miksad, R. W., 1972. Experiments on the nonlinear stages of free-shear-layer transition. Journal of Fluid Mechanics, vol. 56, pp. 695-719.

Mochizuki, M., 1961. Smoke observation on boundary layer transition caused by a spherical roughness element. Journal of the Physical Society of Japan, vol. 16, pp. 995-1008.

Morkovin, M. V., 1969. Critical evaluation of transition from laminar to turbulent shear layers with emphasis on hypersonically traveling bodies. Technical report, Air Force Flight Dynamics Laboratory. 
Nigim, H. H. \& Cockrell, D. J., 1985. Effects caused by small discrete two-dimensional roughness elements immersed in turbulent boundary layers. Journal of Fluid Mechanics, vol. 153, pp. 17-30.

Oberkampf, W. L. \& Trucano, T. G., 2002a. Verification and validation in computational fluid dynamics. Progress in Aerospace Sciences, vol. 38, pp. 209 - 272.

Oberkampf, W. L. \& Trucano, T. G., 2002b. Verification and validation in computational fluid dynamics. Technical report, Sandia National Laboratories.

Pacheco, P. S., 1997. Parallel programming with MPI. Morgan Kaufmann.

Peskin, C., 1977. Numerical analysis of blood flow in the heart. Journal of Computational Physics, vol. 25, pp. 220-252.

Peskin, C., 2002. The immersed boundary method. Acta Numerica, vol. 11, pp. 479-517.

Peskin, C. S., 1972. Flow patterns around heart valves: A numerical method. Journal of Computational Physics, vol. 10, pp. 252-271.

Plogmann, B., Würz, W., \& Krämer, E., 2012. Interaction of a three-dimensional roughness element with a TS-wave near an airfoil leading edge. In Proceedings of the 16th International Conference on Methods of Aerophysical Research, Kazan, Russia.

Prandtl, L., 1904. Über Flüssigkeitsbewegung bei sehr kleiner Reibung. In Verhandlungen des dritten Internationalen Mathematiker-Kongresses in Heidelberf, pp. 484-491.

Press, W. H., Flannery, B. P., Teukolsky, S. A., \& Vetterling, W. T., 1992. Numerical recipes in FORTRAN 77: The art of scientific computing. Cambridge University Press.

Raeen, K., 2008. A study of the Gibbs phenomenon in Fourier series and wavelets. Master's thesis, University of New Mexico.

Reshotko, E., 1976. Boundary-layer stability and transition. Annual Review of Fluid Mechanics, vol. 8, pp. 311-349.

Reynolds, O., 1883. An experimental investigation of the circumstances which determine whether the motion of water shall be direct or sinuous, and of the law of resistance in parallel channels. Philosophical Transactions of the Royal Society of London, vol. 174, pp. 935-982. 
Reynolds, O., 1894. On the dynamical theory of incompressible viscous fluids and the determination of the criterion. Proceedings of the Royal Society of London, vol. 56, pp. 40-45.

Rist, U. \& Fasel, H., 1995. Direct numerical simulation of controlled transition in a flat-plate boundary layer. Journal of Fluid Mechanics, vol. 298, pp. 211-248.

Roache, P. J., 1997. Quantification of uncertainty in computational fluid dynamics. Annual Review of Fluid Mechanics, vol. 29, pp. 123-160.

Roache, P. J., 1998. Verification of codes and calculations. AIAA Journal, vol. 36, pp. 696-702.

Roache, P. J., 2002. Code verification by the method of manufactured solutions. Journal of Fluids Engineering, vol. 124, n. 1, pp. 4-10.

Robinson, S. K., 1991. Coherent motions in the turbulent boundary layer. Annual Review of Fluid Mechanics, vol. 23, pp. 601-639.

Rogenski, J. K., Petri, L. A., \& Souza, L. F., 2015. Effects of parallel strategies in the transitional flow investigation. Journal of the Brazilian Society of Mechanical Sciences and Engineering, vol. 37, pp. 861-872.

Roma, A. M., Peskin, C. S., \& Berger, M. J., 1999. An adaptive version of the immersed boundary method. Journal of Computational Physics, vol. 153, n. 2, pp. 509 - 534.

Rott, N., 1990. Note on the history of the reynolds number. Annual Review of Fluid Mechanics, vol. 22, pp. 1-12.

Roy, C. J., 2005. Review of code and solution verification procedures for computational simulation. Journal of Computational Physics, vol. 205, pp. 131-156.

Roy, C. J., 2010. Review of discretization error estimators in scientific computing. In 48th AIAA Aerospace Sciences Meeting Including the New Horizons Forum and Aerospace Exposition, volume 126, Orlando, Florida.

Roy, C. J., Nelson, C. C., Smith, T. M., \& Ober, C. C., 2004. Verification of Euler/Navier-Stokes codes using the method of manufactured solutions. International Journal for Numerical Methods in Fluids, vol. 44, n. 6, pp. 599-620. 
Roy, C. J. \& Oberkampf, W. L., 2011. A comprehensive framework for verification, validation, and uncertainty quantification in scientific computing. Computer Methods in Applied Mechanics and Engineering, vol. 200, n. 25, pp. 2131-2144.

Saiki, E. M. \& Biringen, S., 1996. Numerical simulation of a cylinder in uniform flow: Application of a virtual boundary method. Journal of Computational Physics, vol. 123, pp. 450-465.

Saiki, E. M. \& Biringen, S., 1997. Spatial numerical simulation of boundary layer transition: Effects of a spherical particle. Journal of Fluid Mechanics, vol. 345, pp. 133-164.

Salari, K. \& Knupp, P., 2000. Code verification by the Method of Manufactured Solutions. Technical report, Sandia National Laboratories.

Schlichting, H., 1933. Zur Entstehung der Turbulenz bei der Plattenströmung. Nachrichten von der Gesellschaft der Wissenschaften zu Göttingen, Mathematisch-Physikalische Klasse, pp. 160-198.

Sedney, R., 1973. A survey of the effects of small protuberances on boundary-layer flows. AIAA Journal, vol. 11, pp. 782-792.

Shih, T. M., 1985. A procedure to debug computer programs. International Journal for Numerical Methods in Engineering, vol. 21, pp. 1027-1037.

Silva, H. G., de Souza, L. F., \& Medeiros, M. A. F., 2010. Verification of a mixed high-order accurate DNS code for laminar turbulent transition by the method of manufactured solutions. International Journal for Numerical Methods in Fluids, vol. 64, n. 3, pp. 336-354.

Silvestrini, J. H., 2000. Dynamics of coherent vortices in mixing layers using direct numerical and large-eddy simulations. Journal of the Brazilian Society of Mechanical Sciences, vol. 22, pp. 53-67.

Slater, J. W., 2008. Validation assessment. www.grc.nasa.gov/WWW/wind/valid/tutorial/valassess.html.

Souza, L. F., de Mendonça, M. T., \& Medeiros, M. A. F., 2005. The advantages of using high-order finite differences schemes in laminar-turbulent transition studies. International Journal for Numerical Methods in Fluids, vol. 48, pp. 565-582.

Souza, L. F. d., 2003. Instabilidade centrífuga e transição para turbulência em escoamentos laminares sobre superfícies côncavas. $\mathrm{PhD}$ thesis, Instituto Tecnológico de Aeronáutica. 
Souza, L. F. d., Oishi, C. M., Cuminato, J. A., \& Silveira Neto, A., 2006. Comparison of Poisson solvers in a transient 2D fluid flow problem with Dirichlet boundary conditions. In Proceedings of 11th Brazilian Congress of Thermal Engineering and Sciences, Curitiba - PR.

Spitaleri, R. M., 2000. Full-FAS multigrid grid generation algorithms. Applied Numerical Mathematics, vol. 32, pp. 483-494.

Steinberg, S. \& Roache, P. J., 1985. Symbolic manipulation and computational fluid dynamics. Journal of Computational Physics, vol. 57, pp. 251-284.

Stemmer, C., 2001. Direct Numerical Simulation of Harmonic Point Source Disturbances in an Airfoil Boundary Layer with Adverse Pressure Gradient. PhD thesis, Universität Stuttgart.

Stemmer, C., Kloker, M. J., \& Wagner, S., 2000. Navier-stokes simulation of harmonic point disturbances in an airfoil boundary layer. AIAA Journal, vol. 38, pp. 1369-1376.

Stuart, J. T., 1971. Nonlinear stability theory. Annual Review of Fluid Mechanics, vol. 3, pp. 347-370.

Stüben, K. \& Trottenberg, U., 1981. Nonlinear multigrid methods, the full approximation scheme, chapter 5, pp. 58-71. Lecture Notes in Mathematics. Köln-Porz.

Tani, I., 1961. Boundary Layer and Flow Control, volume 2, chapter Effect of two-dimensional and isolated roughness on laminar flow, pp. 637-656. Pergamon.

Tani, I., 1969. Boundary-layer transition. Annual Review of Fluid Mechanics, vol. 1, pp. 169-196.

Tani, I., 1977. History of boundary layer theory. Annual Review of Fluid Mechanics, vol. 9, pp. $87-111$.

Tani, I., Komoda, H., \& Komatsu, Y., 1962. Boundary-layer transition by isolated roughness. Technical Report 375, Aeronautical Research Institution.

Tollmien, W., 1929. Über die Entstehung der Turbulenz. 1. Mitteilung. Nachrichten von der Gesellschaft der Wissenschaften zu Göttingen, Mathematisch-Physikalische Klasse, vol. 1929, pp. 21-44.

von Terzi, D. A., Linnick, M. N., Seidel, J., \& Fasel, H. F., 2001. Immersed boundary techniques for high-order finite-difference methods. In AIAA Fluid Dynamics Conference and Exhibit, pp. 1-9, Anaheim, CA. 
Wassermann, P. \& Kloker, M., 2005. Transition mechanisms in a three-dimensional boundary-layer flow with pressure-gradient changeover. Journal of Fluid Mechanics, vol. 530, pp. 265-293.

Williamson, J. H., 1980. Low-storage Runge-Kutta schemes. Journal of Computational Physics, vol. 35 , pp. 48-56.

Wörner, A., 2004. Numerische Untersuchung zum Entstehungsprozess von Grenzschichtstörungen durch die Interaktion von Schallwellen mit Oberflächenrauhigkeiten. $\mathrm{PhD}$ thesis, Universität Stuttgart.

Xu, S. \& Wang, Z. J., 2006. An immersed interface method for simulating the interaction of a fluid with moving boundaries. Journal of Computational Physics, vol. 216, pp. 454-493.

Zang, T. A., Krist, S. E., \& Hussaini, M. Y., 1989. Resolution requirements for numerical simulations of transition. Journal of Scientific Computing, vol. 4, pp. 197-217.

Zhang, J., 1996. Acceleration of five-point red-black Gauss-Seidel in multigrid for Poisson equation. Applied Mathematics and Computation, vol. 80, pp. 73-93.

Zhang, J., 1997. Residual scaling techniques in multigrid, I: Equivalence proof. Applied Mathematics and Computation, vol. 86, pp. 283-303. 


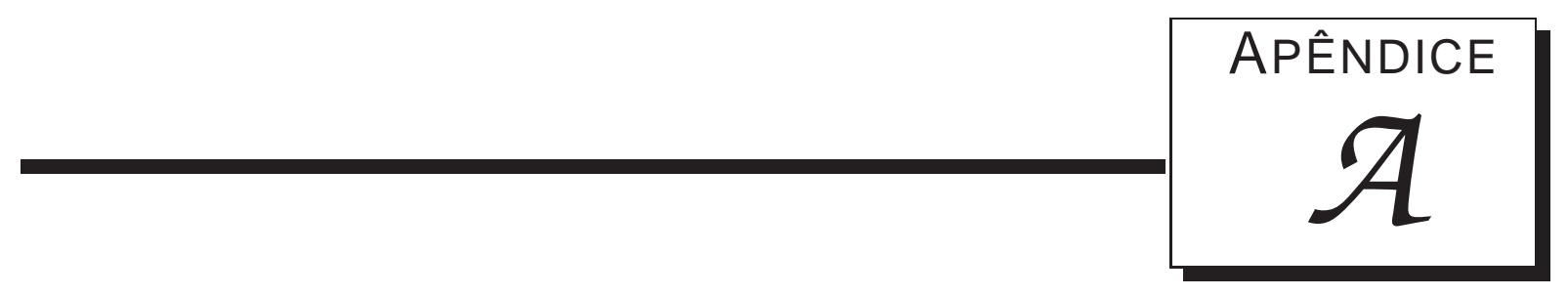

\section{Demais resultados de verificação}

Neste capítulo são apresentados resultados complementares de verificação do código DNS usando o Método das Soluções Manufaturadas.

\section{A.1 Verificação do código base bidimensional}

Uma segunda solução manufaturada foi gerada para o teste do código base com MMS. Esta solução é dada por:

$$
\begin{aligned}
u & =\cos (\alpha x) P^{\prime}(y) \\
v & =\alpha \operatorname{sen}(\alpha x) P(y) \\
\omega_{z} & =\cos (\alpha x)\left[-\alpha^{2} P(y)+P^{\prime \prime}(y)\right]
\end{aligned}
$$

em que $\alpha=0,1$ e o polinômio $P(y)$ é dado pela equação (4.1). As variáveis dessa solução bidimensional podem ser vistas na figura A.1.

As variáveis $u$ e $v$ desta solução satisfazem a equação da continuidade (equação (2.7)) e a variável $\omega_{z}$ foi obtida a partir da definição de vorticidade (equação 2.3). Ainda, para que as equações governantes sejam satisfeitas, termos fontes são adicionados à equação (2.11).

Para este teste, os mesmo parâmetros e conjuntos de malha utilizados na Seção 4.2.3 foram considerados. Na figura A.2 é mostrada a norma do erro para todas as variáveis, para ambos os conjuntos 


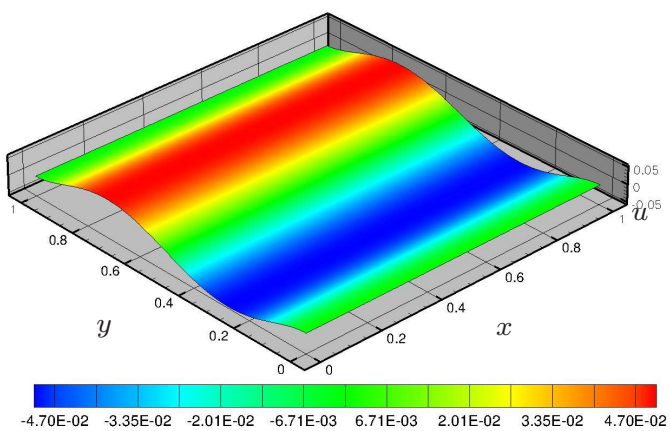

(a) Variável $u$.

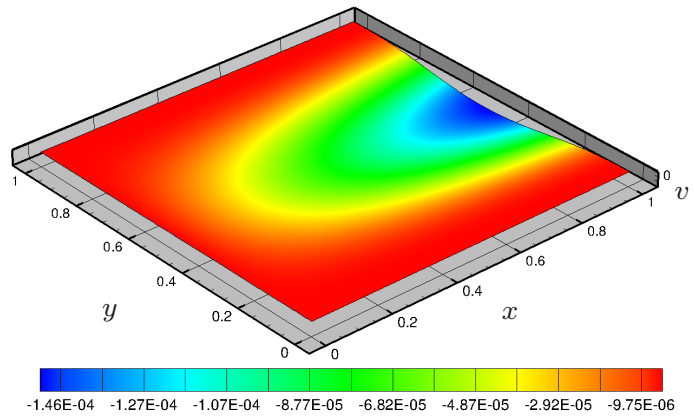

(b) Variável $v$.

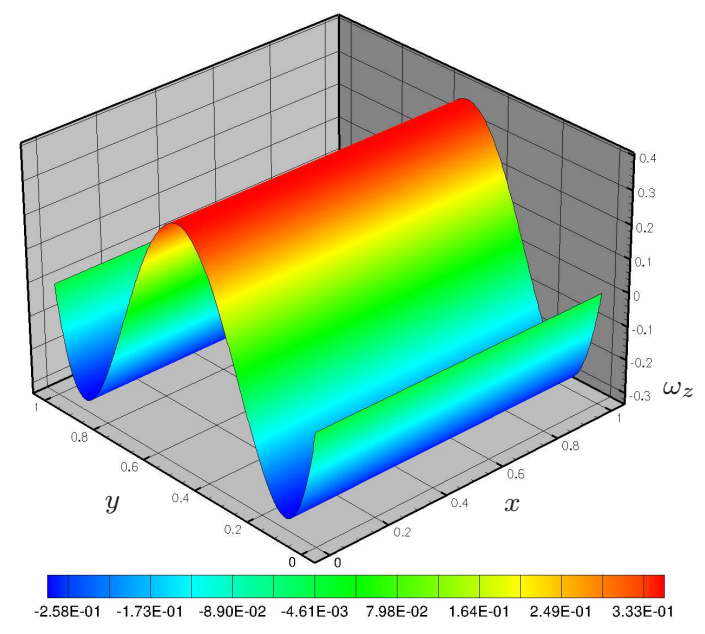

(c) Variável $\omega_{z}$.

Figura A.1: Variáveis da segunda solução bidimensional.

de malhas. Ainda, linhas representando segunda e terceira ordens de convergência são mostradas. Novamente observa-se a redução da norma do erro com o refinamento da malha e um erro maior para as malhas com estiramento na direção $y$.

A ordem de convergência para todas as malhas é mostrada na tabela A.1. Pode-se notar que a ordem de convergência está entre 1,96 e 3,59 para todas as variáveis nas malhas sem estiramento e entre 1,51 e 3,55 nas malhas com estiramento.

O decaimento do erro e as ordens de convergência obtidos com essa solução são parecidos com aqueles apresentados na Seção 4.2.3. Também pode-se perceber a redução na ordem, devido à aproximação das derivadas no contorno superior e ao uso do estiramento de malha. Porém, como já mencionado anteriormente, isso não afeta os resultados para o problema em estudo. 


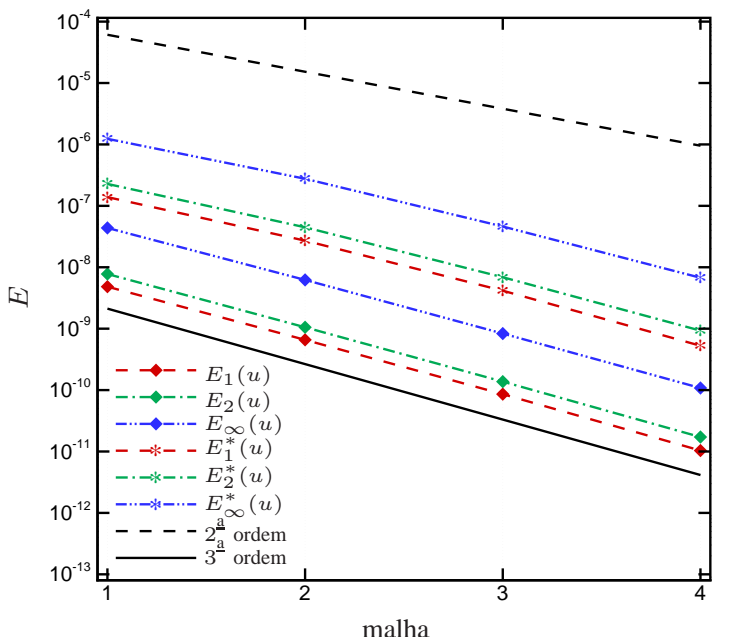

(a) Variável $u$.

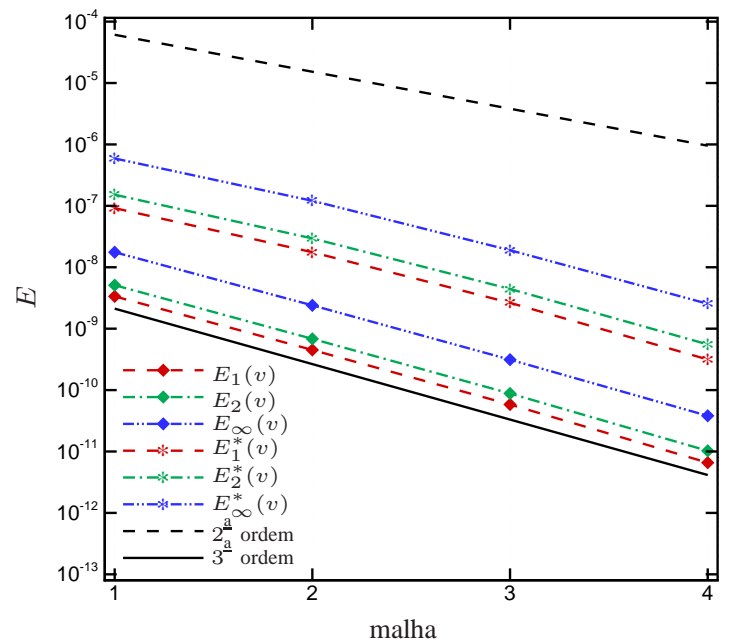

(b) Variável $v$.

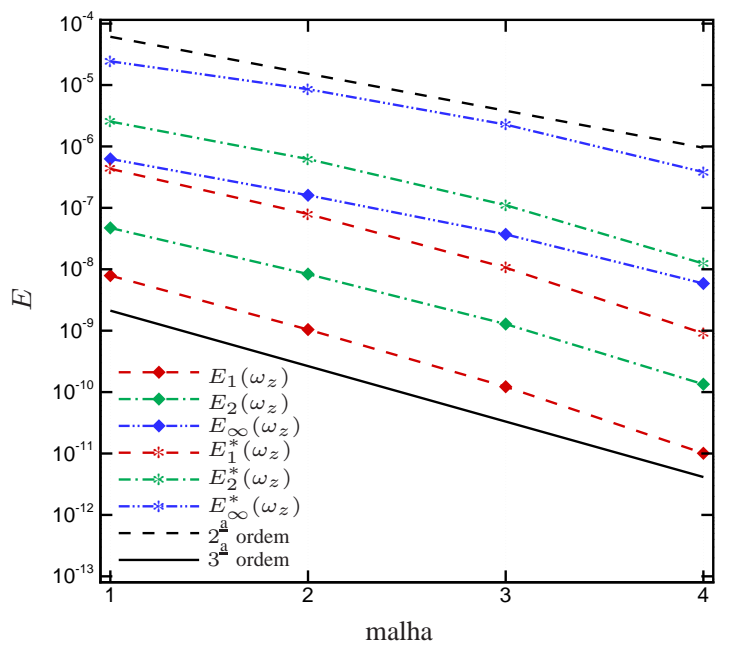

(c) Variável $\omega_{z}$.

Figura A.2: Erro $E$ para a segunda solução bidimensional ( $E$ - em escala logarítmica). ${ }^{*}$ representa as malhas com estiramento na direção $y$.

Tabela A.1: Ordem de convergência para todas as variáveis calculadas com o MMS para o caso bidimensional, com a segunda solução manufaturada. * representa as malhas com estiramento na direção $y$.

\begin{tabular}{|c|c|c|c|c|c|c|c|}
\hline Variável & Malha & $\boldsymbol{E}_{\mathbf{1}}$ & $\boldsymbol{E}_{\mathbf{2}}$ & $\boldsymbol{E}_{\boldsymbol{\infty}}$ & $\boldsymbol{E}_{\mathbf{1}}^{*}$ & $\boldsymbol{E}_{\mathbf{2}}^{*}$ & $\boldsymbol{E}_{\boldsymbol{\infty}}^{*}$ \\
\hline \multirow{4}{*}{$\boldsymbol{u}$} & 2 & 2,87 & 2,88 & 2,81 & 2,35 & 2,34 & 2,16 \\
\cline { 2 - 8 } & 3 & 2,93 & 2,93 & 2,90 & 2,70 & 2,70 & 2,58 \\
\cline { 2 - 8 } & 4 & 3,05 & 2,99 & 2,94 & 2,97 & 2,88 & 2,77 \\
\hline \multirow{3}{*}{$\boldsymbol{v}$} & 2 & 2,89 & 2,90 & 2,87 & 2,38 & 2,36 & 2,29 \\
\cline { 2 - 8 } & 3 & 2,95 & 2,95 & 2,93 & 2,73 & 2,73 & 2,67 \\
\cline { 2 - 8 } & 4 & 3,14 & 3,10 & 3,03 & 3,06 & 2,99 & 2,89 \\
\hline \multirow{3}{*}{$\boldsymbol{\omega}_{\boldsymbol{z}}$} & 2 & 2,91 & 2,49 & 1,96 & 2,44 & 2,03 & 1,51 \\
\cline { 2 - 8 } & 3 & 3,09 & 2,70 & 2,11 & 2,90 & 2,49 & 1,91 \\
\cline { 2 - 7 } & 4 & 3,59 & 3,25 & 2,65 & 3,55 & 3,16 & 2,57 \\
\hline
\end{tabular}




\section{A.2 Verificação do código DNS tridimensional}

Para o caso tridimensional, outras 4 soluções manufaturadas foram geradas. A primeira delas, denominada aqui de solução A, é a mesma solução bidimensional apresentada no Apêndice A.1:

$$
\begin{aligned}
u & =\cos (\alpha x) P^{\prime}(y), \\
v & =\alpha \operatorname{sen}(\alpha x) P(y), \\
w & =0, \\
\omega_{x} & =0, \\
\omega_{y} & =0, \\
\omega_{z} & =\cos (\alpha x)\left[-\alpha^{2} P(y)+P^{\prime \prime}(y)\right],
\end{aligned}
$$

em que $\alpha=0,1$ e o polinômio $P(y)$ é dado pela equação (4.1).

Os parâmetros e as malhas considerados para esse caso são os mesmos do teste da Seção 4.2.4.

A norma do erro para todas as variáveis, em todas as malhas, é mostrada na figura A.3, juntamente com linhas de referência mostrando segunda e quarta ordens de convergência.

Comparando-se com os resultados do caso bidimensional (Apêndice A.1), pode-se observar que o decaimento do erro tem o mesmo comportamento para as malhas sem estiramento na direção $y$, enquanto que para as malhas com estiramento, o erro cai com menor ordem. Esse fato também pode ser observado nos resultados apresentados na tabela A.2.

A ordem de convergência para todas as variáveis, nos dois conjuntos de malhas é mostrada na tabela A.2. Pode-se notar que a ordem de convergência está entre 2,71 e 4,83 para todas as variáveis nas malhas sem estiramento e entre 1,38 e 3,27 nas malhas com estiramento.

A segunda solução manufaturada, denominada de solução B é a mesma solução bidimensional 


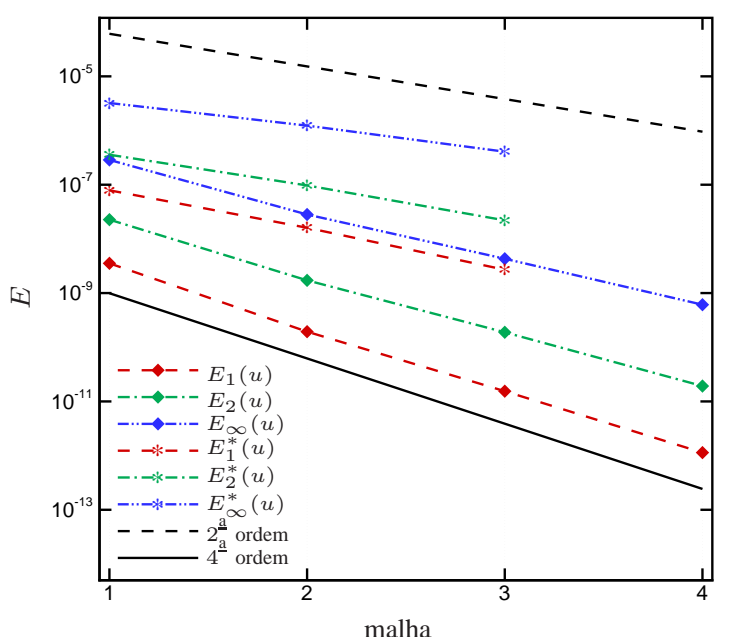

(a) Variável $u$.

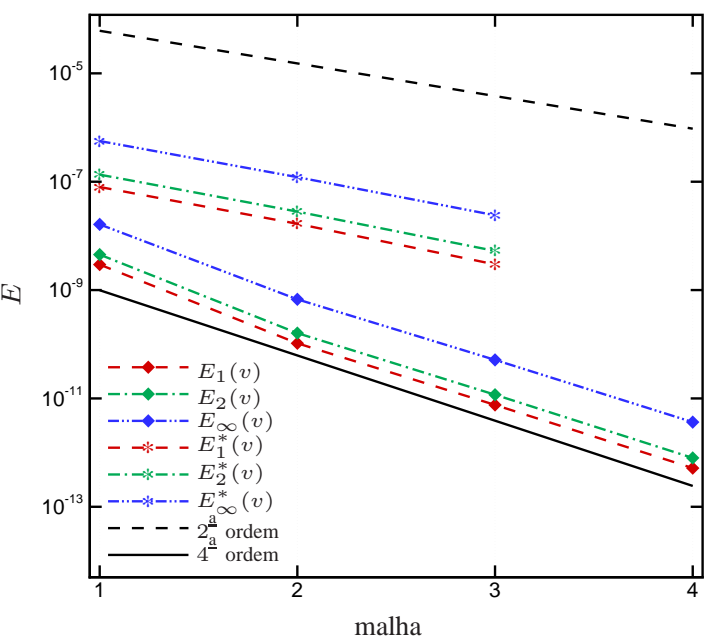

(b) Variável $v$.

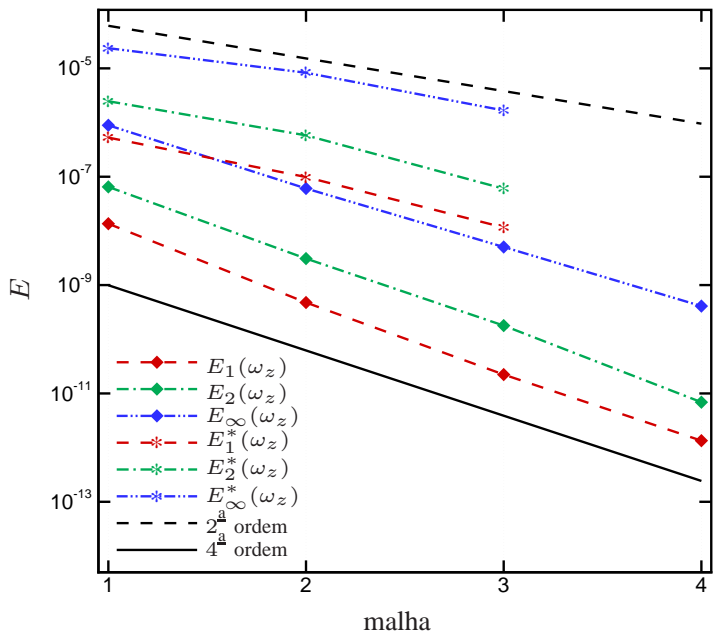

(c) Variável $\omega_{z}$.

Figura A.3: Erro $E$ para a solução tridimensional A ( $E$ - em escala logarítmica). * representa as malhas com estiramento na direção $y$.

Tabela A.2: Ordem de convergência para todas as variáveis calculadas com o MMS para o caso tridimensional, com a solução A. * representa as malhas com estiramento na direção $y$.

\begin{tabular}{|c|c|c|c|c|c|c|c|}
\hline Variável & Malha & $\boldsymbol{E}_{\mathbf{1}}$ & $\boldsymbol{E}_{\mathbf{2}}$ & $\boldsymbol{E}_{\boldsymbol{\infty}}$ & $\boldsymbol{E}_{\mathbf{1}}^{*}$ & $\boldsymbol{E}_{\mathbf{2}}^{*}$ & $\boldsymbol{E}_{\boldsymbol{\infty}}^{*}$ \\
\hline \multirow{4}{*}{$\boldsymbol{u}$} & 2 & 4,19 & 3,72 & 3,34 & 2,29 & 1,88 & 1,38 \\
\cline { 2 - 8 } & 3 & 3,64 & 3,18 & 2,71 & 2,57 & 2,13 & 1,59 \\
\cline { 2 - 8 } & 4 & 3,76 & 3,29 & 2,81 & - & - & - \\
\hline \multirow{3}{*}{$\boldsymbol{v}$} & 2 & 4,82 & 4,81 & 4,59 & 2,25 & 2,26 & 2,21 \\
\cline { 2 - 8 } & 3 & 3,78 & 3,77 & 3,71 & 2,49 & 2,41 & 2,33 \\
\cline { 2 - 8 } & 4 & 3,87 & 3,87 & 3,81 & - & - & - \\
\hline \multirow{3}{*}{$\boldsymbol{\omega}_{\boldsymbol{z}}$} & 2 & 4,83 & 4,39 & 3,87 & 2,41 & 2,09 & 1,50 \\
\cline { 2 - 8 } & 3 & 4,41 & 4,10 & 3,58 & 3,09 & 3,27 & 2,31 \\
\cline { 2 - 8 } & 4 & 4,05 & 4,69 & 3,62 & - & - & - \\
\hline
\end{tabular}


apresentada na Seção 4.2.3:

$$
\begin{aligned}
u & =\operatorname{sen}(\alpha x) e^{-y}\left[P(y)-P^{\prime}(y)\right], \\
v & =\alpha \cos (\alpha x) P(y) e^{-y}, \\
w & =0, \\
\omega_{x} & =0, \\
\omega_{y} & =0, \\
\omega_{z} & =\operatorname{sen}(\alpha x) e^{-y}\left[\left(\alpha^{2}-1\right) P(y)+2 P^{\prime}(y)-P^{\prime \prime}(y)\right],
\end{aligned}
$$

em que $\alpha=0,1$ e o polinômio $P(y)$ é dado pela equação (4.1).

Na figura A.4 é apresentada a norma do erro para todas as variáveis, obtida com os dois conjuntos de malhas. Linhas de referência representando segunda e quarta ordens de convergência são também apresentadas nesta figura. Assim como no caso bidimensional, pode-se observar o decaimento do erro com o refinamento da malha e a diferença entre o erro nas malhas sem e com estiramento.

A ordem de convergência para todas as variáveis nos dois conjuntos de malhas é apresentada na tabela A.3. De acordo com os resultados da tabela A.3, a ordem de convergência para todas as variáveis varia de 2,09 (1,61) a 6,47 (3,33) para a malha sem (com) estiramento.

Tabela A.3: Ordem de convergência para todas as variáveis calculadas com o MMS para o caso tridimensional, com a solução B. ${ }^{*}$ representa as malhas com estiramento na direção $y$.

\begin{tabular}{|c|c|c|c|c|c|c|c|}
\hline Variável & Malha & $\boldsymbol{E}_{\mathbf{1}}$ & $\boldsymbol{E}_{\mathbf{2}}$ & $\boldsymbol{E}_{\boldsymbol{\infty}}$ & $\boldsymbol{E}_{\mathbf{1}}^{*}$ & $\boldsymbol{E}_{\mathbf{2}}^{*}$ & $\boldsymbol{E}_{\boldsymbol{\infty}}^{*}$ \\
\hline \multirow{4}{*}{$\boldsymbol{u}$} & 2 & 3,06 & 2,58 & 2,09 & 2,54 & 2,11 & 1,61 \\
\cline { 2 - 8 } & 3 & 6,47 & 6,30 & 5,72 & 2,47 & 1,96 & 1,38 \\
\cline { 2 - 8 } & 4 & 4,11 & 3,94 & 3,45 & - & - & - \\
\hline \multirow{3}{*}{$\boldsymbol{v}$} & 2 & 3,03 & 3,05 & 3,05 & 2,56 & 2,57 & 2,53 \\
\cline { 2 - 8 } & 3 & 5,70 & 5,72 & 5,82 & 2,66 & 2,60 & 2,48 \\
\cline { 2 - 8 } & 4 & 3,90 & 3,90 & 3,93 & - & - & - \\
\hline \multirow{3}{*}{$\boldsymbol{\omega}_{\boldsymbol{z}}$} & 2 & 3,15 & 2,68 & 2,14 & 2,79 & 2,35 & 1,79 \\
\cline { 2 - 8 } & 3 & 6,23 & 5,94 & 5,12 & 3,33 & 3,03 & 2,25 \\
\cline { 2 - 8 } & 4 & 4,43 & 4,35 & 3,43 & - & - & - \\
\hline
\end{tabular}

Nota-se, em comparação com o caso bidimensional, que a ordem de convergência para todas as variáveis aumentou para as malhas sem estiramento e diminuiu para as malhas com estiramento. Isto mostra que o código tridimensional é mais sensível ao uso de estiramento de malha na direção y.

Outras duas soluções tridimensionais foram geradas. A primeira delas (que representa o terceiro 


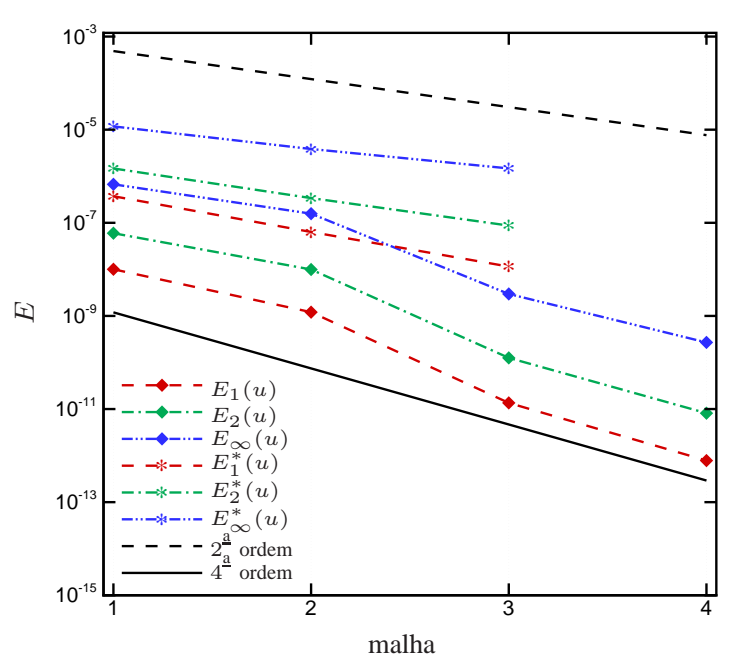

(a) Variável $u$.

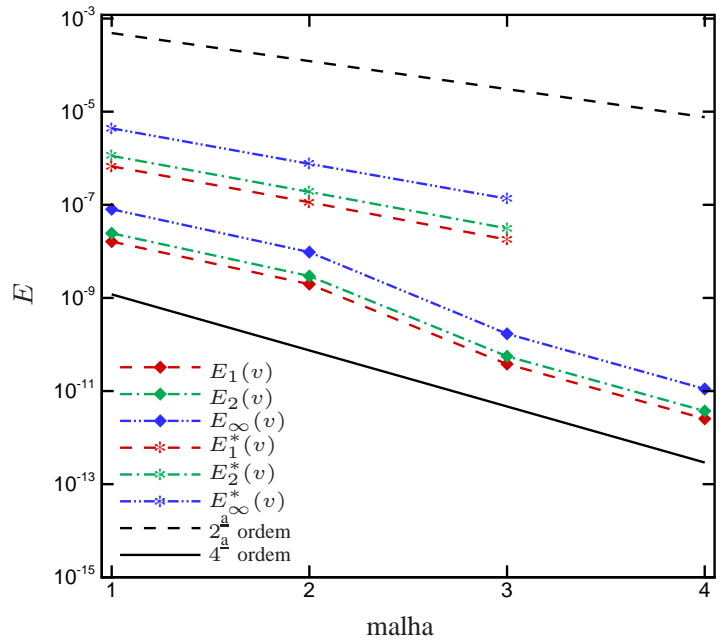

(b) Variável $v$.

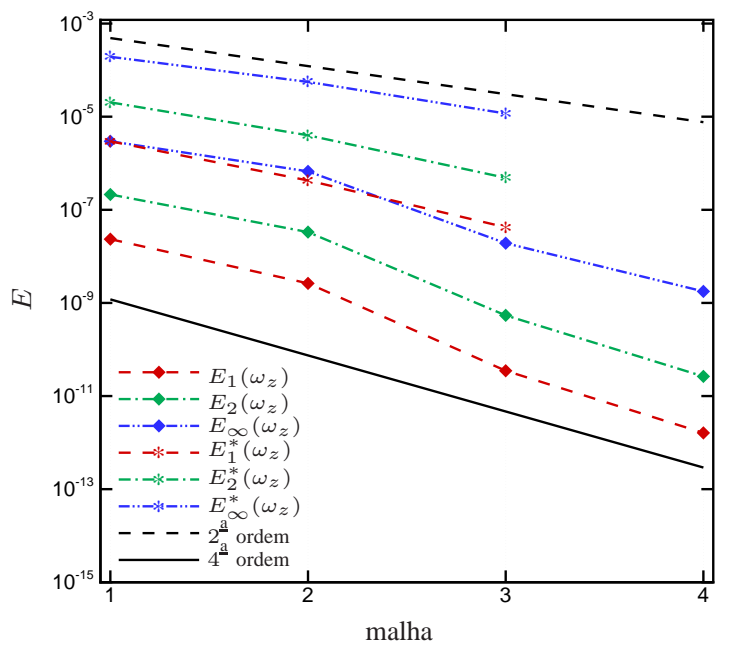

(c) Variável $\omega_{z}$.

Figura A.4: Erro $E$ para a solução tridimensional B ( $E$ - em escala logarítmica). * representa as malhas com estiramento na direção $y$.

teste tridimensional) é denominada de solução C. As variáveis dessa solução também satisfazem a equação da continuidade (2.7) e as definições de vorticidade (2.1)-(2.3). A solução C é dada por:

$$
\begin{aligned}
u & =-\operatorname{sen}(x) \operatorname{sen}(z) P^{\prime}(y), \\
v & =\cos (x) \cos (z) P(y) \\
w & =-\cos (x) P^{\prime}(y)[\cos (z)+\operatorname{sen}(z)], \\
\omega_{x} & =\cos (x)\left\{\operatorname{sen}(z)\left[-P(y)+P^{\prime \prime}(y)\right]+\cos (z) P^{\prime \prime}(y)\right\} \\
\omega_{y} & =\operatorname{sen}(x) P^{\prime}(y)[2 \cos (z)+\operatorname{sen}(z)], \\
\omega_{z} & =\operatorname{sen}(x)\left[\cos (z) P(y)-\operatorname{sen}(z) P^{\prime \prime}(y)\right],
\end{aligned}
$$


com $P(y)$ sendo o polinômio (4.1).

Novamente, os parâmetros e malhas são mantidos. A norma do erro para todas as variáveis, em todas as malhas, é apresentada na figura A.5. Nesta figura também são mostradas linhas de referência de segunda e terceira ordens de convergência. Pode-se observar que o decaimento do erro tem comportamento parecido com o apresentado na Seção 4.2.4.

Na tabela A.4 são mostradas as ordens de convergência para todas as variáveis em ambos os conjuntos de malhas. Os resultados da tabela A.4 mostram ordem de convergência entre 1,92 $(1,52)$ e $3,84(3,19)$ para todas as variáveis, nas malhas sem (com) estiramento.

Tabela A.4: Ordem de convergência para todas as variáveis calculadas com o MMS para o caso tridimensional, com a solução C. ${ }^{*}$ representa as malhas com estiramento na direção $y$.

\begin{tabular}{|c|c|c|c|c|c|c|c|}
\hline Variável & Malha & $\boldsymbol{E}_{\mathbf{1}}$ & $\boldsymbol{E}_{\mathbf{2}}$ & $\boldsymbol{E}_{\boldsymbol{\infty}}$ & $\boldsymbol{E}_{\mathbf{1}}^{*}$ & $\boldsymbol{E}_{\mathbf{2}}^{*}$ & $\boldsymbol{E}_{\boldsymbol{\infty}}^{*}$ \\
\hline \multirow{4}{*}{$\boldsymbol{u}$} & 2 & 2,88 & 2,42 & 1,92 & 2,40 & 1,99 & 1,62 \\
\cline { 2 - 8 } & 3 & 2,98 & 2,50 & 2,01 & 2,46 & 1,97 & 1,52 \\
\cline { 2 - 8 } & 4 & 3,36 & 2,88 & 2,37 & - & - & - \\
\hline \multirow{4}{*}{$\boldsymbol{v}$} & 2 & 2,89 & 2,90 & 2,89 & 2,39 & 2,40 & 2,40 \\
\cline { 2 - 8 } & 3 & 3,01 & 3,00 & 3,00 & 2,61 & 2,57 & 2,49 \\
\cline { 2 - 8 } & 4 & 3,29 & 3,32 & 3,35 & - & - & - \\
\hline \multirow{4}{*}{$\boldsymbol{\omega}$} & 2 & 2,88 & 2,42 & 1,93 & 2,41 & 2,00 & 1,54 \\
\cline { 2 - 8 } & 3 & 2,97 & 2,49 & 2,01 & 2,53 & 2,06 & 1,57 \\
\cline { 2 - 8 } & 4 & 3,31 & 2,84 & 2,35 & - & - & - \\
\cline { 2 - 8 } & 2 & 3,20 & 3,17 & 2,63 & 2,66 & 2,39 & 1,69 \\
\cline { 2 - 8 } & 3 & 3,17 & 3,18 & 3,01 & 2,80 & 2,84 & 2,48 \\
\hline \multirow{4}{*}{} & 2 & 3,26 & 3,35 & 3,77 & - & - & - \\
\cline { 2 - 8 } & 3 & 3,03 & 3,04 & 3,02 & 2,62 & 2,59 & 2,61 \\
\cline { 2 - 8 } & 4 & 3,21 & 3,20 & 3,22 & - & - & - \\
\hline \multirow{3}{*}{$\boldsymbol{\omega}_{\boldsymbol{z}}$} & 2 & 3,58 & 3,06 & 2,61 & 2,73 & 2,19 & 1,66 \\
\cline { 2 - 8 } & 3 & 3,52 & 3,36 & 2,55 & 3,19 & 2,95 & 2,17 \\
\cline { 2 - 8 } & 4 & 3,55 & 3,84 & 2,88 & - & - & - \\
\hline
\end{tabular}

Observa-se que a ordem de convergência da solução C é um pouco menor que a ordem de convergência da solução manufaturada apresentada na Seção 4.2.4. Esse fato pode estar ligado à solução manufaturada utilizada em cada teste.

Finalmente, foi gerada uma quarta solução tridimensional manufaturada, denominada de solução 


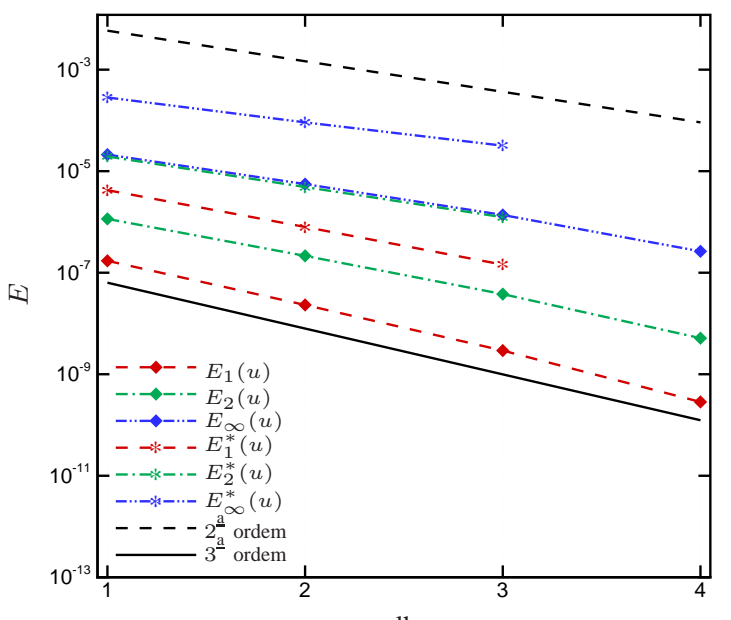

(a) Variável $u$.

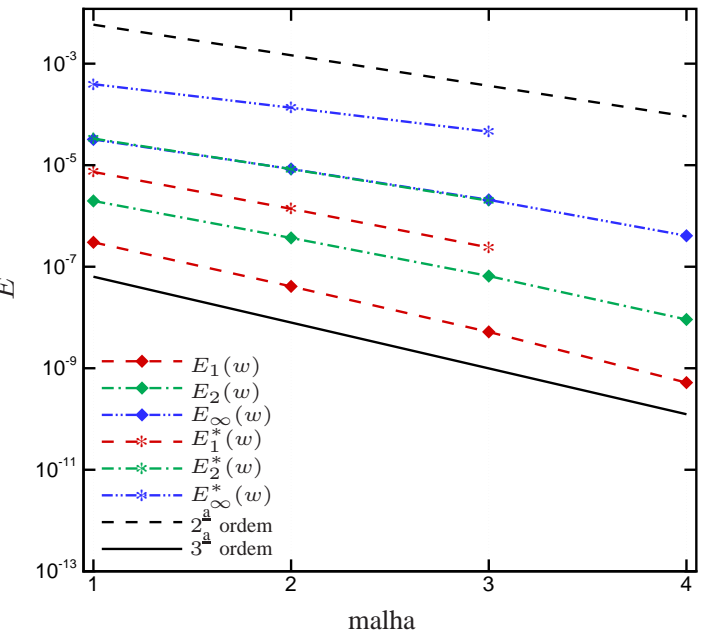

(c) Variável $w$.

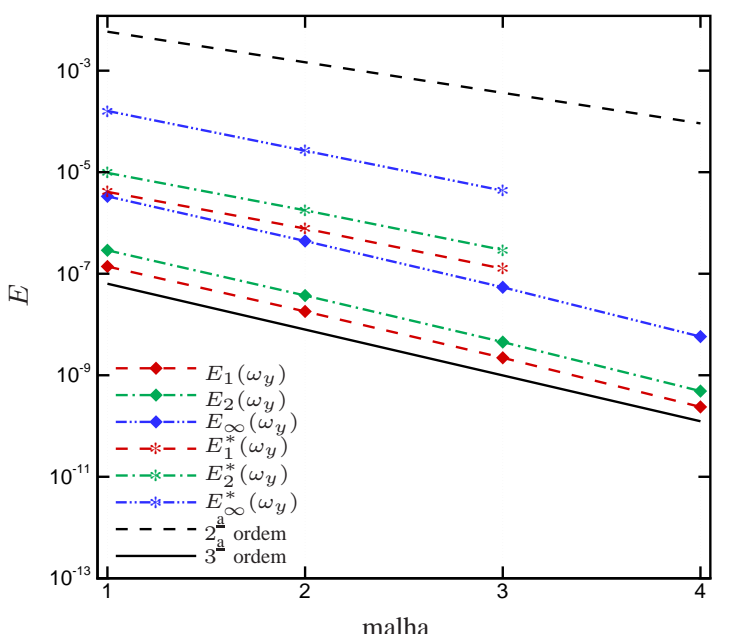

(e) Variável $\omega_{y}$.

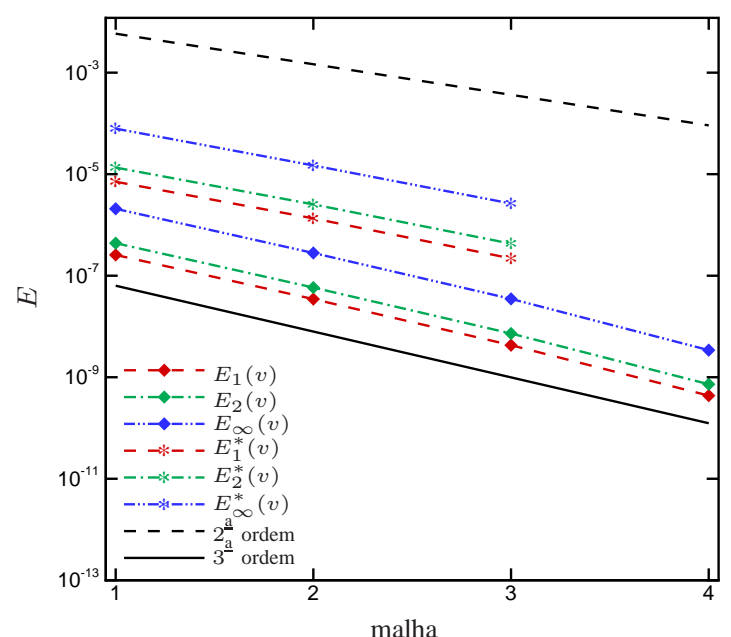

(b) Variável $v$.

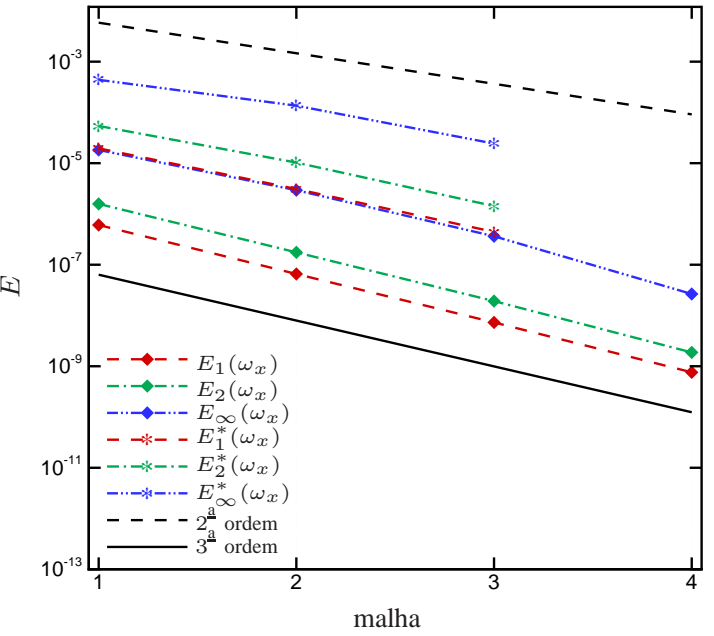

(d) Variável $\omega_{x}$.

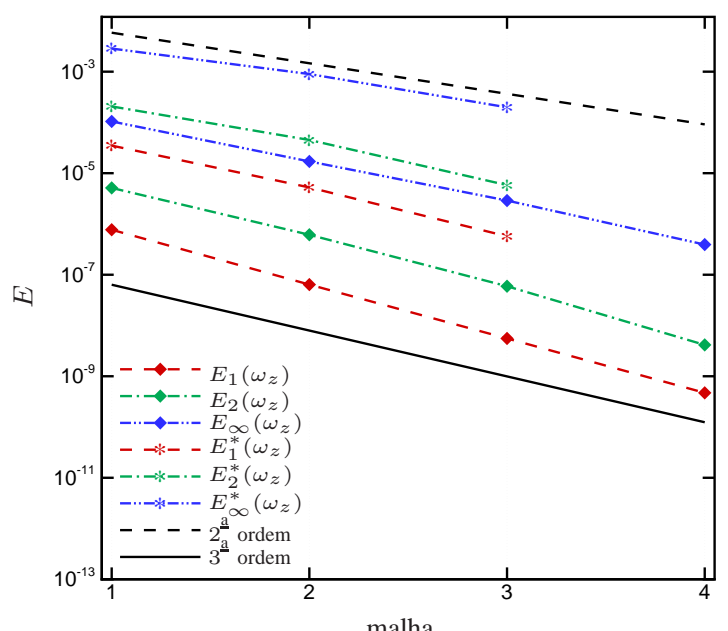

(f) Variável $\omega_{z}$.

Figura A.5: Erro $E$ para a solução tridimensional C ( $E$ - em escala logarítmica). ${ }^{*}$ representa as malhas com estiramento na direção $y$. 
D, e dada por:

$$
\begin{aligned}
u & =-\operatorname{sen}(x) \operatorname{sen}(z) P^{\prime}(y), \\
v & =\cos (x) \cos (z) P(y) e^{-y}, \\
w & =\cos (x)\left\{\operatorname{sen}(z) e^{-y}\left[P(y)-P^{\prime}(y)\right]-\cos (z) P^{\prime}(y)\right\}, \\
\omega_{x} & =\cos (x)\left\{\operatorname{sen}(z) e^{-y}\left[-2 P^{\prime}(y)+P^{\prime \prime}(y)\right]+\cos (z) P^{\prime \prime}(y)\right\}, \\
\omega_{y} & =\operatorname{sen}(x)\left\{\operatorname{sen}(z) e^{-y}\left[-P(y)+P^{\prime}(y)\right]+2 \cos (z) P^{\prime}(y)\right\}, \\
\omega_{z} & =\operatorname{sen}(x)\left\{\cos (z) P(y) e^{-y}-\operatorname{sen}(z) P^{\prime \prime}(y)\right\},
\end{aligned}
$$

em que $P(y)$ é o polinômio (4.1).

Assim como as demais, as variáveis dessa solução satisfazem a equação da continuidade (2.7) e as definições de vorticidade (2.1)-(2.3). Além disso, termos fontes também são adicionados às equações (2.4)-(2.6) para que as equações governantes sejam satisfeitas.

Os mesmos parâmetros e malhas usados nos testes anteriores são novamente usados nesse teste. Na figura A.6 é apresentada a norma do erro para todas as variáveis, em todas as malhas. Linhas de referência de segunda e quarta ordens de convergência são também mostradas na figura A.6.

As ordens de convergência para todas as variáveis, em ambos os conjuntos de malhas são apresentadas na tabela A.5. Os resultados dessa tabela mostram que a ordem de convergência está entre $2,01(1,67)$ e 4,27 $(3,40)$ para todas as variáveis, nas malhas sem (com) estiramento.

Assim como nos testes anteriores, é possível observar que a norma do erro diminui conforme o refinamento da malha. Ainda, pode-se notar que a ordem de convergência tem uma pequena variação dependendo da solução manufaturada utilizada. Porém, o estiramento de malha na direção y causa maior redução na ordem de convergência. Contudo, como mencionado anteriormente, o estiramento de malha não afeta o estudo de escoamentos em camada limite. 


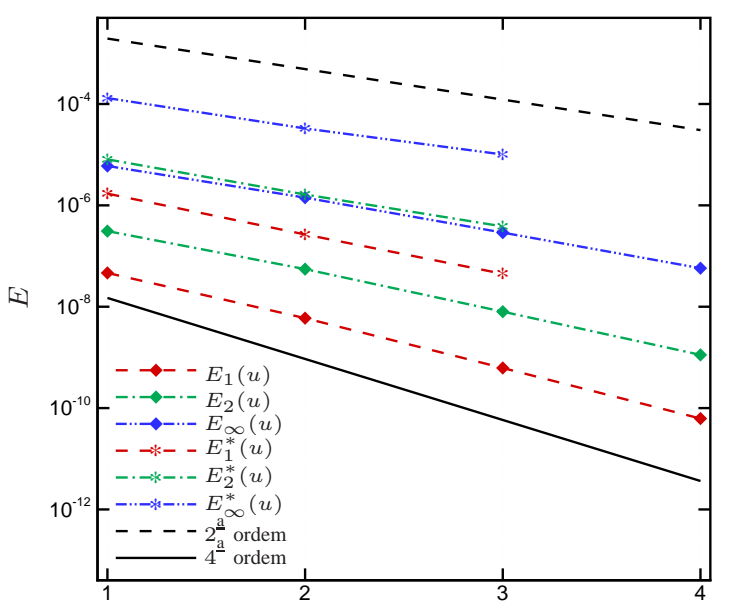

malha

(a) Variável $u$.

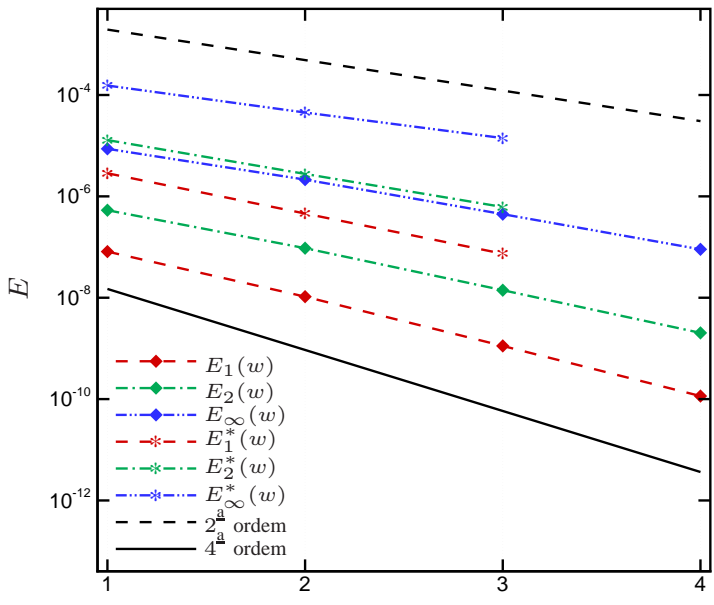

malha
c) Variável $w$.

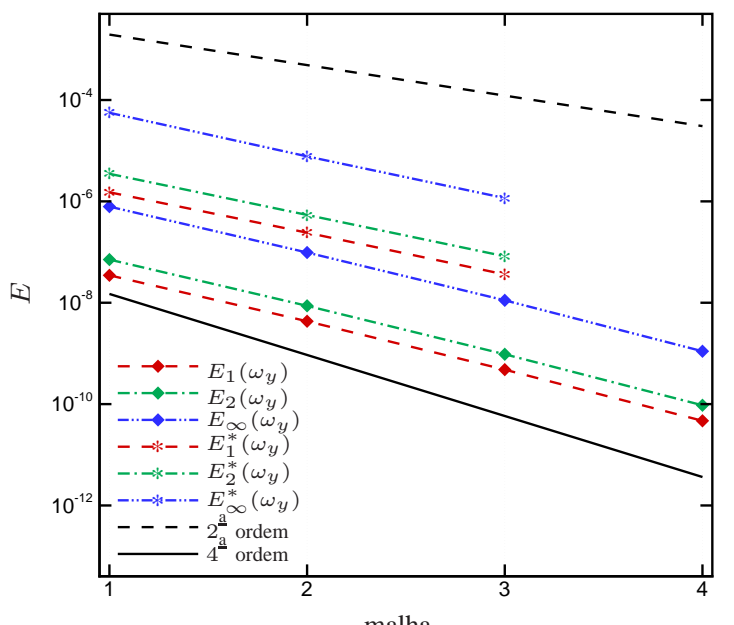

(e) Variável $\omega_{y}$.

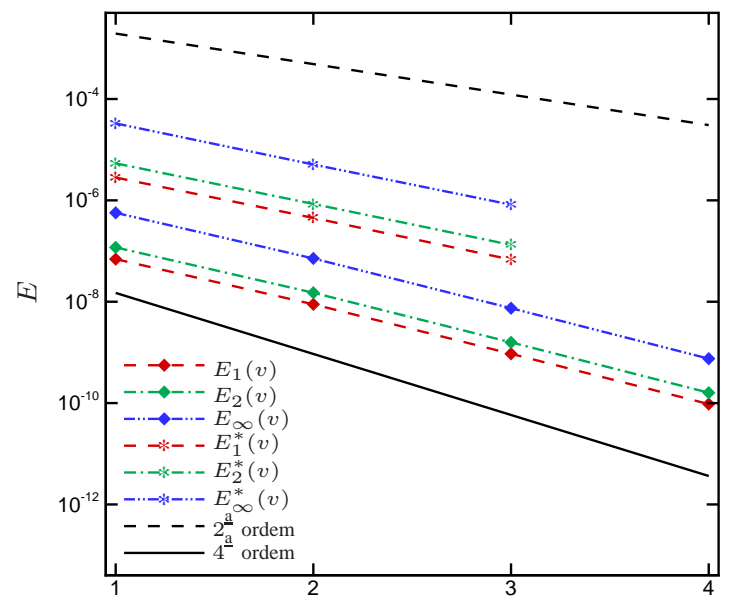

malha

(b) Variável $v$

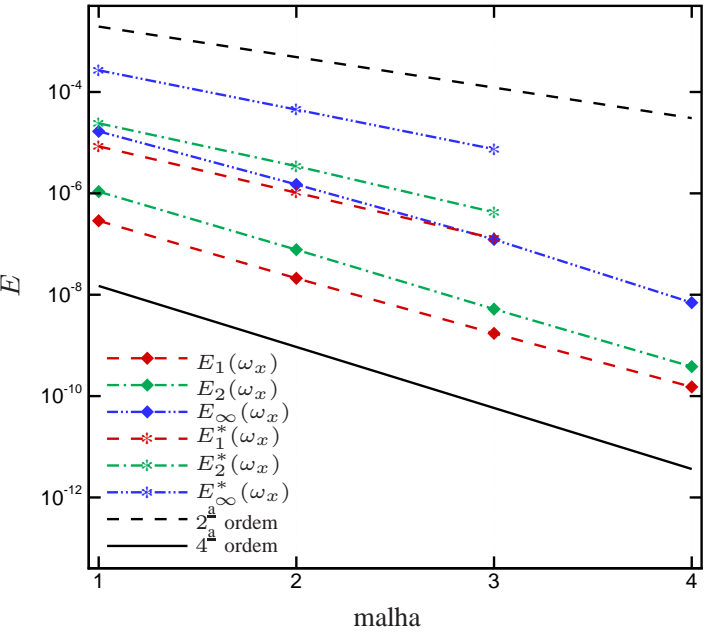

(d) Variável $\omega_{x}$.

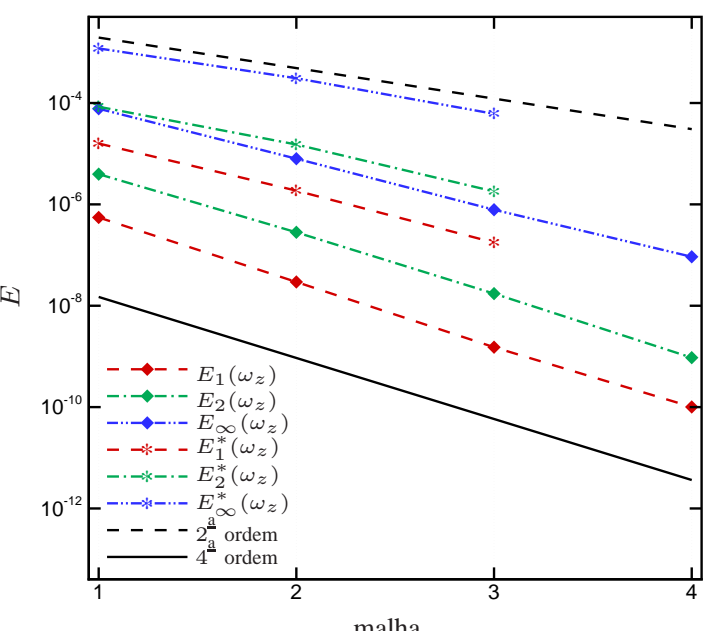

(f) Variável $\omega_{z}$.

Figura A.6: Erro $E$ para a solução tridimensional D ( $E$ - em escala logarítmica). * representa as malhas com estiramento na direção $y$. 
Tabela A.5: Ordem de convergência para todas as variáveis calculadas com o MMS para o caso tridimensional, com a solução D. * representa as malhas com estiramento na direção $y$.

\begin{tabular}{|c|c|c|c|c|c|c|c|}
\hline Variável & Malha & $\boldsymbol{E}_{\mathbf{1}}$ & $\boldsymbol{E}_{\mathbf{2}}$ & $\boldsymbol{E}_{\boldsymbol{\infty}}$ & $\boldsymbol{E}_{\mathbf{1}}^{*}$ & $\boldsymbol{E}_{\mathbf{2}}^{*}$ & $\boldsymbol{E}_{\boldsymbol{\infty}}^{*}$ \\
\hline \multirow{4}{*}{$\boldsymbol{u}$} & 2 & 2,96 & 2,49 & 2,07 & 2,67 & 2,30 & 1,99 \\
\cline { 2 - 8 } & 3 & 3,26 & 2,78 & 2,29 & 2,58 & 2,09 & 1,70 \\
\cline { 2 - 8 } & 4 & 3,31 & 2,83 & 2,33 & - & - & - \\
\hline \multirow{4}{*}{$\boldsymbol{v}$} & 2 & 2,96 & 2,97 & 2,99 & 2,64 & 2,66 & 2,69 \\
\cline { 2 - 8 } & 3 & 3,24 & 3,25 & 3,25 & 2,73 & 2,68 & 2,63 \\
\cline { 2 - 8 } & 4 & 3,29 & 3,29 & 3,30 & - & - & - \\
\hline \multirow{4}{*}{$\boldsymbol{\omega}$} & 2 & 2,95 & 2,48 & 2,01 & 2,63 & 2,21 & 1,76 \\
\cline { 2 - 8 } & 3 & 3,22 & 2,75 & 2,26 & 2,63 & 2,16 & 1,67 \\
\cline { 2 - 8 } & 4 & 3,28 & 2,79 & 2,30 & - & - & - \\
\cline { 2 - 8 } & 2 & 3,77 & 3,80 & 3,48 & 3,04 & 2,81 & 2,57 \\
\cline { 2 - 8 } & 3 & 3,61 & 3,89 & 3,60 & 2,99 & 3,02 & 2,59 \\
\hline \multirow{4}{*}{} & 2 & 3,50 & 3,77 & 4,14 & - & - & - \\
\cline { 2 - 8 } & 3 & 3,17 & 3,03 & 3,00 & 2,64 & 2,69 & 2,85 \\
\cline { 2 - 8 } & 4 & 3,35 & 3,34 & 3,33 & - & - & - \\
\hline \multirow{3}{*}{$\boldsymbol{\omega}_{\boldsymbol{z}}$} & 2 & 4,22 & 3,81 & 3,27 & 3,09 & 2,47 & 1,95 \\
\cline { 2 - 8 } & 3 & 4,27 & 4,01 & 3,34 & 3,40 & 3,07 & 2,33 \\
\cline { 2 - 7 } & 4 & 3,91 & 4,19 & 3,08 & - & - & - \\
\hline
\end{tabular}


APÊNDICE $\mathcal{B}$

\section{Demais resultados de validação}

Neste capítulo são apresentados resultados complementares de validação do código DNS através da comparação com resultados experimentais e da teoria de estabilidade linear.

\section{B.1 Características da camada limite}

Nesta seção, as mesmas características da camada limite da Seção 4.3.1 são consideradas para comparação. Três outros casos foram definidos para a comparação destas características:

Caso A. escoamento com gradiente de pressão próximo de zero, com os parâmetros: velocidade de referência $\tilde{U}_{\infty}=29,4985 \mathrm{~m} / \mathrm{s}$, viscosidade cinemática $\tilde{\nu}=1,56 \times 10^{-5} \mathrm{~m}^{2} / \mathrm{s}$ e número de Reynolds $R e=340367,308$;

Caso B. escoamento com gradiente de pressão próximo de zero, com os parâmetros: velocidade de referência $\tilde{U}_{\infty}=29,4985 \mathrm{~m} / \mathrm{s}$, viscosidade cinemática $\tilde{\nu}=1,55 \times 10^{-5} \mathrm{~m}^{2} / \mathrm{s}$ e número de Reynolds $R e=342563,225$;

Caso C. escoamento com gradiente de pressão favorável, com os parâmetros: velocidade de referência $\tilde{U}_{\infty}=27,935 \mathrm{~m} / \mathrm{s}$, viscosidade cinemática $\tilde{\nu}=1,56 \times 10^{-5} \mathrm{~m}^{2} / \mathrm{s}$ e número de Reynolds $R e=322326,923$. 
Os demais parâmetros de simulação e adimensionalização são os mesmos da Seção 4.3.1. Lembrando que os dados experimentais foram fornecidos pelo aluno de doutorado Dipl.-Ing. Benjamin Plogmann e pelo professor Dr.-Ing. Werner Würz do IAG.

\section{B.1.1 Resultados do caso A}

Os resultados numéricos do código DNS-2D para o caso A são comparados aos dados experimentais na figura B.1. O desvio máximo (em \%) dos resultados numéricos em relação aos dados experimentais do caso A, para cada característica da camada limite, é mostrado na tabela B.1.

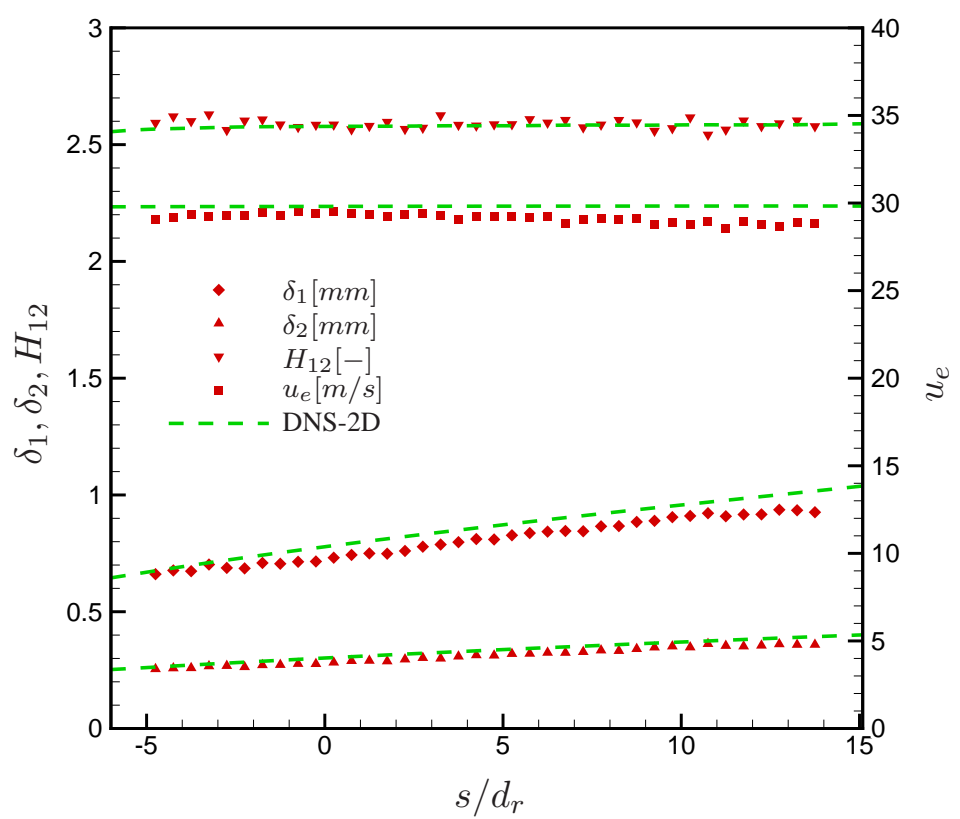

Figura B.1: Características da camada limite para o escoamento do caso A.

Tabela B.1: Desvio máximo (em \%) entre os resultados numéricos e os dados experimentais para o caso A.

\begin{tabular}{|c|c|c|c|c|}
\hline Característica & $\delta_{1}$ & $\delta_{2}$ & $H_{12}$ & $u_{e}$ \\
\hline Desvio máximo (em \%) & 9,8282 & 9,4931 & 2,1418 & 4,4662 \\
\hline
\end{tabular}

É possível observar, na figura B.1, que os resultados numéricos para o perfil de velocidade e os parâmetros integrais da camada limite estão próximos aos dados experimentais. Os resultados da tabela B.1 indicam que o código DNS-2D é capaz de simular este tipo de escoamento em conformidade com resultados experimentais, uma vez que o desvio máximo é menor do que $10 \%$.

\section{B.1.2 Resultados do caso B}

Para o caso B, os resultados numéricos são comparados aos dados experimentais na figura B.2. O desvio máximo (em \%) dos resultados numéricos em relação aos dados experimentais do caso B, 
para cada característica da camada limite, é mostrado na tabela B.2.

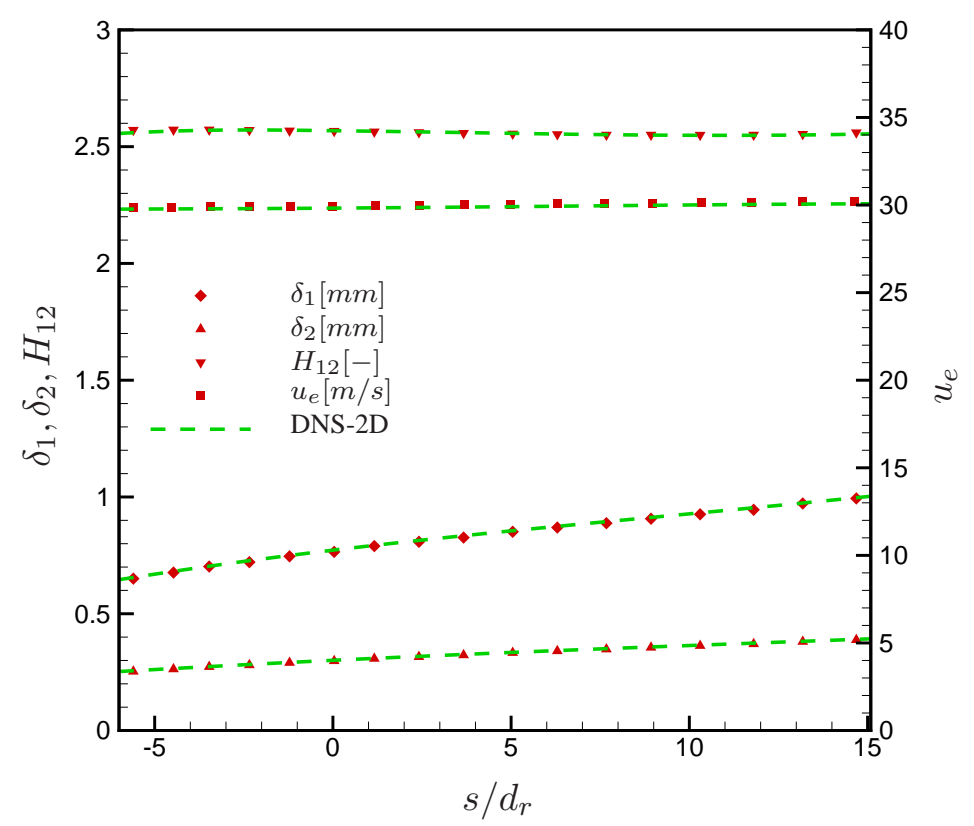

Figura B.2: Características da camada limite para o escoamento do caso B.

Tabela B.2: Desvio máximo (em \%) entre os resultados numéricos e os dados experimentais para o caso B.

\begin{tabular}{|c|c|c|c|c|}
\hline Característica & $\delta_{1}$ & $\delta_{2}$ & $H_{12}$ & $u_{e}$ \\
\hline Desvio máximo (em $\%)$ & 2,3576 & 3,0367 & 0,8313 & 0,6116 \\
\hline
\end{tabular}

Nota-se, na figura B.2, os resultados experimentais e numéricos coincidem tanto para a velocidade $u_{e}$ quanto para os parâmetros integrais da camada limite. Novamente, os resultados da tabela B.2 indicam que o código DNS-2D é capaz de simular este tipo de escoamento em conformidade com resultados experimentais, uma vez que o desvio máximo é menor do que $10 \%$.

Para este caso, também foram fornecidos dados experimentais de perfis de velocidade $u$ ao longo da direção normal à superfície, em várias posições longitudinais. As posições longitudinais adotadas são: $s / d_{r}=-3,25 ;-1,25 ; 0,75 ; 1,25 ; 3,75 ; 6,25 ; 8,75 ; 11,25 ; 13,75$. Estes dados experimentais são comparados aos resultados numéricos na figura B.3. A coordenada normal à parede foi adimensionalizada pelo deslocamento da camada limite e a velocidade $u$ pela velocidade na fronteira da camada limite. O perfil de velocidade para a posição $s / d_{r}=0,75$ foi deslocado de 0,2 , para comparar com os dados experimentais, na posição logo a jusante da rugosidade. O desvio máximo (em \%) dos perfis de velocidade $u$ ao longo da direção $y$ entre os resultados numéricos e os dados experimentais do caso B é mostrado na tabela B.3. 


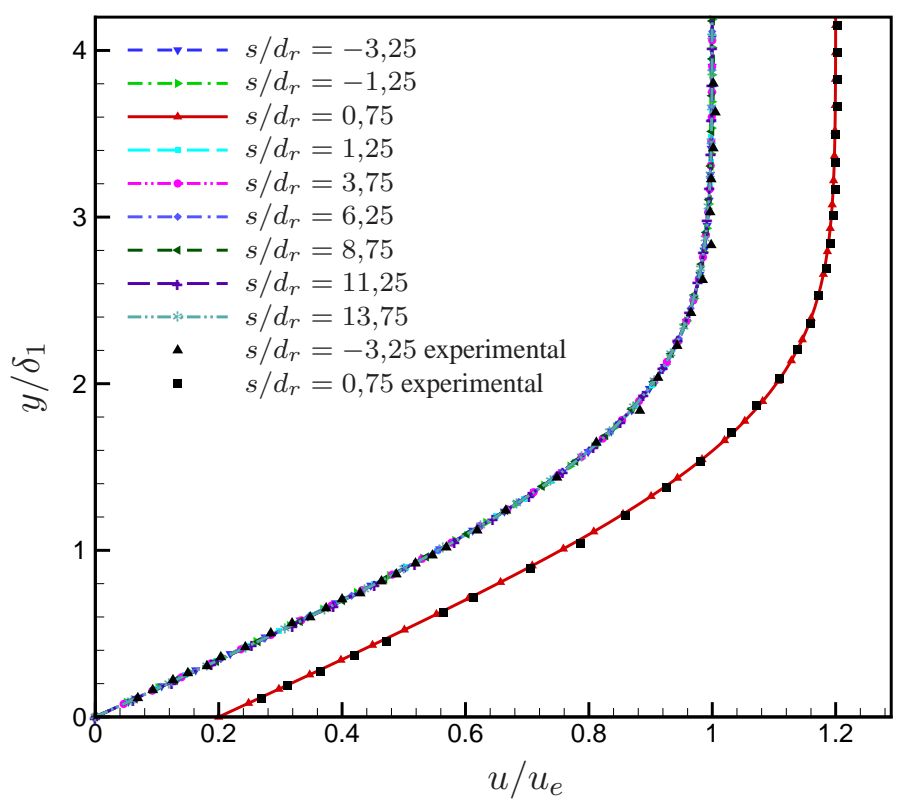

Figura B.3: Perfis de velocidade $u$ ao longo da direção normal à superfície para o escoamento do caso B.

Tabela B.3: Desvio máximo (em \%) dos perfis de velocidade $u$ ao longo da direção $y$, entre os resultados numéricos e os dados experimentais para o caso $\mathrm{B}$.

\begin{tabular}{|c|c|c|}
\hline Posição $\boldsymbol{x}$ & $-3,25$ & 0,75 \\
\hline Desvio máximo (em \%) & 1,5936 & 1,4634 \\
\hline
\end{tabular}

Pode-se observar, na figura B.3, que os perfis de velocidade obtidos com o código DNS-2D estão em conformidade com os dados experimentais. Ainda, na tabela B.3, pode-se ver que o desvio máximo entre os perfis de velocidade é menor do que $2 \%$. Este fato indica que o código numérico consegue prever os perfis de velocidade em concordância com os dados experimentais, reforçando assim a validação do código numérico.

\section{B.1.3 Resultados do caso C}

A comparação dos resultados numéricos do código DNS-2D aos dados experimentais para o caso C são mostrados na figura B.4. O desvio máximo (em \%) dos resultados numéricos em relação aos dados experimentais do caso C, para cada característica da camada limite, é mostrado na tabela B.4.

Tabela B.4: Desvio máximo (em \%) entre os resultados numéricos e os dados experimentais para o caso C.

\begin{tabular}{|c|c|c|c|c|}
\hline Característica & $\delta_{1}$ & $\delta_{2}$ & $H_{12}$ & $u_{e}$ \\
\hline Desvio máximo (em \%) & 7,4445 & 8,8963 & 1,5453 & 0,6309 \\
\hline
\end{tabular}

Assim como nos casos anteriores, é possível observar, na figura B.4, a concordância entre os resultados numéricos e experimentais para o perfil de velocidade e os parâmetros integrais da camada 


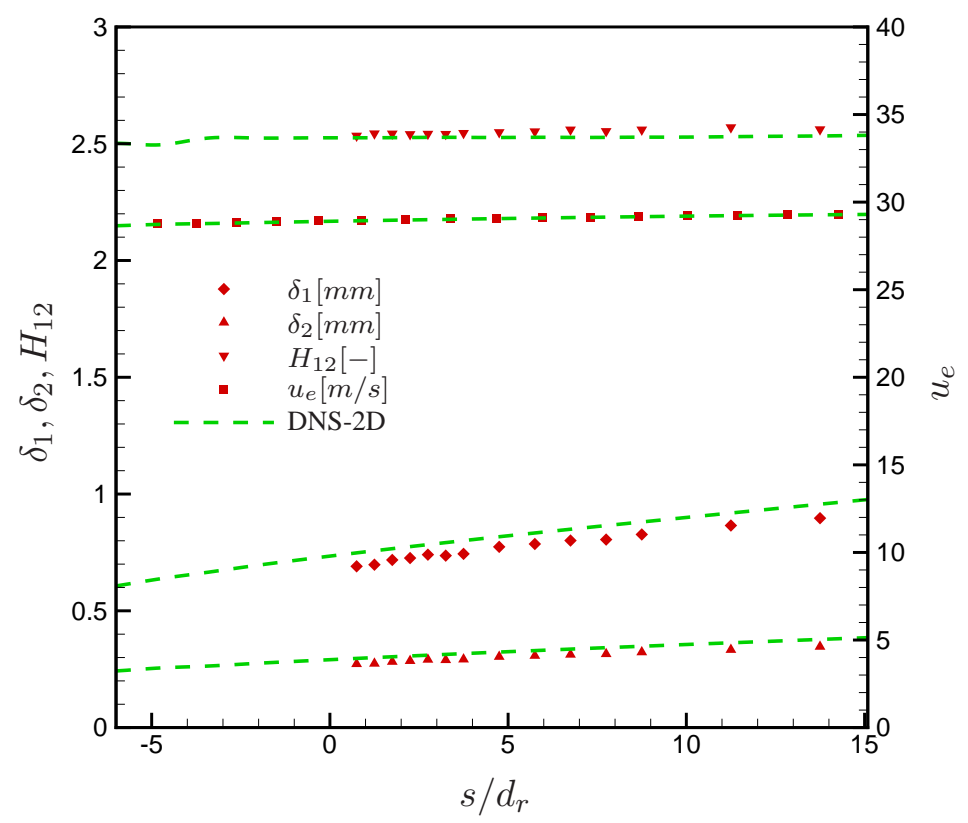

Figura B.4: Características da camada limite para o escoamento do caso C.

limite. Essa concordância também pode ser vista na tabela B.4, que mostra desvios máximos menores do que $10 \%$ para todas as características comparadas.

Outro fato que pode ser notado é a diminuição dos parâmetros integrais e da velocidade $u_{e}$ conforme o gradiente de pressão aumenta.

Esses resultados permitem afirmar que o código numérico bidimensional está validado para a simulação do escoamento base de camada limite.

\section{B.2 Desenvolvimento da amplitude de perturbação}

Na presente seção, um segundo resultado de comparação, envolvendo o desenvolvimento da amplitude de perturbação no escoamento, é apresentado. Para esta simulação foi considerado o caso com gradiente de pressão próximo de zero. Os mesmos parâmetros utilizados na Seção 4.3.2 foram aqui adotados, com exceção da velocidade de referência e do número de Reynolds, que variam de acordo com o gradiente de pressão. Para este caso, a velocidade de referência é $\tilde{U}_{\infty}=29,4985$ e o número de Reynolds é $R e=340367,308$.

Pelo fato de haver dados experimentais apenas para a frequência de perturbação $F=549 \mathrm{~Hz}$, somente essa frequência foi considerada.

A variação na amplitude de perturbação $u^{\prime}$ na direção longitudinal é mostrada na figura B.5. Novamente, os resultados numéricos estão em conformidade com os dados experimentais e de os 
resultados de LST.

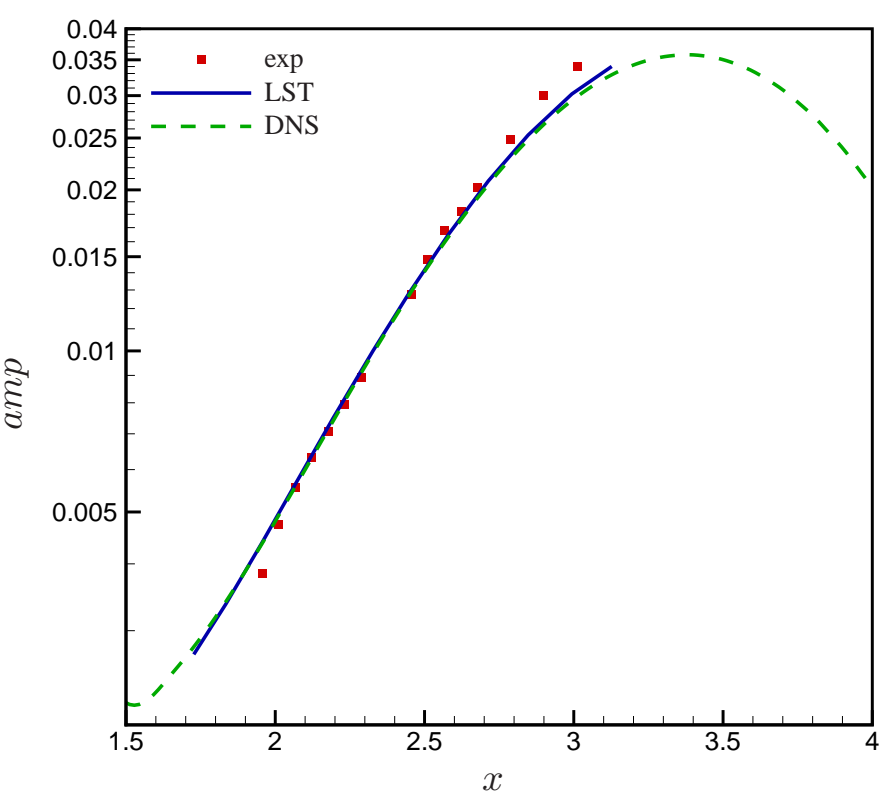

Figura B.5: Amplitude de $u^{\prime}$ na direção $x$, para o escoamento com gradiente de pressão próximo de zero e frequência de perturbação $F=549 \mathrm{~Hz}$ ( $a m p$ - em escala logarítmica).

Nota-se, através dos resultados da figura B.5, que o desenvolvimento espacial de ondas TS é representado corretamente pelo código DNS-3D. 